\title{
NOVEL DOUBLE-SIDED LINEAR GENERATOR FOR THE WAVE ENERGY CONVERSION
}

\author{
by \\ (C) Mihajlo Curcic \\ A Thesis submitted to the \\ School of Graduate Studies \\ in partial fulfillment of the requirements for the degree of
}

Master of Engineering

Faculty of Engineering and Applied Science

Memorial University of Newfoundland

May 2015

St John's

Newfoundland and Labrador 


\begin{abstract}
The direct drive point absorber is a robust and efficient system for wave energy harvesting, where the linear generator represents the most complex part of the system. Therefore, its design and optimization are crucial tasks. The tubular shape of a linear generator's magnetic circuit offers better permanent magnet flux encapsulation and reduction in radial forces on the translator due to its symmetry.
\end{abstract}

A double stator topology can improve the power density of the linear tubular machine. Common designs employ a set of aligned stators on each side of a translator with radially magnetized permanent magnets. Such designs require doubling the amount of permanent magnet material and lead to an increase in the cogging force. The design presented in this thesis utilizes a translator with buried axially magnetized magnets and axially shifted positioning of the two stators such that no additional magnetic material, compared to single side machine, is required. In addition to the conservation of magnetic material, a significant improvement in the cogging force occurs in the two phase topology, while the double sided three phase system produces more power at the cost of a small increase in the cogging force.

The analytical and the FEM models of the generator are described and their results compared to the experimental results. In general, the experimental results compare favourably with theoretical predictions. However, the experimentally observed permanent magnet flux leakage in the double sided machine is larger than predicted theoretically, which can be justified by the limitations in the prototype fabrication and resulting deviations from the theoretical analysis. 


\section{ACKNOWLEDGEMENTS}

NSERC and CREATE funds have enabled this research. I would also like to thank my supervisors - Dr.

Bachmayer and Dr. Quaicoe - and to the MUN machine shop staff - D. Snook and A. George - for their knowledge and patience. 


\section{Table of Contents}

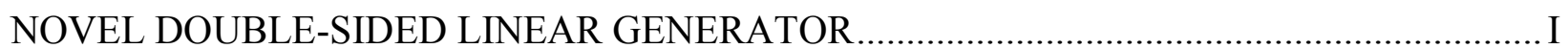

FOR THE WAVE ENRGY CONVERSION ….................................................................

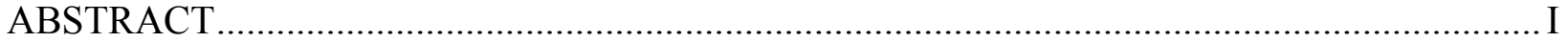

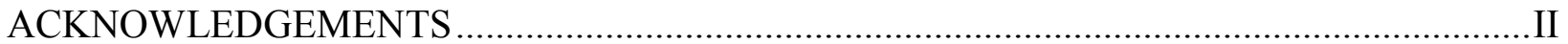

LIST OF FIGURES …................................................................................................

LIST OF SYMBOLS, NOMENCLATURE OR ABBREVIATIONS ..................................... XI

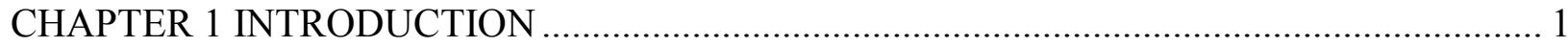

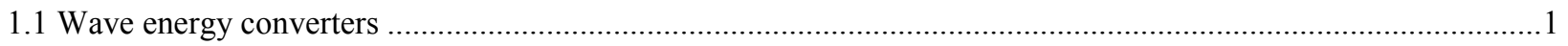

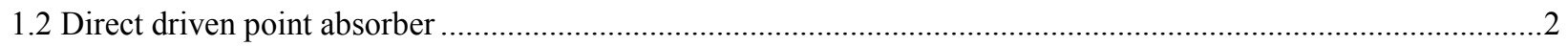

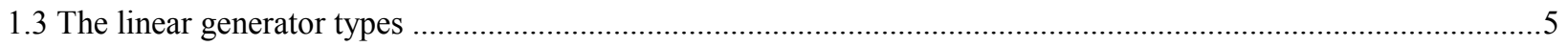

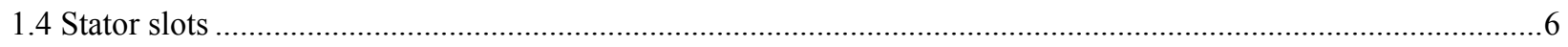

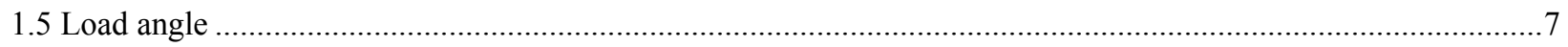

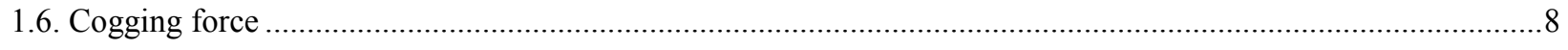

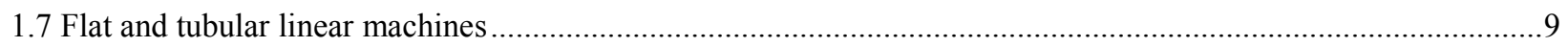

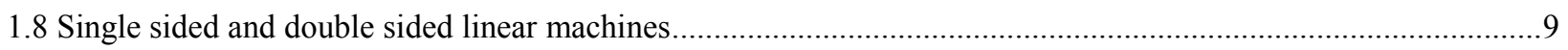

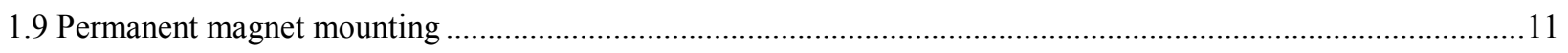

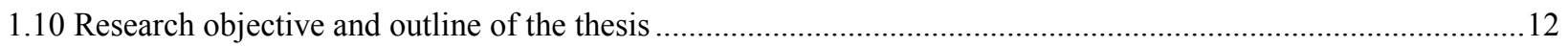

CHAPTER 2 DOUBLE SIDED LINEAR PERMANENT MAGNET GENERATOR .............. 15

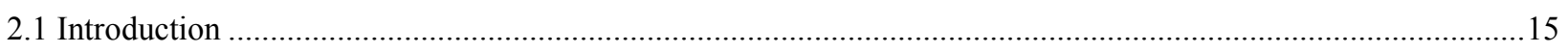

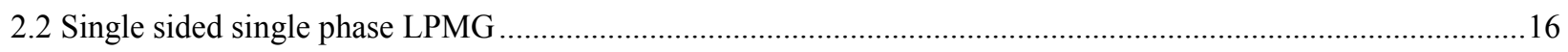

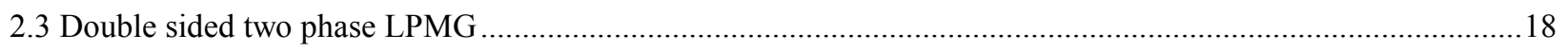

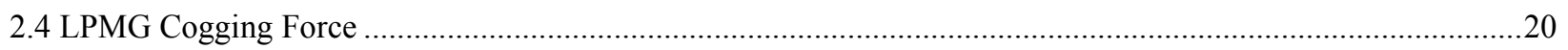

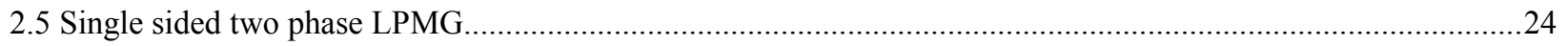




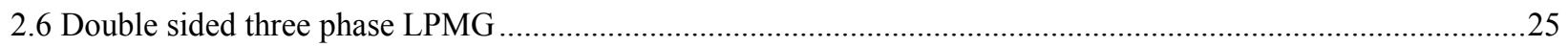

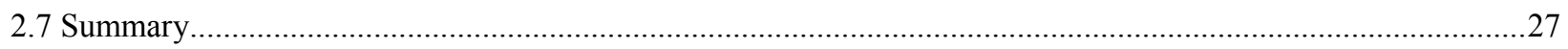

CHAPTER 3 SYSTEM MODELING …...................................................................... 29

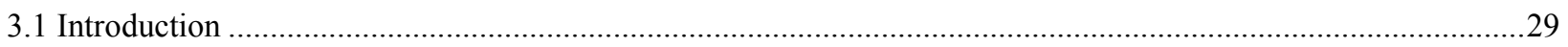

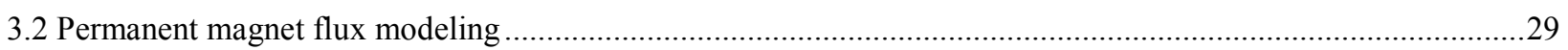

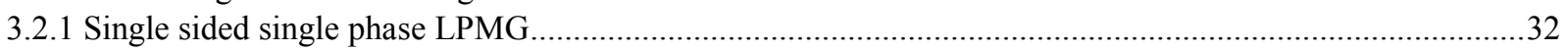

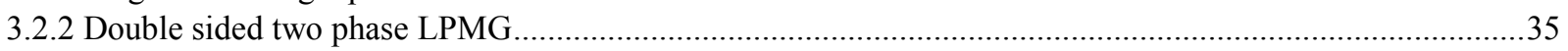

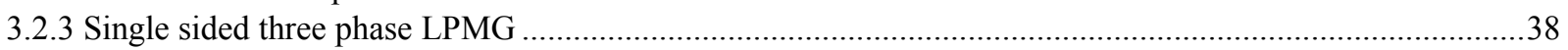

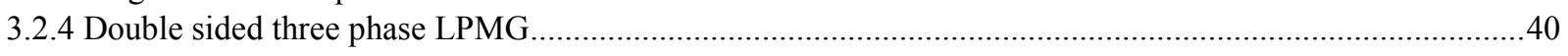

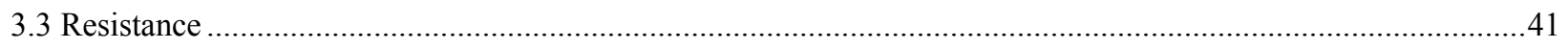

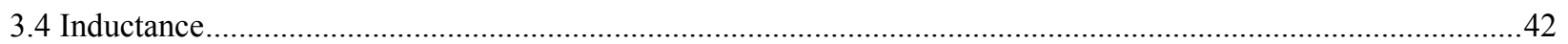

3.4.1 Single sided single phase and Double sided two phase inductance ...........................................................4

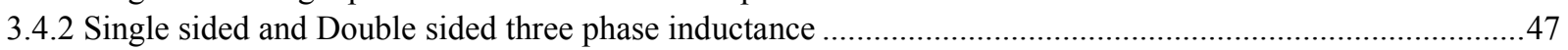

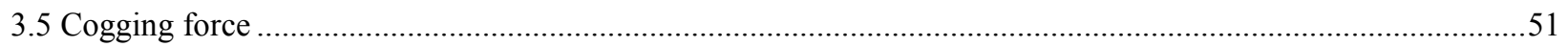

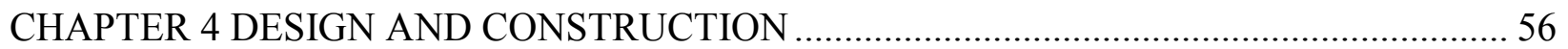

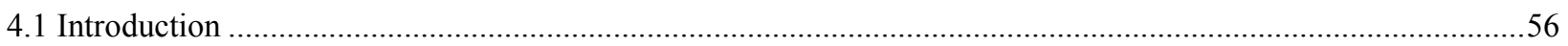

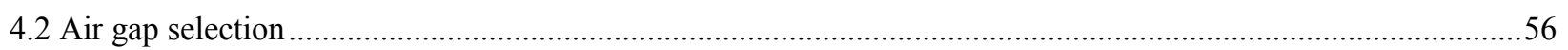

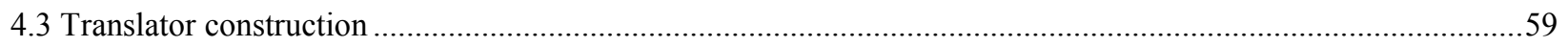

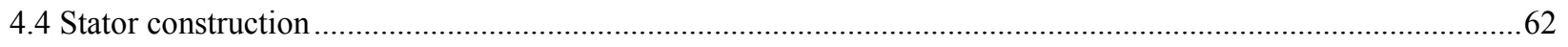

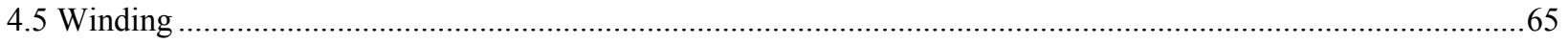

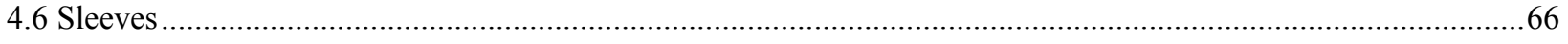

4.7 Summary

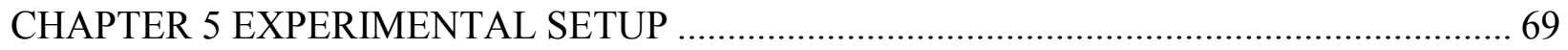

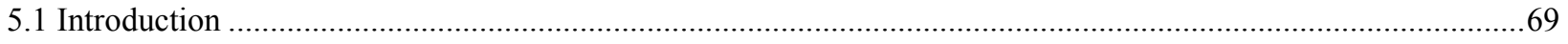

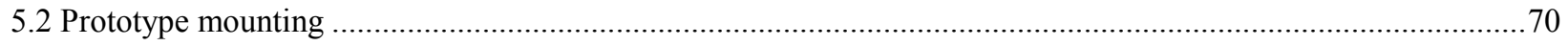

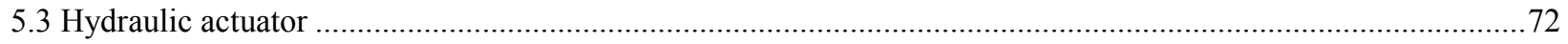

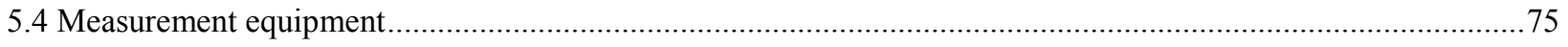

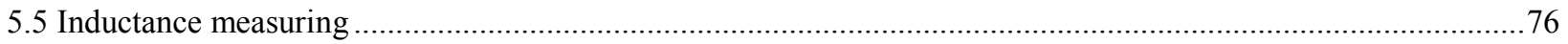




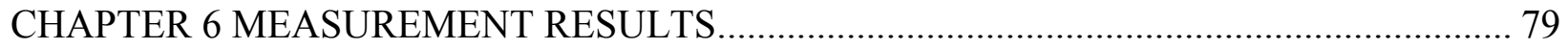

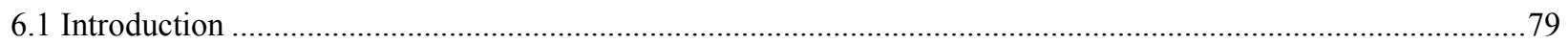

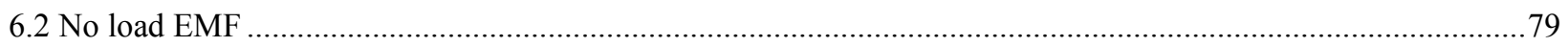

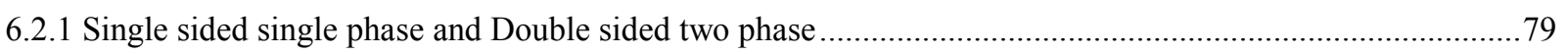

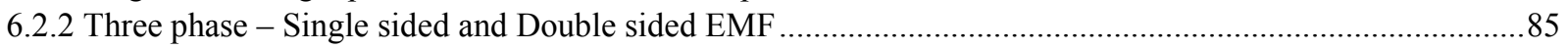

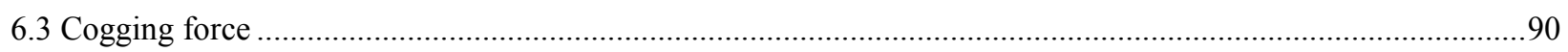

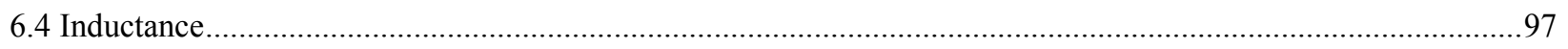

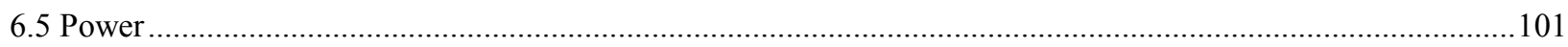

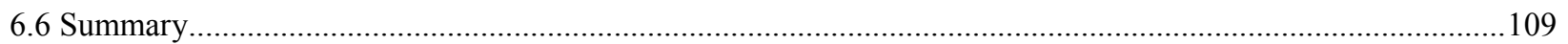

CHAPTER 7 CONCLUSION AND FUTURE WORK ................................................... 110

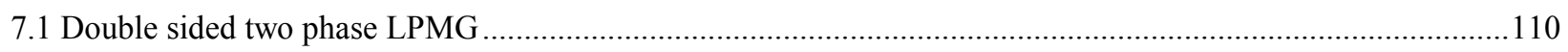

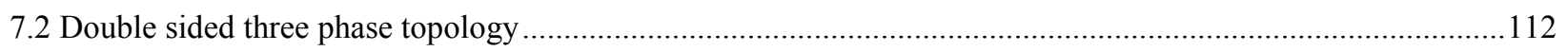

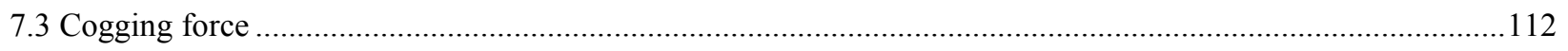

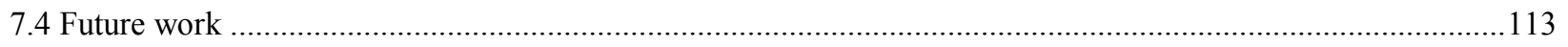

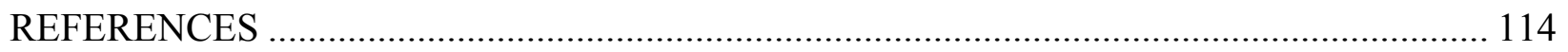

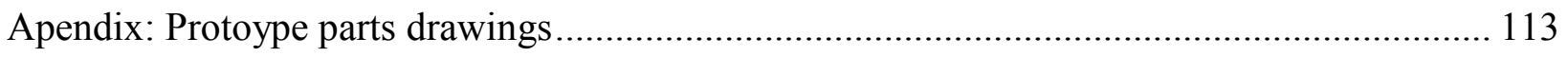




\section{List of Figures}

Figure 1-1 Linear generator (LGEN) coupled with a buoy (point absorber) in two positions: on the wave crest (left) and in the wave trough (right) ........................................................... 3

Figure 1-2 Semi closed (left) and open (right) stator slots .............................................. 7

Figure 1-3 Generator phasor diagram: $E 0$ - no load electromotive force (EMF); $V$ - terminal voltage; $I$-load current; $x$ - armature reactance; $\mathrm{r}$ - armature resistance; $\phi$ - phase angle; $\sigma$-load (power) angle 7

Figure 1-4 Flat stator (left) and cross-section of the tubular stator (right) .............................. 9

Figure 1-5 Double sided flat stator (left) and cross-section of Double sided tubular stator (right)

Figure 1-6 a) Radially aligned surface mounted magnets; b) and axially aligned buried ........... 12

Figure 2-1 Permanent magnet translator and main flux orientation in the SS generator............. 16

Figure 2-2 a) Translator flux radial orinetation b) main flux path in the machine (cross-section

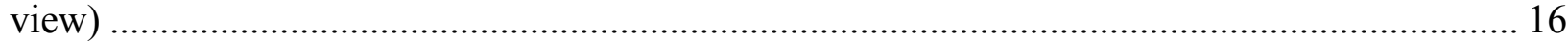

Figure 2-3 FEM model PM flux distribution for two characteristic translator positions in the single phase generator

Figure 2-4 Double sided two phase generator a)3D Model b) Flux distribution for two translator positions 18

Figure 2-5 Two phase generator output power for each phase (A and B) and total output power

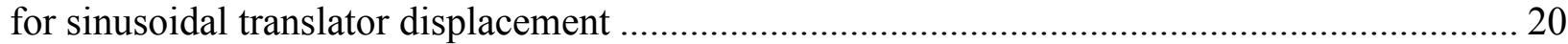

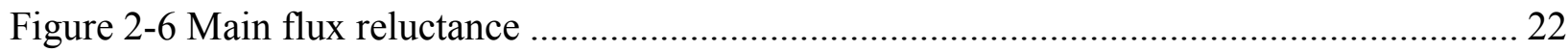

Figure 2-7 a) Magnet entering DS magnetic circuit; b) associated stored magnetic energy in SS and DS magnetic circuit for different magnet positions (external air gap g2 $=1 \mathrm{~mm}$ and internal air

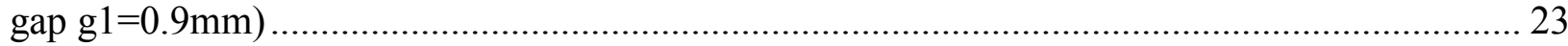

Figure 2-8 PM flux reluctance network includeing the leakage ........................................... 24

Figure 2-9 PM flux distribution in the single sided two phase generator ................................ 25

Figure 2-10 Main flux in three phase SS (left) and DS topology (right) ............................... 26

Figure 2-11 a) DS three phase machine main PM flux distribution b) phasors for the internal and

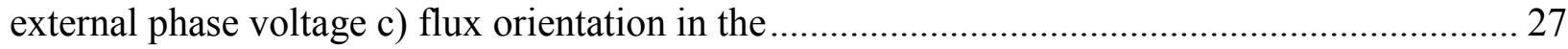

Figure 3-1 a) Flux lines between parallel and b) perpendicular surfaces ................................. 30

Figure 3-2 Dimensions of two coaxial cylinders for internal reluctance calculation .................. 31

Figure 3-3 Elements of SS single phase magnetic circuit included in reluctance network .......... 32

Figure 3-4 SS single phase LPMG reluctance network .................................................. 33

Figure 3-5 FEM calculation of total linked PM flux for position of the translator $\mathrm{z}=12.7 \mathrm{~mm}$.... 34

Figure 3-6 SS Single phase flux - the analytical and FEM model predictions .......................... 35 
Figure 3-7 Leakage flux due to the additional stator in the DS two phase LPMG.................... 36

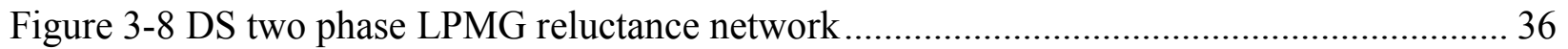

Figure 3-9 Leakage of a translator magnet aligned with the external stator............................. 37

Figure 3-10 DS Two phase fluxes - the analytical and FEM model ....................................... 38

Figure 3-11 SS three phase PM Flux distribution a) expected (b) FEM (c) main flux reluctance

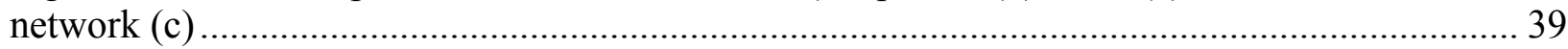

Figure 3-12 SS Three phase fluxes - the analytical and FEM model ................................... 39

Figure 3-13 DS three phase PM Flux distribution a) expected (b) FEM (c) main flux reluctance

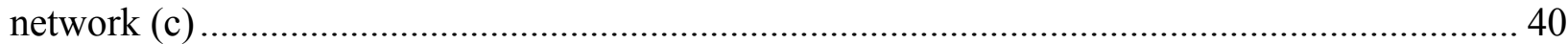

Figure 3-14 DS Three phase fluxes - the analytical and FEM model.................................... 41

Figure 3-15 SS single phase winding: elements of the inductance modeling network for aligned

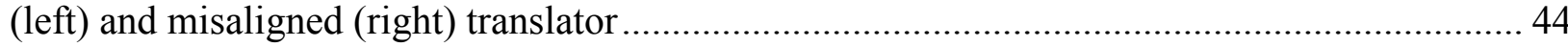

Figure 3-16 SS single phase machine self-inductance FEM and analytical predictions; FEM predictions for the DS two phase machine self-inductance ............................................... 44

Figure 3-17 Internal stator self-inductance predictions .................................................. 45

Figure 3-18 Reluctance network elemets for the mutual inductance estimation of the DS two

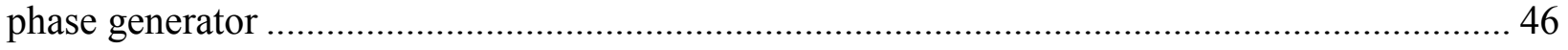

Figure 3-19 DS Two phase mutual inductance predictions ................................................. 46

Figure 3-20 Reluctance network elemets for the SS three phase self-inductance calculation...... 47

Figure 3-21 Analytical and FEM predictions for the SS three phase self-inductance................ 48

Figure 3-22 Reluctance network elements for inductance estimation of the DS three phase generator (left) and the FEM predictions for the armature flux distribution (right) .................. 49

Figure 3-23 Analytical and FEM DS predictions for the three phase self-inductance ............... 50

Figure 3-24 Analytical and FEM DS predictions for the three phase mutual inductance ........... 51

Figure 3-25 FEM predictions for the cogging force in the single sided single phase and two phase

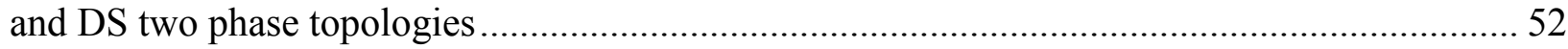

Figure 3-26 Internal component of the cogging force in the SS and DS three phase topologies . 53

Figure 3-27 a) DS three phase stator segments and period of the cogging force end component;

b) summation of end cogging force contributions coming from each segment........................ 54

Figure 3-28 FEM predictions for the cogging force in three phase topologies: single sided, double sided and double sided with segments ................................................................. 54

Figure 4-1 Reluctances for translator aligned with external stator ......................................... 58

Figure 4-2 Peak to peak cogging force in DS two phase topology for different external air gap

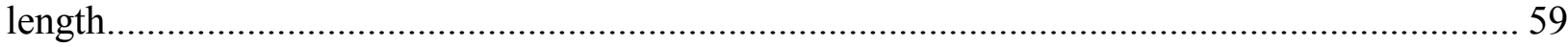

Figure 4-3 Three phase translator rings stacked up on a jig ............................................. 60 
Figure 4-4 Force on a magnet being added to a translator for single phase and three phase pole

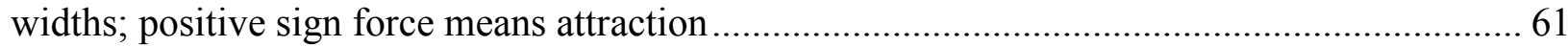

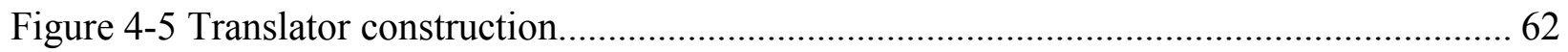

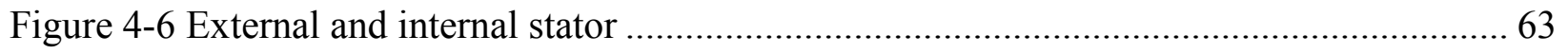

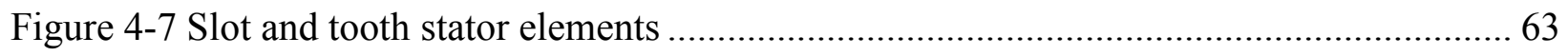

Figure 4-8 a) Iron parts cutting pattern b) Waterjet CNC cutting the three phase translator pole

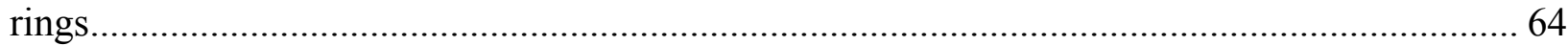

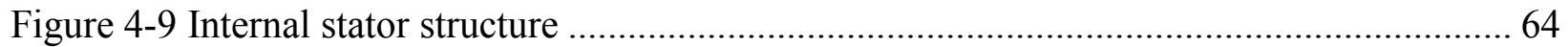

Figure 4-10 a) Winding of the internal stator b) external stator coils c) placement of the external

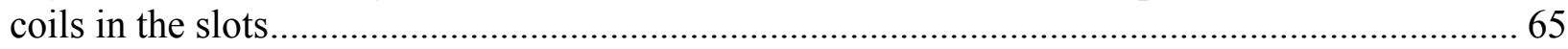

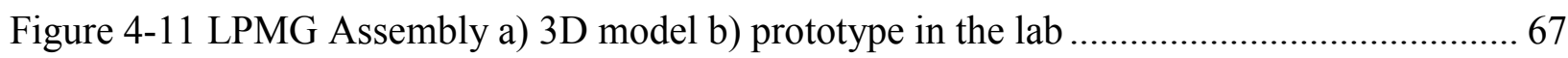

Figure 4-12 a) External sleeve attached to the external stator b) manufacturing of internal sleeve c) attachment of internal sleeve to the translator's end plate is located between the shaft collars 68

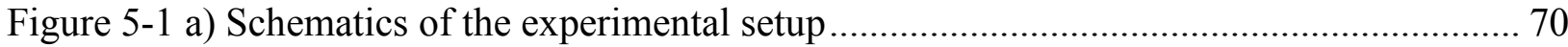

Figure 5-2 a) Forces on the prototype base plate without and with cetral leg b) shafts fixing the base plate to the floor $\mathrm{c}$ ) central leg mounted on the plate 72

Figure 5-3 Motion profile of the actuator piston for 40mm peak to peak amplitude prescribed

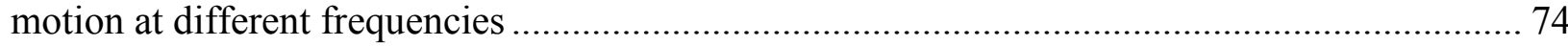

Figure 5-4 Drop in translator displacement peak to peak amplitude with motion frequency....... 74 Figure 5-5 a) Servo controller b) Load cell c) two channel oscilloscope, DAS and PC d) four

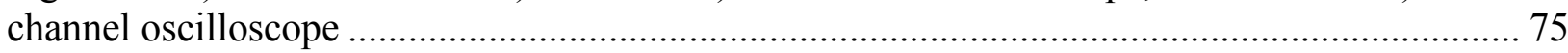

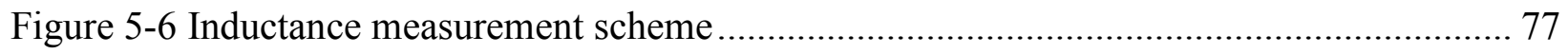

Figure 6-1 SS single phase LPMG no load EMF for the stroke amplitude $26 \mathrm{~mm}$ (a) $0.15 \mathrm{~Hz}$ b) $0.3 \mathrm{~Hz})$.....

Figure 6-2 SS single phase a) measured no load EMF vs frequency for $26 \mathrm{~mm}$ amplitude and b) $\mathrm{EMF} /$ frequency fot the same amplitude. 80

Figure 6-3 SS single phase no load EMF: measured, FEM and analytical simulation [26mm

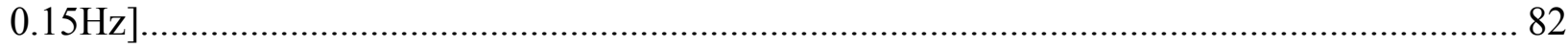

Figure 6-4 DS Two Phase no load EMF: measured, FEM and analytical simulation [26mm

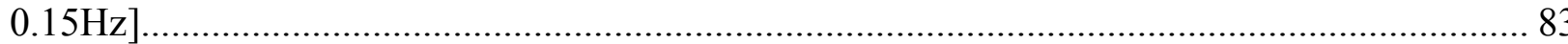

Figure 6-5 DS two phase External ( $a$ and b) and Internal (c and d) stator measured no load EMFs

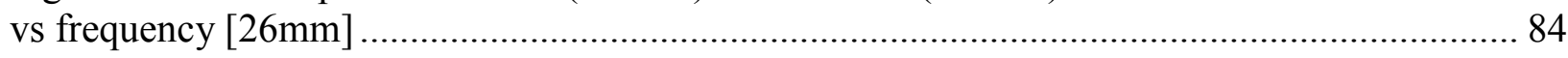

Figure 6-6 a) Measured EMF RMS for SS single phase and DS two phase LPMG b) RMS over

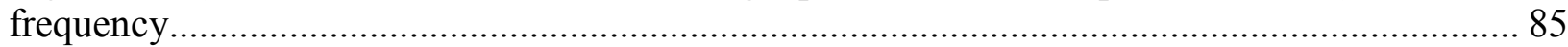

Figure 6-7 Three phase no load measured EMFs: a) single sided and b) double sided [39mm

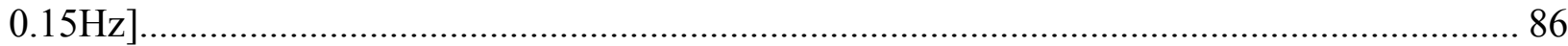


Figure 6-8 SS three phase no load EMFs: measured, FEM and analytical simulation [39mm $0.15 \mathrm{~Hz}]$.

Figure 6-9 DS three phase no load EMF: measured, FEM and analytical simulation [39mm $0.15 \mathrm{~Hz}]$ 88

Figure 6-10 Comparison of each phase no load EMF in SS and DS three phase topology......... 89

Figure 6-11 SS single phase LPMG force reading and translator displacement ...................... 91

Figure 6-12 SS Single phase machine - measured force................................................... 92

Figure 6-13 SS Single phase machine cogging force - test and FEM model........................... 92

Figure 6-14 Dammage on internal stator surface from interaction with the translator sleeve...... 93

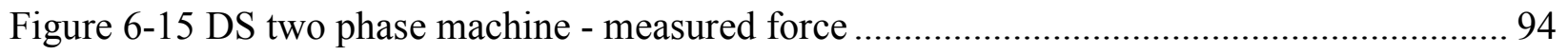

Figure 6-16 DS two phase - measurement cogging force and FEM prediction......................... 94

Figure 6-17 SS three phase - force measurement .............................................................. 95

Figure 6-18 SS three phase - measured cogging force and FEM prediction ............................ 95

Figure 6-19 DS three phase force measurement and friction humps (encircled) ...................... 96

Figure 6-20 DS three phase -measured cogging force (before and after the friction interuption -

Test' and Test") and FEM prediction ............................................................................... 96

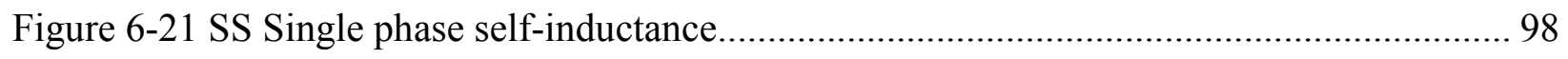

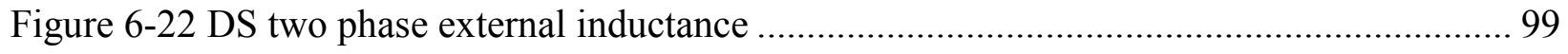

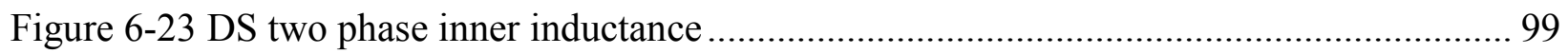

Figure 6-24 SS three phase self-inductance.................................................................. 100

Figure 6-25 SS three phase mutual inductance............................................................. 100

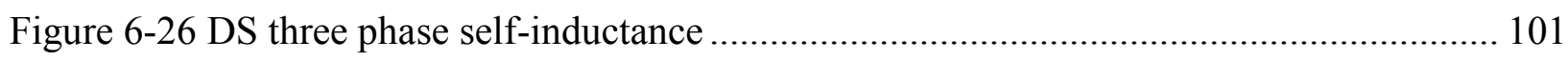

Figure 6-27 DS three phase mutual inductance ................................................................ 101

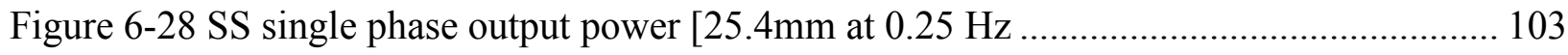

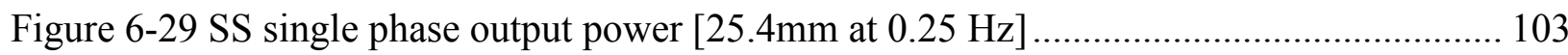

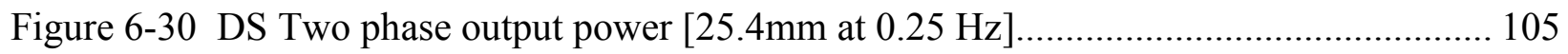

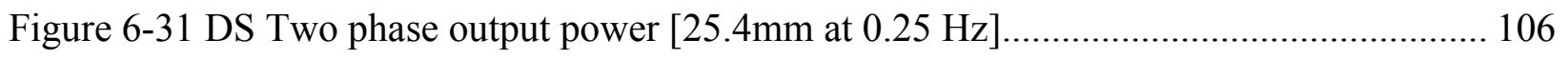

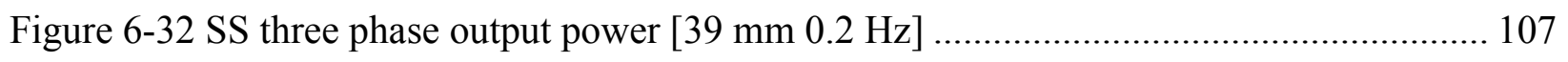

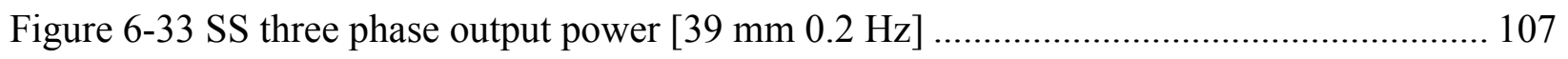

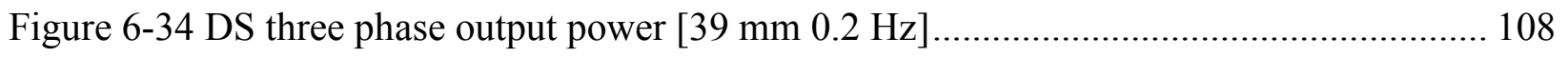

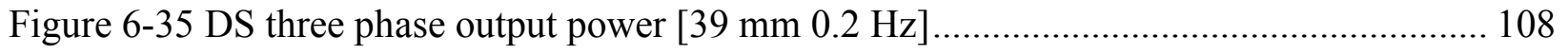

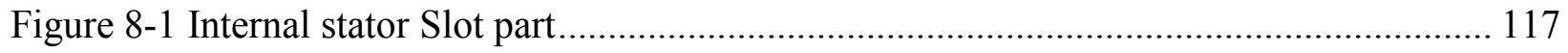

Figure 8-2 Different Internal stator tooth parts........................................................... 118 


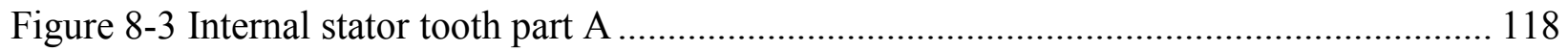

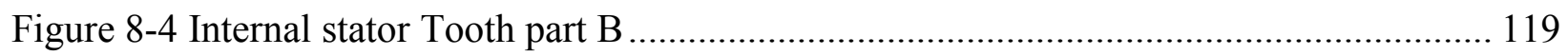

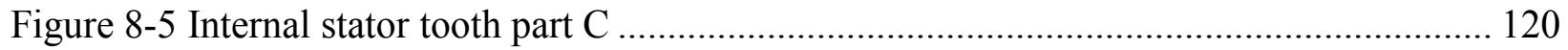

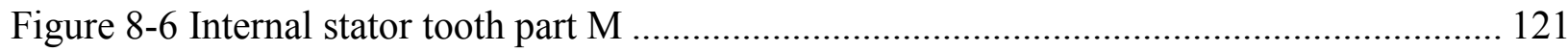

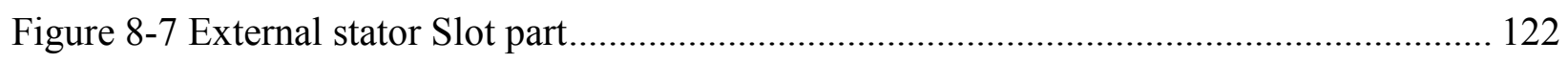

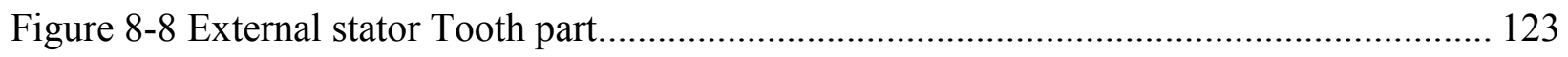

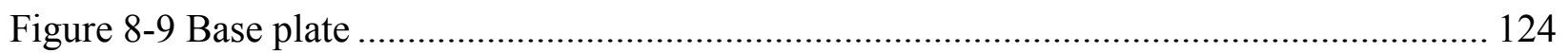

Figure 8-10 Translator-Actuator contact plate................................................................... 125

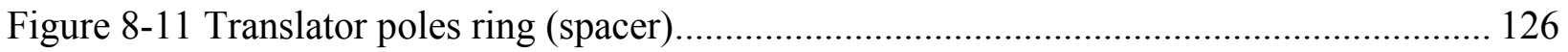

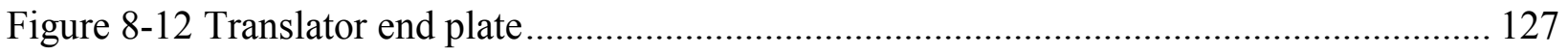




\section{List of Symbols, Nomenclature or Abbreviations}

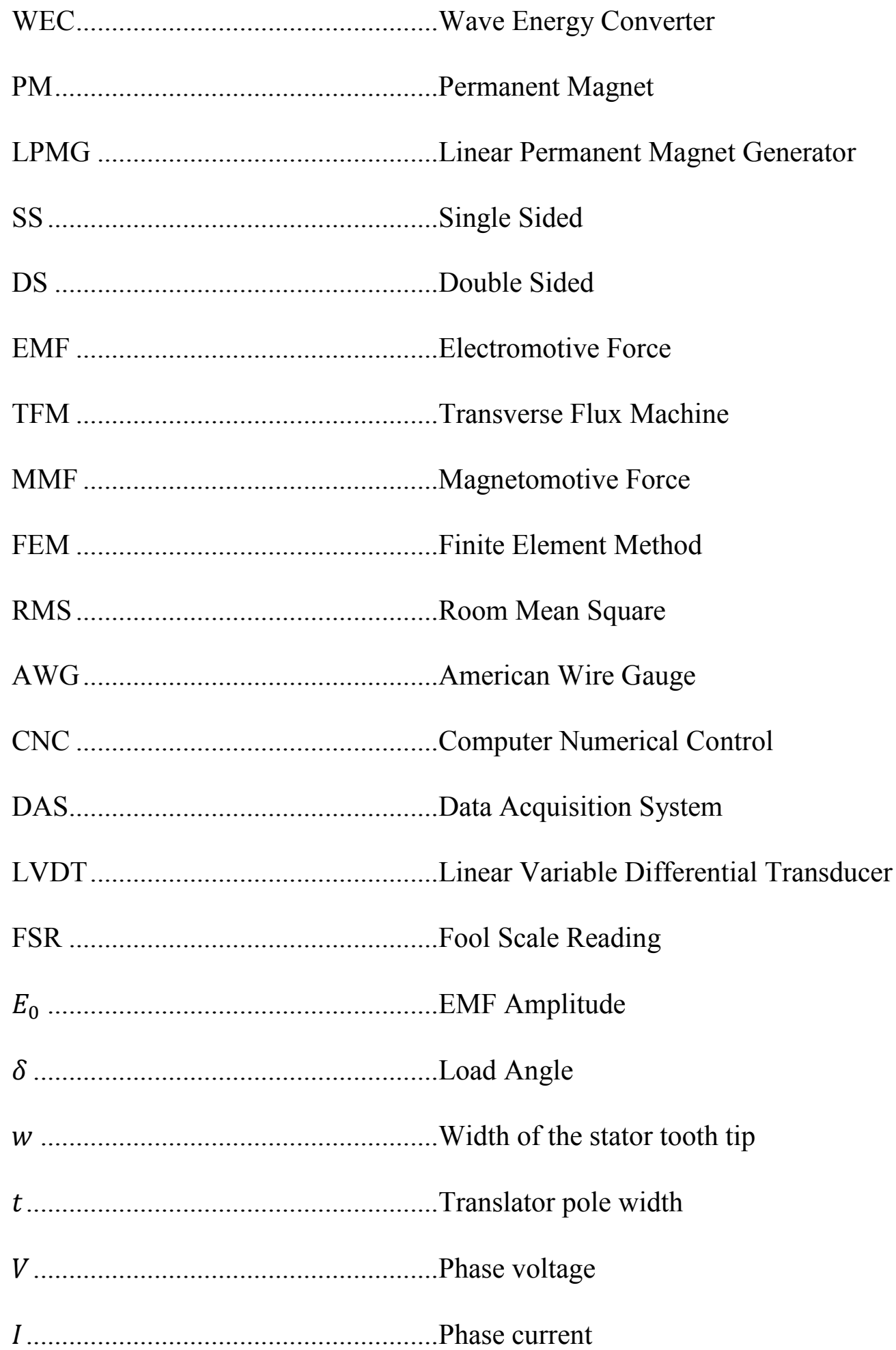




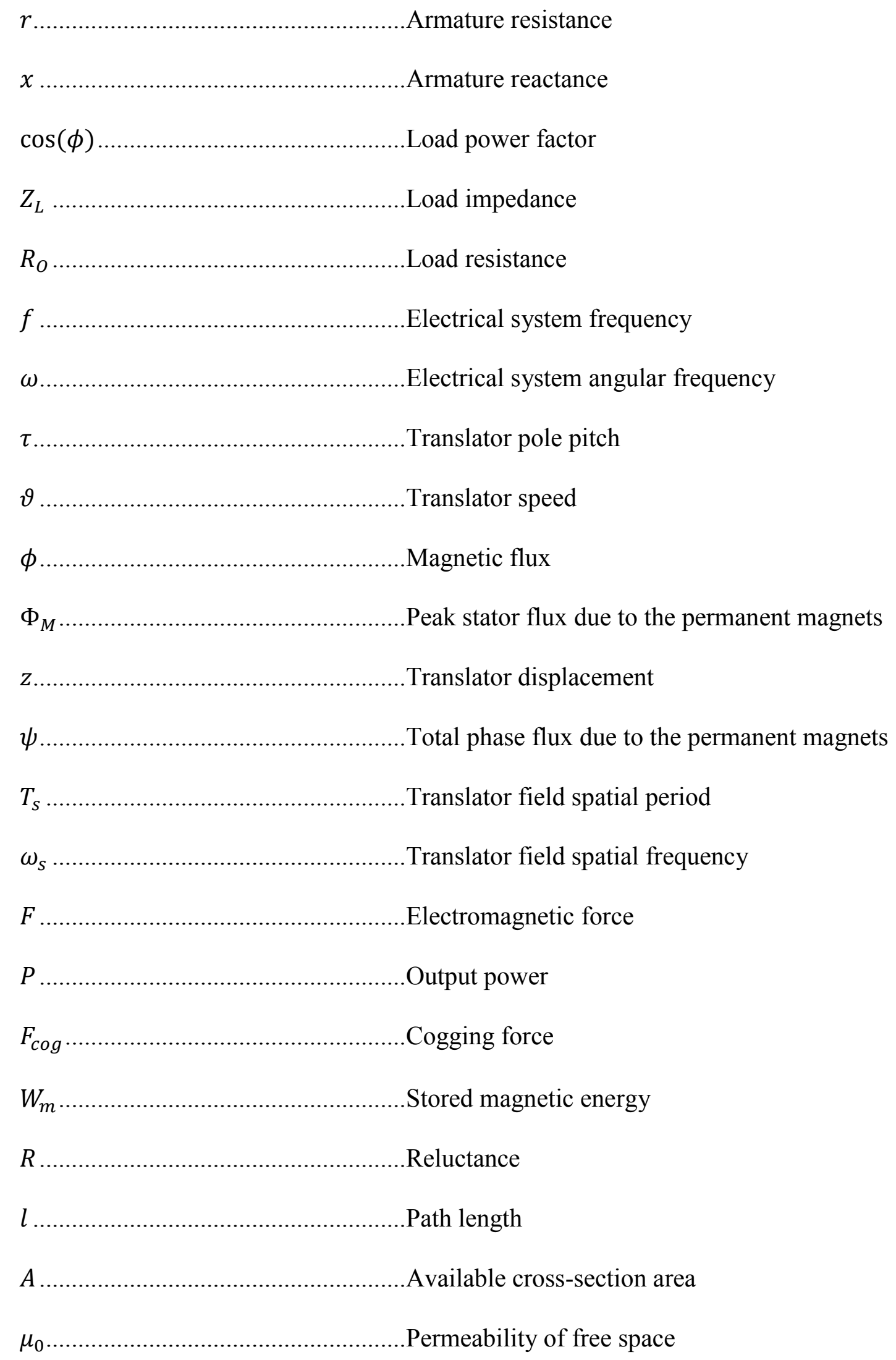




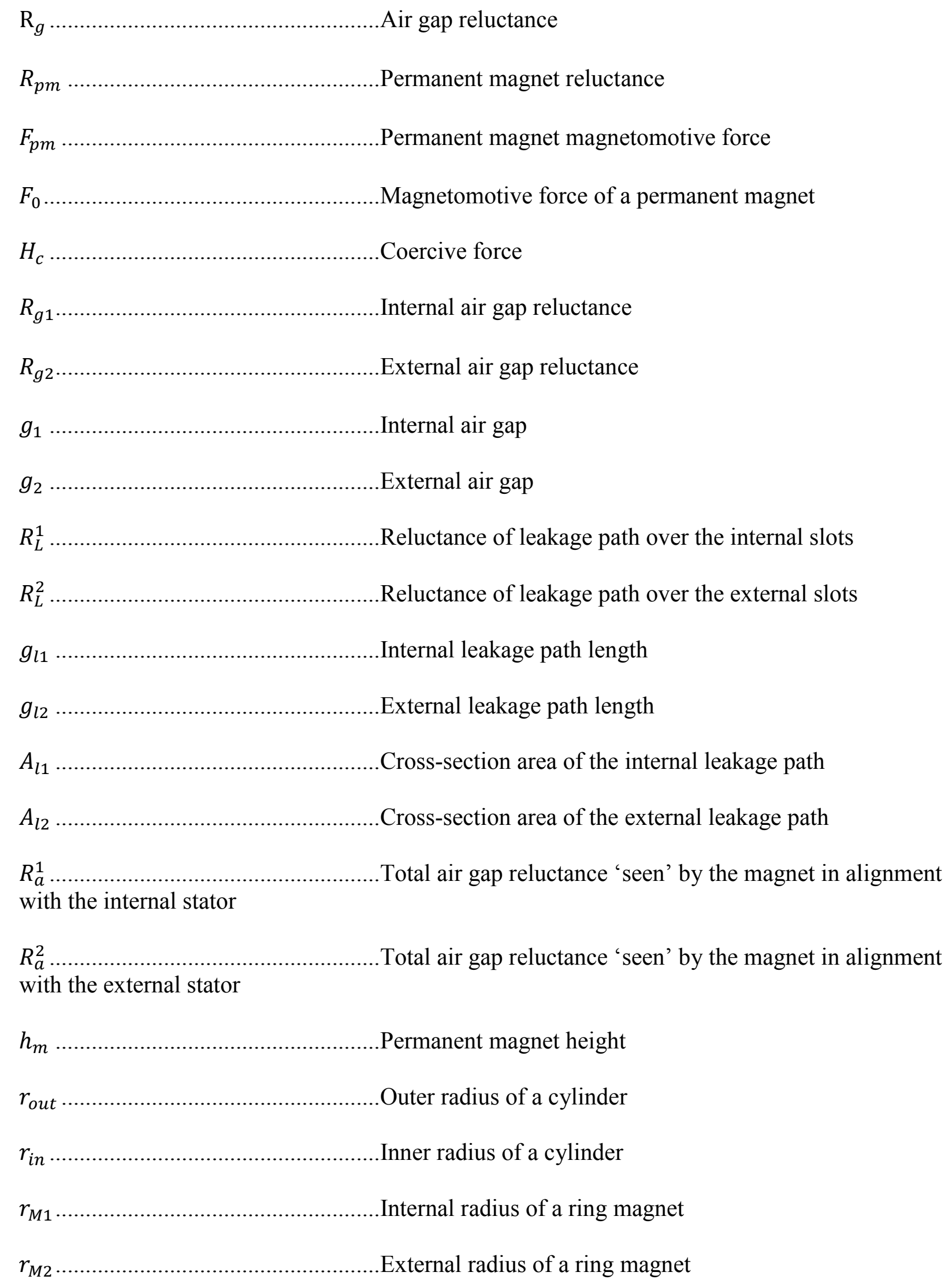




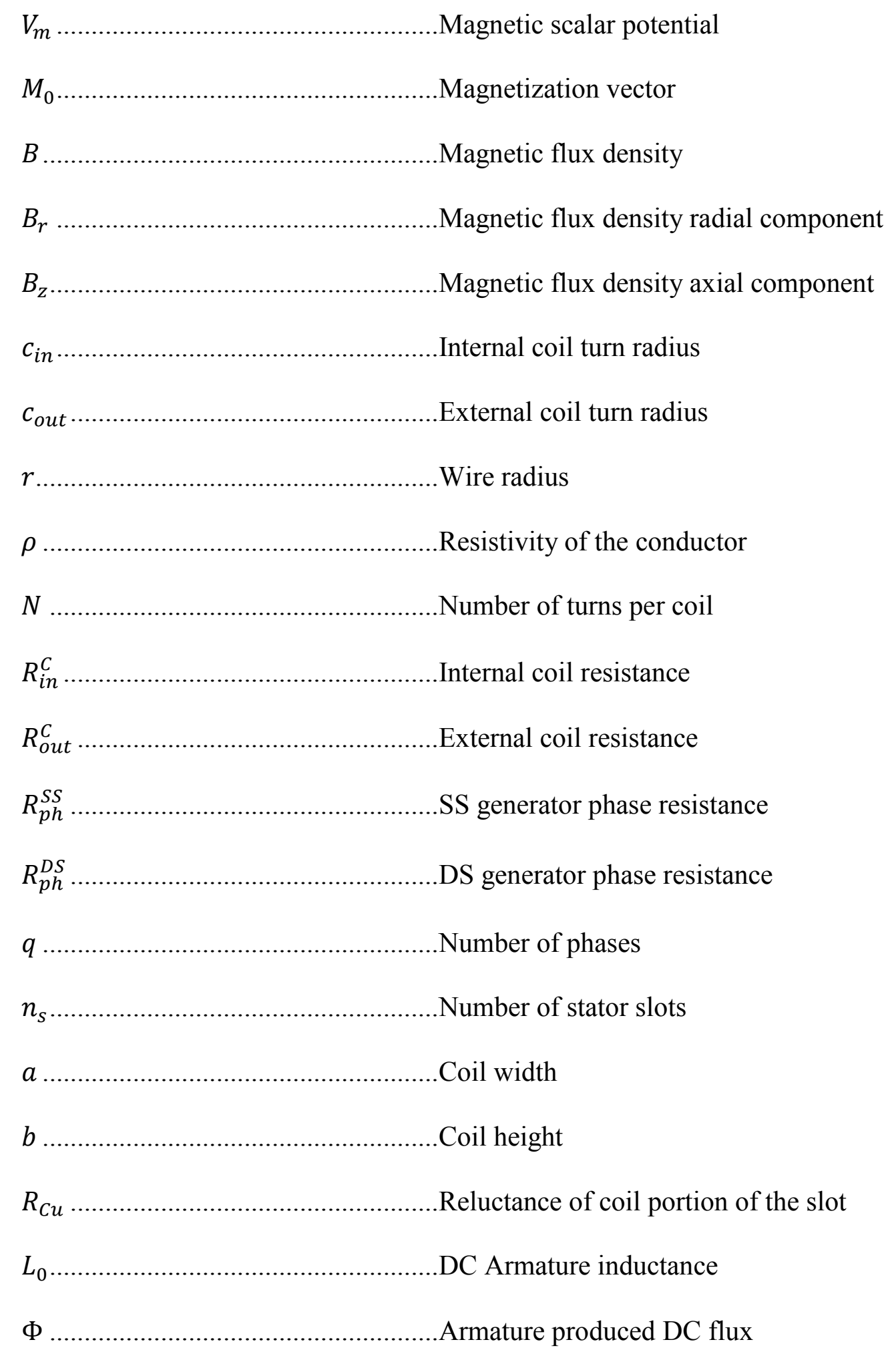

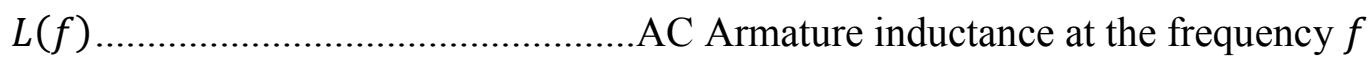




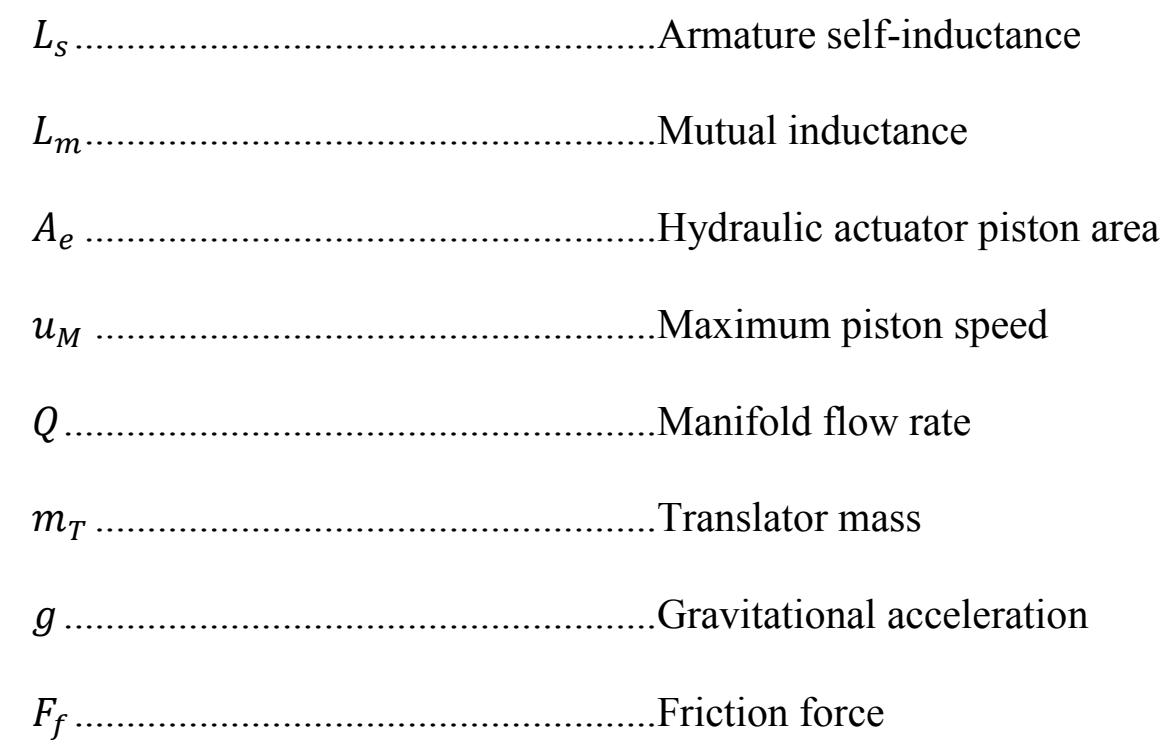




\section{Chapter 1}

\section{Introduction}

\subsection{Wave energy converters}

Ocean waves are a result of wind activity, which is in turn a consequence of solar radiation. With each transformation, energy becomes more spatially concentrated, leaving the ocean waves with the highest power flow density [Falnes, 2007]. Energy of ocean waves has a global potential whose partial utilization might contribute significantly to the global renewable energy production [Muetze, 2006]. However, large scale power production based in this resource is still far away. Modern wave energy research started in Japan in the 1950s, where Y. Masuda designed the first wave powered navigation buoys [Masuda, 1988]. Initialization of wider usage of low power stations would be a good way to gain valuable knowledge about the resource and raise awareness of its potential, while satisfying energy needs of ocean oriented consumers.

Standard conversion technology is established for historically more exploited renewable energy sources, such as wind and solar. In the case of wave energy, that is not yet the case. A large number of different Wave energy conversion devices (WECs) is still under development and testing [Tietje, 2009].

Proposed concepts for WEC devices include the following: 
- Attenuator (hinged contour device) is a long (compared to the surface wave length) device consisting of few joint floaters whose relative motion is driving hydraulic pumps [Thomson, 2011].

- Oscillating water column has a chamber in which passing wave builds up oscillation of air pressure. Pressure oscillation produces bidirectional air flow through a Well's turbine [Muetze, 2006].

- Overtopping WECs are particularly shaped floating reservoirs filled by upcoming ocean wave. Their content drains through a water turbine [Polinder, 2004].

- Point absorbers capture the wave energy by using a float whose dimensions are small compared to the ocean wave length. Heaving motion of the float is either converted to rotation (by mechanical or hydraulic system) or directly used by a linear generator.

\subsection{Direct driven point absorber}

Presented study is solely concerned with the direct driven point absorbers. Unlike other WEC devices that use some kind of mediator for supplying the wave energy in a form suitable for high-speed rotary generators, the direct driven point absorber directly employs heaving motion of ocean waves by using low speed linear generator. Few decades ago, linear generators have been pushed out from the ocean wave energy pursuit as excessively big and expensive [Leijon, 2005]. However, lower price of rare earth permanent magnets and the improvement in their strength have prompted the research and development of the direct driven WEC projects [Polinder, 2004]. 


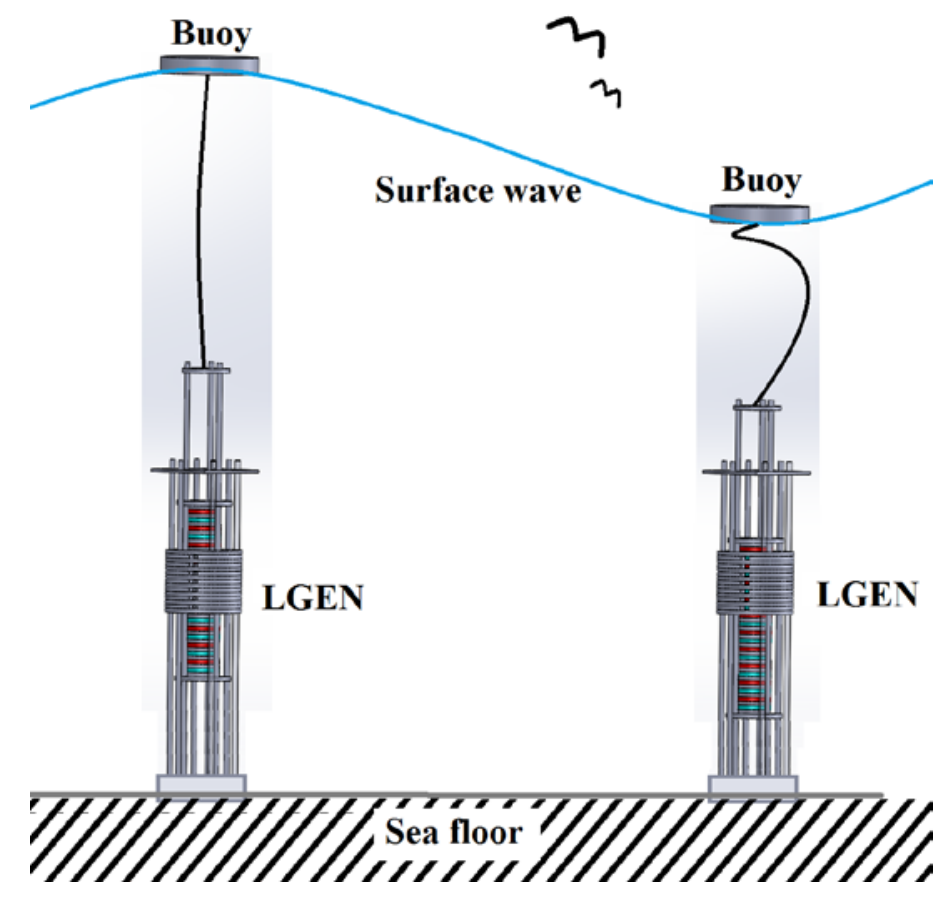

Figure 1-1 Linear generator (LGEN) coupled with a buoy (point absorber) in two positions: on the wave crest (left) and in the wave trough (right)

Depending on the purpose, direct driven point absorber system can be realized over the vast scale of power capacities, ranging from few tents of watts to megawatts [Pirisi, 2010 \& Mueller, 2002]. Various studies have shown potential of small direct driven wave energy converters to satisfy energy needs of the marine communication, surveillance and signalization equipment in a persistent and sustainable manner [Pirisi, 2013]. Right now, it seems that those small power consumers might be the most suitable first assignment for the developing point absorbers technology.

Work in remote and harsh ocean environments and desire to make wave energy more competitive, impose certain requirements on the overall system design [Grilli 2010]:

- robustness

- low cost 
- high efficiency

Searching for solution that fulfils these requirements, different types of direct driven point absorbers have been proposed. All of them share basic common feature: they use linear electrical generator by coupling its prime mover (translator) with a force coming from the heaving motion of ocean waves. The coupling can be realized by connecting generator's prime mover with a floating body (called point absorber) (Fig. 1-1) or by using subsurface fluctuations of water pressure to move a lid of a sealed chamber housing the linear generator (as in the Archimedes Wave Swing [Polinder, 2004]). Either way, direct bond between prime mover and wave heaving motion brings robustness to the system by eliminating components such as rack and pinion and gear box from the WEC [Ivanova, 2005]. At the same time, elimination of a stage in the energy conversion chain implies higher overall system efficiency.

If the linear generator is moored under the water surface (Fig. 1-1), wave action during the swell period causes the point absorber (buoy) to pull the translator upwards. Afterwards, spring system (or the translator weight) brings it down. This reciprocating movement of the translator produces changing magnetic field in the generator and induces voltage in the armature winding. Speed of the translator is not constant. Therefore, induced voltage has changing frequency and amplitude. Current needs to be rectified and stored in batteries so that electrical energy can be conveniently used.

Ability of the direct driven WECs to directly utilize low speed wave motion, had to be paid by the greater size of linear machine. It makes the linear generator the most expensive part of the system and its selection, design and optimization become crucial problems. 


\subsection{The linear generator types}

Linear generator is electromagnetic device that converts mechanical energy of linear reciprocating motion to the AC electrical energy. Different linear machines (induction, synchronous, switched reluctance) share the same energy conversion principle with their rotary counterparts and are topologically equivalent to their 'unfolded' versions [Boldea, 1997]. Based upon the type of the excitation it uses, linear generator can be:

- induction generator (with and without secondary iron)

- switched reluctance generator

- synchronous permanent magnet generator (with iron and air cored stator).

In terms of efficiency at low speeds, robustness and price, synchronous permanent magnet generators with iron on both stator and translator are the best solution for wave energy conversion [Polinder, 2005]. They are commonly composed of stator that hosts armature windings and translator with permanent magnets. Absence of electrical contacts with the translator is a benefit that helps machine's robustness [Prudell, 2009].

Independently from the type of their excitation system, one can divide linear electrical machines into following categories, based upon the spatial distribution of magnetic circuit material [Gieras, 2011]:

- transverse flux or longitudinal flux

- slotted or slotless

- iron cored or air cored

- flat or tubular 
- single sided or double sided

Most of the commonly used electrical machines belong to the longitudinal flux group. Their flux paths (and the plains to which the flux lines belong to) are parallel to the direction of developed

electromagnetic force. In the case of transverse flux (TF) machines, flux and force and perpendicular to each other. TF generators are permanent magnet machines, generally characterized by high force densities and design freedom [Garcia, 2007]. However, they have low power factor which increases the rating and price of the power electronics converter. TF machines have not yet been widely put into context of the wave energy conversion [Polinder, 2005].

\subsection{Stator slots}

Armature winding can be either fixed by epoxy in the air gap between the back-iron of the slotless stator and the translator [Batzel, 2000] or placed in the stator slots. Slotless stator would eliminate good part of the cogging force from the system, which would be highly appreciated feature in any permanent magnet machine. However, due to its large equivalent air gap (the space occupied by the coils contribute to the air gap), slotless generator requires more magnetic material to establish certain flux linkage and EMF. It is therefore difficult to make inexpensive WEC with the slotless generator. Efficient operation of the slotless and air cored machines is possible only in the zone of high speed prime mover motion [Polinder, 2005].Therefore, iron cored, slotted stator machines are the most suitable choice for a WEC with a direct driven (thus low speed) generator. Possible shapes of stator slots for the LPMG are:

- open

- semi-closed 

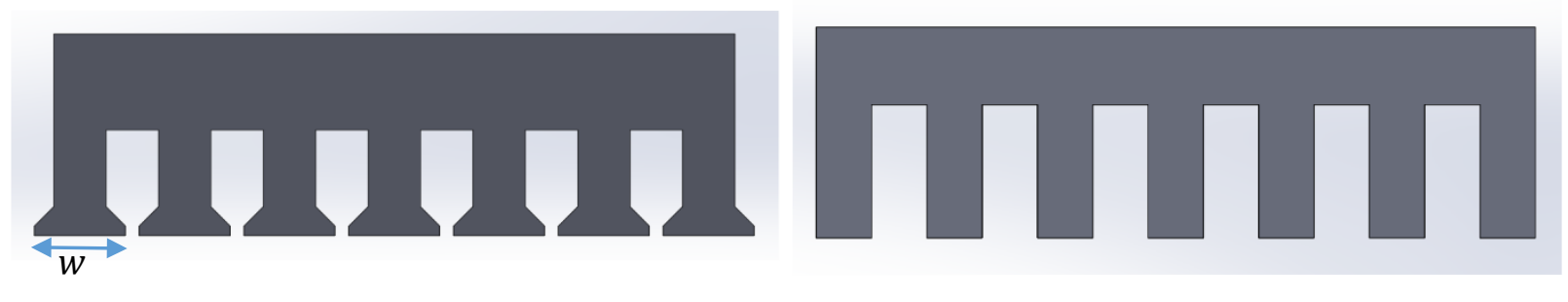

Figure 1-2 Semi closed (left) and open (right) stator slots

Two shapes have different implications on the important performance parameters, such as armature inductance, flux linkage and cogging force.

\subsection{Load angle}

Larger tooth tip width $(w)$ increases effective cross-section area between translator magnets and stator and improves flux linkage of the two. However, wide tooth tip lowers the reluctance for armature leakage, which augments the leakage inductance. Load angle is the angle between the induced EMF $E_{0}$ and the output voltage $V$ (Fig. 1-3). Low value of generator load angle enables usage of cheap and simple diode rectifiers whose operation would otherwise be too inefficient [Danielsson, 2005].

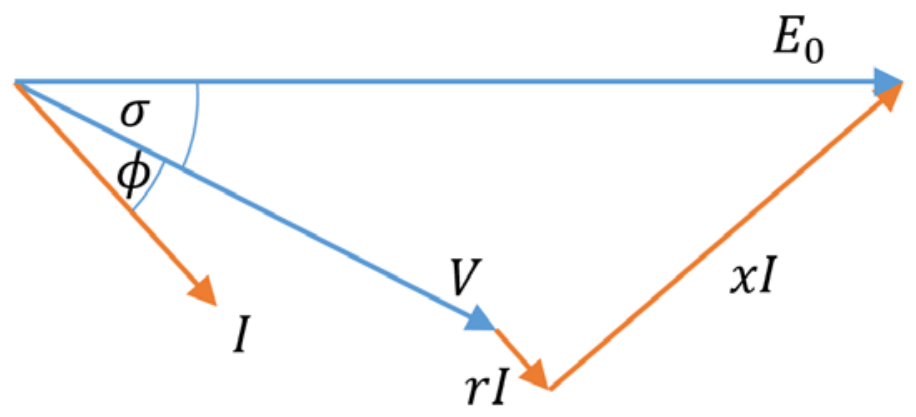

Figure 1-3 Generator phasor diagram: $E_{0}$ - no load electromotive force (EMF); $V$-terminal voltage; Iload current; $x$-armature reactance; $r$-armature resistance; $\phi$ - phase angle; $\sigma$-load (power) angle 
From the phasor diagram (Fig. 1-3), load angle can be calculated as $\sigma=\tan ^{-1}\left(\frac{x}{Z_{L}+\frac{r}{\cos \phi}}\right)$, where $Z_{L}$ is the load impedance with power factor of $\cos (\phi)$. Therefore, the load angle is directly proportional to the armature inductance $x$. Open slots help limit the armature inductance and generator load angle.

\subsection{Cogging force}

Cogging (detent) force produces multiple unwanted effects, such as output power and velocity fluctuations, mechanical vibrations and additional wear on the bearings [Ivanova, 2004]. Before examining the efect slot shapes have on the cogging force, let us briefly explain its origins in the LPMG.

In order to maintain constant active surface area between the stator and translator for the scale of wave amplitudes (translator displacements), either stator or translator needs to be longer. Making the stator longer would increase overall length of armature winding and copper losses, so in most of the cases translator is prolonged. This leads to increased cost of permanent magnet material and to the presence of strong end component in the cogging force [Prudell, 2010]. Each time a translator magnet leaves or enters the stator magnetic circuit, stored magnetic energy associated with its flux severely changes, producing a force. This end force is the reason why linear machines have larger cogging force than their rotary counterparts [Yu-wu Zhu, 2009]. Internal component of cogging force is produced by the attraction between translator magnets and stator teeth. As well as end force component, this attraction force is a result of fluctuations in the stored magnetic energy between different magnet positions. Wider tooth tip makes flux and energy transition less severe, resulting in smaller internal cogging force component. 


\subsection{Flat and tubular linear machines}

In terms of shape and absence or existence of lateral ends, the stator can be tubular or flat (Fig. 1-4). Either one of them is complemented by the appropriate translator. Flat stator can have many sides, forming one enclosed structure with the purpose of normal force minimization. Normal force on the translator is very harmful for machine bearings and can lead to severe damages and even disable system's normal operation [Ivanova, 2004]. In theory, tubular machine has inherently zero radial force between the stator and translator, which is one of the reasons why it has been preferred in many linear generator projects. Furthermore, tubular stator provides better flux encapsulation and uses magnetic material more efficiently. In the tubular topology, open slots should be used due to the simpler manufacturing and winding process [Boldea, 1997].
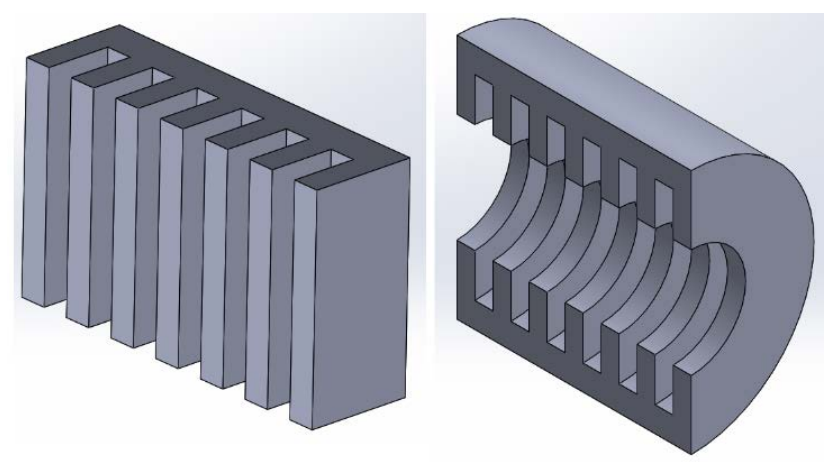

Figure 1-4 Flat stator (left) and cross-section of the tubular stator (right)

\subsection{Single sided and double sided linear machines}

Linear machines can be single sided or double sided, having a stator on only one or on each translator's side. Part of the reason why double sided machines are used in flat topology is to reduce normal forces between the stator and translator. In the double sided configuration, 
permanent magnet generator can obtain higher utilization of magnetic material [Gieras, 2011], and better use of space occupied by the machine [Joseph, 2007]. Additional stator increases effective cross-section area between the stator and translator, thus leading to enhanced flux linkage for the same amount of magnetic material. Many tubular designs with external stator and significant overall radius provide a volume of unoccupied space that could be used by an additional armature system. This is coupled with additional manufacturing difficulties [Gieras, 2011], but may notably improve utilization of magnetic material and reduce overall volume of the machine.
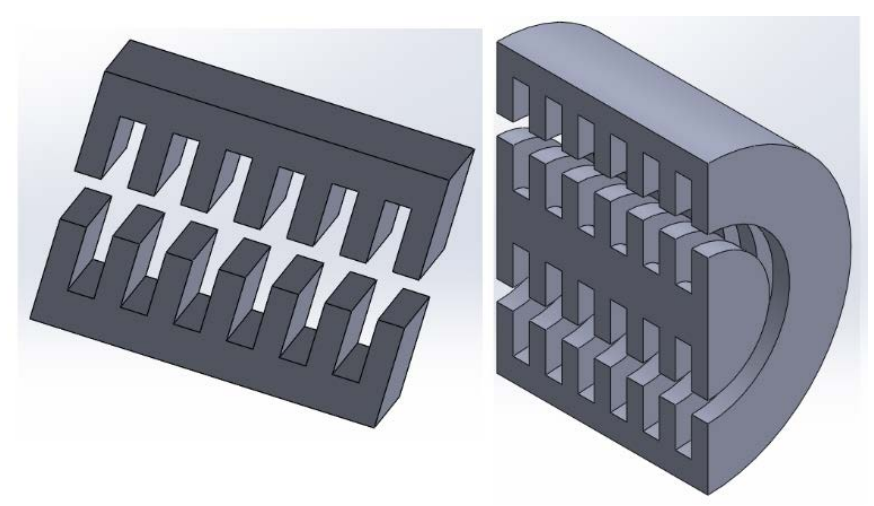

Figure 1-5 Double sided flat stator (left) and cross-section of Double sided tubular stator (right)

For the DS tubular topology, both stators' parts can be cut out of the same piece of ferromagnetic material. That way, no additional expense for the iron is required.

It would be useful to explore the scope of possible improvements in both magnetic material utilization and cogging force two open slot stators can bring. Their proper placement can affect total magnetic circuit and stored magnetic energy, in a way that would supress internal cogging force component, despite usage of plain open slots. 


\subsection{Permanent magnet mounting}

Finally, there are different ways of mounting the magnets on the translator. Translators with axially aligned buried and radially aligned surface mounted magnets are the most common in the linear PM generators. Surface mounted magnets are radially magnetized and fixed on the surface of the translator's back iron (Fig. 1-6 a). Surface mounting is most widely used in the flat topologies and has been proposed for usage in the DS linear generator [Joseph, 2007]. However, such DS topology would require doubling the amount of the PM material on the translator to establish the same air gap flux density as in the SS case. Buried magnets are magnetized in the direction of translator movement and their flux is conveyed to stator through ferromagnetic poles (Fig. 1-6 b). Buried mounting results with higher flux and force capabilities of the machine [Joseph, 2007]. 

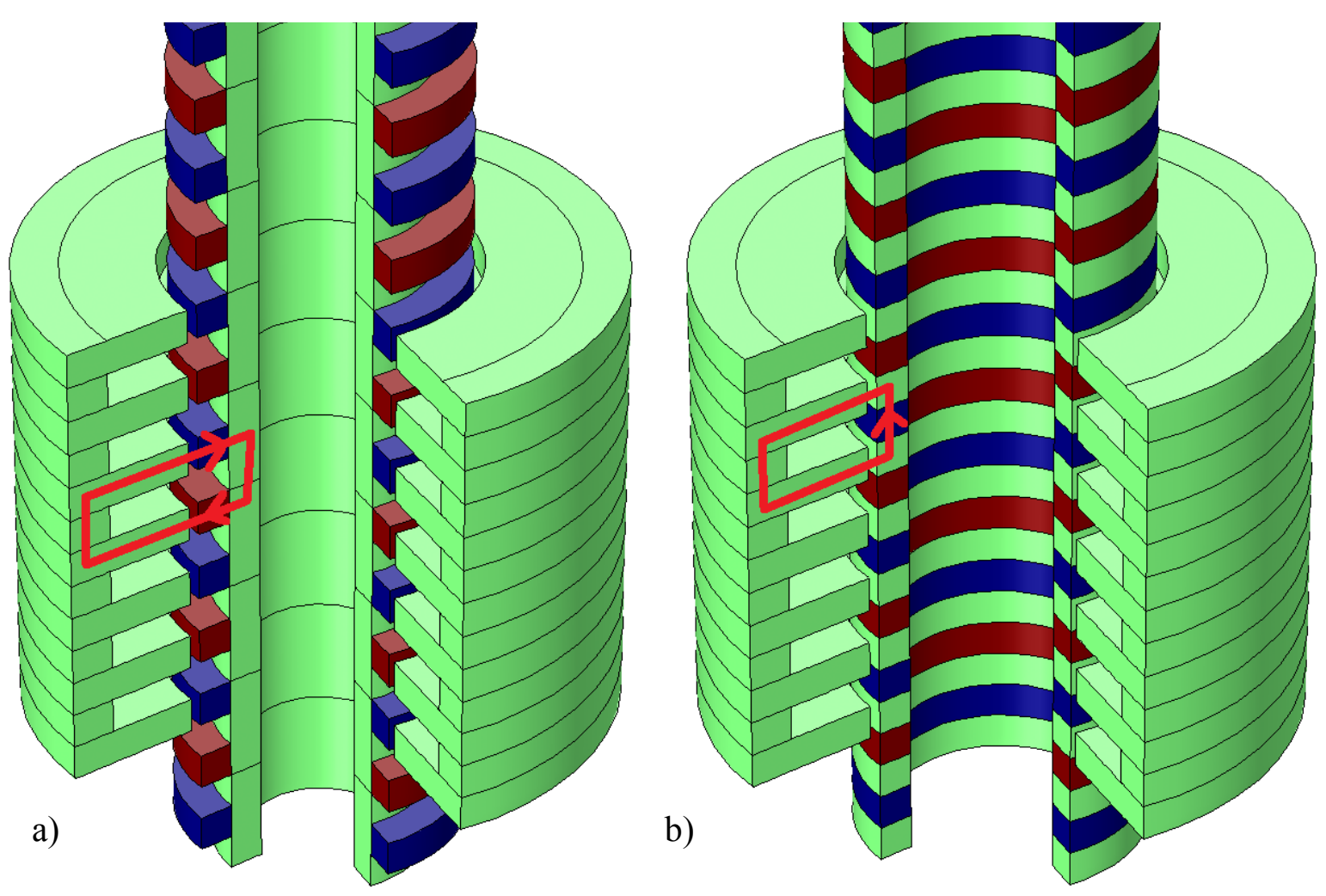

Figure 1-6 a) Radially aligned surface mounted magnets; b) and axially aligned buried

Surface mounted magnets can direct their flux only in one direction. If they are mounted on external surface of the translator, they can establish the filed on that side only. Buried magnets on the other hand, can produce flux in both inwards and outwards direction, depending on the present magnetic circuit on each side. This feature of buried mounted magnets can be exploited in DS topology to supply both internal and external stator with the flux of the same magnets.

\subsection{Research objective and outline of the thesis}

For the direct driven WEC linear generators, permanent magnets are the most suitable excitation source. They provide excitation field in a robust and simple manner. Tubular design supresses the radial force on the translator and enables good PM flux encapsulation. In order to combine good usage of the magnetic material with the manufacturing simplicity, iron cored, tubular 
LPMG with open slot stators has been selected. Buried magnets mounting is preferable because it can establish field in both internal and external stator of a DS LPMG.

Thesis analyses performance of such generator in different topologies, focusing on the PM flux linkage, i.e. no load EMF and the cogging force. The main question is how far does double stator topology improve performance of single sided machine in terms of magnetic material utilization and cogging force.

Chapter 2 describes magnetic circuit of the double sided (DS) linear generator. Mechanism this design uses for enhanced utilization of the magnetic material, i.e. enhanced PM flux production is explained through a comparison with the appropriate single sided (SS) topology. Chapter 2 also explains magnetic interaction between the translator magnets and stator slots that is causing the cogging force. Beneficial effect of the DS structure on the cogging force is identified, together with the optimal air gap condition for the cogging force minimization. Two phase and three phase cases are analysed.

Results of the analyses in Chapter 2 have been verified by the analytical and FEM simulations in Chapter 3. Exact scope of the PM flux enhancement and the cogging force reduction have been obtained. Modeling procedures are later used in the prototype design process, which is described together with prototype construction in Chapter 4. It is important to identify possible practical difficulties in construction of the DS tubular machine. The prototype has been built in a way that facilitates testing of the generator in different topologies, with minor adjustments in the magnetic circuit. 
Finally, after the experimental setup has been described in Chapter 5, measurement results were given in Chapter 6. Measurements were used to verify initial considerations and model predictions about performance of the DS generator. 


\section{Chapter 2}

\section{Double sided Linear Permanent}

\section{Magnet Generator}

\subsection{Introduction}

Open slots make stator manufacturing uncomplicated and cheap. They help keep the slot leakage low and reduce the generator's load angle. On the other hand, they produce weaker flux linkage between the stator and permanent magnets and higher cogging force. Therefore, it is desirable to identify a design solution that would keep the convenience of the open slot structure, but still be able to account for its shortcomings.

Double sided LPMG uses particularly positioned pair of stators to enhance magnetic linkage between the permanent magnets and armature winding, at the same time aiming for suppression of the cogging force. The translator employs buried axially magnetized magnets to establish similar air gap flux density as in the SS topology, without the additional magnetic material. Proposed design is analysed for the DS two phase and the DS three phase topologies. Enhanced PM flux leakage due to the presence of the additional stator has been identified. The leakage has important role in the estimation of the optimal reluctance for the cogging force minimization. 


\subsection{Single sided single phase LPMG}

DS topology is a result of efforts to improve performance of the single sided (SS) single phase generator. Single phase generator is a tubular, linear machine with the ring shaped, axially magnetized permanent magnets on the translator. The magnets are oriented in such a way that the sides of the same polarity are facing each other (Fig. 2-1). Ferromagnetic (iron) rings are stacked between magnets and they form the translator poles. They direct the PM flux into the radial direction, i.e. to the stator (Fig. 2-2).

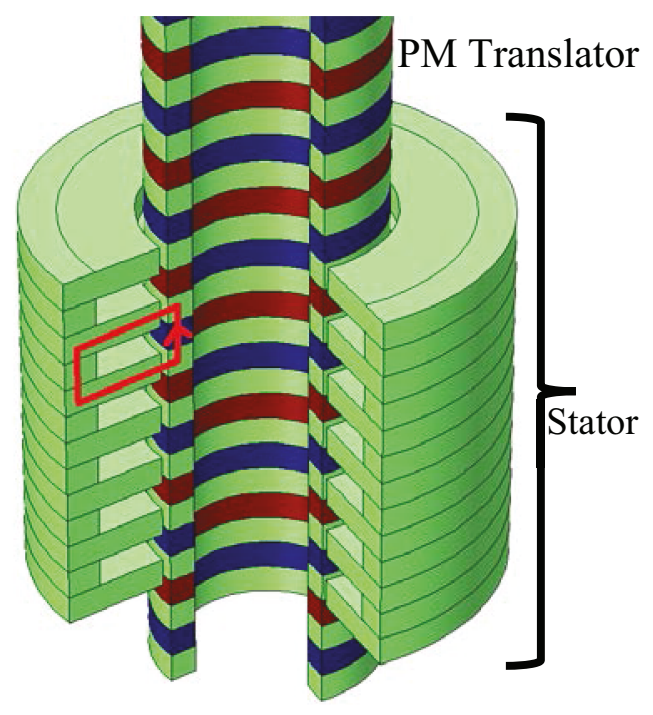

Figure 2-1 Permanent magnet translator and main flux orientation in the SS generator
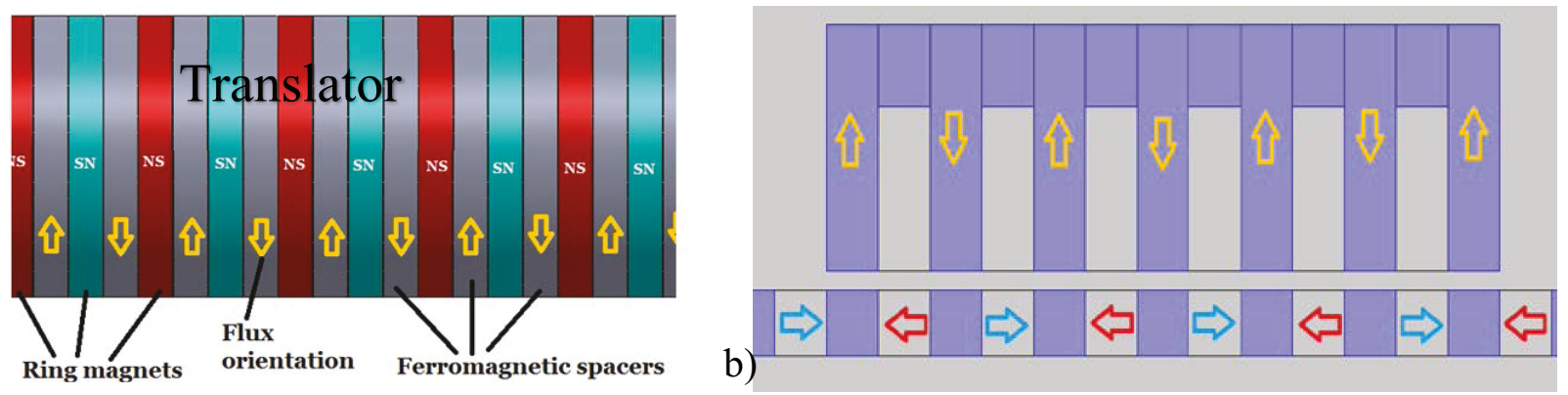

Figure 2-2 a) Translator flux radial orinetation b) main flux path in the machine (cross-section view) 
Stator is ferromagnetic structure housing armature coils in its slots. In the single phase topology PM fluxes in all coils are in phase. From the point of view of the stator PM flux, two characteristic positions should be analysed. Flux linkage between the magnets and the stator is maximum only when translator poles and stator teeth are perfectly aligned (Fig. 2-3 a). PM flux would turn completely into leakage when the poles are aligned with the stator slots (Figure 2-3 b). Such severe fluctuations in produced PM flux are accompanied by fluctuations in the stored magnetic energy, which produce strong cogging force.
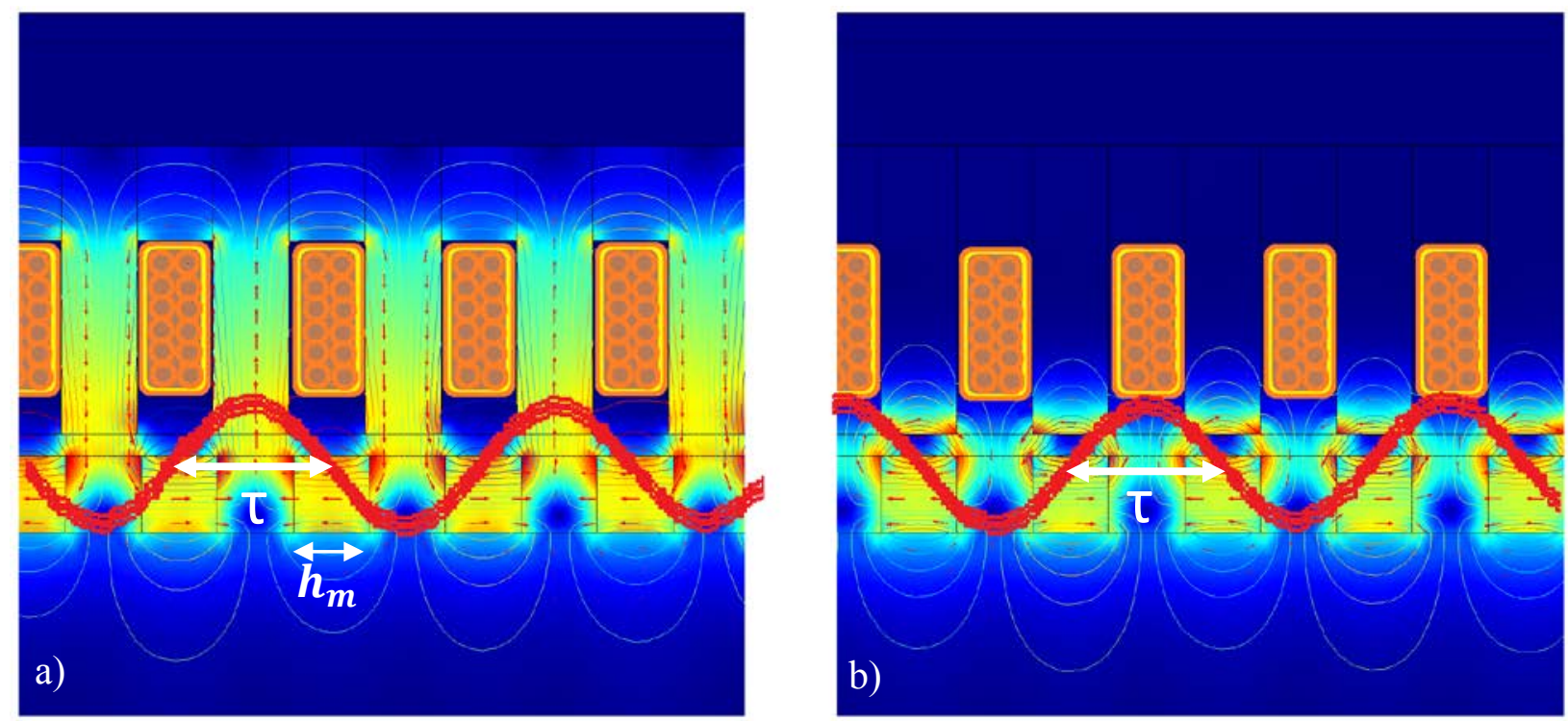

Figure 2-3 FEM model PM flux distribution for two characteristic translator positions in the single phase generator

Every single phase generator is also characterized by oscillations of the output power and developed electromagnetic force at the frequency of electrical system: $\omega=\frac{\pi}{\tau} \vartheta$, where $\tau$ is the translator pole pitch and $\vartheta$ is translator velocity. 


\subsection{Double sided two phase LPMG}

Double sided two phase machine is a topology that tries to utilize PM flux for a continuum of translator positions and at the same time reduce the cogging force. This is obtained by installation of internal stator in addition to the external stator present in the single sided device (Fig. 2-4).

a)

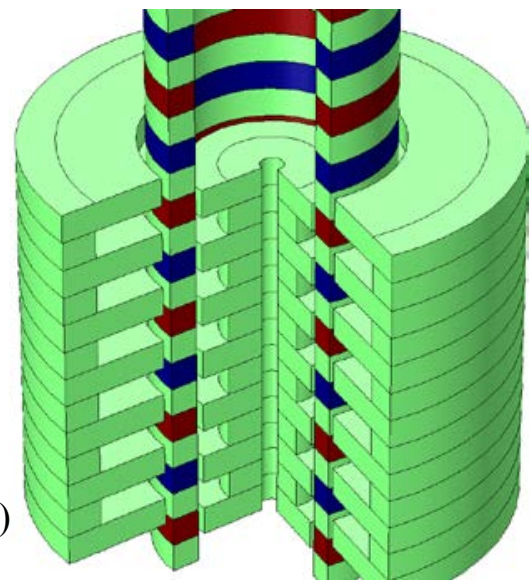

b)

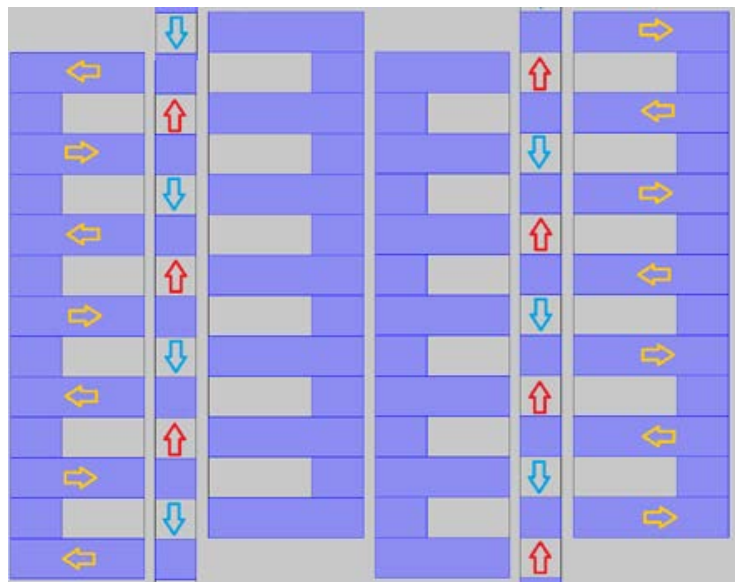

Figure 2-4 Double sided two phase generator a)3D Model b) Flux distribution for two translator positions

Relatively to each other, two stators are shifted along the machine's axis for the length of one magnet height, i.e. one half of the pole pitch $\tau$. As soon as a translator pole stars departing from the external tooth, its flux gradually starts to transfer to the internal stator. Two phase double sided machine preserves full flux linkage between the stator and permanent magnets over a continuum of translator positions, despite having simple open slot geometry. Since the relative displacement between the internal and external stator equals $\frac{\tau}{2}$, phase difference between their EMFs is $\frac{\pi}{2}$, forming a two phase system. It should ideally (limitations will be analysed later) be possible to add an identical phase to the single phase generator and create a two phase system by merely utilizing the translator leakage flux. 
Two phase LPMG eliminates electrical frequency oscillations in developed output power which are present in the SS single phase case. EMF in the each phase is proportional to derivative of the linked flux over the translator position $\frac{d \Phi}{d z}$ and to the translator speed $\dot{z}\left(E=-\frac{d \Phi}{d z} \dot{z}\right)$. Derivatives of the internal and external stator flux EMFs $\left(\frac{d \Phi_{a}}{d z}\right.$ and $\left.\frac{d \Phi_{b}}{d z}\right)$ are displaced by a quarter of translator field's spatial period $\left(T_{s}=\frac{2 \pi}{\omega_{s}}=2 \tau\right)$, so that the induced EMFs take the following form:

$$
\begin{aligned}
& E_{a}=E_{0} \sin \left(\frac{\pi}{\tau} z\right) \dot{z} \\
& E_{b}=E_{0} \cos \left(\frac{\pi}{\tau} z\right) \dot{z}
\end{aligned}
$$

Powers developed in each phase for the resistive load $R_{O}$ add up to:

$$
\frac{E_{a}^{2}}{R_{O}}+\frac{E_{b}{ }^{2}}{R_{O}}=\frac{E_{0}{ }^{2}}{R_{O}} \dot{z}\left(\sin \left(\frac{\pi}{\tau} z\right)^{2}+\cos \left(\frac{\pi}{\tau} z\right)^{2}\right)=\frac{E_{0}{ }^{2}}{R_{O}} \dot{z}
$$

Figure 2-5 demonstrates the smoothness of the total output power $P$ of a linear two phase generator for sinusoidal translator movement. Developed electromagnetic force is $F=\frac{P}{\dot{Z}}$ which is also free of ripple. 


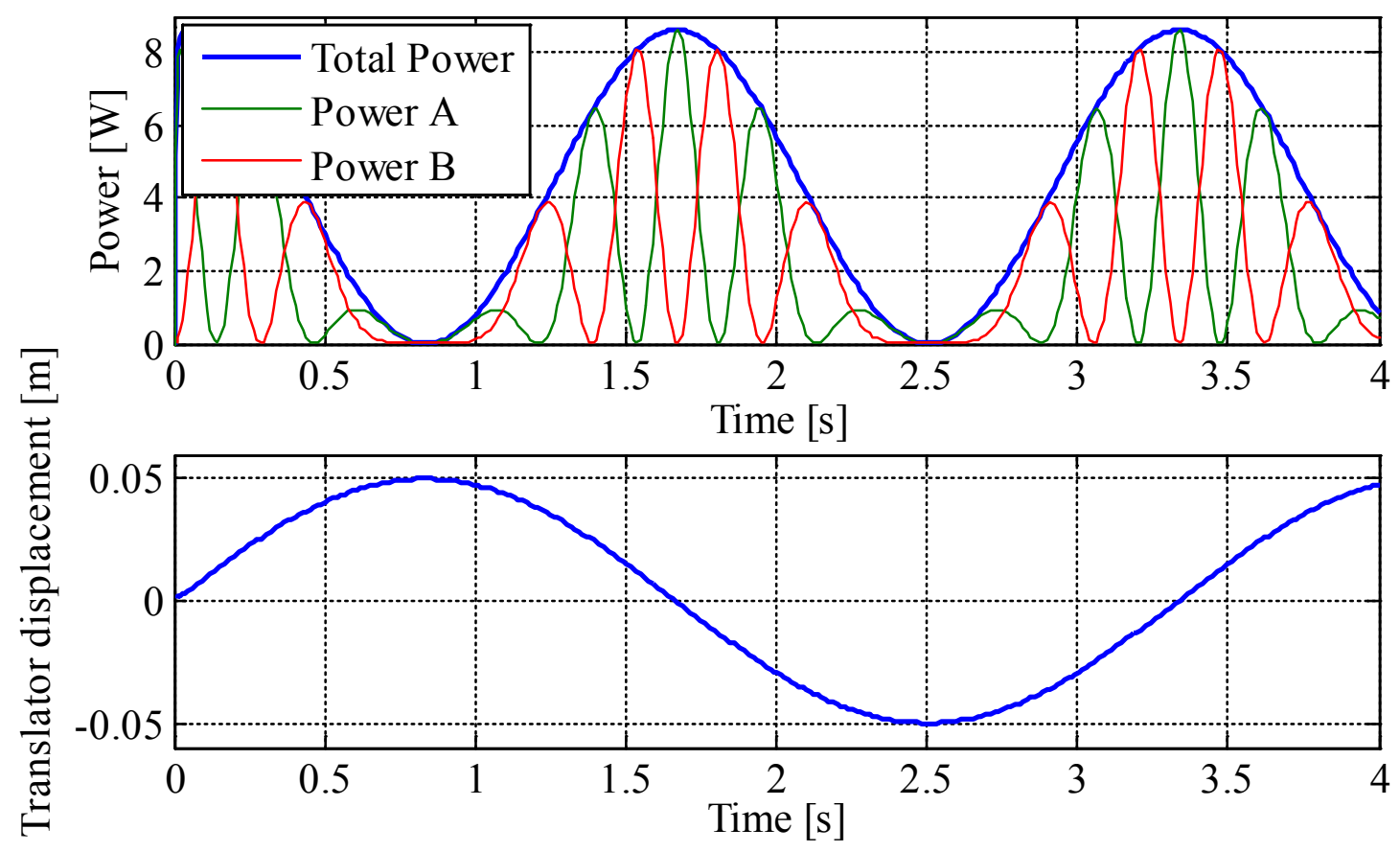

Figure 2-5 Two phase generator output power for each phase (A and B) and total output power for sinusoidal translator displacement

\subsection{LPMG Cogging Force}

Each magnet produces its own contribution to the cogging force. Fractional coil pitch moves these components out of phase and prevents them from adding up. However, it also reduces the winding factor and total phase EMF. Proposed double sided generator has improved cogging force characteristics compared to the single sided single phase machine, despite having the same full pitch winding.

In a linear permanent magnet machine cogging force can be expressed as a derivative of total stored magnetic energy $W_{m}$ over the translator axial position $z$ :

$$
F_{c o g}=-\frac{d W_{m}}{d z}
$$


Practically all magnetic energy is stored in the air elements of the magnetic circuit. The reluctance of a flux path through the air can be calculated as:

$$
R=\frac{l}{\mu_{0} A}
$$

where $l$ is the length of the path and $A$ is the available cross-section area. If the translator poles are fully aligned with the stator teeth (Fig. 2-3 a), cross-section area between stator teeth and translator poles is maximized and the flux experiences the smallest reluctance. In any other translator positon, the reluctance is greater. Therefore, the reluctance of the air path occupied by the PM flux depends on the translator position and will be denoted by $R_{g}(z)$. Appropriate air gap reluctance is $R_{g}(z)$ and the magnet reluctance is $R_{p m}$. The magnet reluctance does not depend on the translator position; it is determined by dimensions of the magnet. Permanent magnet is considered to be a source of the magneto-motive force (MMF) $F_{p m}$ which is responsible for the flux in the air gap $\phi$. The stored magnetic energy in the air gap can be calculated as [Brown, 2006]:

$$
W_{m}(z)=\frac{\phi^{2}}{2}
$$

From the magnetic circuit at Fig. 2-6, which assumes the infinite permeability of ferromagnetic elements, PM flux follows as:

$$
\phi=\frac{F_{p m}}{\left(R_{g}(z)+R_{p m}\right)}
$$


Therefore, equation 2.6 for the stored magnetic energy takes the following form:

$$
W_{m}=\frac{\left(F_{p m}\right)^{2}}{2} \frac{R_{g}(z)}{\left(R_{g}(z)+R_{p m}\right)^{2}}
$$

and finally from eq. 2.4 we have expressed the cogging force as a function of the fluctuations in the air gap reluctance $R_{g}(z)$ 'seen' by the translator magnets:

$$
F_{c o g}=-\frac{\left(F_{p m}\right)^{2}}{2} \frac{d}{d z}\left(\frac{R_{g}(z)}{\left(R_{g}(z)+R_{p m}\right)^{2}}\right)
$$

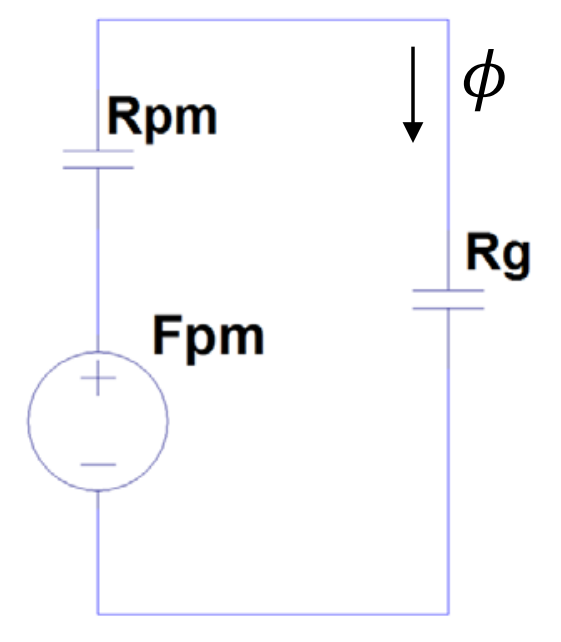

Figure 2-6 Main flux reluctance

Proposed positioning of two stators (Fig. 2-4 b) aims to level out air gap reluctance for different translator positions by matching the reluctances of alignment with internal $\left(R_{g 1}\right)$ and external stator $\left(R_{g 2}\right)$. If the two reluctances are matching, then the air gap reluctance should not change with translator position and the cogging force should be eliminated. Figure 2-7 b) displays FEM calculations for total stored magnetic energy of a single translator cell (permanent magnet joined by two iron poles), entering stator magnetic circuit for both SS and DS case. 
a)
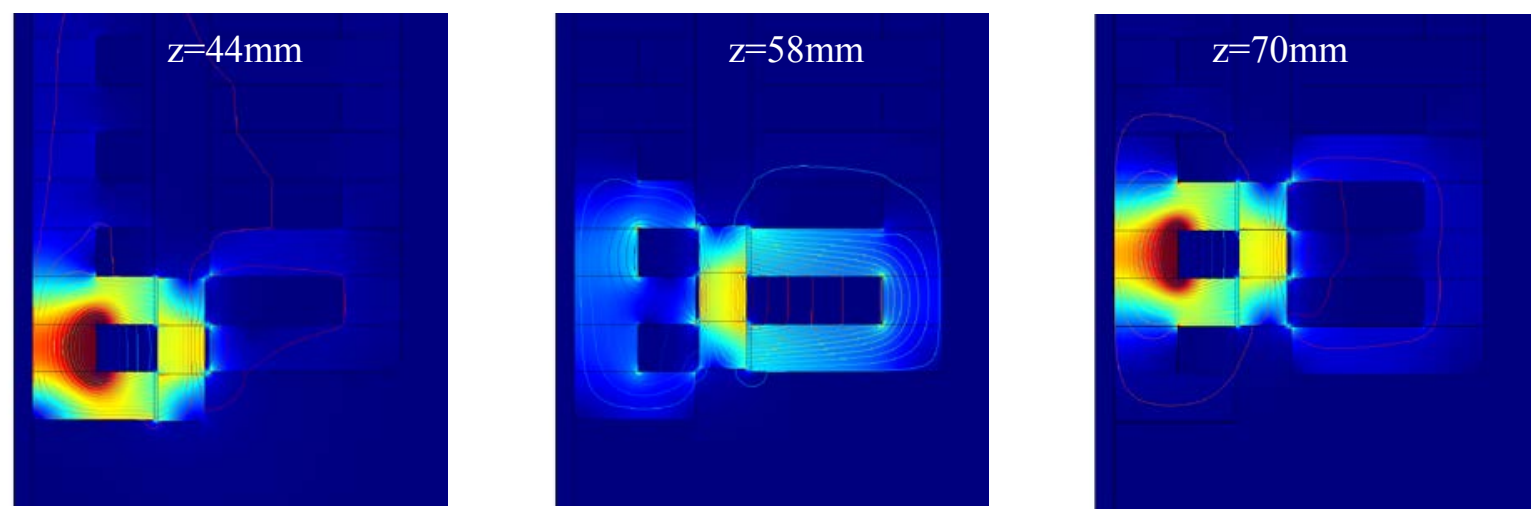

b)

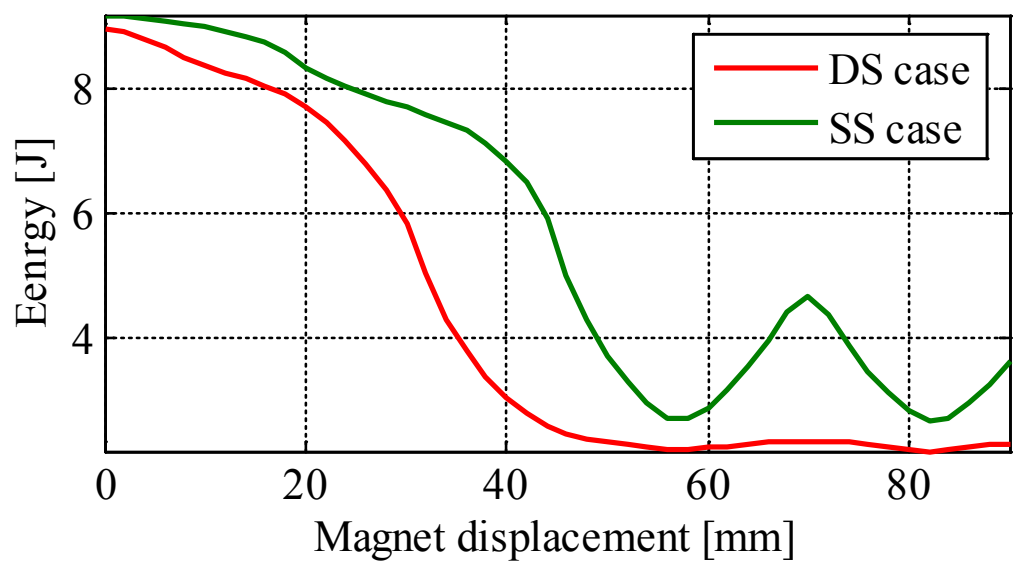

Figure 2-7 a) Magnet entering DS magnetic circuit; b) associated stored magnetic energy in SS and DS magnetic circuit for different magnet positions (external air gap g2=1mm and internal air gap

$$
g 1=0.9 \mathrm{~mm})
$$

As it can be seen from Figure 2-7, the DS topology minimizes cogging force component that comes from interactions of magnets and stator slots (teeth). Contribution to the cogging force also comes from the change in the stored energy $(z \in(20 \mathrm{~mm}, 50 \mathrm{~mm})$ at Fig. $2-8 \mathrm{~b})$ of a magnet entering or leaving stator's magnetic circuit, assuming longer translator. It should be noted that the DS topology does not provide any significant contribution to reduction of the cogging force end component.

Before cogging force reduction is further analysed, it is important to note that the presence of another stator enhances PM flux leakage and affects the overall PM flux distribution (Fig. 2-8). 

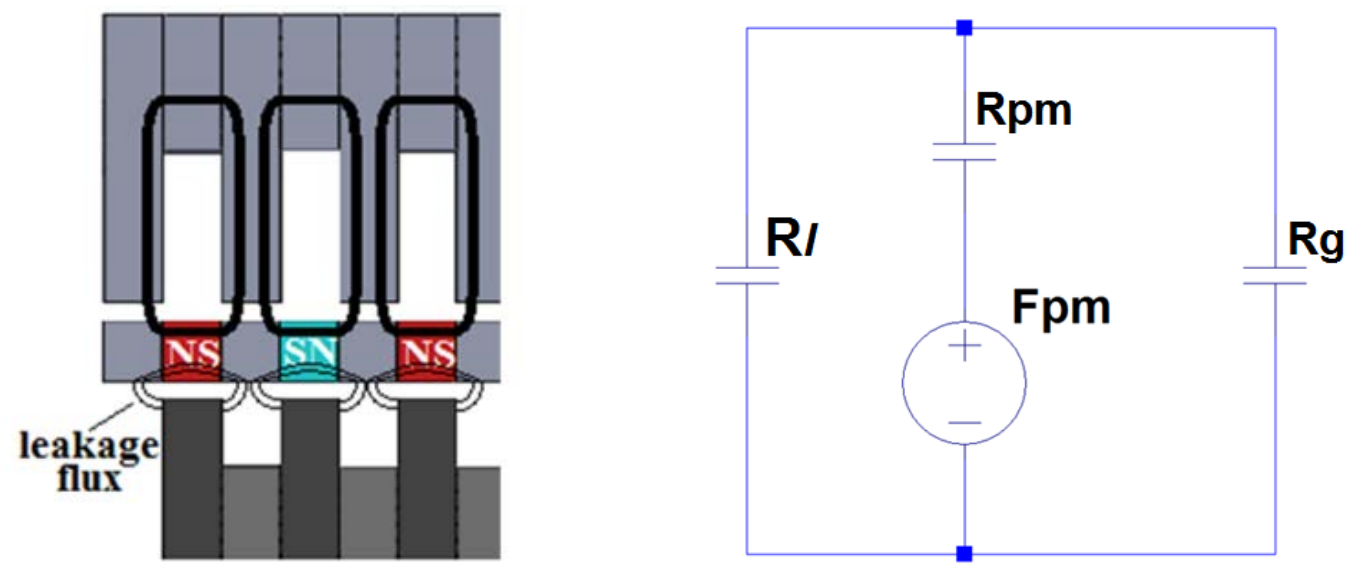

Figure 2-8 PM flux reluctance network includeing the leakage

When the translator is aligned with the external (internal) stator, PM magneto-motive force establishes flux through two parallel reluctances: main flux in the external (internal) air gap and the leakage flux that transverses the internal (external) slot openings. Total air gap reluctance when the translator is aligned with the external (internal) stator is therefore: $R_{a}^{2}=R_{g 2} \| R_{L}^{1}$ $\left(R_{a}^{1}=R_{g 1} \| R_{L}^{2}\right)$,where $R_{L}^{1}\left(R_{L}^{2}\right)$ is the reluctances of the leakage flux path over the internal (external) slots. Thereafter, if the internal air gap has been fixed, optimum length of the external air gap can be deduced from the equation:

$$
R_{a}^{1}=R_{a}^{2}
$$

Enhanced PM flux leakage is the reason why each stator (phase) of the DS two phase machine has smaller peak flux and EMF compared to the SS single phase case.

\subsection{Single sided two phase LPMG}

In the SS single phase and DS two phase machine, translator pole pitch equals the distance between adjacent stator slots. Translator pole pitch of a single sided two phase machine would have to be twice as wide in order to produce phase difference of $\frac{\pi}{2}$ between adjacent coils. 
Assuming the same amount on magnetic material on both translators, SS two phase translator would have twice as much magnetic material per pole (Fig. 2-9). Therefore, it would produce approximately twice as high peak flux $\Phi_{M}$ in each stator coil. At the same time, longer pole pitch halves the frequency $\omega \sim \frac{1}{\tau}$ of the induced EMF. Knowing that the coil EMF is proportional to both peak flux and the frequency $\left(E_{0} \sim \omega \Phi_{M}\right)$, one can conclude that the SS and DS two phase machines would have the same EMF per coil. The only difference is that the DS translator is feeding twice as many coils, which results with twice as high phase EMF for the same stator and translator length.

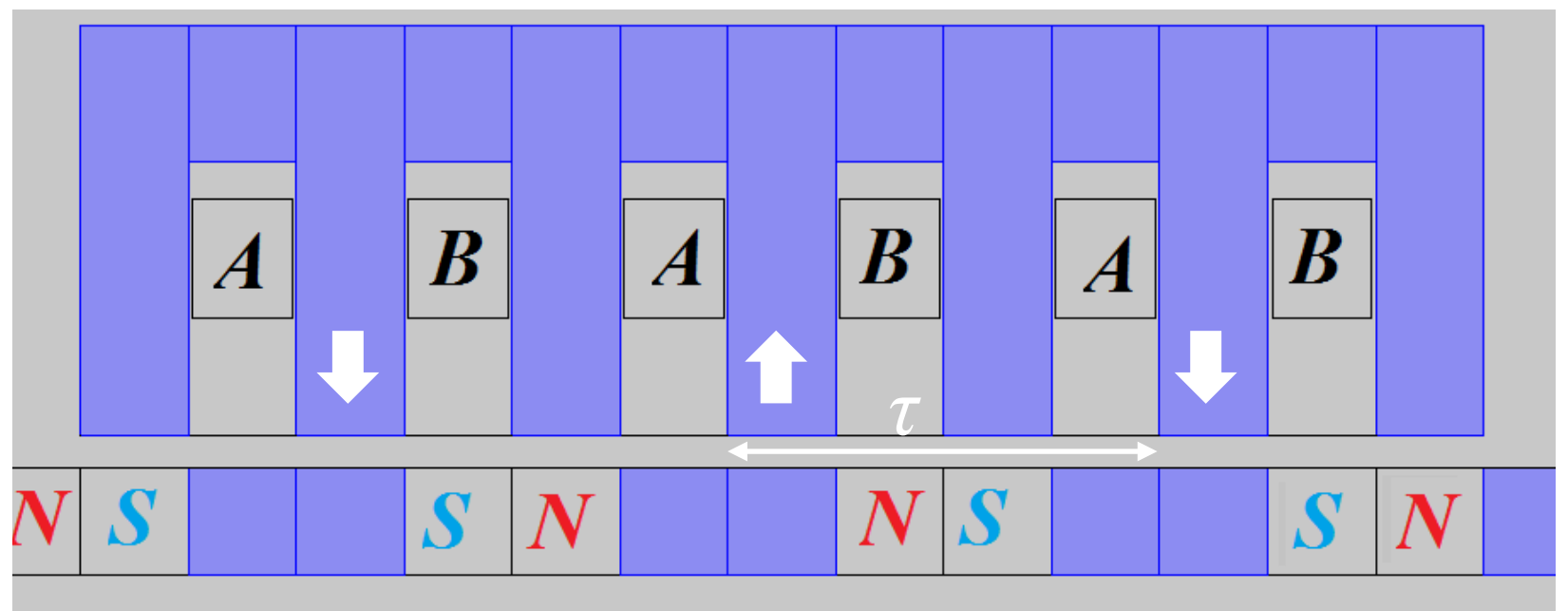

Figure 2-9 PM flux distribution in the single sided two phase generator

\subsection{Double sided three phase LPMG}

Open slot three phase generators with buried permanent magnets are uncommon in direct driven wave energy converters. Design with axially magnetized magnets buried in translator does exist but it includes extruded pole tips on both stator and translator [Andrea].Such shape of magnetic circuit leads to improved flux linkage and smaller cogging force. Its drawbacks are enhanced manufacturing complexity and overall radial dimensions. 
This study investigates whether the addition of an extra stator would improve performance of SS open slot three phase machine with buried magnets. In the SS three phase machine half of the translator magnets have their flux linked with the stator coils while the rest is mostly producing leakage flux (Figure 2-10 a). This leakage flux is in phase with the main flux. Presence of the additional stator would make it possible to increase the peak of the main flux by effectively joining this leakage to it. Enhancement in the PM flux is limited by the leakage produced by the presence of additional stator. Exact scope of the improvement will be analysed by the simulations and experiment.

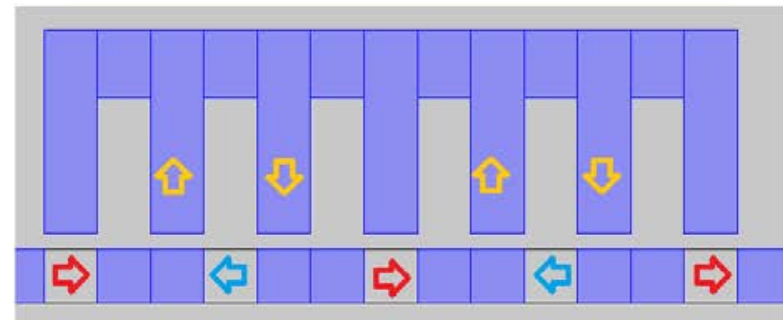

a)

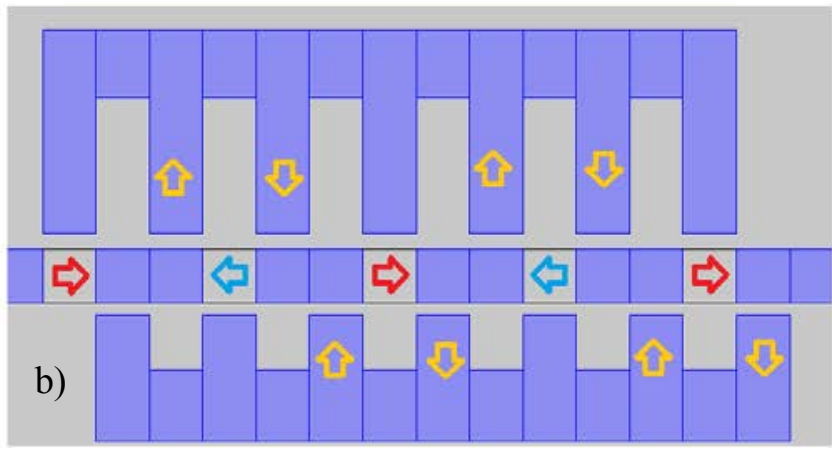

Figure 2-10 Main flux in three phase SS (left) and DS topology (right)

Three phase translator has $\frac{3}{2}$ times wider pole pitch than the single phase and DS two phase translator. This is achieved by using the same magnets with the iron rings which are twice as high (Fig. 2-10). Three phase system is induced in each stator's winding. The shift between stators equals $\frac{1}{3}$ of the pole pitch. This means that three phase systems of internal and external stator should have phase difference of $\frac{\pi}{3}$ between themselves. Phase diagram of the induced phase voltages and winding outline are shown at Figure 2-11 a)-b). 


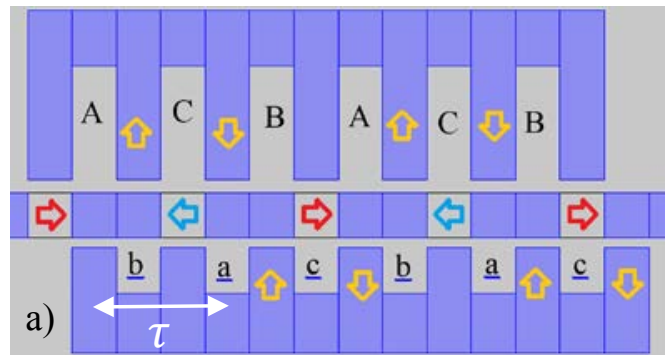

b)
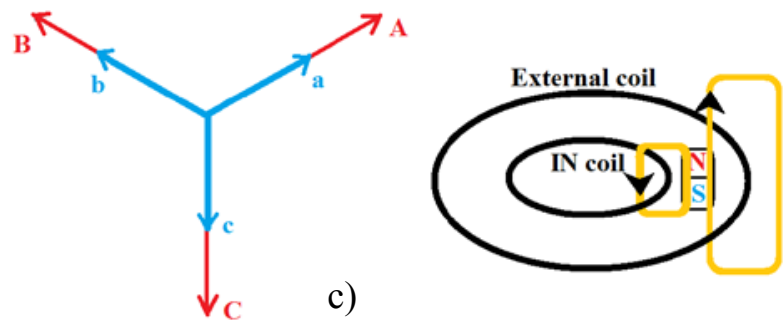

Figure 2-11 a) DS three phase machine main PM flux distribution b) phasors for the internal and external phase voltage c) flux orientation in the

Phase diagram on Figure 2-11 b) indicates that induced voltages and fluxes in coils $A$ on the external stator and $a$ on the internal stator are in phase. This might be curious because they are displaced by only one slot pitch $\tau_{3 \phi}$ i.e. by $\pi$. However, the fact that external and internal stator lie on different sides of the PM translator causes the same magnet to produce flux of different vertical orientation in the external stator coil and the internal stator coil (Fig. 2-11 c), therefore adding up an extra $\pi$ to the phase angle between external and internal fluxes. This is mainly important for the modeling purposes.

\subsection{Summary}

DS topology is able to improve the flux linkage between stator and translator in the two phase and three phase topologies. However, additional stator intensifies the PM flux leakage and somewhat reduces positive flux augmentation. In the following chapters, exact scope of the stator flux and EMF enhancement will be analysed by modeling and experimental means.

Two cogging force components have been identified. One comes from the interaction of translator poles and stator teeth (internal component), while the stator ends produce the second (end component). In both cases, changing reluctance of the PM flux path (for different translator positions) generates the force. Complementary placement of two stators in the DS topology 
reduces oscillations of reluctance seen by the magnets and suppresses the internal cogging force component. 


\section{Chapter 3}

\section{System modeling}

\subsection{Introduction}

Both analytical and FEM approach have been used to model behaviour of different LPMG topologies and see how do they compare in terms of the PM flux linkage, inductance and cogging force. The analytical model is based upon simple reluctance networks of the magnetic circuit. In terms of the main flux and inductance predictions, it has mostly been in good agreement with the FEM simulations. However, where highly accurate knowledge of magnetic flux spatial distribution is necessary for the quality of results, such as in cogging force calculation, the FEM simulations were solely used.

Simulation models have been built based upon the actual prototype. Comparison between the model results and experimental results follows in the Measurement results chapter.

\subsection{Permanent magnet flux modeling}

Analytical estimate of PM flux in stator is based upon a magnetic circuit equivalent network. Its elements account for present magneto-motive forces (MMFs) and reluctances. Reluctance networks commonly neglect reluctance of ferromagnetic material and include only reluctance of air gaps and permanent magnets, together with the magnet's MMF. Reluctance network has been constructed for the translator position producing peak stator flux. From the network, peak value 
of the stator PM flux has been determined. Therefore, based upon the peak flux value and the length of the translator pole pitch (that determines the spatial period of the translator magnetic field) dependence of the stator PM flux on the translator position has been determined. This result rests on the assumption of sinusoidal variations of the flux with the translator position.

Flux lines between two parallel equipotential ferromagnetic surfaces are assumed to be straight lines, perpendicular to the surfaces (Fig. 3-1 a). Flux lines between two perpendicular ferromagnetic surfaces are placed on circumferences of concentric circles (Fig. 3-1 b). Based upon these assumptions, it has been possible to determine reluctances of each air gap section of interest. Relative permeability of the magnets is usually very close to the permeability of air. For purposes of the analytical model it can be assumed that they are identical.
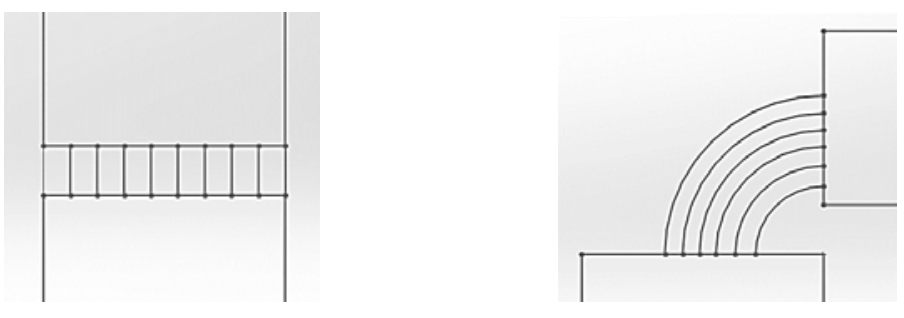

Figure 3-1 a) Flux lines between parallel and b) perpendicular surfaces

Equation (3.1) yields reluctance of air between two equipotential, coaxial surfaces of length $h$, and radii $r_{\text {in }}$ and $r_{\text {out }}$ (Fig. 3-2):

$$
R=\frac{1}{2 \pi \mu_{0} h} \ln \left(\frac{r_{\text {out }}}{r_{\text {in }}}\right)
$$




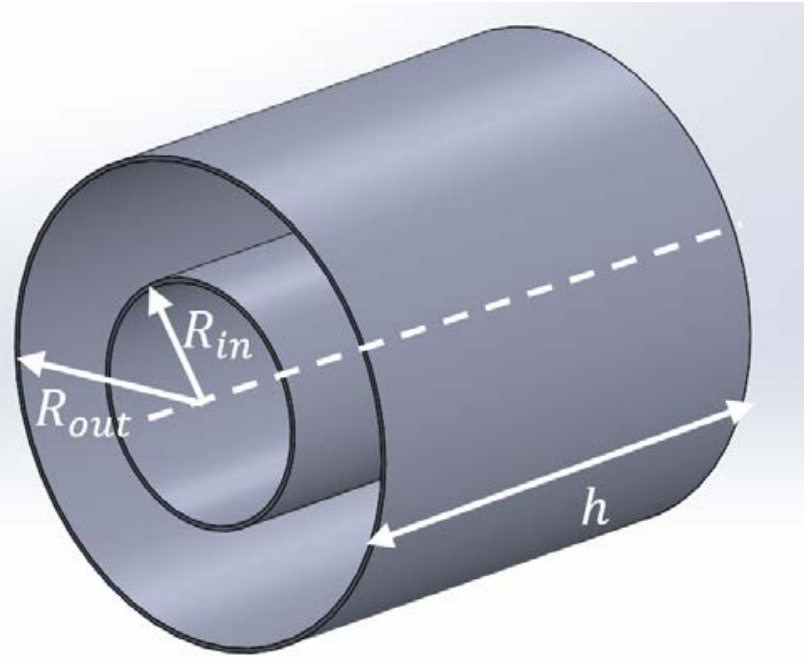

\section{Figure 3-2 Dimensions of two coaxial cylinders for internal reluctance calculation}

This equation can be used to determine reluctance between the stator tooth and translator pole in the tubular machine. For the particular cases of internal and external air gaps with perfect overlap between the translator and stator pole (Fig. 3-3), equation 3.1 respectively takes the following forms:

$$
\begin{aligned}
& R_{g 1}=\frac{1}{2 \pi \mu_{0} h_{m}} \ln \left(\frac{r_{M 1}}{r_{M 1}-g_{1}}\right) \\
& R_{g 2}=\frac{1}{2 \pi \mu_{0} h_{m}} \ln \left(\frac{r_{M 2}+g_{2}}{r_{M 2}}\right)
\end{aligned}
$$

where $g_{1}$ and $g_{2}$ are the internal and external air gap lengths, $r_{M 1}$ and $r_{M 2}$ are internal and external radius of the ring magnet and $h_{m}$ is the magnet height which matches the stator tooth height (Fig. 3-3). 
Permanent magnet is modeled through the serial connection of its equivalent MMF and reluctance. The MMF is calculated based upon the magnet's coercive force $H_{c}$ and height $h_{m}$ as [Boldea, 1997]:

$$
F_{P M}=h_{m} H_{c}
$$

Reluctance of ring shaped axially magnetized permanent magnet is determined by its dimensions:

$$
R_{P M}=\frac{h_{m}}{\pi \mu_{0}\left(r_{M 2}{ }^{2}-r_{M 1}^{2}\right)}
$$

\subsubsection{Single sided single phase LPMG}

Leakage of the PM flux for the translator positions which is providing the peak stator flux is not significant in the case of the single sided single phase machine (Fig. 3-3).

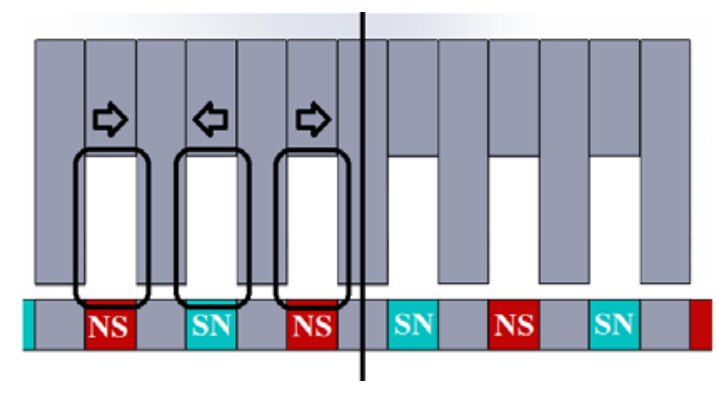

Figure 3-3 Elements of SS single phase magnetic circuit included in reluctance network

This yields very simple equivalent network of the machine's magnetic circuit (Fig. 3-4). It contains only the PM MMFs, PM reluctances and air gap reluctances of the main flux paths. The network has been constructed only for one half of the machine due to its symmetry. 


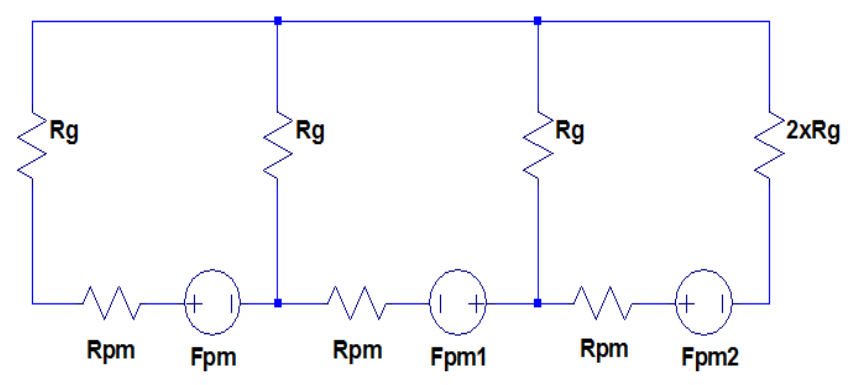

Figure 3-4 SS single phase LPMG reluctance network

Axially symmetrical, tubular topology of the proposed machine enables its representation in two dimensions for the purpose of the FEM analysis. Construction of the model geometry is therefore facilitated and computational time is reduced. For analysis of the flux distribution produced by the permanent magnets, COMSOL® uses Magnetic fields, no currents physics. In this mode, the dependant variable is magnetic scalar potential $V_{m}$ [Permanent magnet, 2015]. Since the system is current free, the model uses following equation (eq. 3.6) to calculate the value of $V_{m}$ :

$$
-\nabla\left(\mu_{0} \nabla V_{m}-\mu_{0} \overrightarrow{M_{0}}\right)=0
$$

where $\nabla$ is nabla operator and $\overrightarrow{M_{0}}$ is magnetization vector. The model does not contain time dependant variables and it uses only stationary analysis. Regions of the PM material have been constituted through relation between the amplitude of the magnetization vector, flux density $\vec{B}$ and magnetic field vector $\vec{H}$ :

$$
\vec{B}=\mu_{0}\left(\vec{H}+\overrightarrow{M_{0}}\right)
$$


Magnetization vector value is obtained from Neodymium rare earth grade N42 material specification sheet [Demagnetization $(\mathrm{BH})$ curve, 2015]. PM material regions in the model only have axial magnetization vector component.

Mesh size has been fixed when further improvement in the mesh quality stopped producing any changes in the calculated flux. Simulation found solutions for spatial flux density distribution (Fig. 3-5) for a scale of different translator positions. This way, after the integration of flux density over the stator yoke (Fig. 3-5), a full period of the stator flux has been obtained. Lacking angular flux component, total flux has been calculated as an integral of radial and axial flux density contributions:

$$
\phi=\int_{1,3,5} \sqrt{{B_{r}}^{2}+B_{z}^{2}} \operatorname{sign}\left(B_{z}\right)-\int_{2,4,6} \sqrt{{B_{r}}^{2}+B_{z}^{2}} \operatorname{sign}\left(B_{z}\right)
$$

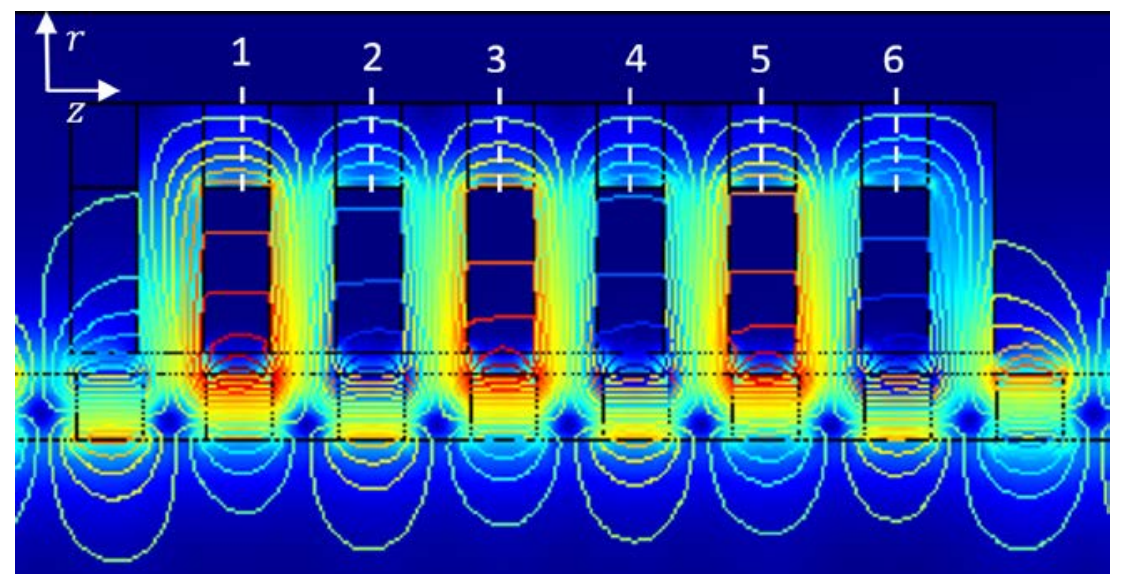

Figure 3-5 FEM calculation of total linked PM flux for position of the translator $z=12.7 \mathrm{~mm}$

Figure 3-6 provides analytical and FEM predictions for the stator flux as a function of the translator position. Small discrepancy comes from the effects unaccounted in analytical model. Most significant among them are the leakage on the ring's internal periphery and stator slot leakage, as well as the reluctance of the magnetic circuit elements. 


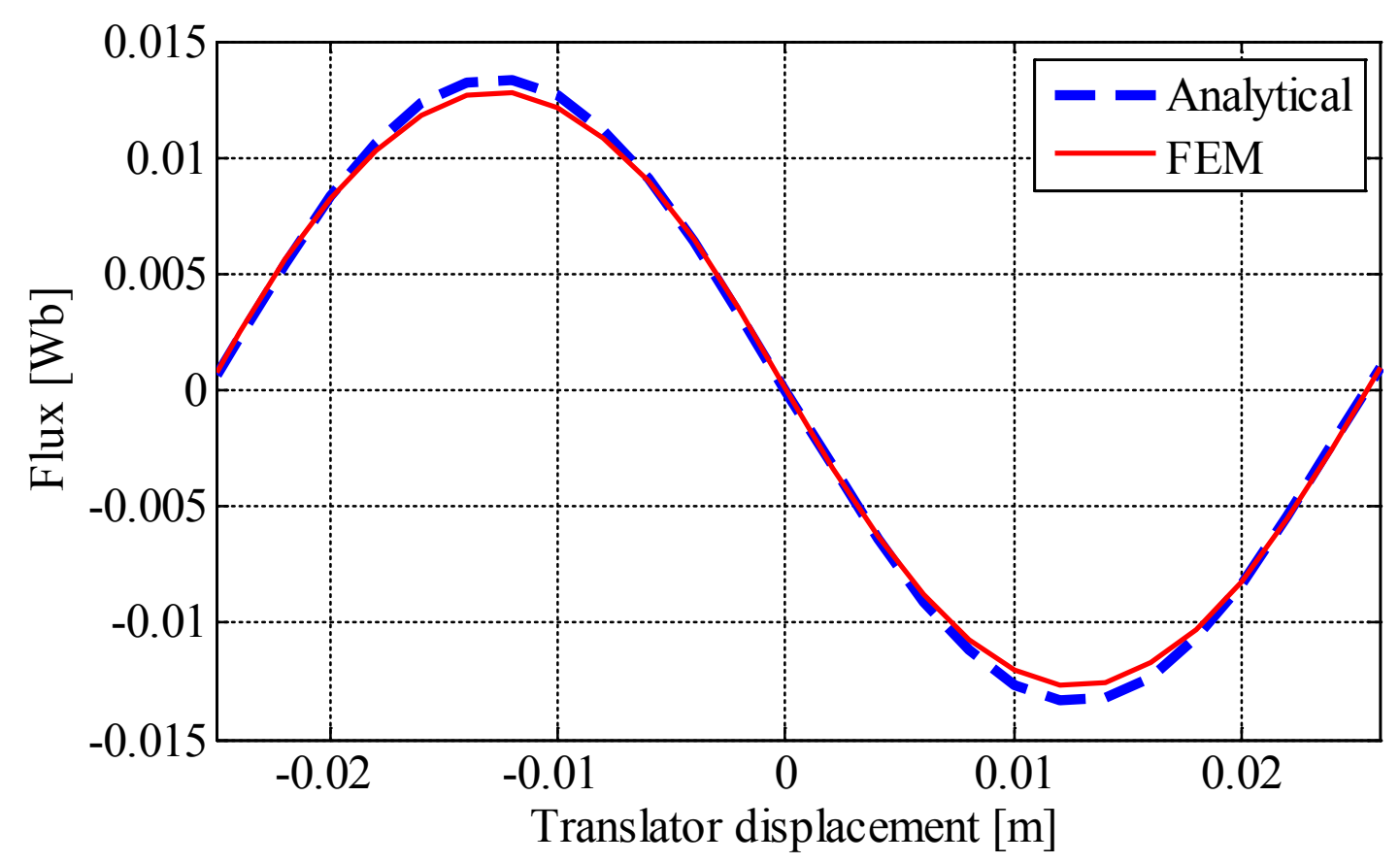

Figure 3-6 SS Single phase flux - the analytical and FEM model predictions

\subsubsection{Double sided two phase LPMG}

Presence of additional ferromagnetic material changes the PM flux spatial distribution in the double sided topology. The PM flux leakage becomes more significant due to reduced reluctance of the leakage flux path (Fig. 3-7). Consequently, amplitude of the useful stator flux decreases compared to the case of the single stator machine. In order to accurately estimate newly established amplitude of the useful stator flux, changes have to be made in the reluctance network and reluctance of the leakage path have to be included. Leakage flux branches are added to the existing SS reluctance network in parallel with the PM elements (Fig. 3-8). 


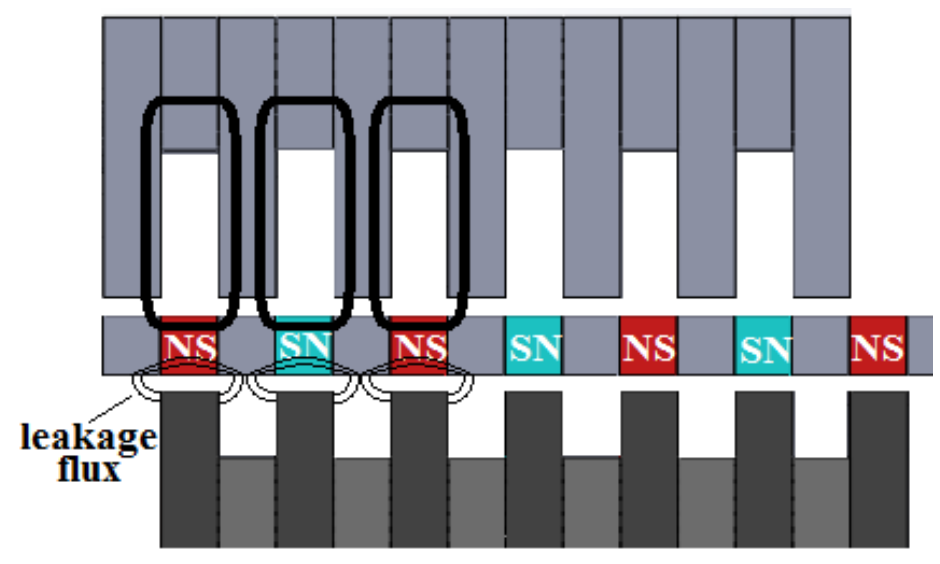

Figure 3-7 Leakage flux due to the additional stator in the DS two phase LPMG

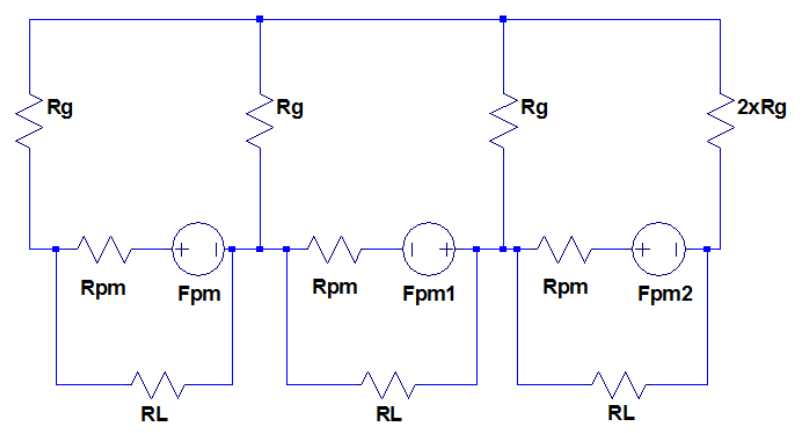

Figure 3-8 DS two phase LPMG reluctance network

The reluctance elements in the branch account for the air gap portion of the leakage path. One magnet's leakage flux occupies one half of the translator's pole width $t\left(t=h_{m}\right.$ and $\left.\frac{t}{2}=\frac{\tau}{4}\right)$. It has been assumed that the leakage flux lines lie on a circle circumference between the translator pole and unaligned stator tooth (Fig. 3-9). 


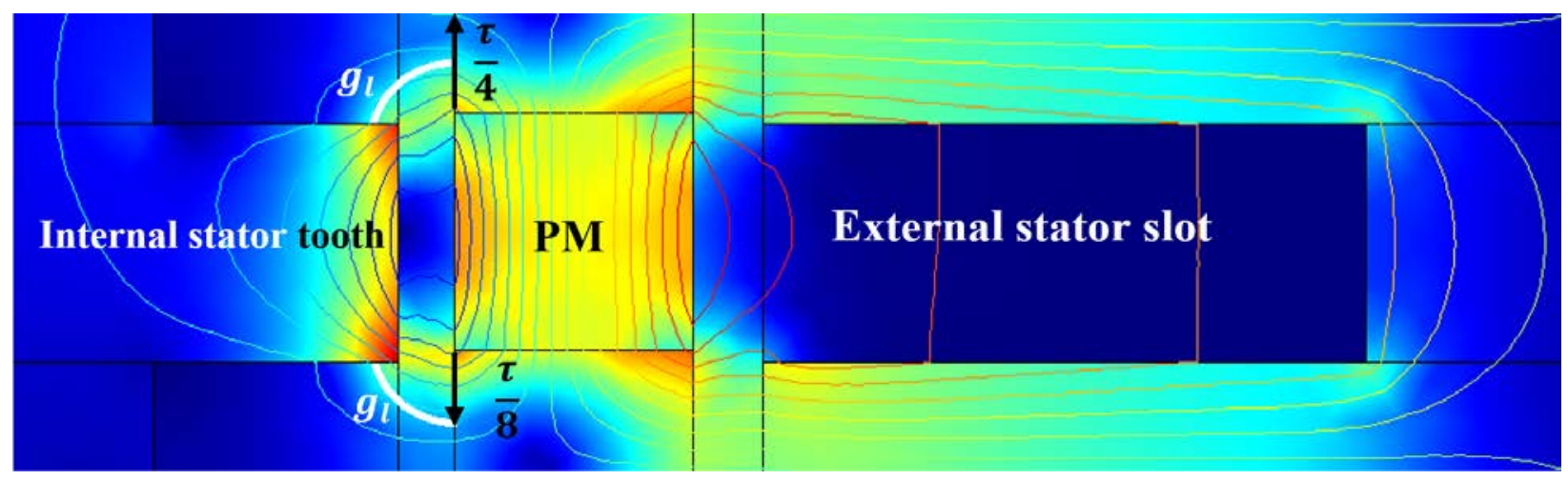

Figure 3-9 Leakage of a translator magnet aligned with the external stator

This assumption enables calculation of the mean air gap distance $g_{l 1}$ covered by the leakage flux lines, as well as of the area $A_{l 1}$ available for the flux lines to spread:

$$
\begin{gathered}
g_{l 1}=\frac{1}{4} \frac{\tau}{8} 2 \pi \\
A_{l 1}=\frac{1}{4} \tau 2 \pi R_{M 1}
\end{gathered}
$$

From $g_{l 1}$ and $A_{l 1}$, internal air gap leakage reluctance follows as:

$$
R_{L}^{1}=2 \frac{g_{l 1}}{\mu_{0} A_{l 1}}=2 \frac{1}{\mu_{0} 8 R_{M 1}}
$$

with the 2 factor accounting for the fact that flux lines pass through the air gap twice before enclosing. Similar network has been constructed for the internal stator flux calculation, with the external leakage $R_{L}^{2}=2 \frac{1}{\mu_{0} 8 R_{M 2}}$.

Figure 3-10 compares the analytical and FEM predictions for the flux of each stator of the DS two phase generator. Both models predict that the peak external stator flux will be about $10 \%$ 
lower in the DS topology than in the SS topology (Fig. 3-6). Furthermore, the flux in internal stator would be about $20 \%$ lower than in the case of the single external stator.

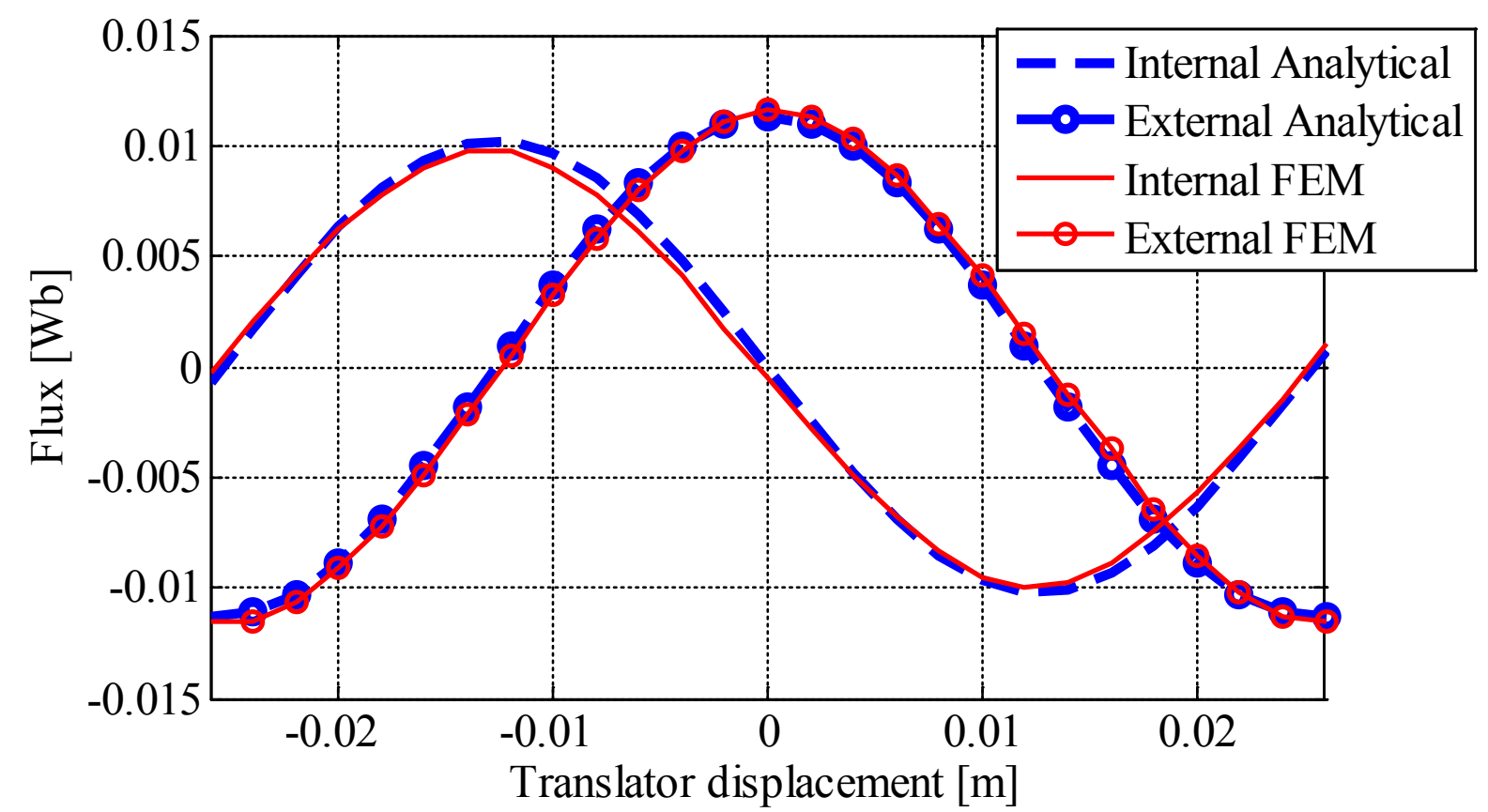

Figure 3-10 DS Two phase fluxes - the analytical and FEM model

\subsubsection{Single sided three phase LPMG}

In order to obtain basic analytical estimation of the SS three phase PM flux, it is sufficient to regard only one flux loop, containing one magnet and two stator teeth. While one magnet has its flux fully aligned with stator magnetic circuit, its neighbours are confined to almost full leakage (Fig. 3-11 a)). This way, magnetic circuit used for analytical prognosis of the stator useful PM flux becomes just a loop serially connecting PM MMF, PM and air gap reluctance (Fig. 3-11 c)). The conclusion is partially confirmed through FEM analysis of magnetic flux density vector distribution (Fig. 3-11 b)). However, it can be observed that some flux lines of the neighbouring magnets do share the same stator teeth. This is one of the reasons for the discrepancy between 
the FEM and analytical predictions (Fig. 3-12), since the analytical model resides on the assumption of fully decoupled flux paths of the neighbouring magnets.

a)

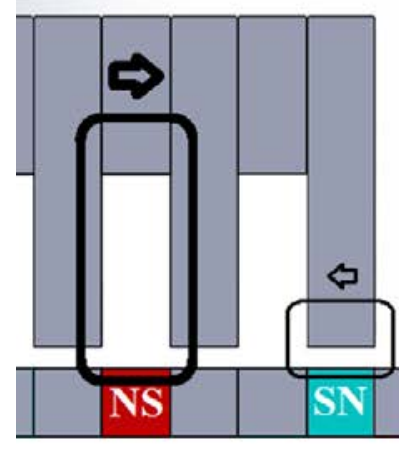

b)

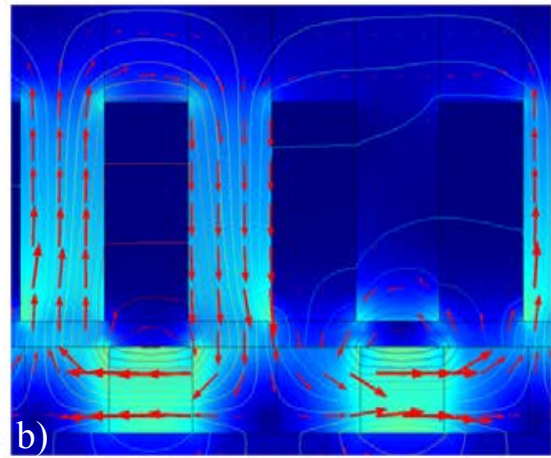

c)

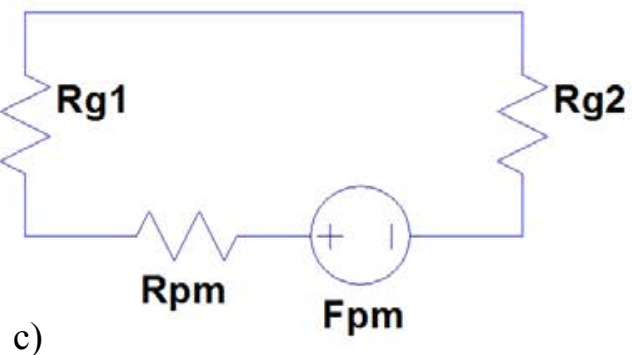

Figure 3-11 SS three phase generator: a) expected PM Flux distribution (b) FEM model PM Flux distribution (c) main flux reluctance network

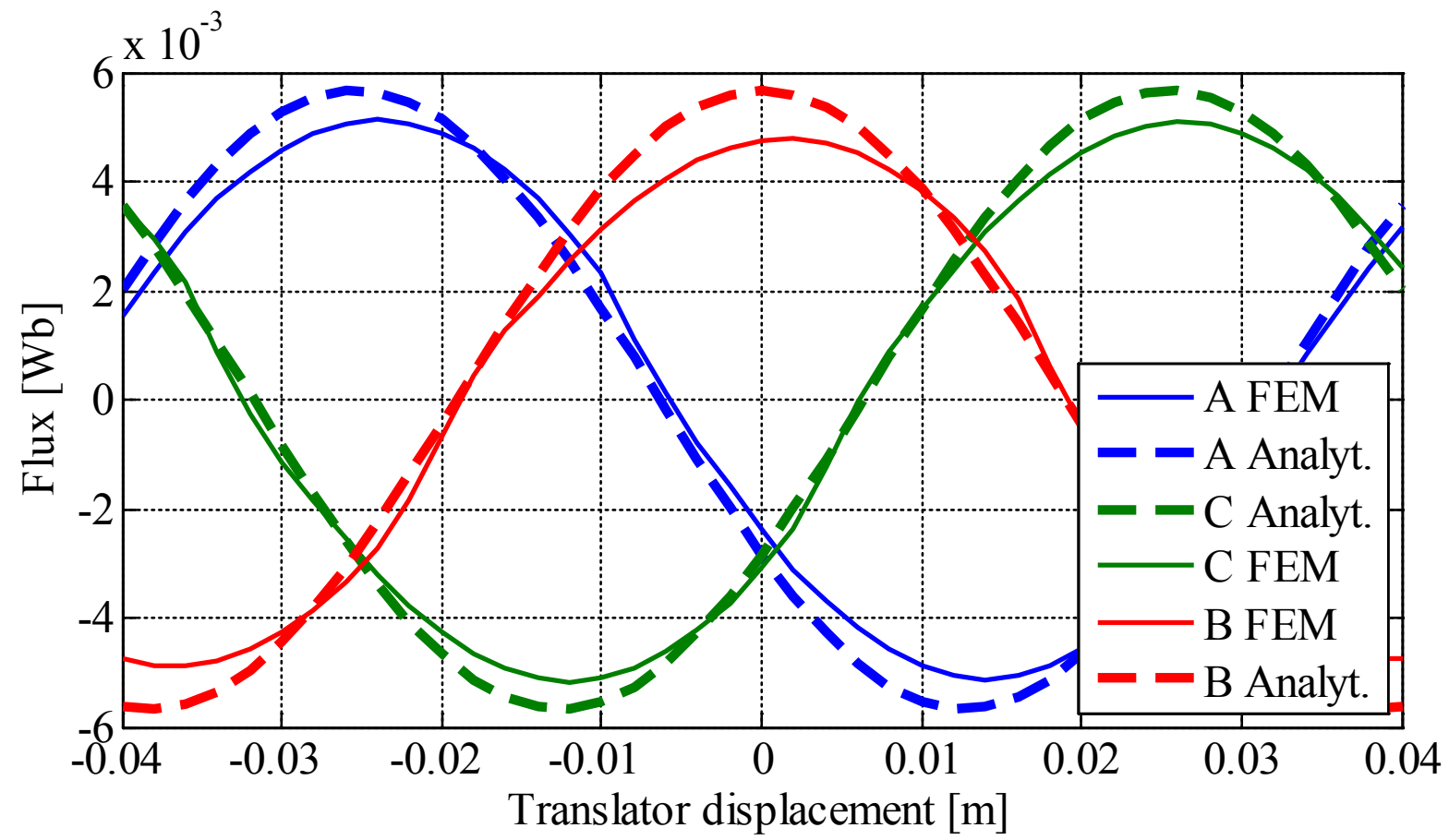

Figure 3-12 SS generator three phase $(A, B, C)$ fluxes due to the permanent magnet - the analytical and FEM model 


\subsubsection{Double sided three phase LPMG}

As in the DS two phase case, in the DS three phase case leakage becomes important in overall PM flux distribution. Due to the wider three phase translator poles, the leakage flux is not limited to immediate unaligned tooth, but it can also use neighbouring teeth (Fig. 3-13 a-b). Therefore, PM flux leakage reluctance in the DS three phase case is about a half of the one in the SS two phase network.

a)

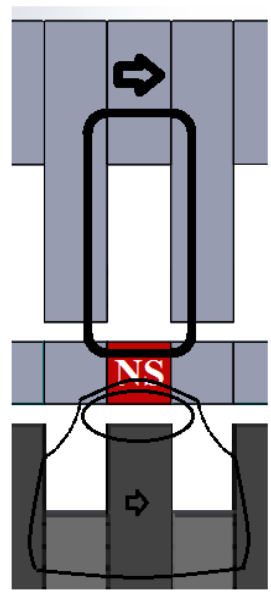

b)

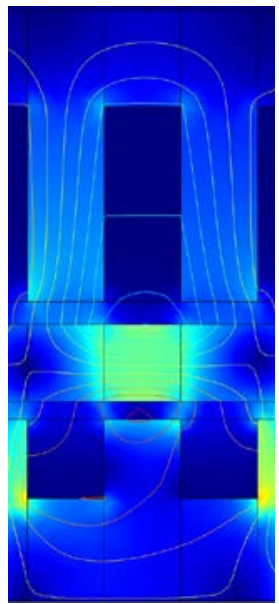

c)

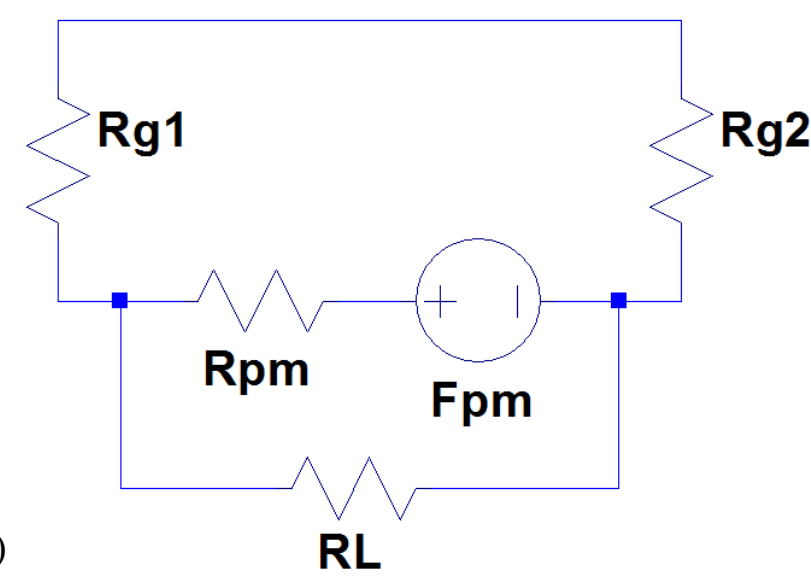

Figure 3-13 DS three phase generator: a) expected PM Flux distribution (b) FEM model PM Flux distribution (c) main flux reluctance network

Reluctance network flux compares well with the FEM simulation (Fig. 3-14), but the assumption of fully separate flux paths of neighbouring magnets again overestimates the circuit permeance (the inverse of reluctance) and the linked PM flux. Both models predict augmentation of the linked PM flux compared to the SS case of about $40 \%$. 


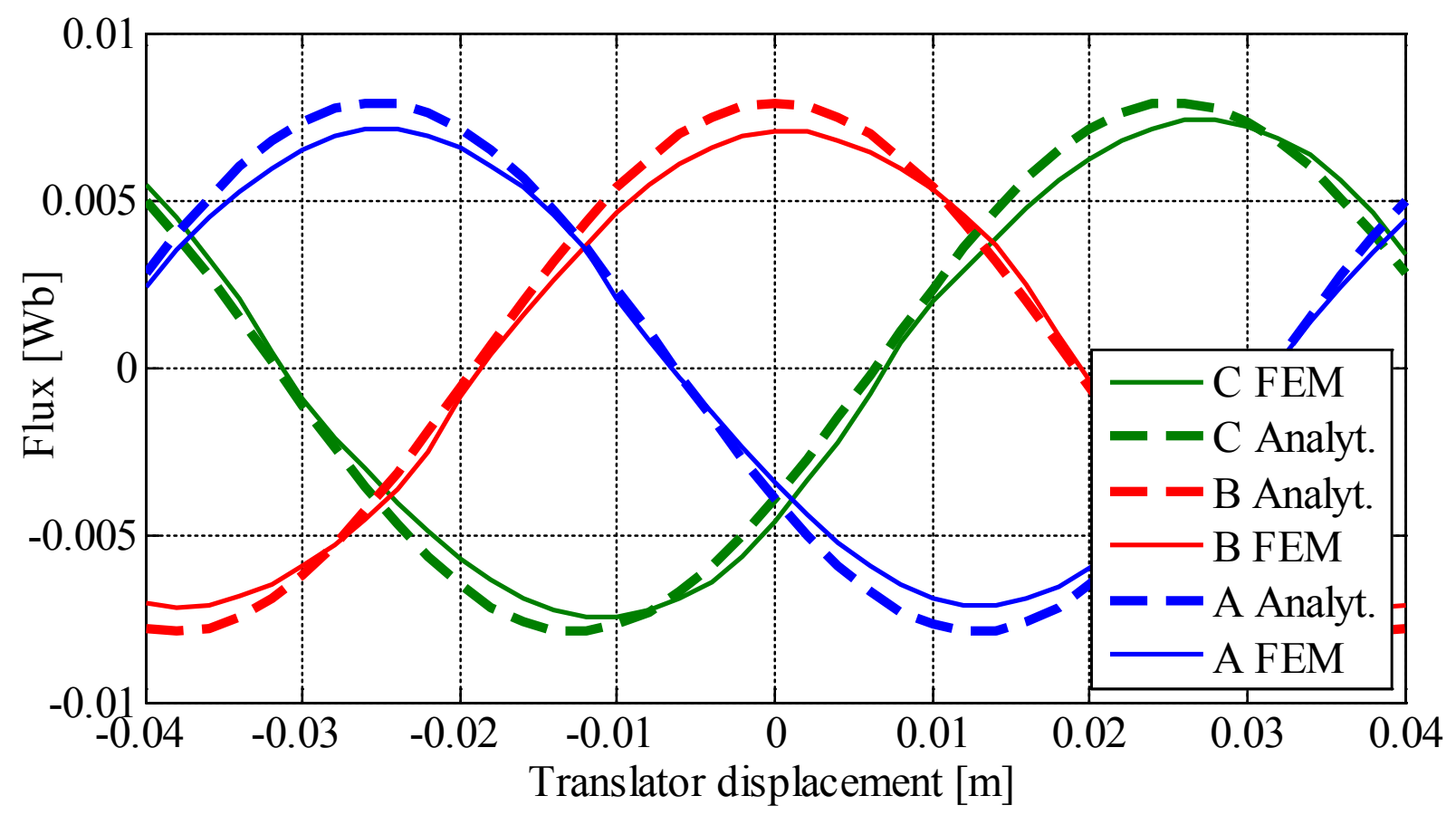

Figure 3-14 DS generator three phase $(A, B, C)$ fluxes due to the permanent magnet - the analytical and FEM model

\subsection{Resistance}

Resistance of the individual stator coil depends on the wire radius $r$, mean coil radius $\left(c_{i n}\right.$ or $\left.\left.c_{\text {out }}\right)\right)$ and number of the coil turns per slot $N$. It is obvious that the internal and external stator coils will have different resistance. Values of the internal and external coil resistances are respectively:

$$
\begin{gathered}
R_{\text {in }}^{C}=N \rho 2 \pi \frac{c_{\text {in }}}{r^{2} \pi} \\
R_{\text {out }}^{C}=N \rho 2 \pi \frac{c_{\text {out }}}{r^{2} \pi}
\end{gathered}
$$

where $\rho$ is the resistivity of conductor. 
Overall phase resistance depends on the generator's topology, i.e. on the way stator coils have been interconnected. If $n_{s}$ is the total number of slots in each stator and $q$ is the total number of phases, then phase resistances for the single sided and double sided topologies are as follows:

-single sided single phase $(q=1)$ and three phase $(q=3): R_{p h}^{S S}=\frac{n_{s}}{q} R_{\text {out }}^{C}$

-double sided two phase $(q=2)$ and three phase $(q=3): R_{p h}^{D S}=\frac{n_{s}}{q}\left(R_{\text {in }}^{C}+R_{o u t}^{C}\right)$

\subsection{Inductance}

Simple reluctance networks have been sufficient to obtain good estimate of peak stator flux due to the permanent magnets. On the other hand, inductance estimation is concerned with the armature-produced flux and it depends on more detailed reluctance network. Additional network elements include reluctance of the stator slot and air gap leakage between the stator teeth tips. Flux lines crossing the winding portion of the slot link only part of its turns. Because of that, reluctance of the slot part occupied by the conductor had to be evaluated separately for the purpose of self-inductance calculation [Boldea, 1997]:

$$
R_{C u}=\frac{2 b}{\mu_{0} a L}
$$

where $a$ and $b$ are coil width and height (Fig. 3-15), while $L$ is coil circumference.

Reluctance of the main flux path (flux linking stator and translator) changes for different translator positions. For positions in which the magnets are either fully aligned or fully misaligned with the stator teeth, appropriate reluctance networks have been built (Fig. 3-15). 
Those two network models have provided values of armature flux in these particular positions. It has been assumed that the armature flux as a function of translator position has sinusoidal shape between these two points. From estimated values of the armature-produced flux, the selfinductance follows as:

$$
L_{s}=N \frac{\Phi}{I}
$$

where $\Phi$ is total armature produced flux, $N$ is the number of coil turns per slot and $I$ is the armature (DC) current.

\subsubsection{Single sided single phase and Double sided two phase inductance}

For the purpose of self-inductance analytical modeling, presence of the additional stator in double sided topologies has been neglected. Otherwise, much more complex network would have to be built. FEM model shows that the self-inductance of the external armature increases only slightly for the double sided case (Fig. 3-16). Analiticaly predicted inductance is in good agreement with the COMSOL ${ }^{\circledR}$ model. 


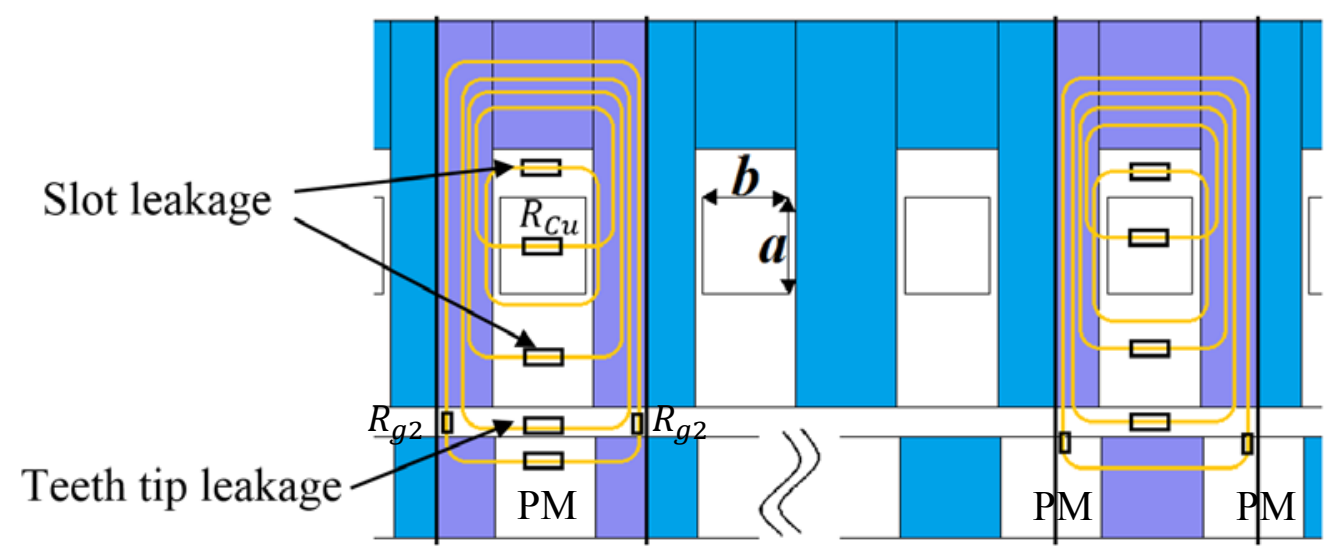

Figure 3-15 SS single phase winding: elements of the inductance modeling network for aligned (left) and misaligned (right) translator

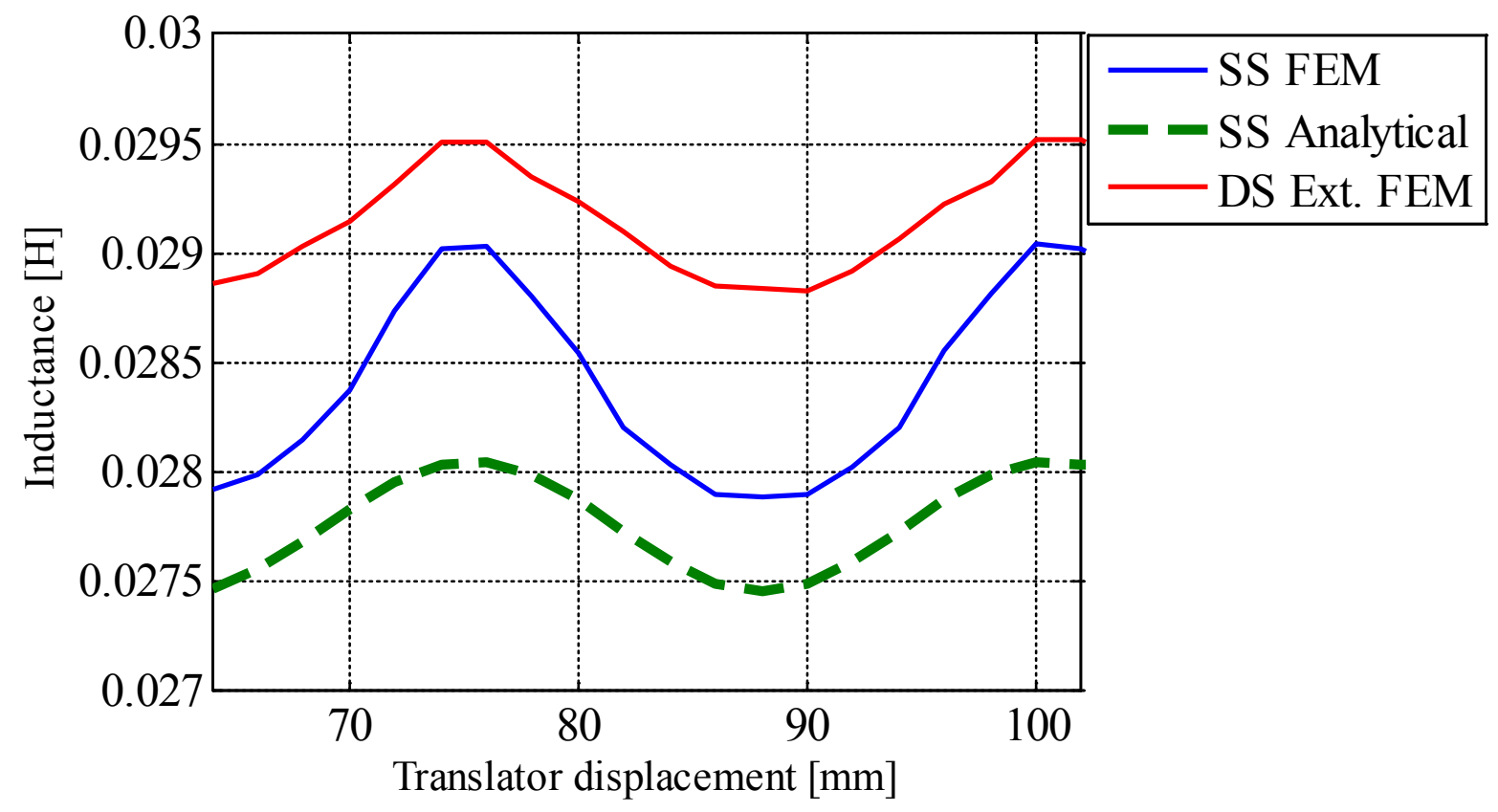

Figure 3-16 SS single phase machine self-inductance FEM and analytical predictions; FEM predictions for the DS two phase machine self-inductance

Similar network and the FEM model have been built for the internal stator winding. Their predictions do not match with the same proximity as for the external armature (Fig. 3-17), but the results are satisfactory, considering the simplicity of the reluctance network. 


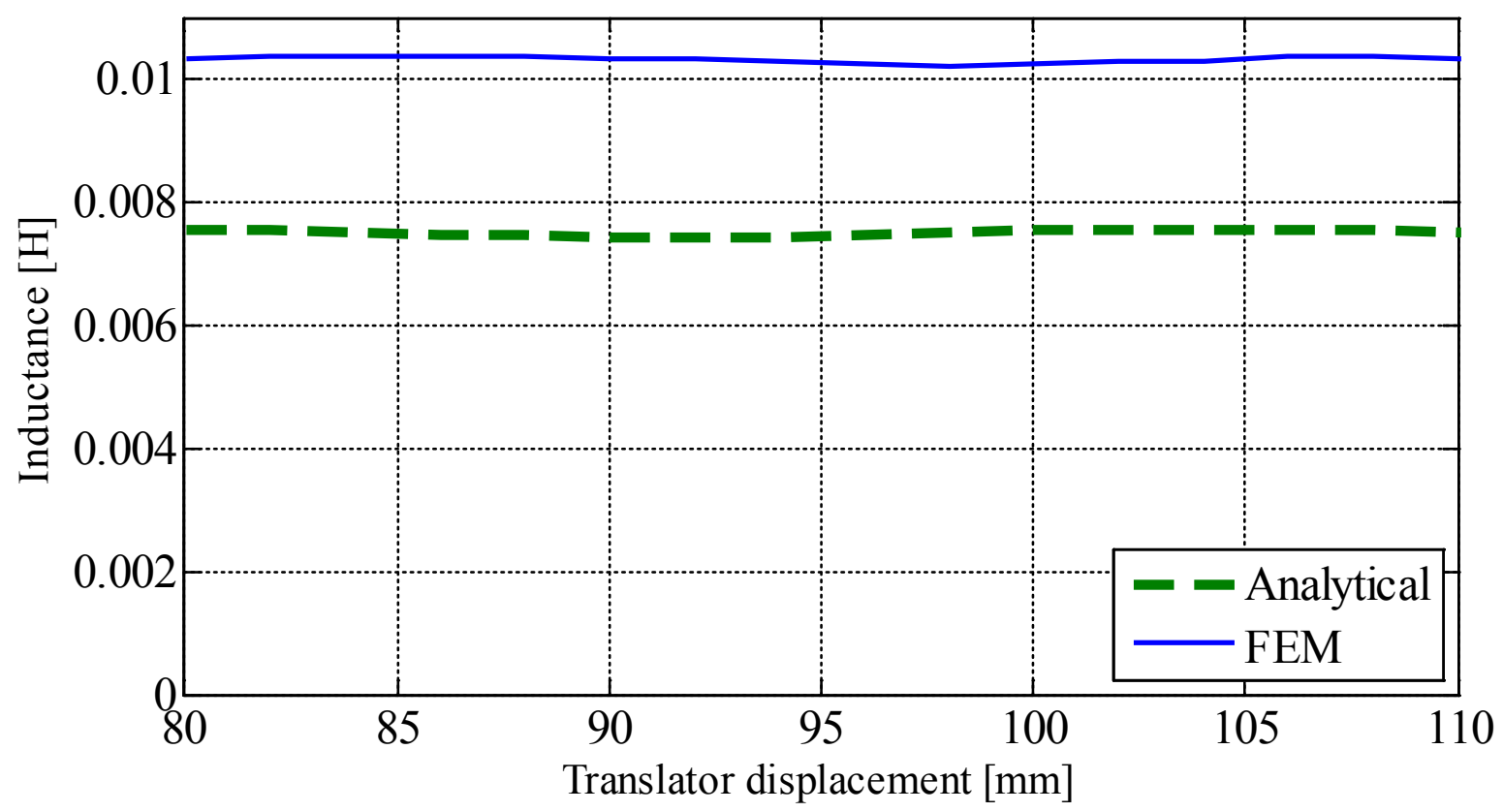

Figure 3-17 Internal stator self-inductance predictions

Value of the mutual inductance between the internal and external stator winding strongly depends on the position of the translator. Translator iron can bridge internal and external stator teeth, providing the low reluctance path for the flux between two windings (Fig. 3-18 right network). Their mutual inductance is expected to be at its lowest once the translator pole is fully aligned with teeth of one stator (Fig. 3-18 left network).

The FEM model has shown that the armature flux occupies paths that are more complex than the analytical model assumes. However, the analytical model gives predictions that are in good agreement with the FEM results (Fig. 3-19). 


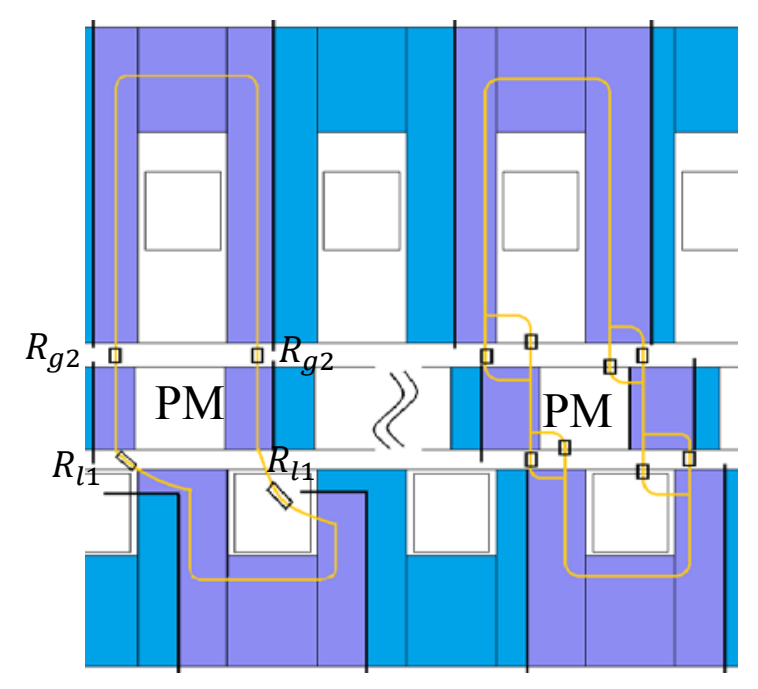

Figure 3-18 Reluctance network elemets for the mutual inductance estimation of the DS two phase generator

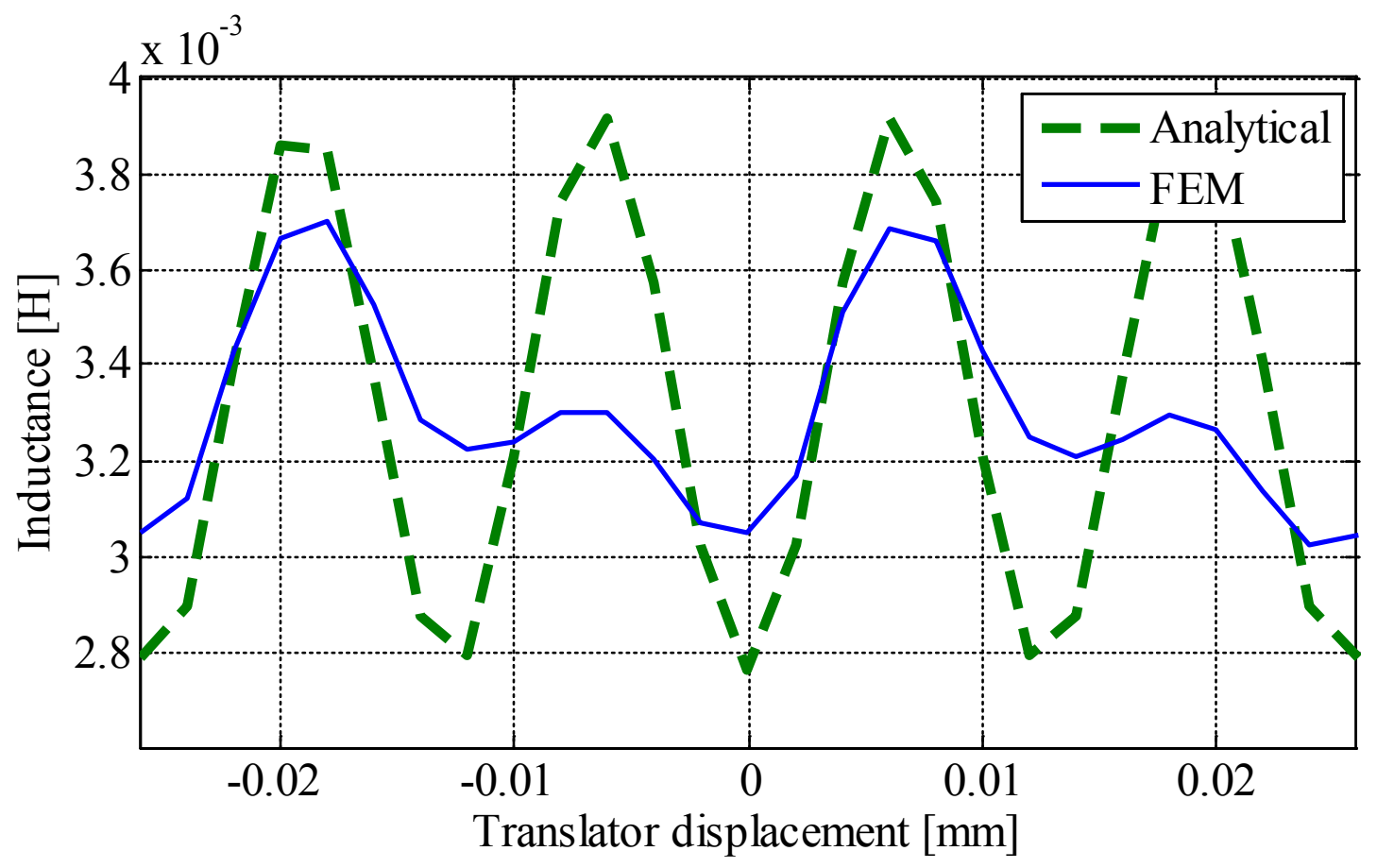

Figure 3-19 DS Two phase mutual inductance predictions 


\subsubsection{Single sided and Double sided three phase inductance}

Presence of the buried permanent magnets in the translator increases its reluctance in the axial direction. Therefore, any two coils of the SS three phase machine are regarded as magnetically decoupled, i.e. their mutual flux is assumed to be near zero (FEM model puts it about 1mH). Reluctance network for the self-inductance evaluation thus contains flux of a single coil (Fig. 320). The model produces prediction for the SS three phase self-inductance that is in good agreement with the FEM results (Fig. 3-21).

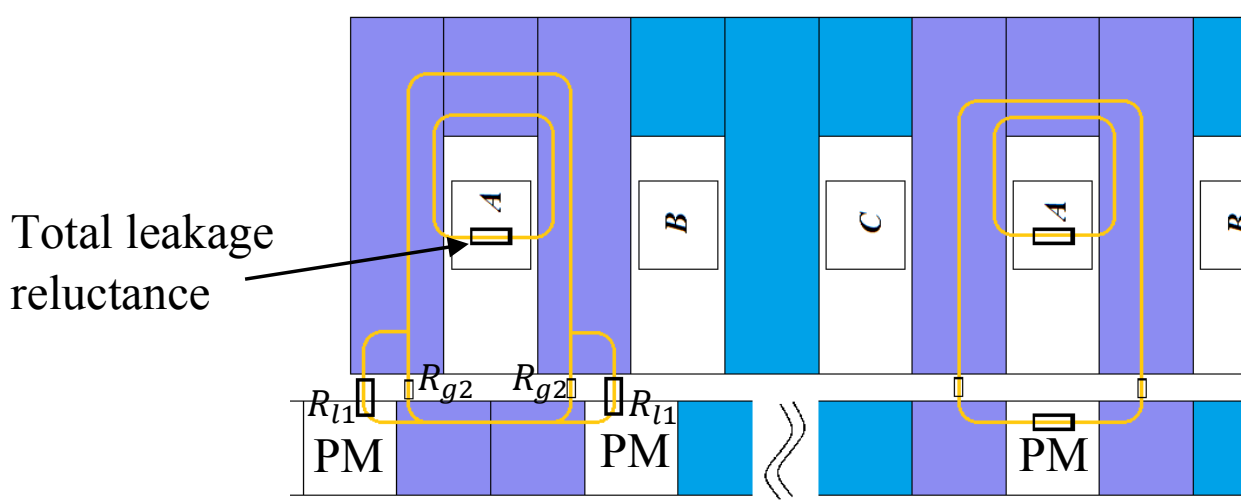

Figure 3-20 Reluctance network elemets for the SS three phase self-inductance calculation 


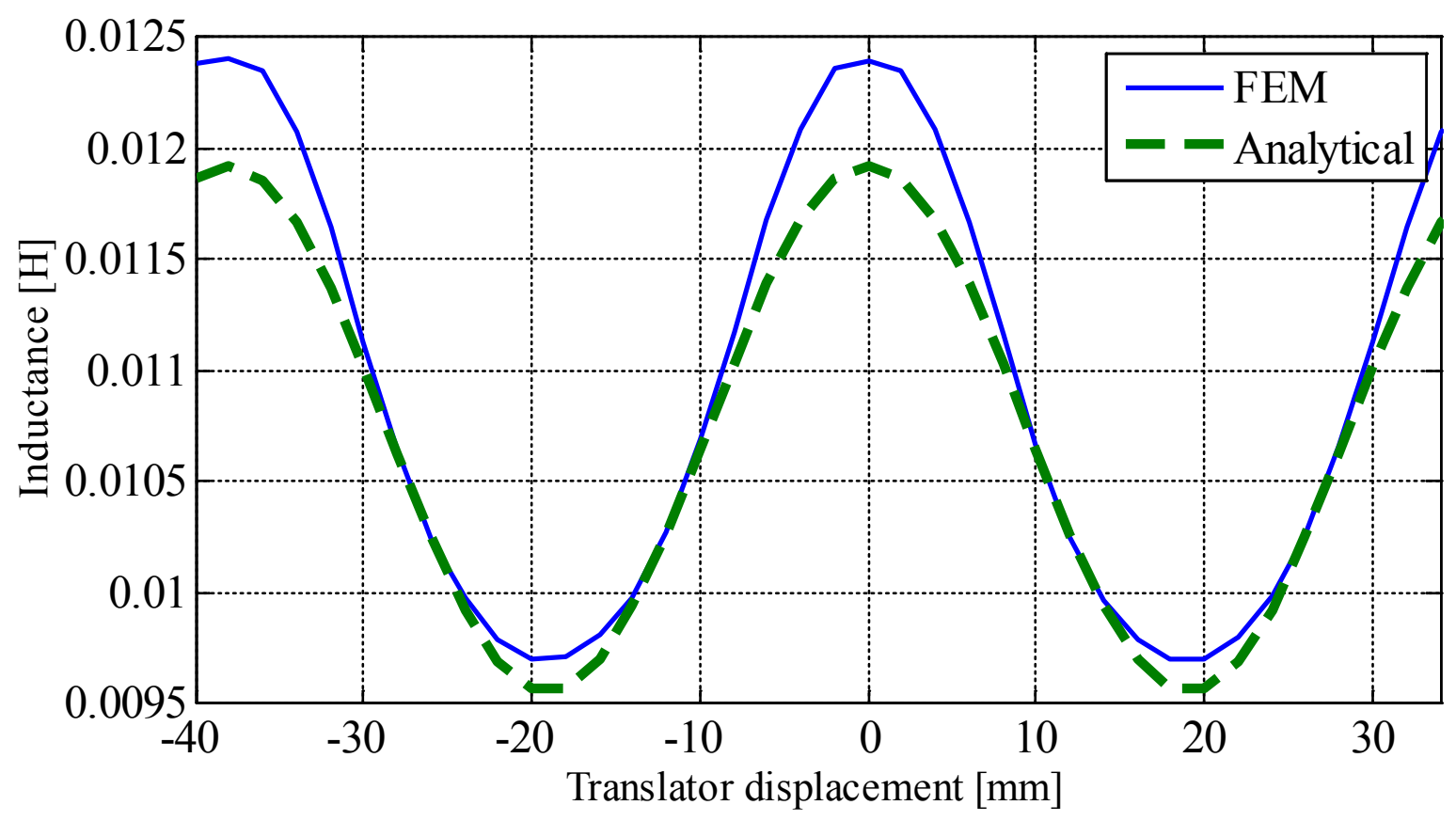

Figure 3-21 Analytical and FEM predictions for the SS three phase self-inductance

Unlike in the SS case, coils of the DS three phase machine are strongly coupled and the reluctance network cannot neglect mutual flux linkage. The main reason for it is that wide iron poles of the three phase translator provide very low reluctance bridge between the internal and external stator. Furthermore, same phase coils at different stators produce flux lines that add up, magnifying overall phase inductance and making appropriate reluctance network more complex.

Figure 3-22 shows one half of the machine's magnetic circuit network for the translator position that is expected to produce the highest self-inductance. The figure shows the flux lines produced by two coils of phase A and the way they link coils of phases B and C. 

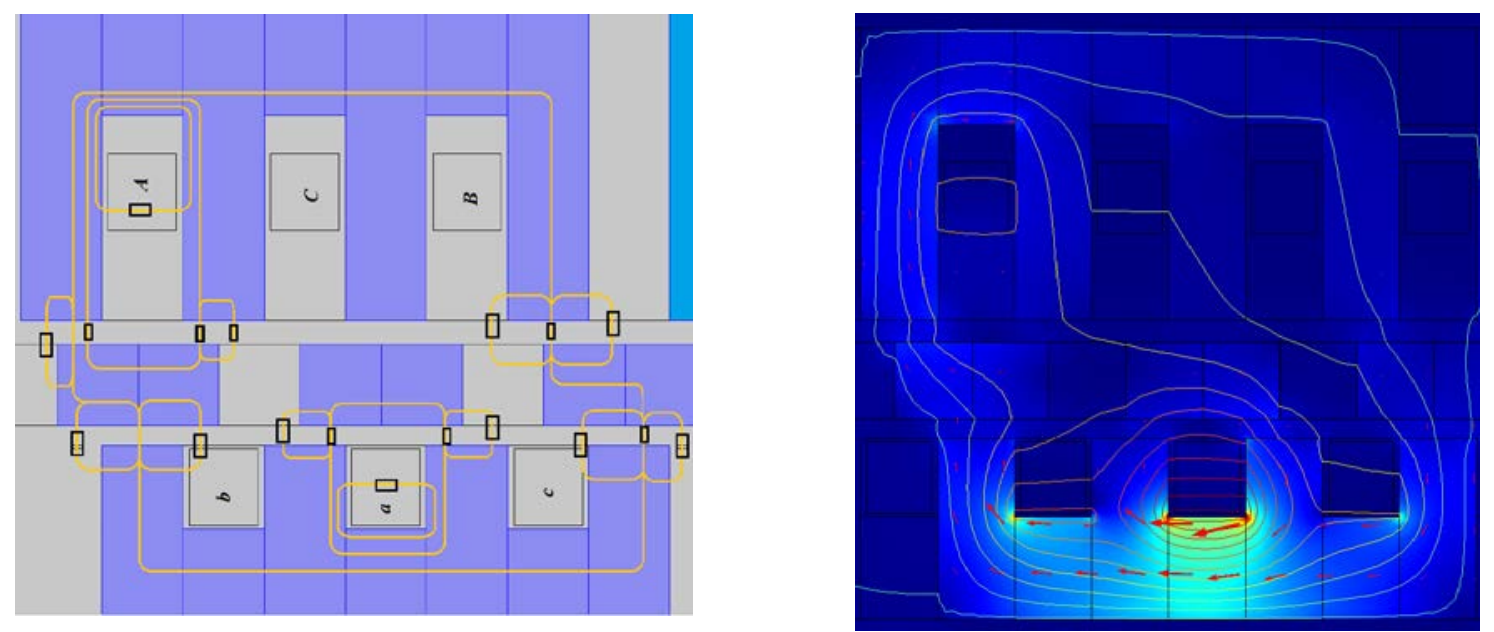

Figure 3-22 Reluctance network elements for inductance estimation of the DS three phase generator (left) and the FEM predictions for the armature flux distribution (right)

The reluctance network and the FEM model have estimated total flux produced by phase A. Thereafter, two self-inductance estimates have been produced and they are compared at Figure 323. Waveforms have similar amplitude, but are out of phase a little. This phase shift reflects more complex actual flux distribution than anticipated in the analytical model. DS three phase topology doubles the phase self-inductance compared to the SS case. 


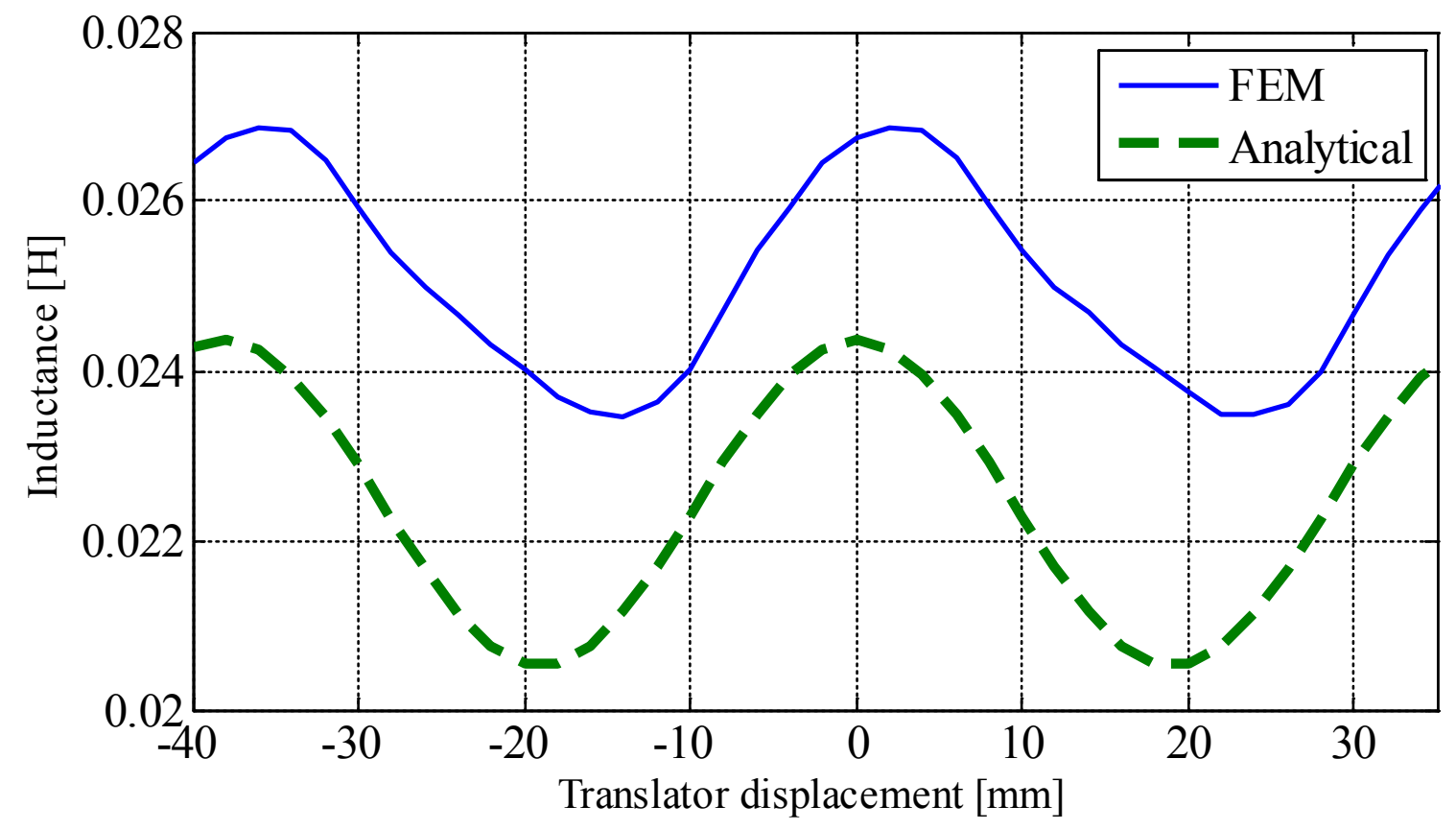

Figure 3-23 Analytical and FEM DS predictions for the three phase self-inductance

Constructed network also estimates the size of the flux portion linked with the other two phases, therefore enabling the calculation of the mutual inductance. Discrepancy between this estimate and the FEM predictions (Fig. 3-24) reflects the fact that extreme values of self-inductance and mutual inductance do not occur for same translator positions. Therefore, the reluctance networks designed for self-inductance calculation would only give rough prediction about the magnitude of mutual inductance. Its more accurate estimation would require development of particular reluctance networks. 


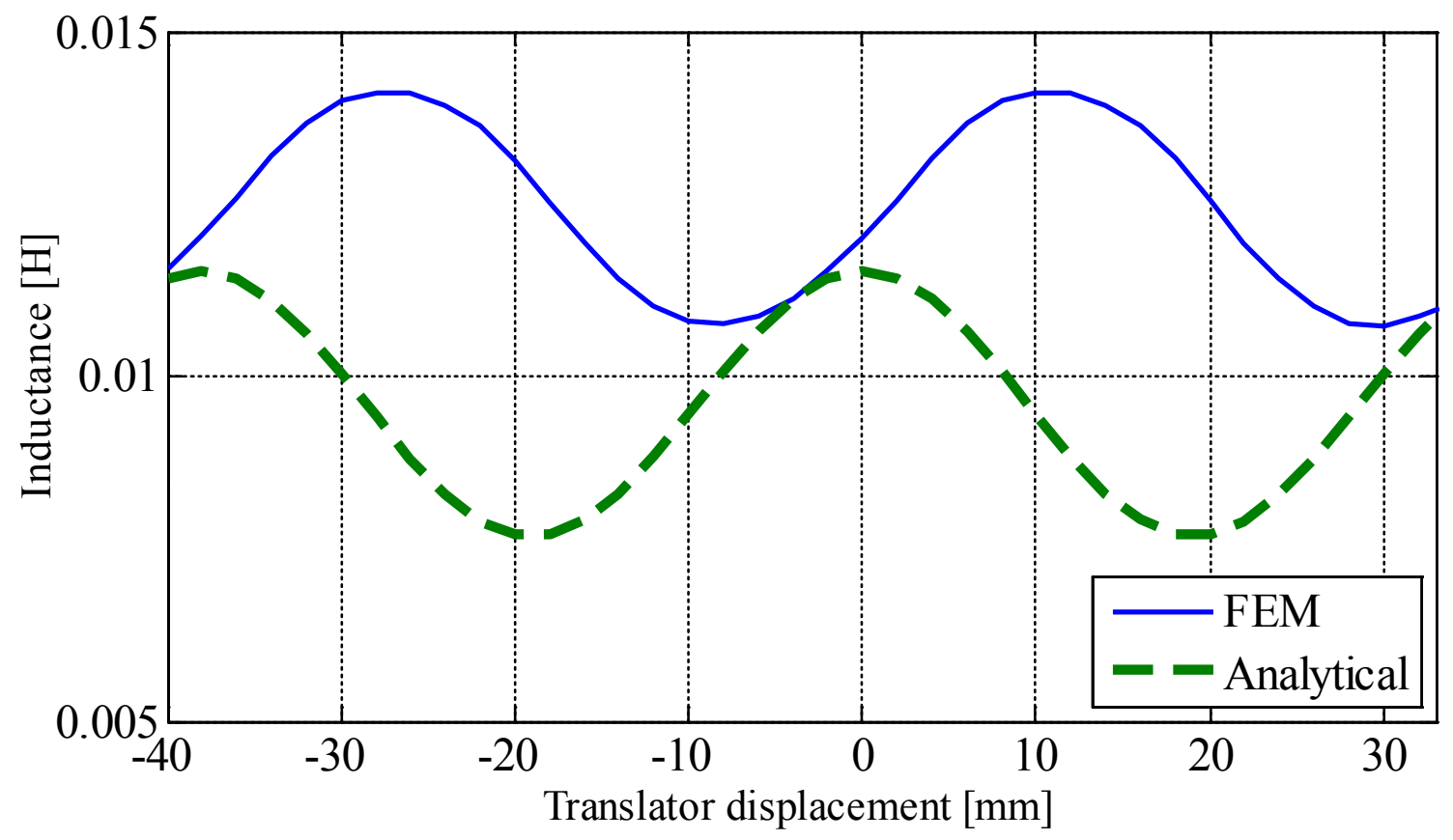

Figure 3-24 Analytical and FEM DS predictions for the three phase mutual inductance

\subsection{Cogging force}

Reluctance network model has provided results for the PM flux linkage and the armature inductance that have agreed reasonably well with the FEM model. However, simple reluctance network can hardly be a tool for obtaining accurate predictions for the translator cogging force, that requires detailed information about the spatial flux density. Therefore, the cogging force modeling has only been conducted in the FEM environment. FEM results have started to converge once very fine mesh quality has been applied over the model's geometry. COMSOL® calculates the total magnetic force on the translator by integrating the force density (obtained from the Maxwell's stress tensor):

$$
\frac{d f}{d x}=-\frac{1}{2} \vec{n} \cdot(\vec{H} \cdot \vec{B})+(\vec{n} \cdot \vec{H}) \vec{B}^{T}
$$


over the edges of the translator geometry, where $\vec{n}$ is the unit vector perpendicular to the translator surface, $H$ is the magnetic field vector and $B$ is the flux density vector.

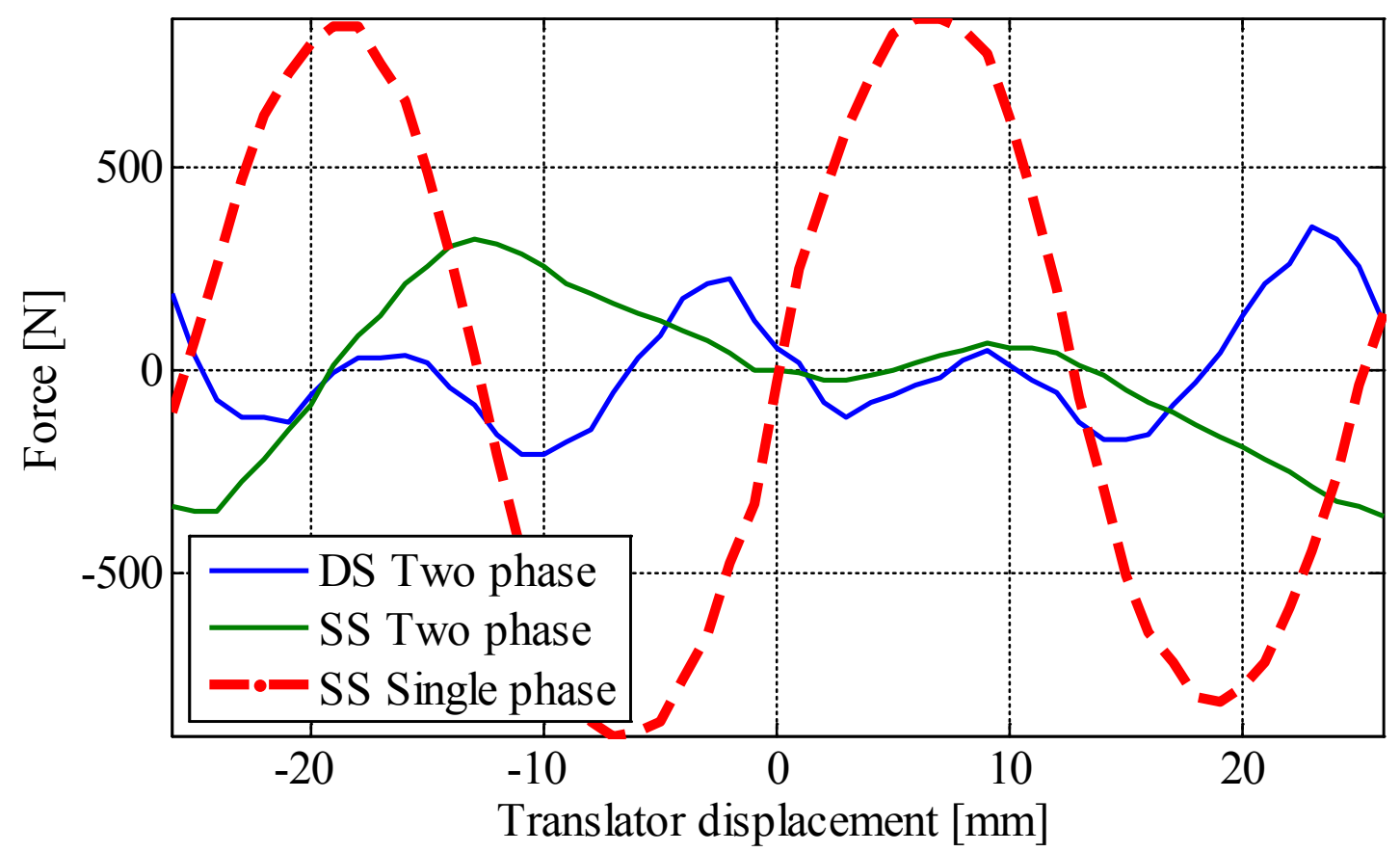

Figure 3-25 FEM predictions for the cogging force in the single sided single phase and two phase and DS two phase topologies

Due to its wider translator pole and reduced fluctuations of total linked PM flux, SS three phase LPMG has low cogging force. The FEM simulations of the prototype machine (internal air gap $3 \mathrm{~mm}$ and external air gap $3.75 \mathrm{~mm}$ ) have shown that the internal component of the force does not become significantly reduced with insertion of the additional stator (Fig. 3-26). FEM simulations have however, shown greater suppression of the internal cogging force component for smaller air gaps. 


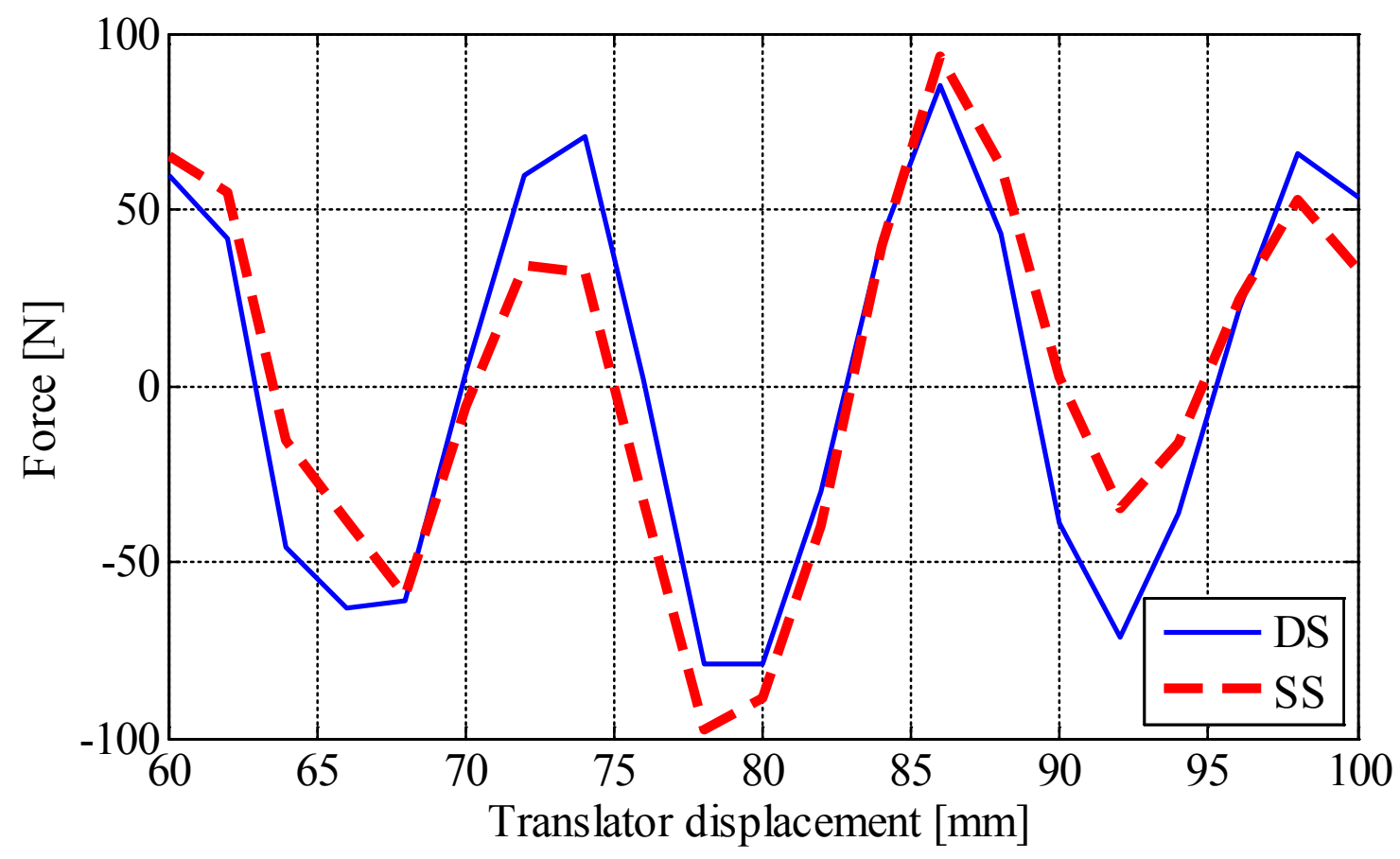

Figure 3-26 Internal component of the cogging force in the SS and DS three phase topologies

In the three phase DS topology, machine exhibits even larger total cogging force than the SS machine. This should be attributed to the end force component (internal components are similar in both cases). End component of the cogging force has a period of one translator pole pitch ( $\mathrm{Yu}-$ wu Zhu, 2009).

In order to suppress it, both the internal and external stator are built out of two segments (Fig. 327 a). These segments are displaced by two thirds of the end component period, in order to reduce the resultant amplitude (Fig. 3-27 b). This method is able to reduce the total cogging force peak-to-peak amplitude and bring it close to the SS case, which however remained superior (Fig. $3-28)$. 

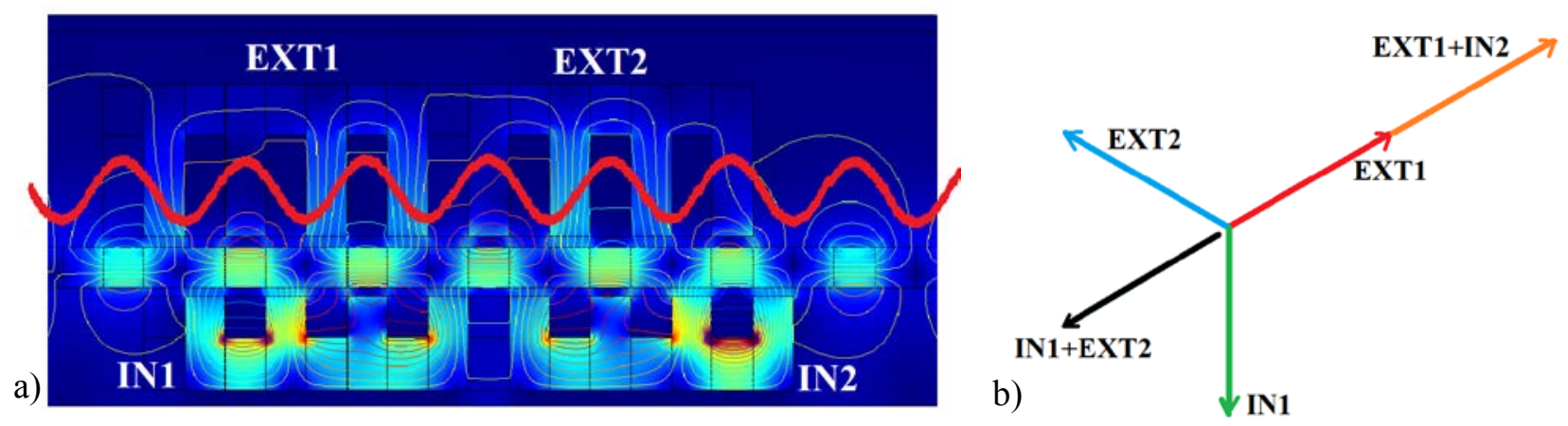

Figure 3-27 a) DS three phase stator segments and period of the cogging force end component; b) summation of end cogging force contributions coming from each segment

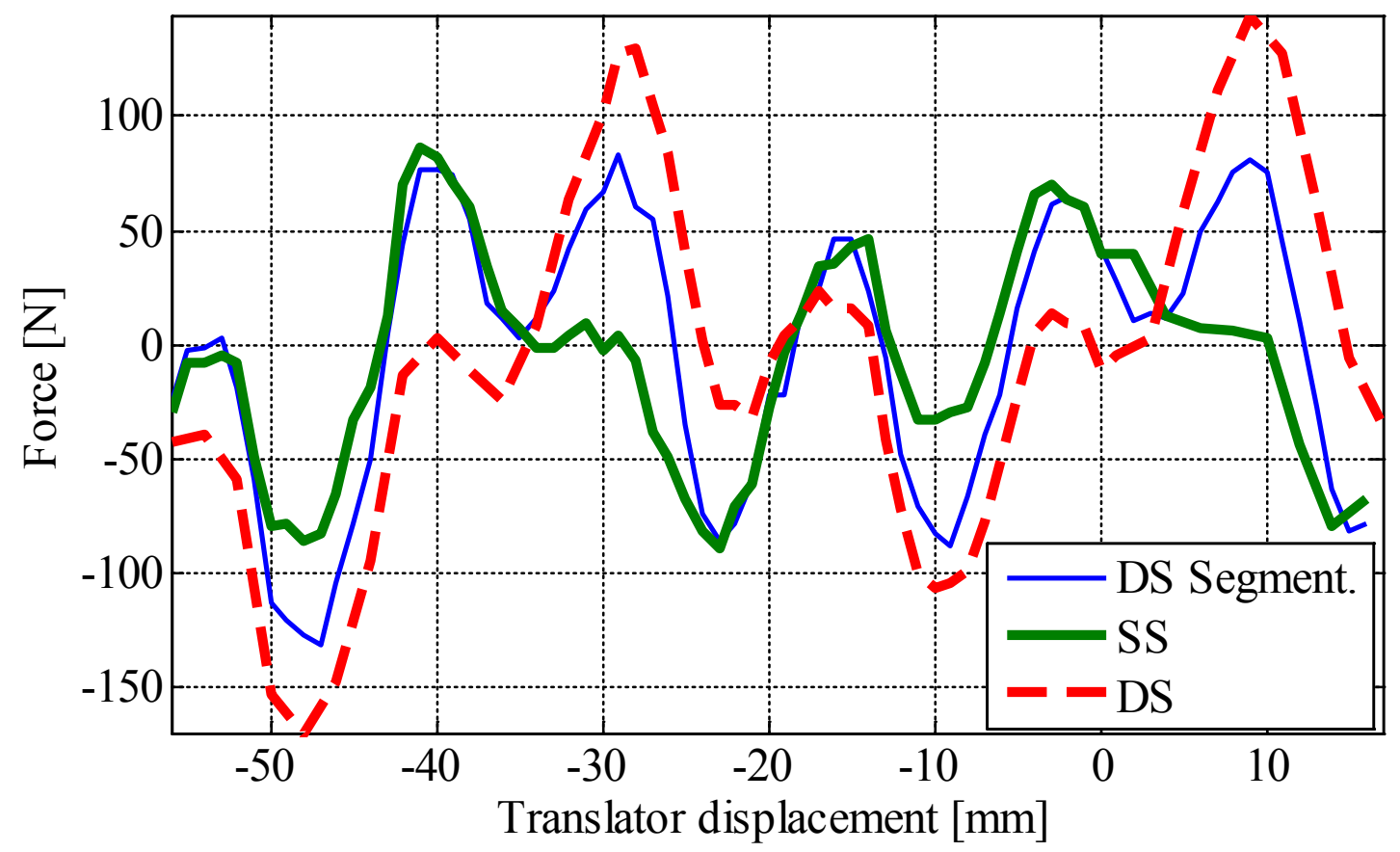

Figure 3-28 FEM predictions for the cogging force in three phase topologies: single sided, double sided and double sided with segments

\subsection{Summary}

Magnetic circuits of different LPMG topologies have been approximated with reluctance networks. These networks have been used to determine their peak PM flux linkages and inductances. Obtained results are in good agreement with the FEM simulations. However, 
agreement between two models worsens for more complex flux distribution, with less localised flux paths, like in the case of the armature-produced flux in the DS three phase topology.

Models have shown that the enhanced leakage in the DS two phase topology reduces the peak flux in the external and internal phase compared to the SS single phase case by about $10 \%$ and $20 \%$ respectively. Therefore, instead of having one single phase machine with $100 \%$ of phase voltage it is possible to have two phase machine with $90 \%$ and $80 \%$ of phase voltage for the external and internal stator respectively, with the same usage of magnetic material.

The model predicts very small increase in the external stator self-inductance in the DS two phase topology compared to the SS single phase. However, SS three phase self-inductance doubles in the DS three phase topology. This augmentation in the self-inductance is accompanied by high value of the mutual inductance that was negligible in the SS topology.

The FEM model has simulated cogging force characteristics for different topologies. It has shown that the DS two phase topology produces less peak to peak cogging force than both SS single phase and SS two phase machine. However, in the case of three phase machines, the DS topology displayed weaker cogging force performance. In order to improve it, the segmented design has been implemented. 


\section{Chapter 4 \\ Design and construction}

\subsection{Introduction}

This chapter gives details about the analytical and FEM procedure for the selection of the optimal air gap length. It also describes the manufacturing of machine's constitutive elements: namely translator, stator and winding. Dimensions of the available ring magnets have limited the size and design freedom for the internal stator diameter and depth of its slots.

Manufactured translator support has been found to be insufficiently strong to maintain its alignment with the generator axis. Therefore, the additional guidance has been provided to its motion in the form of internal and external sleeves.

\subsection{Air gap selection}

In the internal stator, flux coming from the translator magnets becomes focused, i.e. its density is increased. Ring magnets need to have their internal radius big enough to accommodate large internal stator and avoid excessive saturation of its flux density. Selection of the ready-made ring magnets whose size would be appropriate for the DS linear generator is not very wide. Therefore, once the magnet of sufficiently large inner radius has been found, the prototype has been designed around its dimensions and specifications. 
Neodymium N42 magnets ( 4 in OD $x 3$ in ID x $1 / 2$ in) were selected. Their choice also determines the width of the stator tooth tip ( $w=h_{m}=\frac{1}{2}$ in). The ferromagnetic material for the stator and translator poles is low carbon steel. Based upon the mechanical constraints and the magnetic saturation constraints, length of the internal air gap has been fixed to $g_{1}=3 \mathrm{~mm}$. Analytical calculations and the FEM model show that the selected air gap keeps the iron flux density well bellow the saturation value, thus limiting hysteresis losses in the iron. From the mechanical prospective, smaller air gap would require more rigid translator design and more expensive manufacturing process.

The criteria for selection of the external air gap was minimization of the cogging force peak-topeak amplitude in the DS two phase topology. Its length has significant influence on the force.

As stated, the optimum length of the external air gap can be found from the condition that overall reluctance seen by the magnets in both positions of alignment with the internal and external air gap be the same:

$$
R_{a}^{2}=R_{a}^{1}
$$

For these two positions $R_{a}^{2}$ and $R_{a}^{1}$ account for both the main flux reluctance and the leakage reluctance: $R_{a}^{2}=R_{g 2} \| R_{L}^{1}$ and $R_{a}^{1}=R_{g 1} \| R_{L}^{2}$ (Fig. 4-1). 


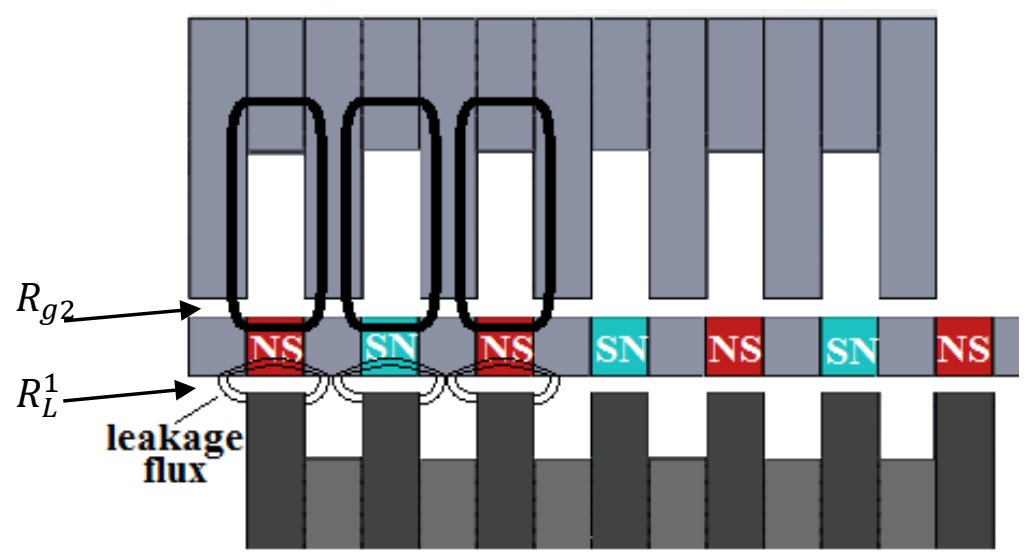

Figure 4-1 Reluctances for translator aligned with external stator

If the expressions for $R_{g 2}, R_{g 1}, R_{L}^{1}$ and $R_{L}^{2}$ (eq. 3.2,3.3,3.11) are substituted into the eq. 4.1 , it takes the following form:

$$
\frac{\frac{1}{8 \mu_{0} r_{M 2}} \frac{1}{2 \pi \mu_{0} \frac{h_{m}}{2}} \ln \left(\frac{r_{M 1}}{r_{M 1}-g_{1}}\right)}{\frac{1}{8 \mu_{0} r_{M 2}}+\frac{1}{2 \pi \mu_{0} \frac{h_{m}}{2}} \ln \left(\frac{r_{M 1}}{r_{M 1}-g_{1}}\right)}=\frac{\frac{1}{8 \mu_{0} r_{M 1}} \frac{1}{2 \pi \mu_{0} \frac{h_{m}}{2}} \ln \left(\frac{r_{M 2}+g_{2}}{r_{M 2}}\right)}{\frac{1}{8 \mu_{0} r_{M 1}}+\frac{1}{2 \pi \mu_{0} \frac{h_{m}}{2}} \ln \left(\frac{r_{M 2}+g_{2}}{r_{M 2}}\right)}
$$

and it can be solved for $g_{2}$ :

$$
g_{2}=r_{M 2}\left(e^{\frac{\ln \left(\frac{r_{M 1}}{r_{M 1}-g_{1}}\right)}{\pi h_{m}} \ln \left(\frac{r_{M 1}}{r_{M 1}-g_{1}}\right)+1}-1\right)
$$

Substituting magnet's inner and outer radius and height $\left(r_{M 1}, r_{M 2}\right.$ and $\left.h_{m}\right)$ and internal air gap length $g_{1}$ into the solution, one can obtain the optimum value for the external air gap length:

$$
g_{2}=3.6 \mathrm{~mm} \text {. }
$$


In order to confirm this result, the FEM model produced cogging force profiles for different lengths of the external air gap. Their peak to peak amplitudes are compared at Figure 4-2. Analytically predicted optimum air gap length agrees well with the FEM results. However the FEM model indicates little higher optimum value $(3.75 \mathrm{~mm}$, see Figure $4-2)$, due to higher saturation in the iron of the internal stator and therefore increased internal reluctance.

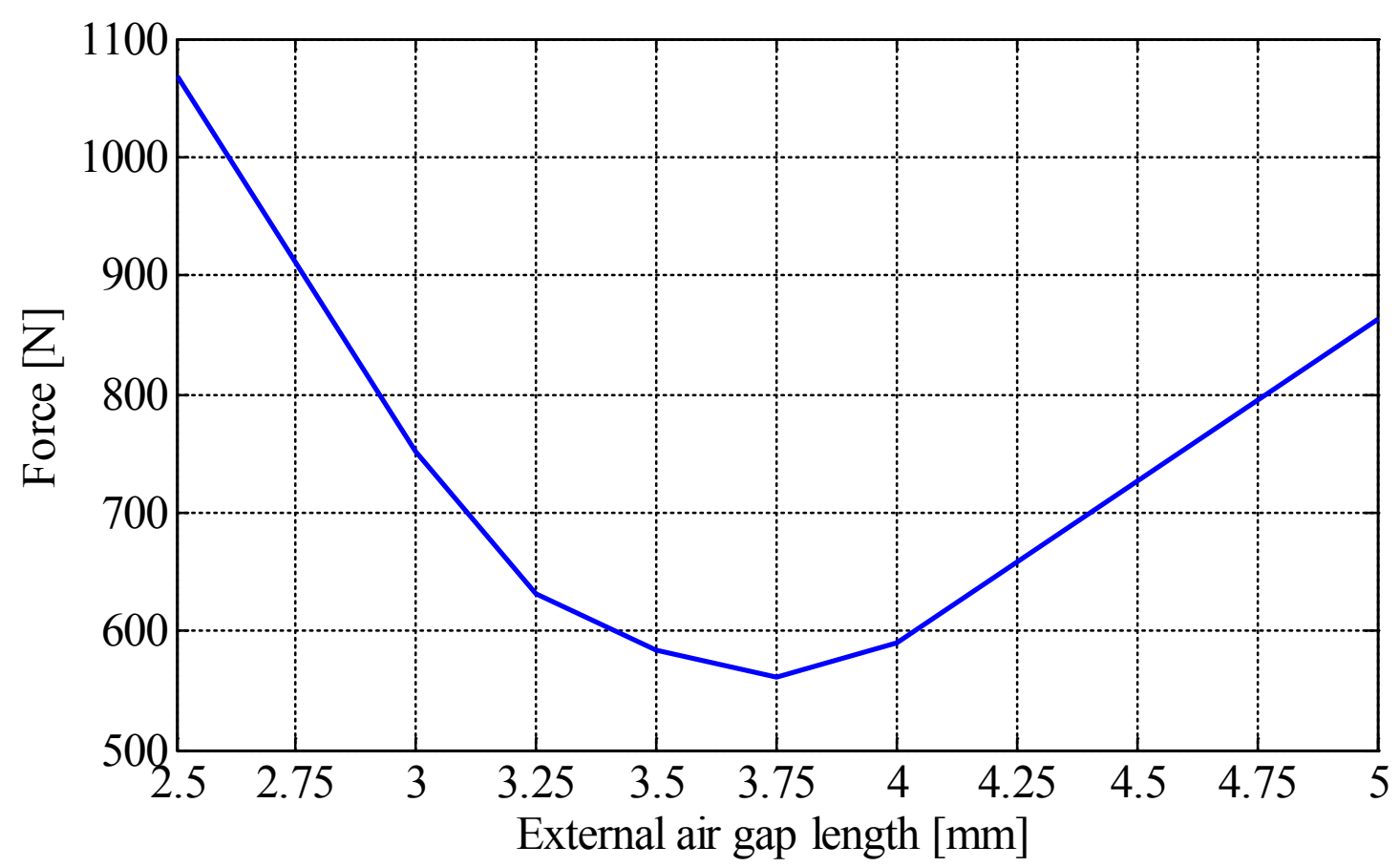

Figure 4-2 Peak to peak cogging force in DS two phase topology for different external air gap length

\subsection{Translator construction}

One by one, translator rings have been stacked on a jig that ensures their proper alignment (Fig. 4-3). Since the magnet sides of the same polarity are facing each other, the structure repels every new magnet (starting with the second one). However, once additional magnet is brought close enough to the iron pole, presence of the pole dominates and the magnet becomes attracted by the structure. Entire structure ends up in the stable equilibrium, despite the polarity of the magnets. 


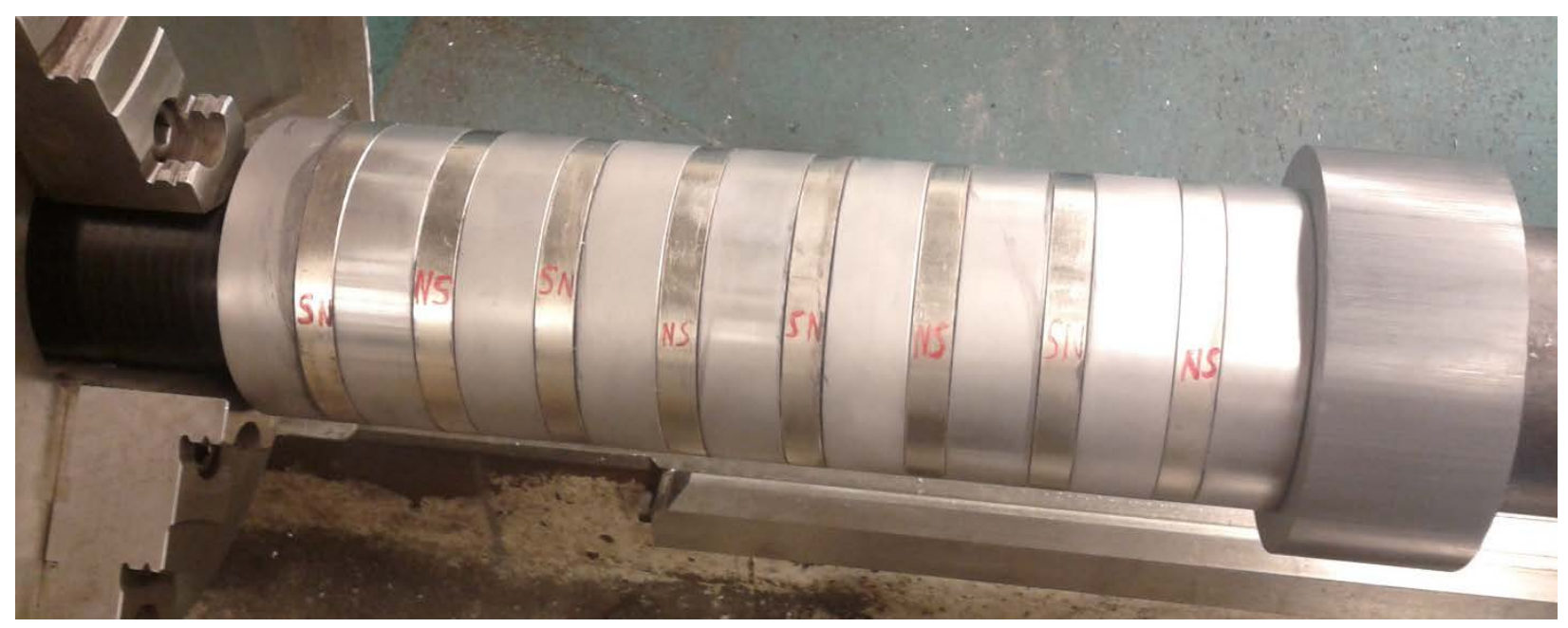

Figure 4-3 Three phase translator rings stacked up on a jig

The FEM simulations predict such force reversal behaviour and show that due to the wider poles, it is easier (the distance is larger and the work required is smaller) to reach critical distance in the three phase translator topology (Fig. 4-4). If the three phase translator pole rings were made by stacking two single phase pole rings (as initially planned), they would repel each other and disturb the stability of the structure. Therefore, three phase poles were separately cut from twice as thick (1 inch) steel plate. 


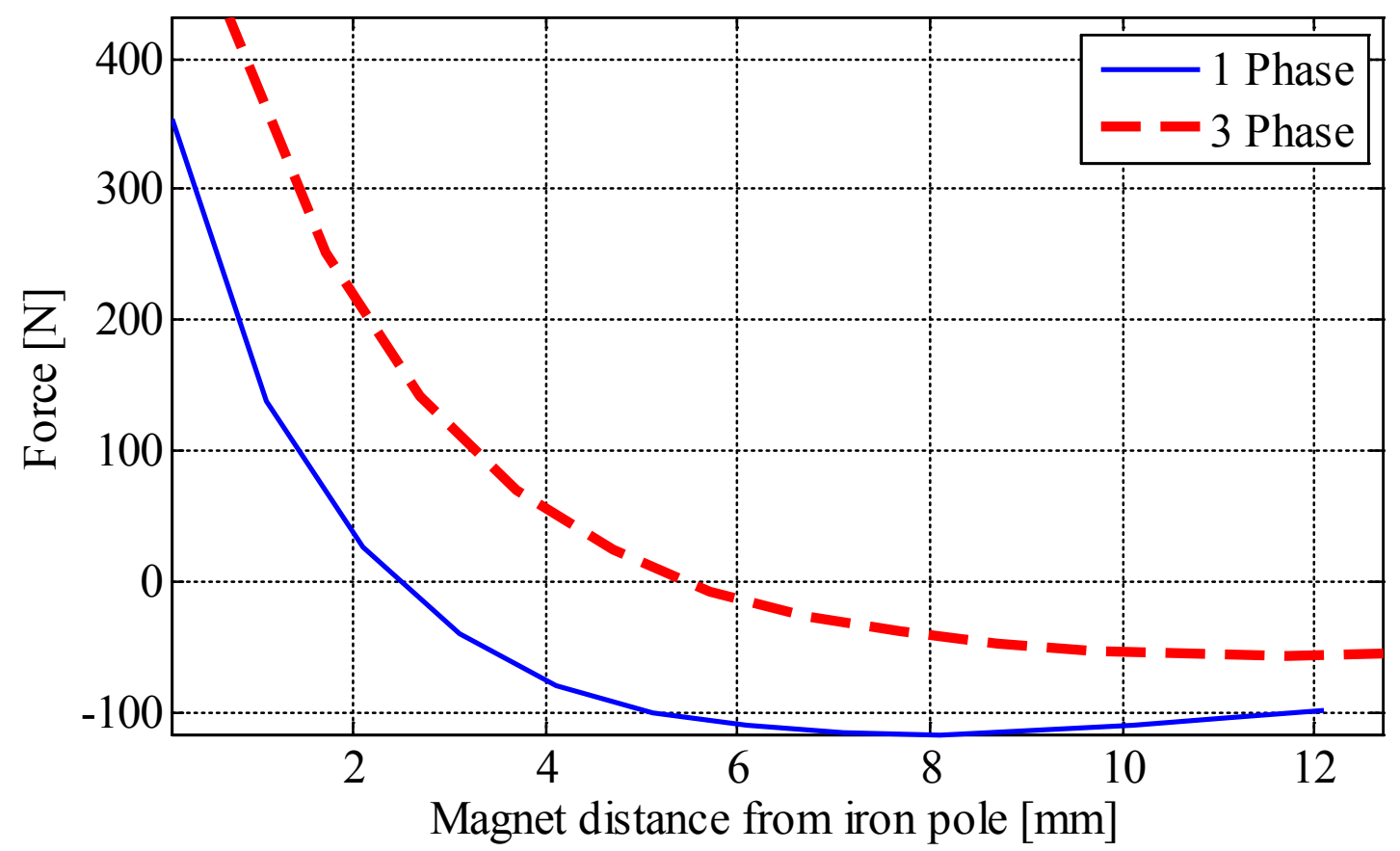

Figure 4-4 Force on a magnet being added to a translator for single phase and three phase pole widths; positive sign force means attraction

In order to ensure that translator rings will remain together once exposed to normal forces during the manipulation, adhesive (Loctite ${ }^{\circledR} 380$ blackmax) was applied over the contact surfaces. Before that, the surfaces have been sanded and cleaned.

Three sliding shafts are placed about the translator perimeter, to provide support and enable its motion. The shafts had to be made out of non-ferromagnetic material in order to avoid excessive PM flux leakage. Two end plates and shaft collars fix position of the translator on the shafts. Oil impregnated brass bushings serve as a guide for the shafts motion. The bushings are fixed in the base plates (Fig. 4-5). This translator design does not require any custom shaped PM parts and enables simple replacement of the single phase magnets arrangement with the three phase arrangement, which facilitates conduction of experiments with various topologies. 


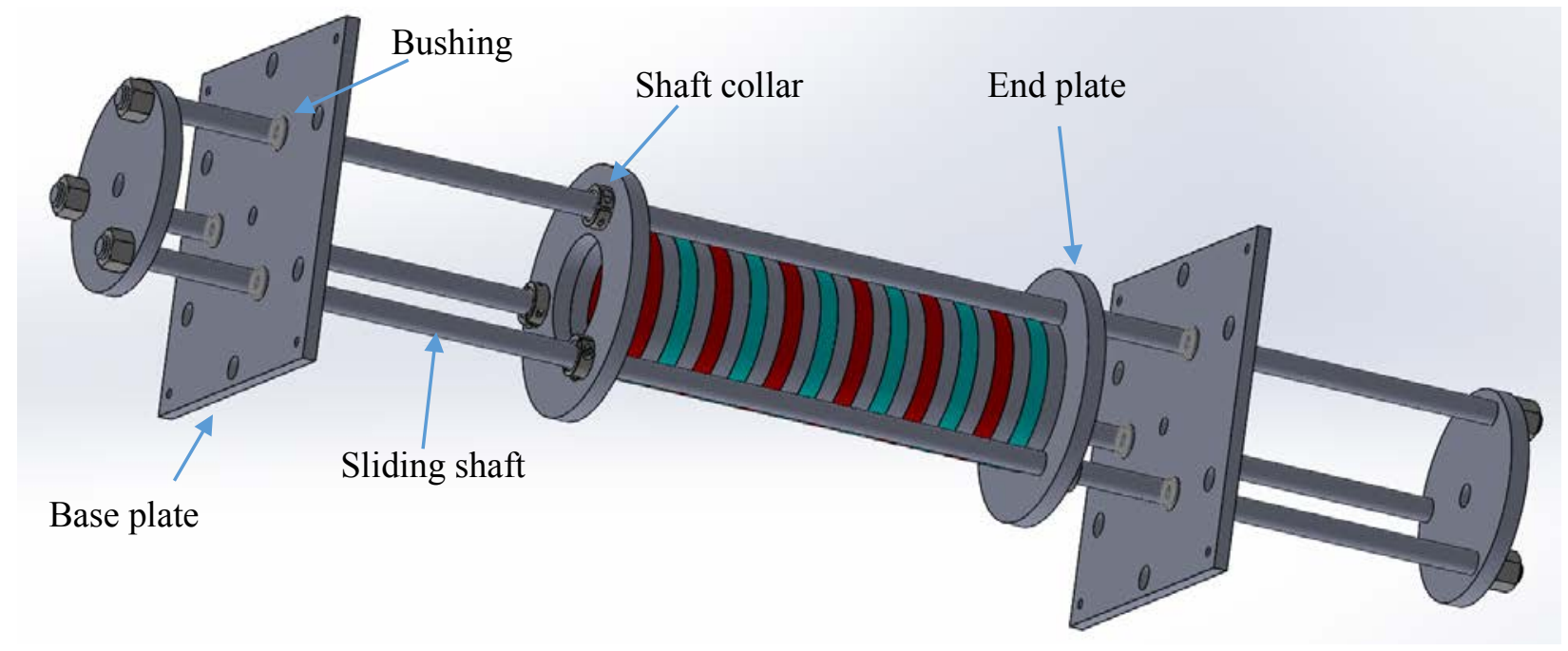

Figure 4-5 Translator construction

\subsection{Stator construction}

Such translator design required insertion of three channels into the external stator's teeth to accommodate the sliding shafts (Fig. 4-6). The channels reduce effective surface between the external stator poles and translator poles by about $9 \%$. Adjustment in the value for $g_{2}$ used in the actual design is used to compensate for the channels so that $g_{2}=0.91 * 3.75 \mathrm{~mm} \sim 3.5 \mathrm{~mm}$.

Shafts also penetrate the space belonging to the external stator slots. To be able to install the same amount of the winding material on both stators, depth of the external stator slots had to be increased. (Fig. 4-7).

Stators are built out of solid steel parts. All the parts belong to two groups. Parts belonging to the first group (slot group) only contribute to the back iron, while the parts from the second group (tooth group) contain a tooth as well (Fig. 4-7). 


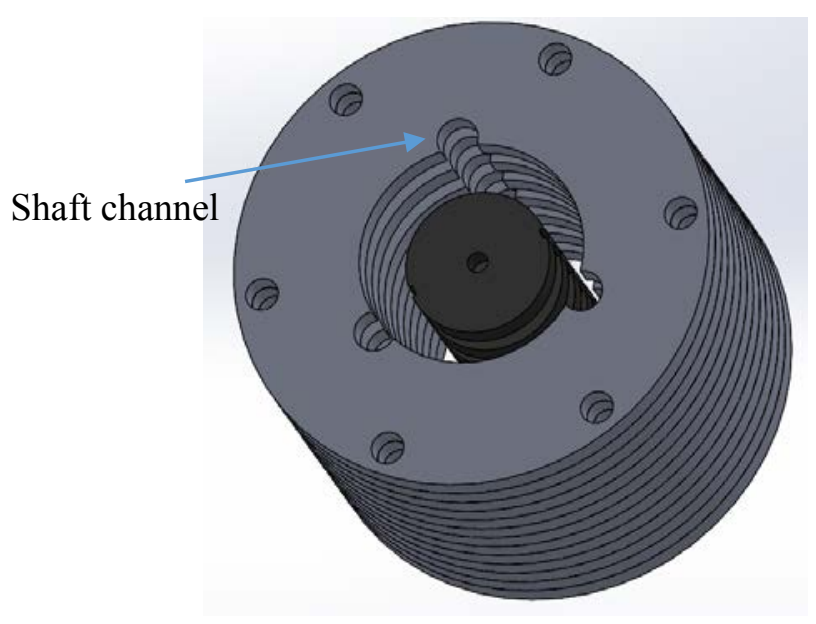

Figure 4-6 External and internal stator
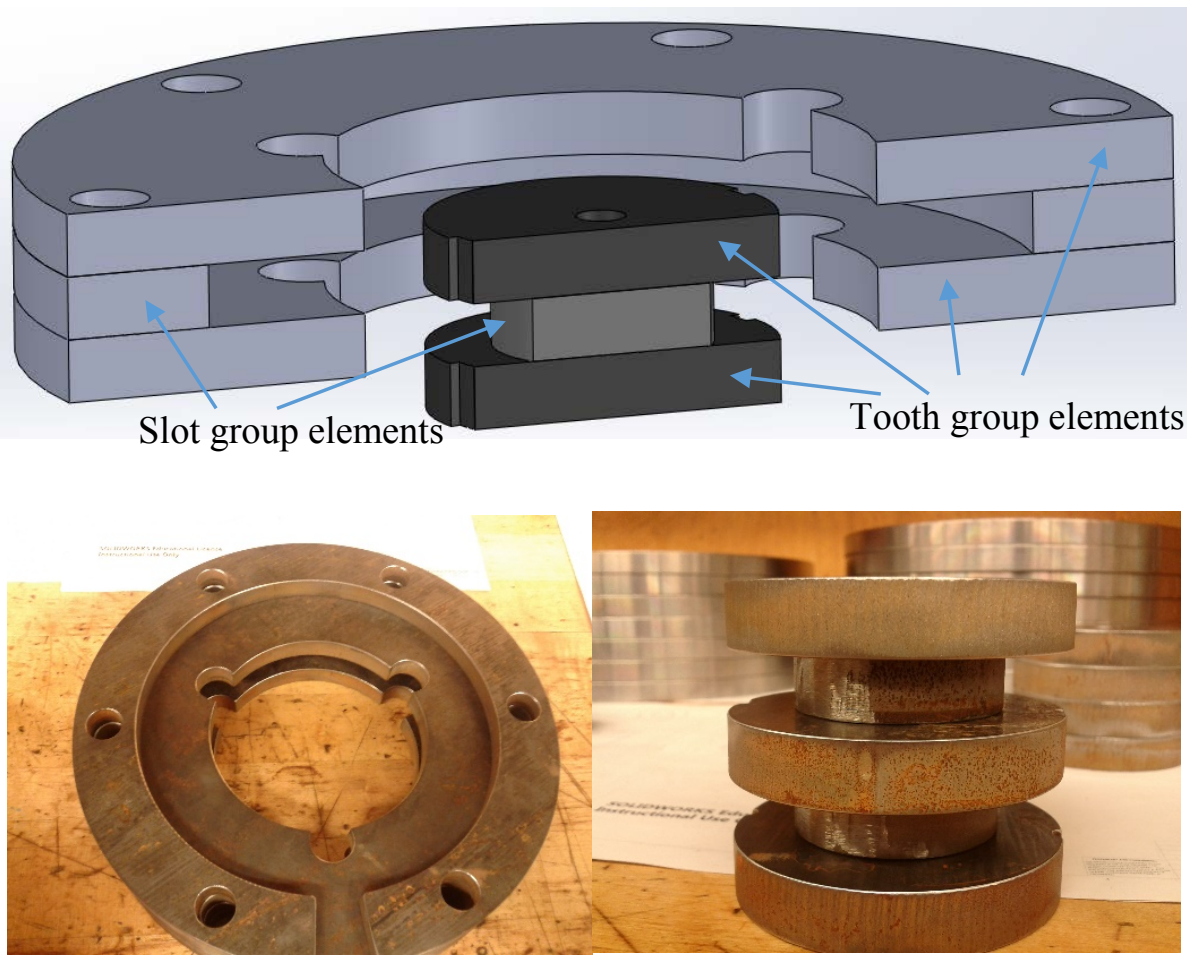

Figure 4-7 Slot and tooth stator elements 
Parts for the internal and external stator and single phase translator poles have been cut out of the same steel plate, achieving high utilization of the material (Fig. 4-8 a)). After they have been cut by a $\mathrm{CNC}$ waterjet, the parts needed only minor surface machining.

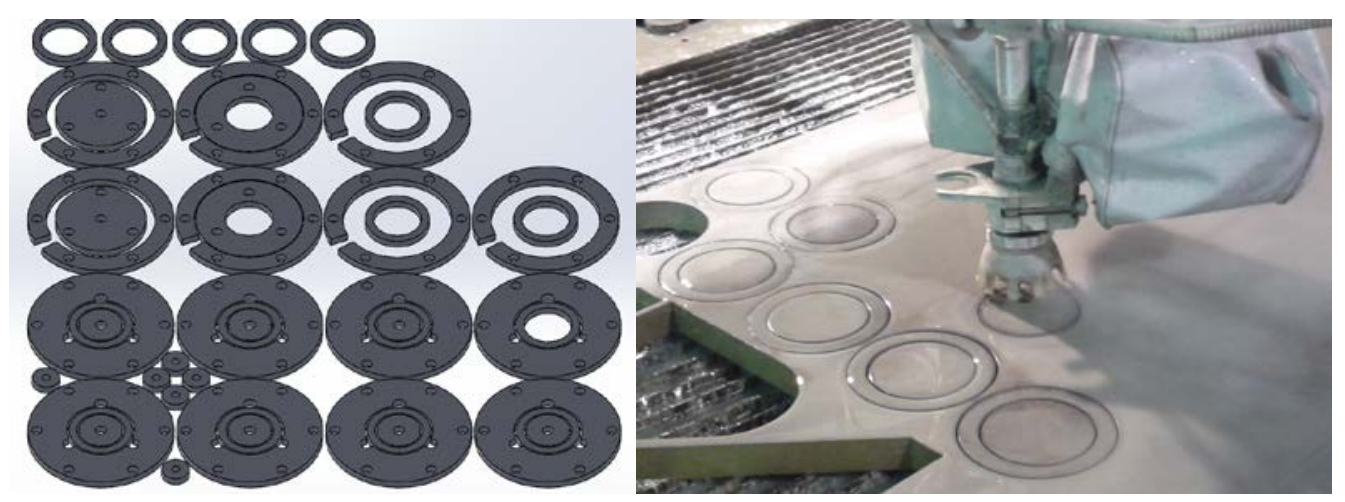

Figure 4-8 a) Iron parts cutting pattern b) Waterjet CNC cutting the three phase translator pole rings

Six threaded support shafts penetrate all external stator elements, link them to the base plates and maintain the alignment of the entire structure. Nuts underneath and above the external stator fix its vertical position (Fig. 4-11 a). Placement and support for the internal stator has been similarly realized with one central shaft penetrating its axis (Fig. 4-9). The internal stator has little channels carved in it that facilitate placement of the coils and extraction of coil terminals. Their influence on the flux distribution is not significant.

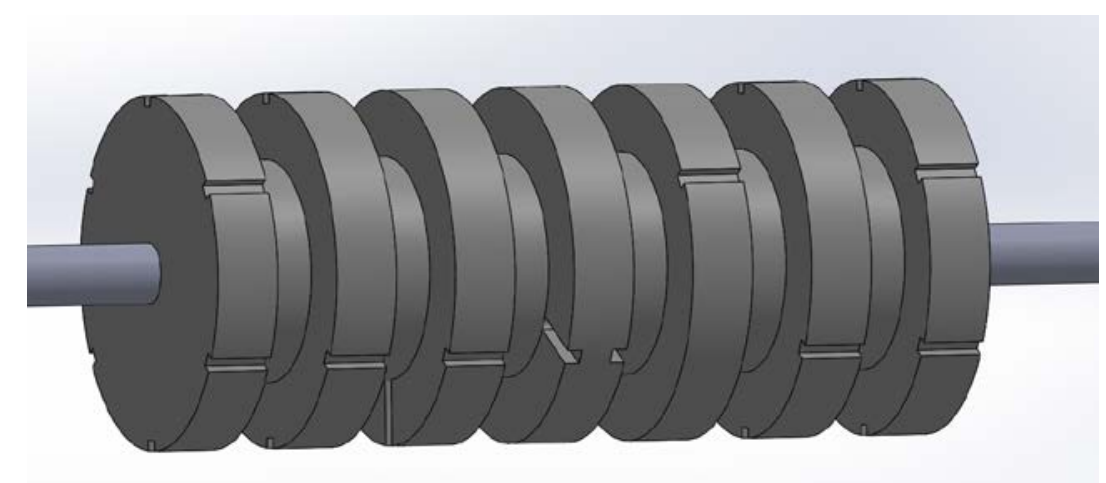

Figure 4-9 Internal stator structure 


\subsection{Winding}

Diameter of the internal stator, as well as depth of its slots, has been determined by dimensions of the ring magnets. Each stator coil has 60 turns of AWG16 wire. For the experimental conditions described in the following chapter (translator speed: $u<0.1 \mathrm{~m} / \mathrm{s}$ and load resistance: $1 \Omega<R_{L}<10 \Omega$ ), smaller number of turns would reduce the output power. On the other hand, slot dimensions and wire rating limit further increase in the number of wire turns. St. John's Pennecon workshop manufactured the windings. Internal coils were directly wound on the stator iron. The iron parts have been previously isolated to prevent possible contact with the wires (Fig. 4-10 a).

Direct winding of the external stator would be impossible; therefore, external coils were firstly wound on a jig, then isolated and inserted in the stator (Fig. 4-10 b-c).
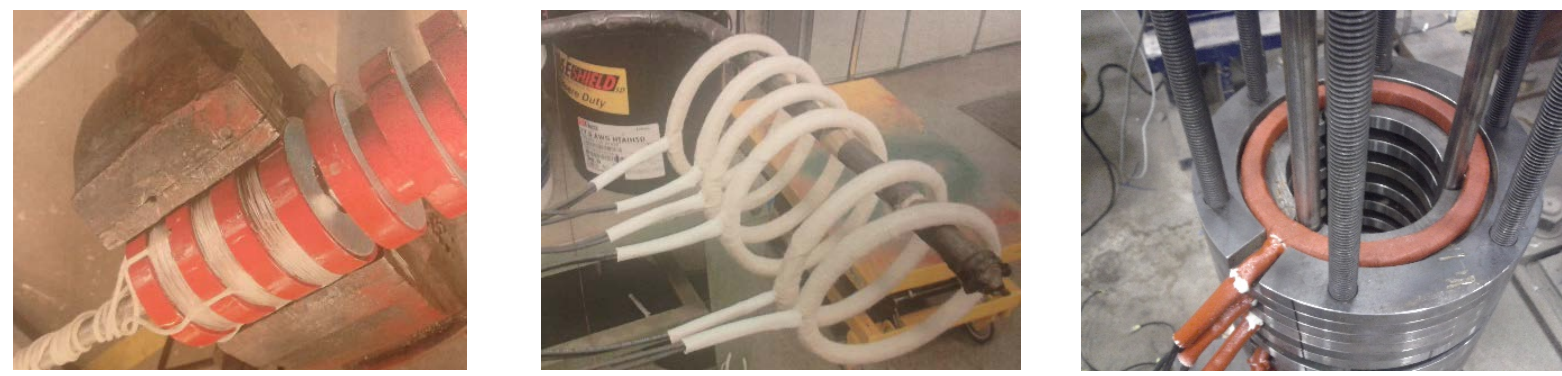

Figure 4-10 a) Winding of the internal stator b) external stator coils c) placement of the external coils in the slots

All the coil terminals were collected at one panel (Fig. 4-11 b)). This facilitated realization of different connections among the coils when going from one topology to another. 


\subsection{Sleeves}

Placement of the translator in the stator has exposed presence of strong radial forces that have been displacing the translator and the internal stator out of the axis. Polyvinyl sleeves were acquired to maintain the translator alignment and the lengths of internal and external air gap. The external sleeve was attached to the external stator (Fig. 4-12) and internal to the translator. 

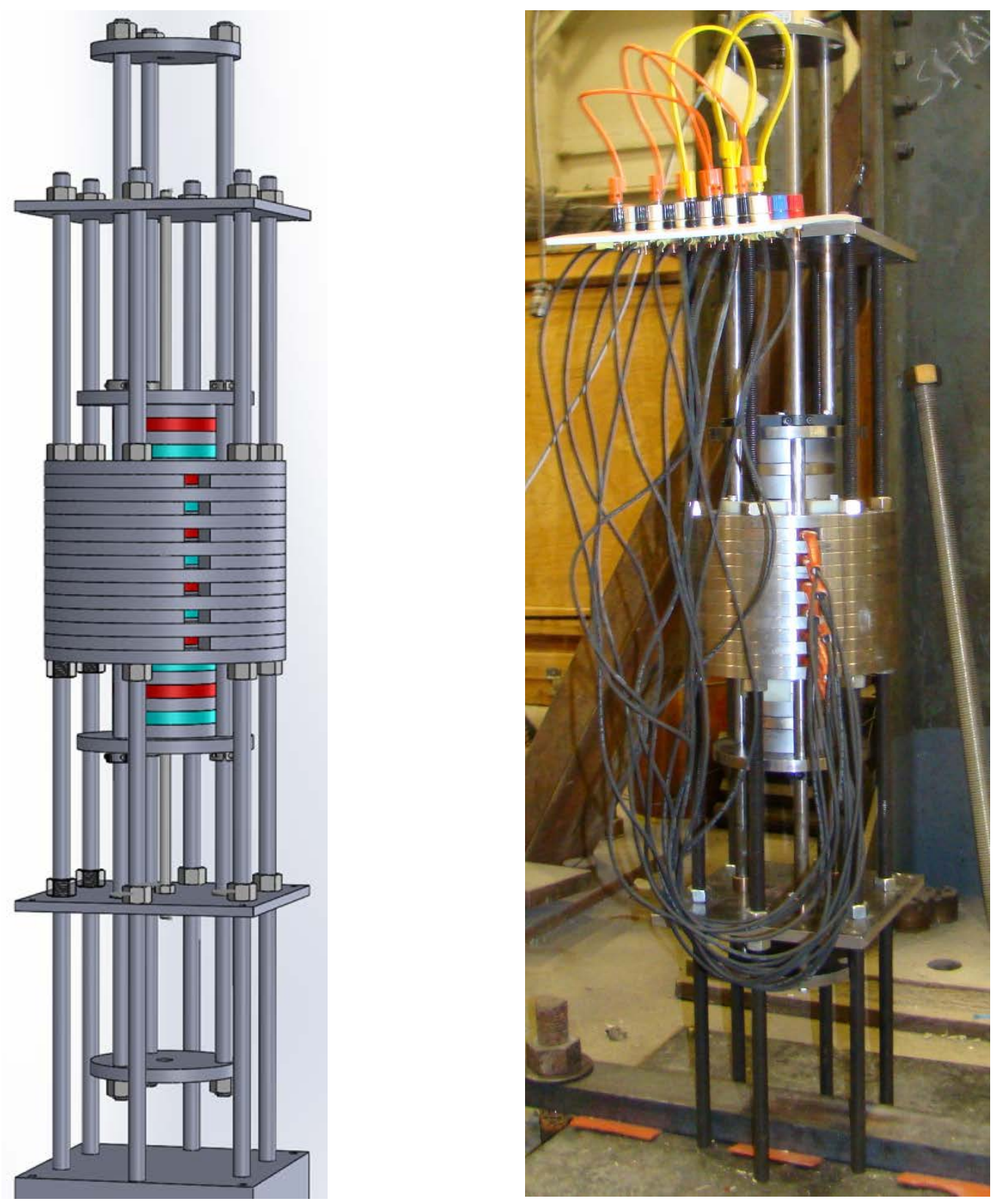

Figure 4-11 LPMG Assembly a) 3D model b) prototype in the lab 

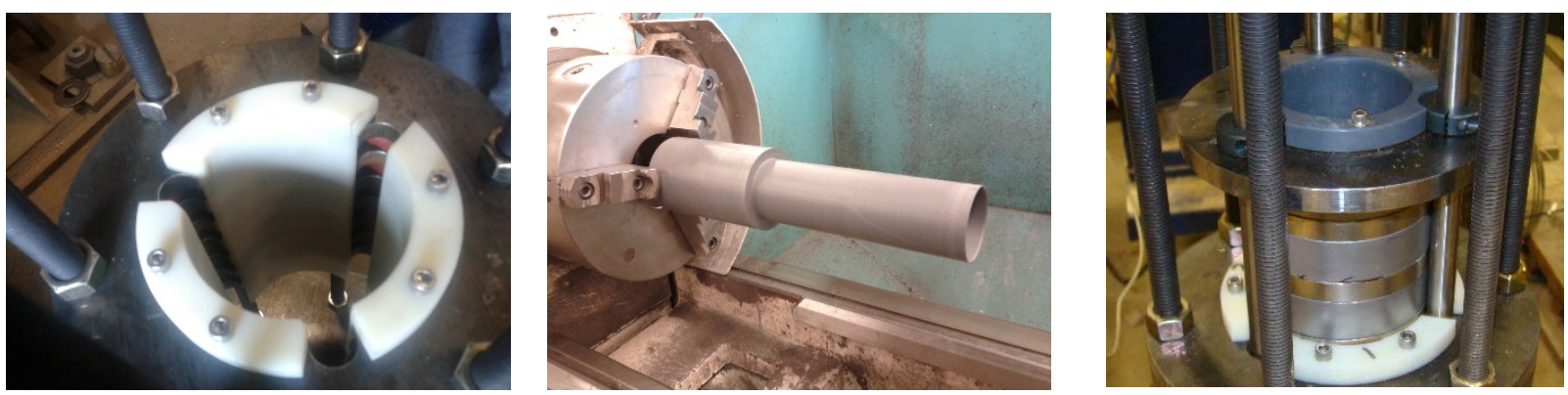

Figure 4-12 a) External sleeve attached to the external stator b) manufacturing of internal sleeve c) attachment of internal sleeve to the translator's end plate is located between the shaft collars

Stronger translator structure can be obtained with an internal support frame. Its presence would take some of the space occupied by the magnetic material and require manufacturing of custom shaped magnets.

\subsection{Summary}

Analytical approach and the FEM simulations were used to obtain optimum size of the external air gap, based upon the criteria of the cogging force minimization in the DS two phase topology.

Translator design does not require custom-made permanent magnets. However, stator magnetic circuit had to be adjusted to accommodate such design. Magnetic circuit elements have simple construction, which is mostly realized by the $\mathrm{CNC}$ machine. Radial forces cause misalignment of the translator and the internal stator. For the purpose of the experiment, this issue has been handled by insertion of the guiding sleeves. Practical application would require a translator with its own support frame. 


\section{Chapter 5}

\section{Experimental setup}

\subsection{Introduction}

This chapter describes the experimental setup used to test the constructed prototype. The linear hydraulic actuator has been used to drive the translator, while force and electrical measurements were collected. Cogging force can be extracted from a totality of the load cell reading that also contains weight and friction components. Experiment provides comparison between different topologies in terms of important machine parameters, such as no load EMF, load power and inductance profile for different translator positions. Limitations for the actuator performance and instrumentation accuracy are given.

Prototype's translator is a couple of pole pitches longer than the stator. Therefore, only limited translator excursion is possible. However, it is still suitable for conducting the no load EMF and cogging force measurements.

LPMG configurations that were tested include:

- Single sided single phase LPMG

- Double sided two phase LPMG

- Single sided three phase LPMG

- Double sided three phase LPMG 


\subsection{Prototype mounting}

Linear hydraulic actuator (MTS Series 243.45) is capable of providing low frequency, linear reciprocating movement with more than sufficient forces in both directions [Series 243 Actuators, 2015]. This makes it very suitable for the LPMG testing under the regular wave conditions. Experimental setup uses the actuator mounted on a massive, rigid beam above the generator prototype. Particularly manufactured adapter connects the actuator to the generator's translator across a pancake style load cell.

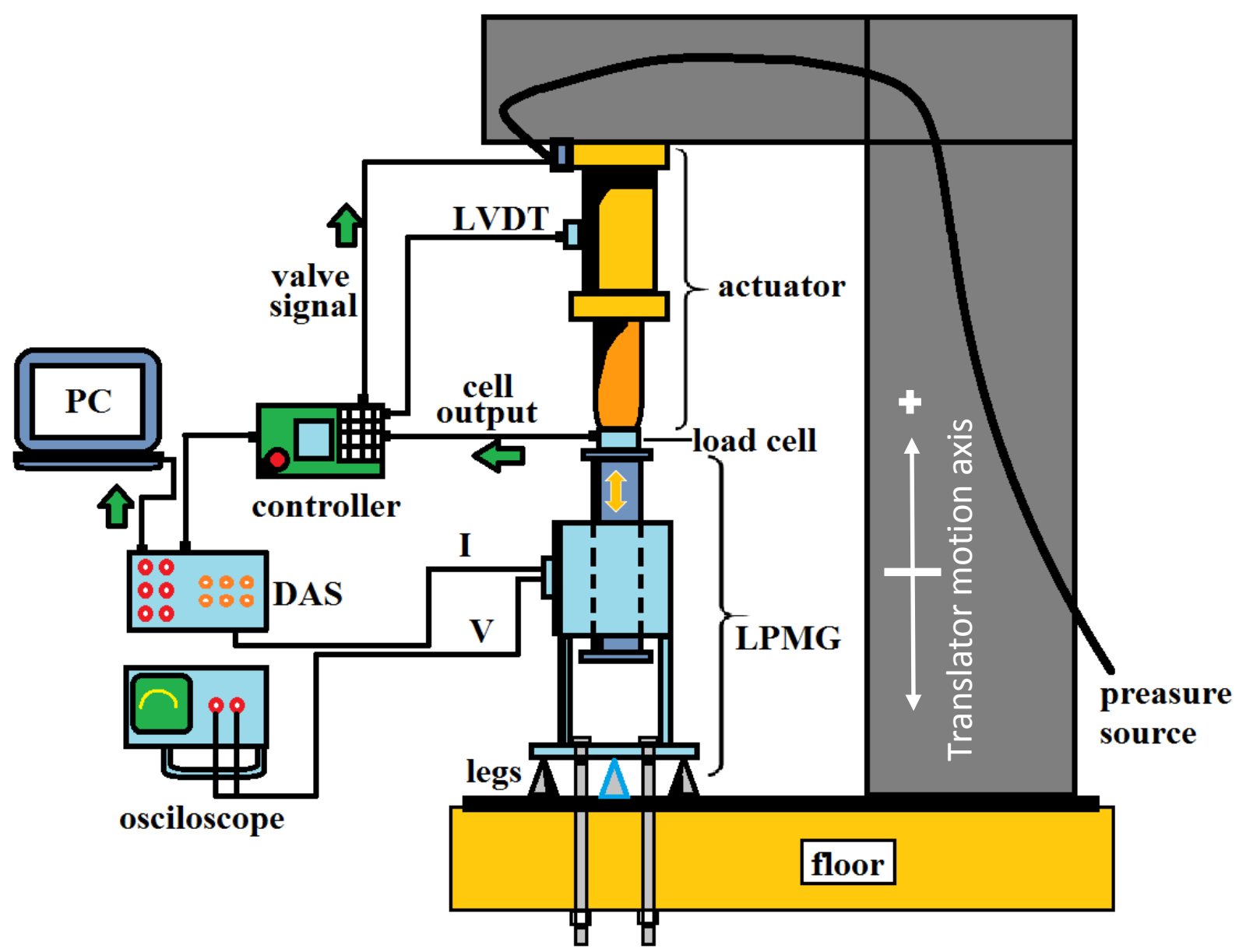

Figure 5-1 a) Schematics of the experimental setup 
It was essential that the actuator and generator be aligned as good as possible. Possible misalignment might lead to the additional friction, noise and even damage the prototype. To obtain satisfactory alignment, the translator was attached to the actuator and the whole generator was lifted of the ground. After being straightened by its own weight, the generator is gently lowered until the ground can be reached by unscrewing of its base legs. It should be noted that cogging force (in the SS single phase topology) was strong enough to make rest of the generator follow the pulled up translator, otherwise translator would have to be mechanically locked to the stator. Afterwards, the generator's base is fixed to the ground by insertion of steel shafts through it and the floor. Nuts attached to the shafts on the other side of the floor prevent them from moving.

Servo-controller (MTS 407) [MTS 407 Controller, 2015] provides the servo-valve drive signal and governs the actuator's pressure. It is able to prescribe different shaped waveforms to the actuator's piston. The first test has shown that the translator movement was not very smooth. Depending on the frequency and amplitude of the prescribed motion, more or less intense mechanical vibrations were present in the system. Their source is most likely related to the situation of the machine's base plate on its four legs (Fig. 5-2 b). The base is a steal plate standing on four corner legs. The base center experiences strong axial force that comes from the interaction between the moving translator, bearings and the stator.

Placing an extra leg at the center of the base plate (Fig. 5-2 c) has helped the base to balance this force leading to much smoother translator movement and much less machine vibrations. Additionally, rubber patches were placed at the contact between the legs and the concrete floor. 


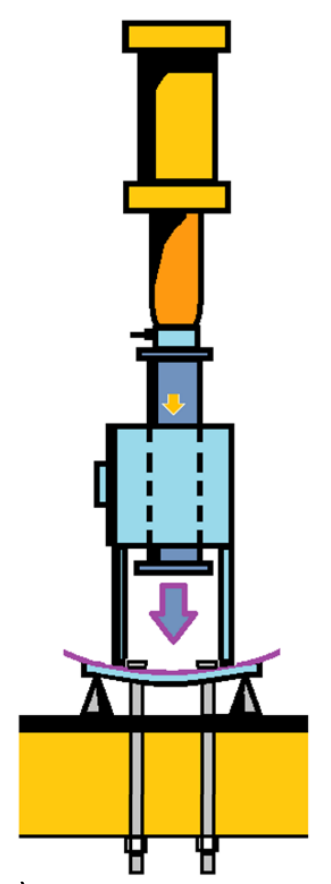

a)

Figure 5-2 a) Forces on the prototype base plate without and with cetral leg b) shafts fixing the base plate to the floor c) central leg mounted on the plate
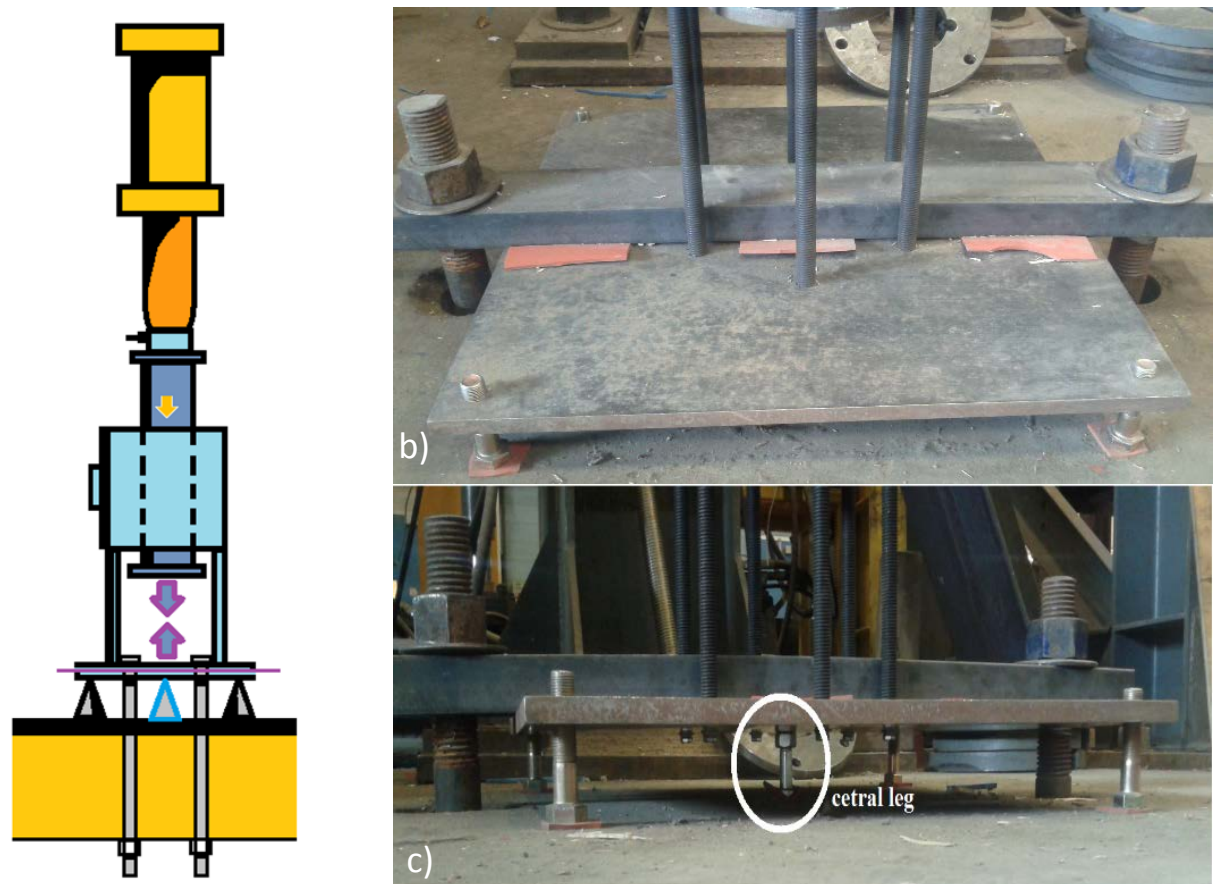
Nominal maximum speed of the piston $u_{M}$ during the extension is more critical due to larger available piston area $A_{e} ; u_{M}$ can be calculated from maximum flow rate $Q$ of the hydraulic manifold [Series 293 Manifolds, 2015] and area of the actuator piston $A_{e}$ [Series 243 Actuators, 2015] as:

$$
u_{M}=\frac{Q}{A_{e}}=\frac{0.00315 \frac{\mathrm{m}^{3}}{\mathrm{~s}}}{0.0324 \mathrm{~m}^{2}}=0.0972 \frac{\mathrm{m}}{\mathrm{s}}
$$

Maximum speed prescribed to the actuator during the $0.6 \mathrm{~Hz}$ profile (Fig. 5-3) is $0.0754 \frac{\mathrm{m}}{\mathrm{s}}$ and it is close to actuators critical extension speed $u_{M}$. Other factors such as age of the equipment, might have contributed to the fact that stroke shortening occurs even before nominal critical speed has been surpassed.

Thereafter, testing has been conducted in the frequency bandwidth whose curtailment of prescribed range was less than $4 \%$ (Fig. 5-4). 


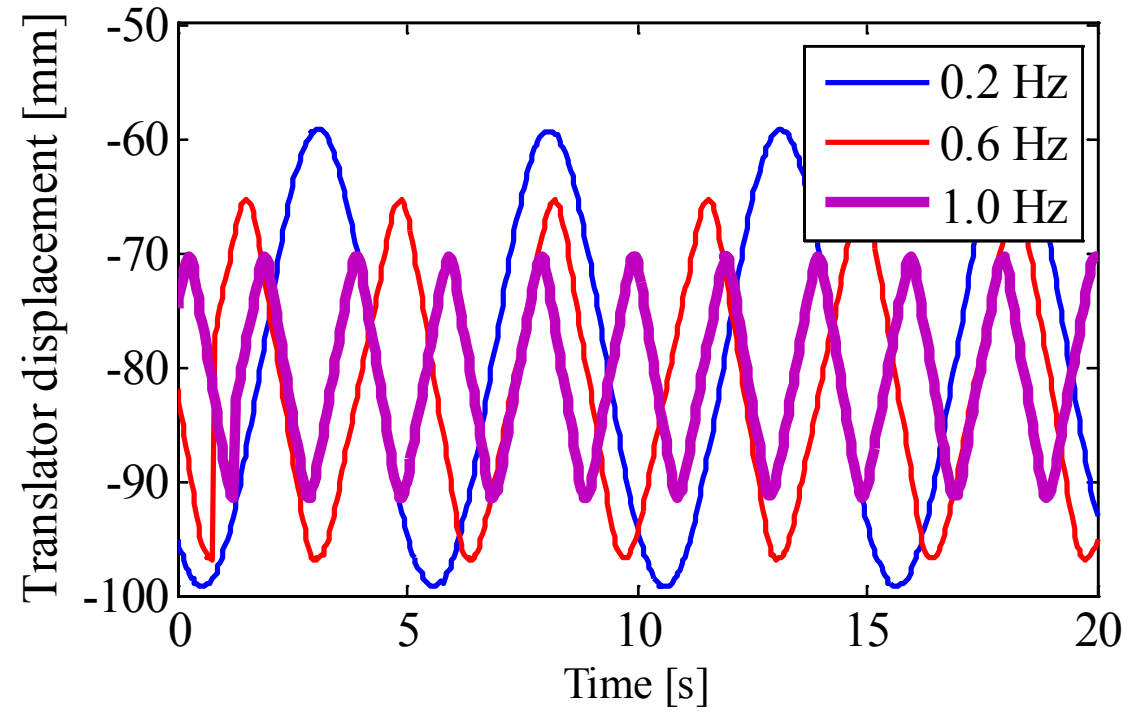

Figure 5-3 Motion profile of the actuator piston for $40 \mathrm{~mm}$ peak to peak amplitude prescribed motion at different frequencies

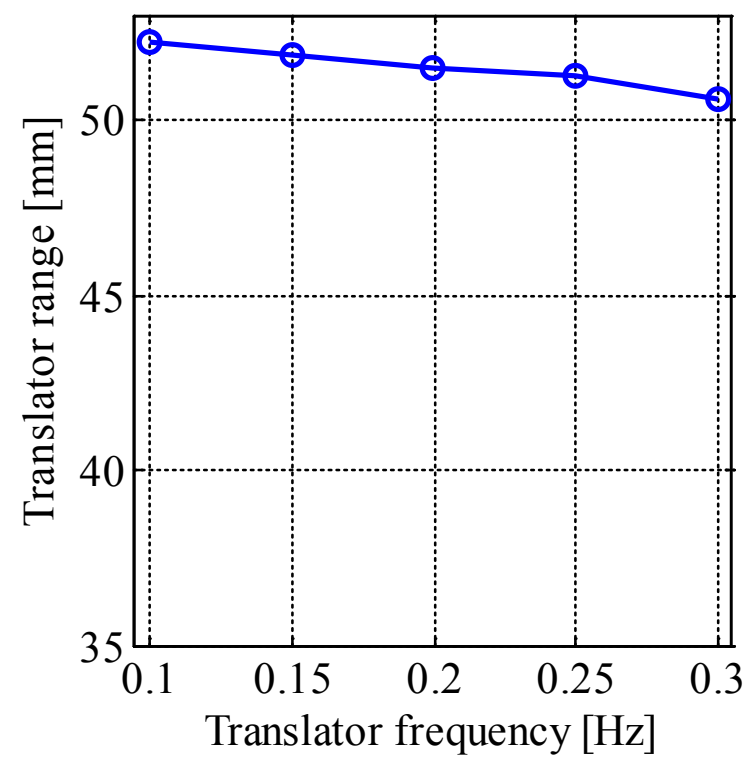

Figure 5-4 Drop in translator displacement peak to peak amplitude with motion frequency 


\subsection{Measurement equipment}

Servo controller can also manage signals from AC transducers. This feature has been used to collect the piston displacement readings from LVDT (linear variable differential transducer) and the load cell readings. Data acquisition system (DAS [9063 Data Acquisition and Control Interface, 2015] leads both signals to PC through its USB cable. Displacement and force readings are processed, viewed and stored by LVDAC-EMS software. The load cell used is 5klbs OMEGADYNE LCHD-5K (Fig. 5-5 b)). For forces above $50 \mathrm{lbs}$, it is characterized by hysteresis of $0.08 \%$ and repeatability of $0.03 \%$ FSR (full scale reading) which respectively equal to about $4 \mathrm{lbs}(17.8 \mathrm{~N})$ and $1.5 \mathrm{lbs}(4.4 \mathrm{~N})$ [Low-profile load cells, 2015].
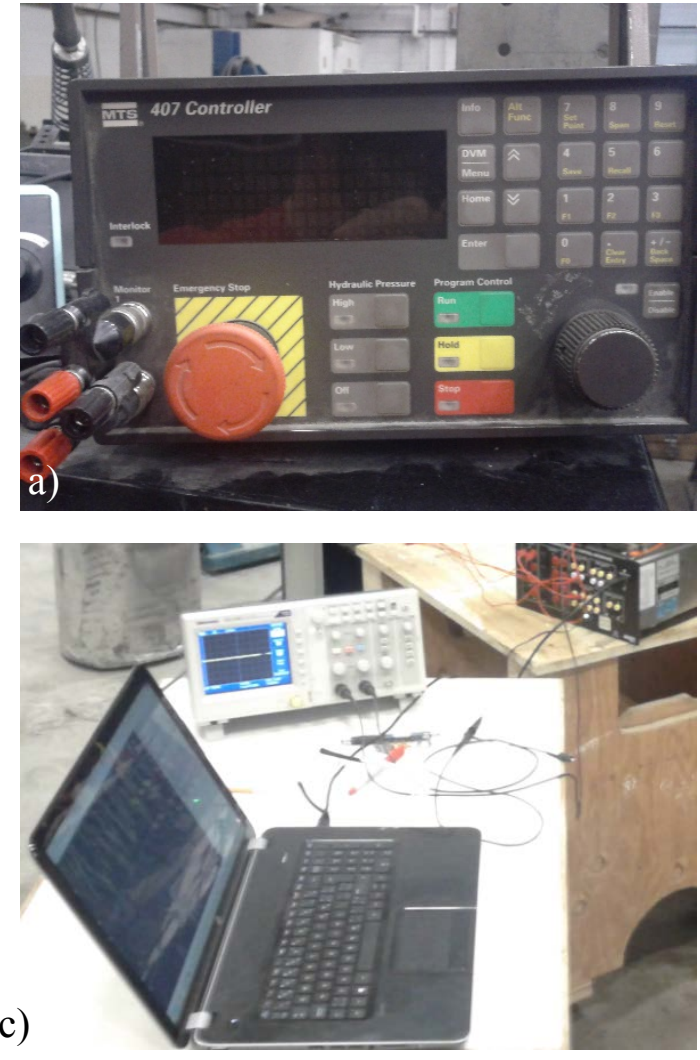
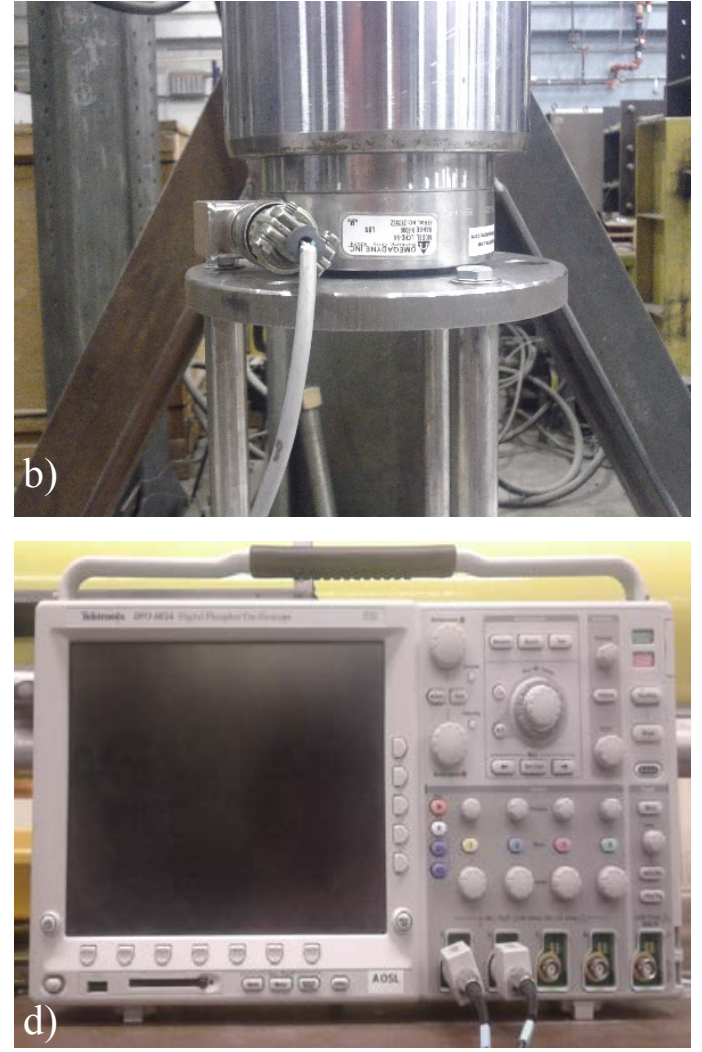

Figure 5-5 a) Servo controller b) Load cell c) two channel oscilloscope, DAS and PC d) four channel oscilloscope 
The DAS is equipped with the voltmeter and ammeter channels. The later was used for current measurement. The ammeter is characterized by $50 \mathrm{~m} \Omega$ of internal resistance for current under 4A and measurement accuracy of $1 \%$ on the frequency range between DC and $10 \mathrm{KHz}$ [9063 Data Acquisition and Control Interface, 2015].

The DAS voltmeter noise has been found to be excessive for measuring low amplitude voltage. Instead, two channel TEKTRONIX TBS1062 oscilloscope was used for voltage measurement in single and two phase topologies; three phase voltage was measured by TEKTRONIX DPO4034 four channel oscilloscope. They both have input impedance of $1 M \Omega$, while DPO4034 has $1.5 \%$ DC voltage accuracy [DPO4000B Series Datasheet, 2015] compared to 3\% of TBS1062 [TBS1000 Series Datasheet, 2015].

Tenma 72-7740 multi-meter provided resistance measurement for phase windings and load resistors. All measured resistances were under to $400 \Omega$. In this range the multi-meter measures resistance with resolution of $0.1 \Omega$ and accuracy of $(1.2 \%+2)$ [TENMA Operating Manual, 2015].

\subsection{Inductance measuring}

For inductance measurements, prime mover was kept still over a scale of positions. For each position, variable autotransformer supplied voltage $V_{S}$ to winding ends, while oscilloscope measured the voltage and the DAS measured phase current $I$ (Fig. 5-6). Self-inductance $L_{S}$ follows from the measurements as:

$$
L_{s}=\frac{\sqrt{\left(\frac{V_{s}}{I}\right)^{2}-R^{2}}}{2 \pi f}
$$


where $f$ is the frequency of the supplied voltage and $R$ is the resistance of the circuit. Mutual inductance follows from measured open circuit voltage in another phase $V_{p h}$ as:

$$
L_{m}=\frac{V_{p h}}{2 \pi f I}
$$

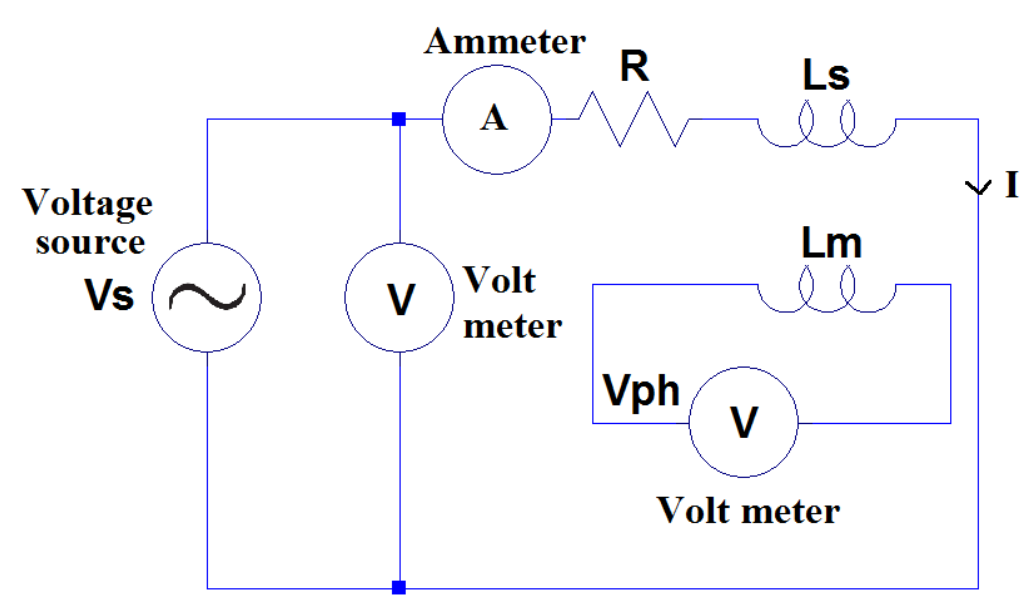

Figure 5-6 Inductance measurement scheme

\subsection{Summary}

The hydraulic actuator is used to prescribe sinusoidal motion to the translator. Due to its maximum flow rate, actuator speed is limited. Tests were conducted within the zone where the actuator was able to produce proper sine wave motion. Additional support to the base plate solved problem with generator vibrations. Accuracy of measurement devices is found to be satisfactory. 


\section{Chapter 6}

\section{Measurement Results}

\subsection{Introduction}

Hydraulic actuator has been prescribing sinusoidal motion to the LPMGs translator. No load EMF, force and power results have been collected. These measurements provide experimental comparison of different topologies in terms of the no load EMF, cogging force and output power. Measured values are also compared to the simulation predictions in order to evaluate the simulation quality. Furthermore, experimental results help us learn how big effect imperfections in the prototype manufacturing have on the magnitude of the flux leakage, i.e. on the reduction of the main PM flux and no load EMF in the DS topology.

\subsection{No load EMF}

The translator has been put into sinusoidal motion of different frequency. Winding terminals are kept open and no load EMF in each phase is measured. Afterwards, measurements are compared to the analytical and FEM results.

\subsubsection{Single sided single phase and Double sided two phase}

Figure 6-1 shows no load EMF waveforms in the SS single phase LPMG for two different prime mover frequencies. 

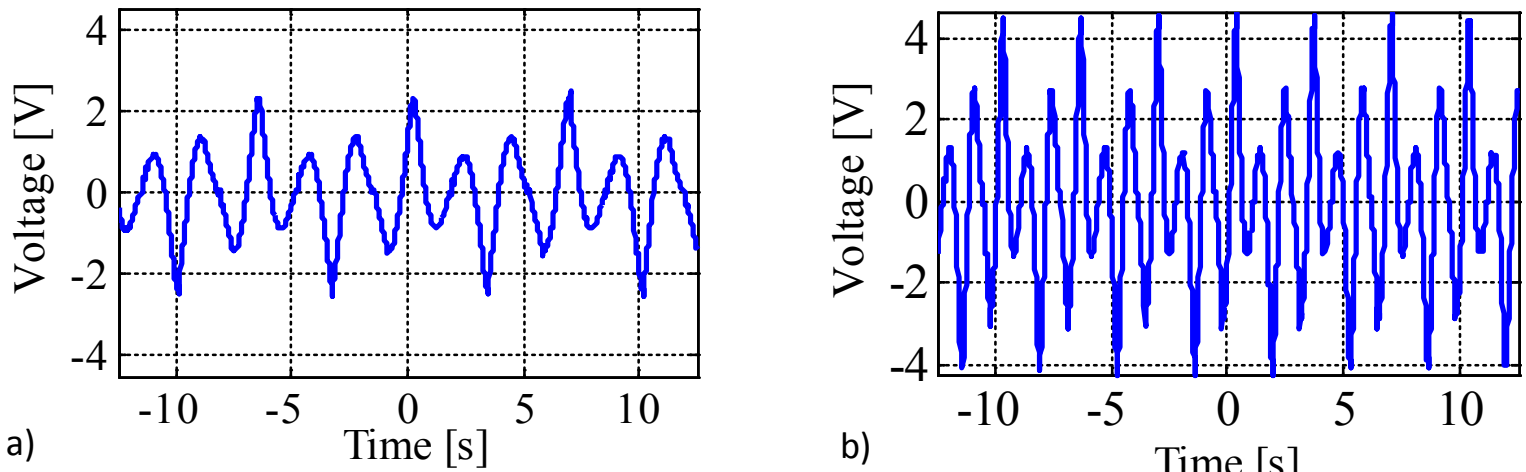

Figure 6-1 SS single phase LPMG no load EMF for the stroke amplitude $26 \mathrm{~mm}$ (a) $0.15 \mathrm{~Hz}$ b) $0.3 \mathrm{~Hz}$ )

Proportionality between frequency of the translator's movement and induced EMF has been verified at Figure 6-2 a). As expected, obtained function seems linear and its slope $K_{f}$ is almost constant. However, small drop in the slope magnitude has been observed for higher frequencies (Fig. 6-2 b). This irregularity should be attributed to already observed (Figure 5-4) inability of the actuator to fully maintain desired displacement waveform in this frequency range.
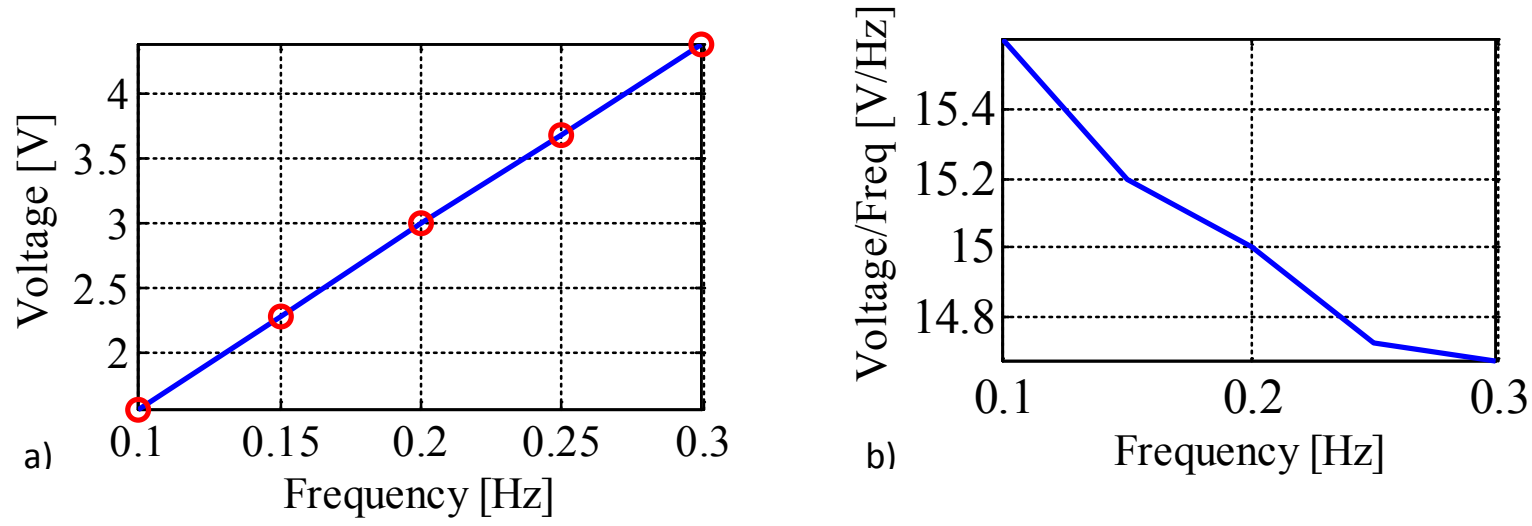

Figure 6-2 SS single phase a) measured peak no load EMF vs frequency for 26 mm amplitude and b) (peak EMF)/frequency fot the same amplitude

From the analytical estimate for the stator flux due to permanent magnets, value for $K_{f}$ can easily be estimated. Stator flux as a function of translator position is assumed to be perfectly sinusoidal: 


$$
\psi=N \Phi_{m} \cos \left(\frac{\pi}{\tau} z\right)
$$

where $N$ is number of stator coil turns per slot, $\Phi_{m}$ is peak total stator flux, $\tau$ is translator pole pitch and $z$ is translator displacement. Then the induced EMF follows as:

$$
\begin{gathered}
E_{0}=-\frac{d \psi}{d t}=-N \Phi_{m} \frac{d}{d t} \cos \left(\frac{\pi}{\tau} A_{w} \sin \left(\omega_{w} t\right)\right) \\
E_{0}=N \Phi_{m} \frac{\pi}{\tau} A_{w} 2 \pi f_{w} \sin \left(\frac{\pi}{\tau} A_{w} \sin \left(\omega_{w} t\right)\right) \cos \left(\omega_{w} t\right) \\
\underbrace{L}_{K_{f}}
\end{gathered}
$$

where $A_{w}$ and $\omega_{w}$ stand for amplitude and angular frequency of prescribed sinusoidal movement. The equation 6.3 yields $K_{f}=2 \pi \frac{\pi}{\tau} A_{w} N \Phi_{m}=16.25[\mathrm{~V} / \mathrm{Hz}]$, which is in good agreement with the results at Figure 6-2 b).

Agreement between the analytical, FEM and measured no load EMF waveform is very satisfactory and builds up confidence in developed models (Fig. 6-3). Waveform's shape strongly depends on the initial position of translator. Slight disagreement in shape between analytical, FEM and measured waveforms probably indicates small offset in starting translator position and deflection of its actual trajectory from the ideal sine wave. 


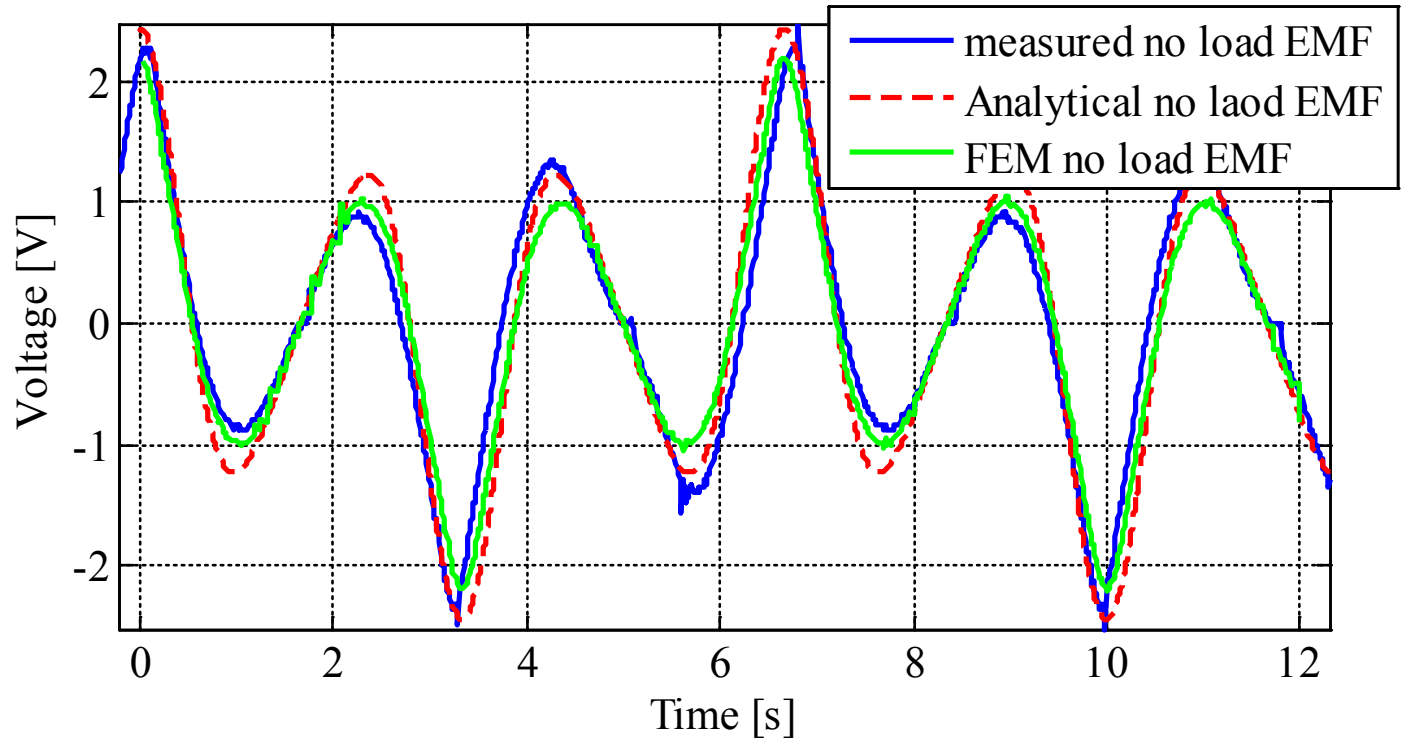

Figure 6-3 SS single phase no load EMF: measured, FEM and analytical simulation [26mm 0.15Hz]

Time dependant study in the COMSOL $®$ model permits to define the translator position as a function of time and directly obtain the no load EMF waveforms. Thus, time dependant study allows calculation of induced voltage in each stator coil. Addition of Electrical Circuit (cir) physics to the model enables summation of the coil voltages to obtain total phase voltage. Presence of two stators in the magnetic circuit of the DS machine makes flux distribution more complex, however analytical model yields predictions that are in good agreement with both FEM and measured no load EMF results (Fig. 6-4). 


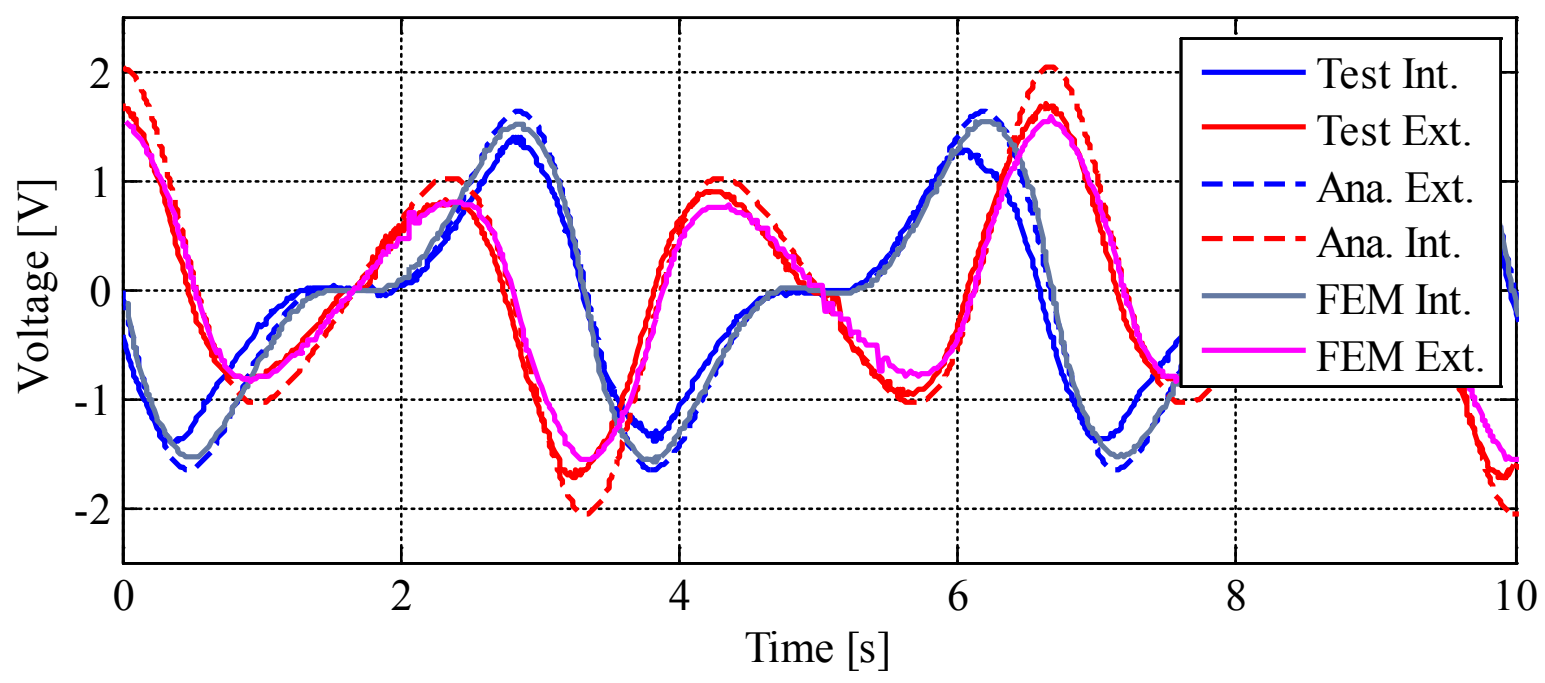

Figure 6-4 DS Two Phase no load EMF: measured, FEM and analytical simulation [26mm 0.15Hz] 

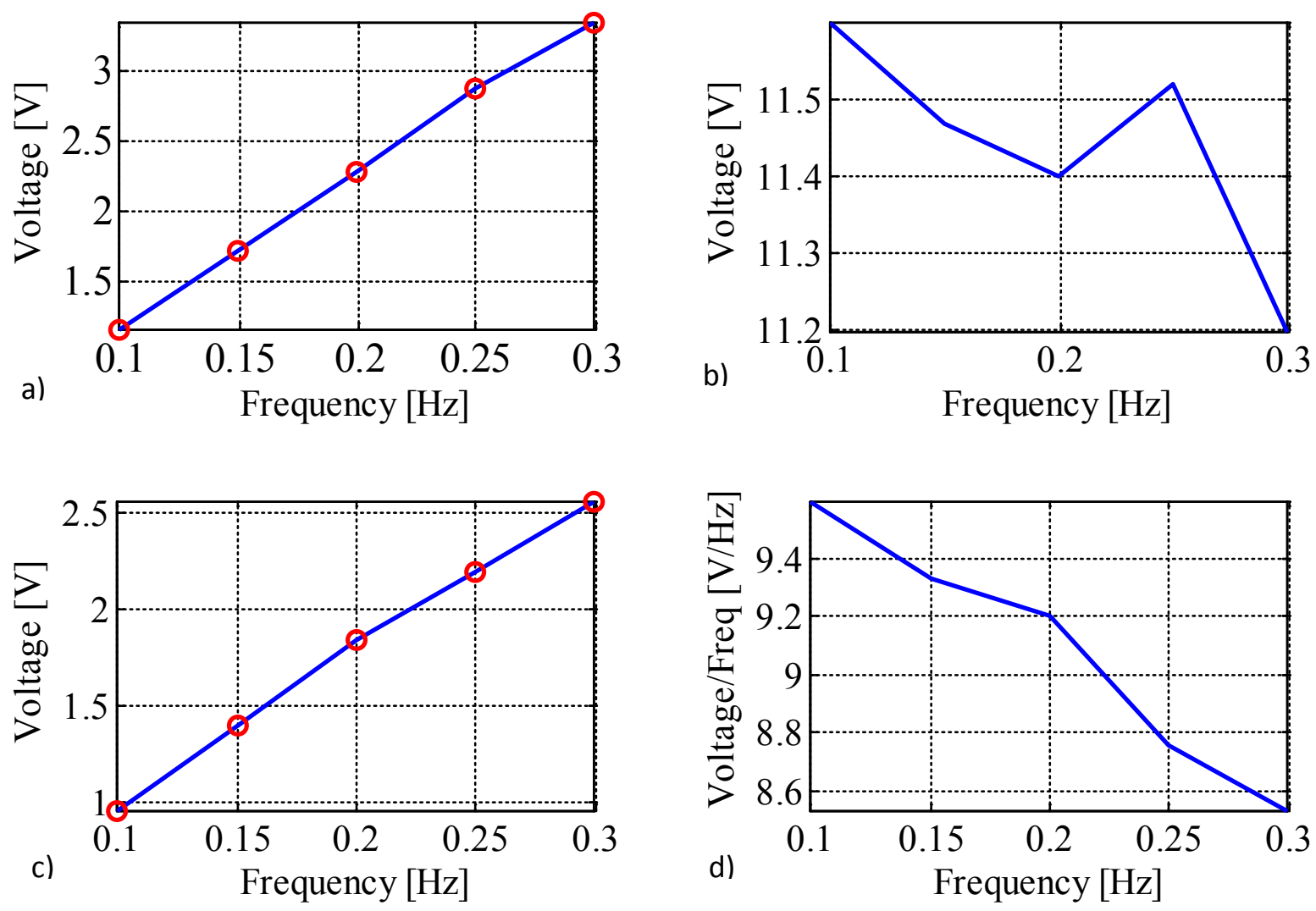

Figure 6-5 DS two phase External ( $a$ and $b$ ) and Internal ( $c$ and d) stator measured no load EMFs vs frequency [26mm]

Comparison of the Figure 6-2 b) to the Figures 6-5 b) and d) indicates how much of the SS machine's flux linkage has actually remained with each stator of the DS two phase machine. If purely sinusoidal PM flux profile is assumed for each stator of so far considered topologies, than it can be concluded that peak internal and external stators' fluxes amounts to $\left(\frac{0.96}{1.56}=\right) 61.5 \%$ and $\left(\frac{1.16}{1.56}=\right) 74.4 \%$ of the SS machine's peak flux. These values are lower than the ones predicted by the analytical and FEM models. Later one predicts flux correction for external stator to be 0.929 and for internal 0.787. On the other hand, measured RMS values of the induced EMF are higher than its peak values in comparison to the appropriate single sided measurements (Figure 6-6). RMS values of the induced EMF in the external and internal stator compare to RMS of the single 
sided machine's EMF as $\left(\frac{0.56}{0.7}=\right) 80 \%$ and $\left(\frac{0.51}{0.7}=\right) 72.8 \%$, respectively. Discrepancy between the test and simulation in terms of bigger no load EMF drop in the DS topology can be justified by differences between the modeled and manufactured machine, such as little prolonged internal stator (due to isolation layers) and the translator shaft channels in the external stator's teeth.
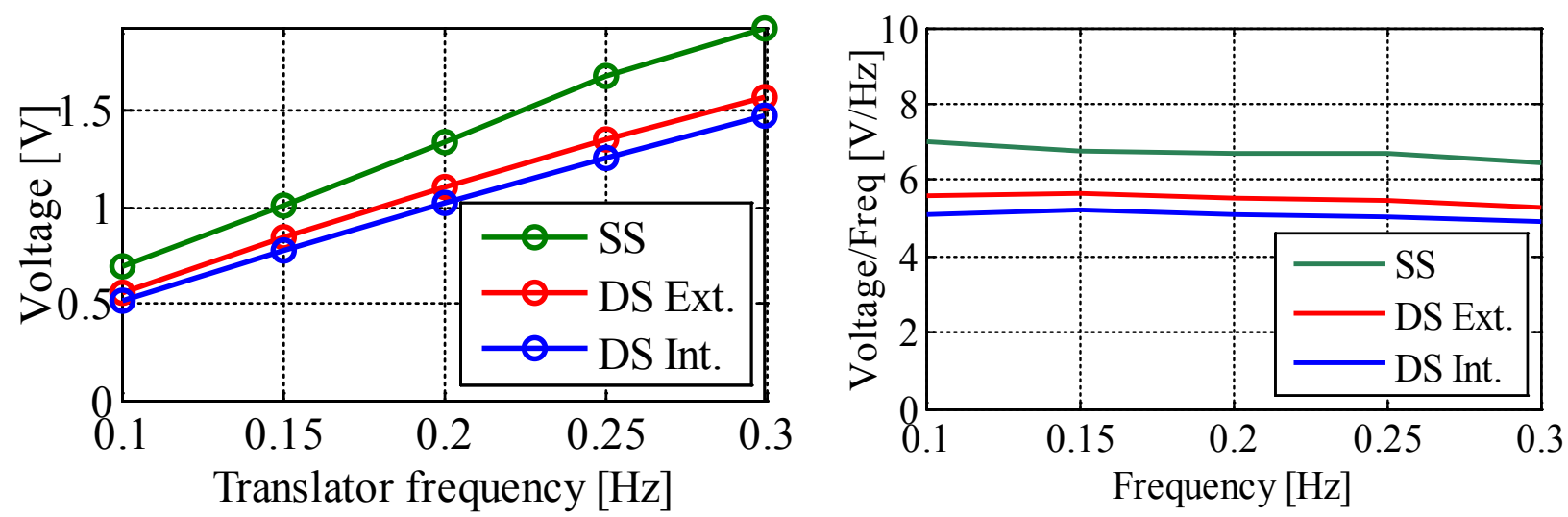

Figure 6-6 a) Measured EMF RMS for SS single phase and DS two phase LPMG b) RMS over frequency

\subsubsection{Three phase - Single sided and Double sided EMF}

Figure 6-7 (a-b) provides no load EMF measurements for the three phase SS and DS generator. Comparison between the Fig. 6-7 and Fig. 6-10 shows beneficial effects of enhanced PM flux linkage in DS configuration on the amplitude of phase EMF. Increase in the EMF for each phase takes the following values:

$$
\frac{E_{A}^{D S}}{E_{A}^{S S}}=1.518 ; \frac{E_{B}^{D S}}{E_{B}^{S S}}=1.469 ; \frac{E_{C}^{D S}}{E_{C}^{S S}}=1.405
$$

The average increase (1.464) is similar to the analytically predicted proportion between linked PM flux in the double sided and single sided three phase machine (1.384).

When it comes to the RMS values for each phase EMF, they compare as: 


$$
\frac{E_{A}^{D S}}{E_{A}^{S S}}=1.637 ; \frac{E_{B}^{D S}}{E_{B}^{S S}}=1.414 ; \frac{E_{C}^{D S}}{E_{C}^{S S}}=1.330
$$
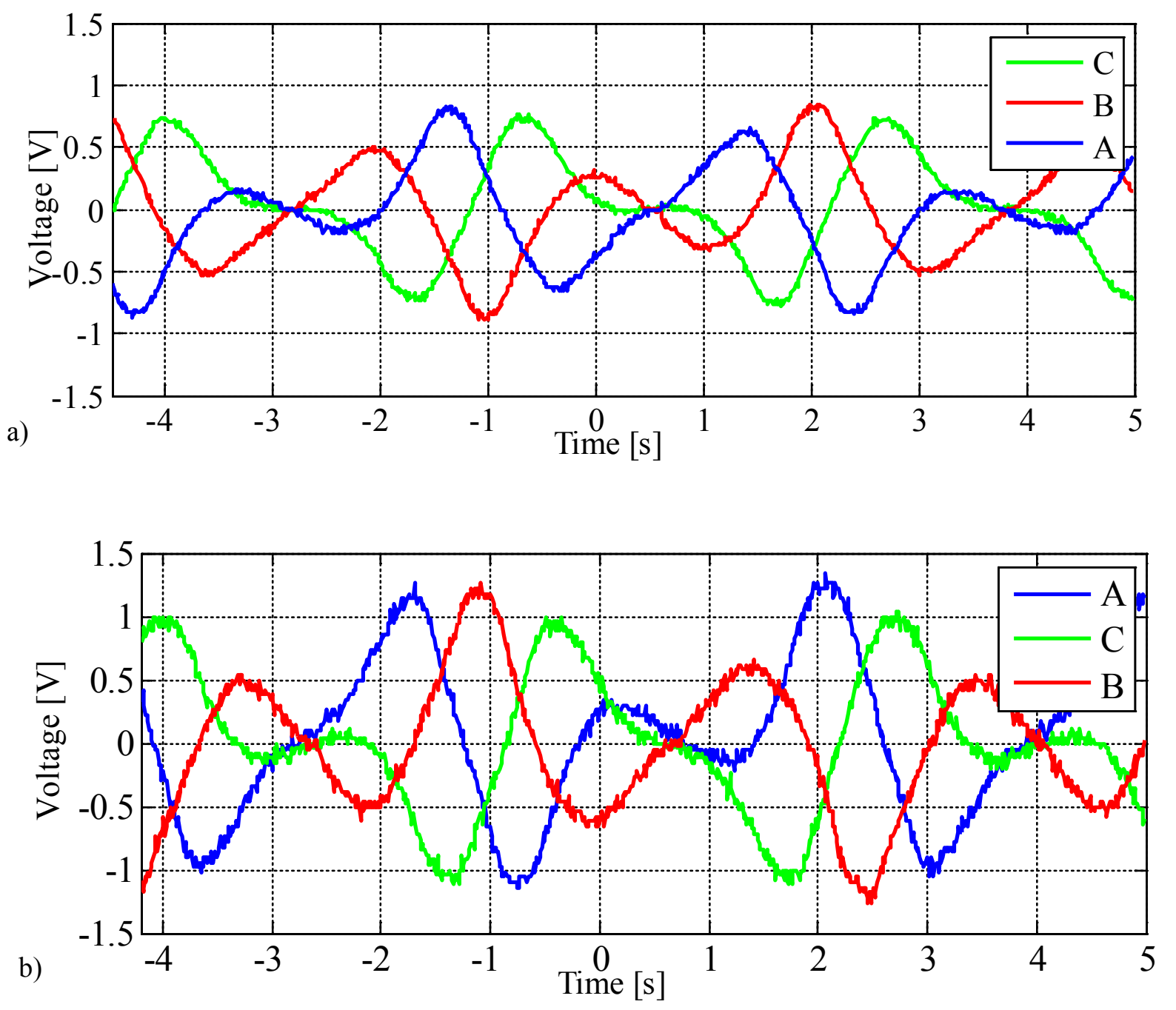

Figure 6-7 Three phase no load measured EMFs: a) single sided and b) double sided [39mm 0.15Hz]

Following set of figures (Fig. 6-8 a-c and Fig. 6-9 a-c) show good agreement between the EMF predictions for each phase of the SS and DS topology. Figure 6-10 compares phase EMFs of the SS and DS topology. 

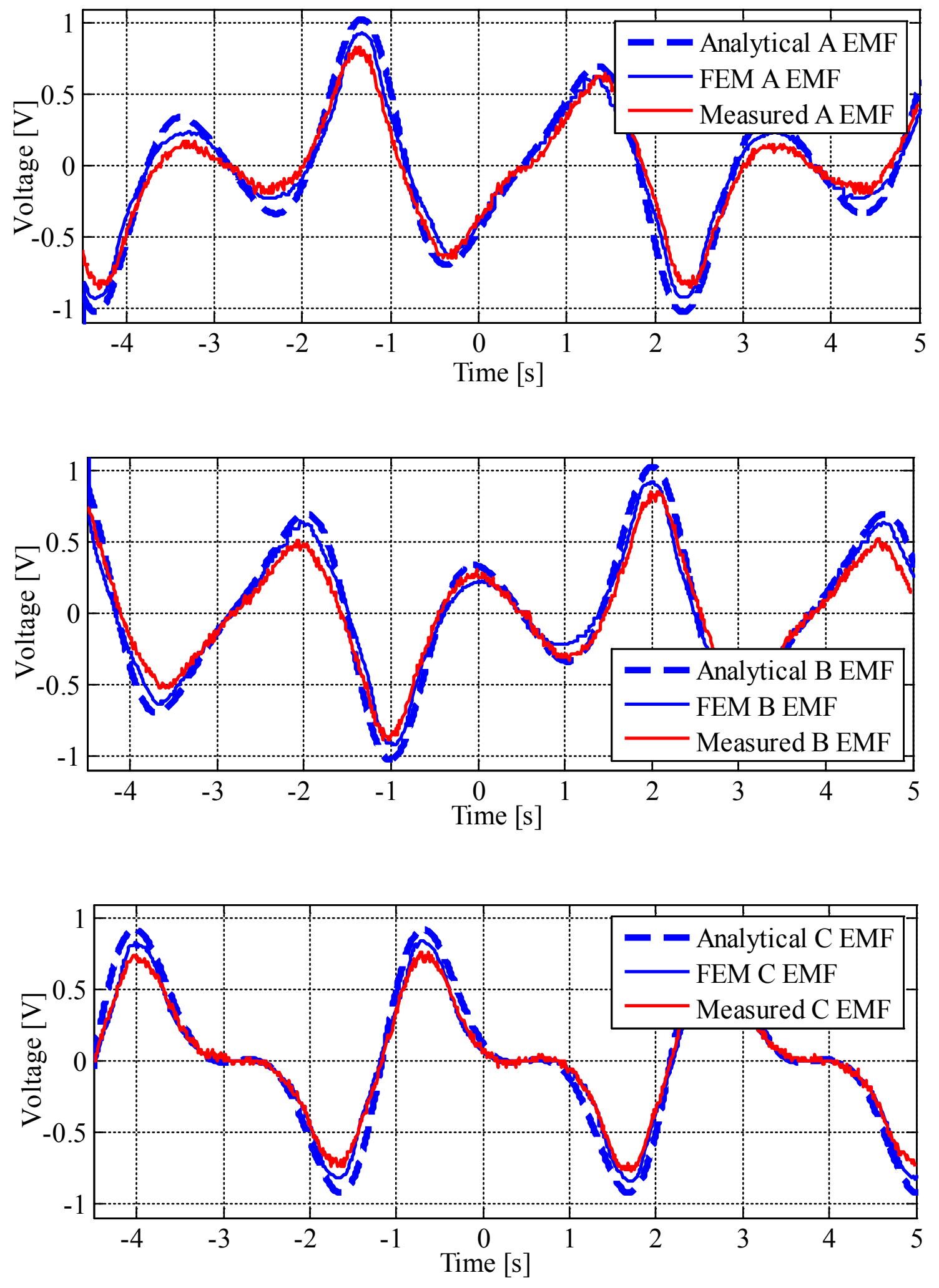

Figure 6-8 SS three phase no load EMFs: measured, FEM and analytical simulation [39mm 0.15Hz] 

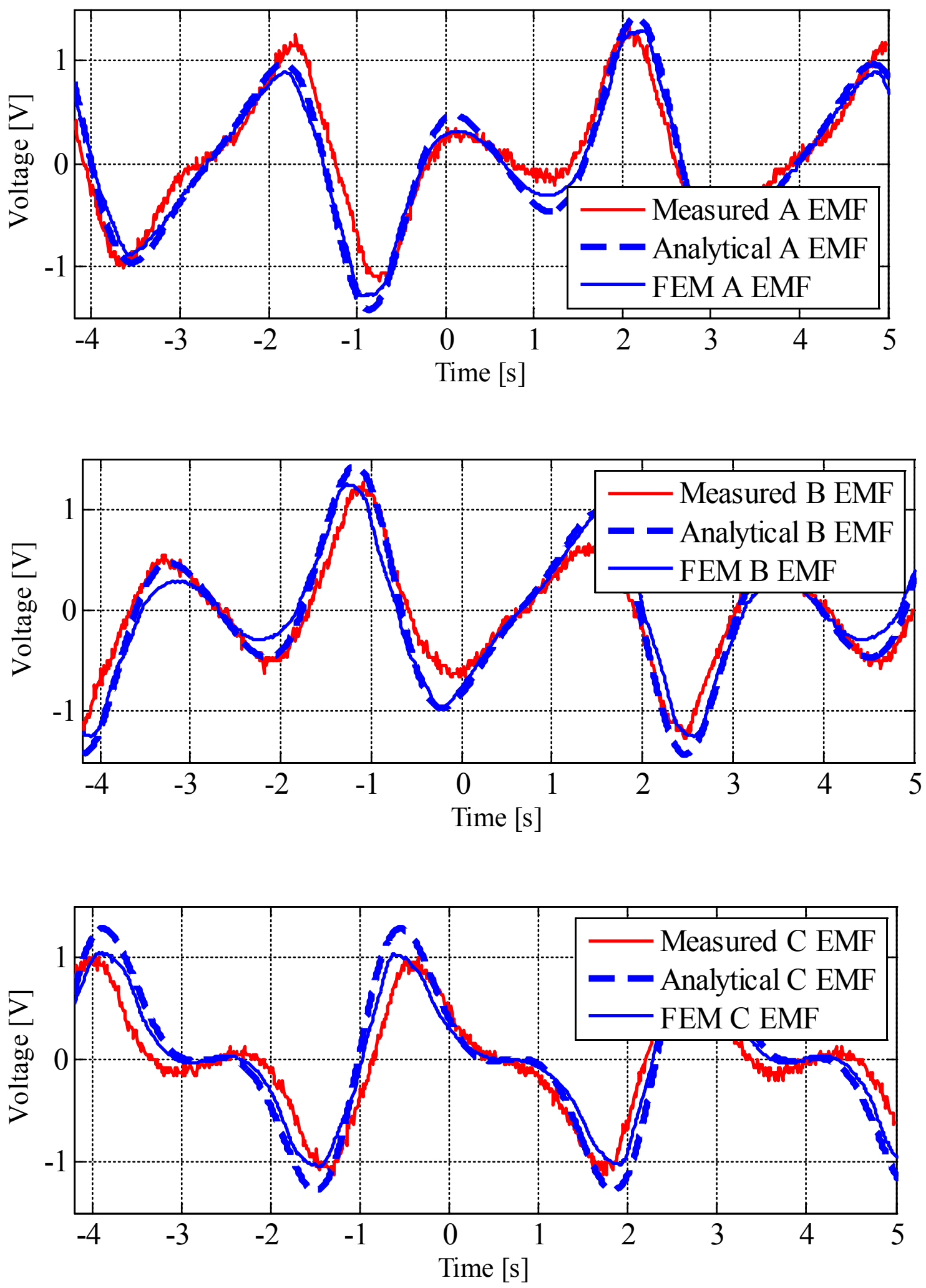

Figure 6-9 DS three phase no load EMF: measured, FEM and analytical simulation [39mm 0.15Hz] 

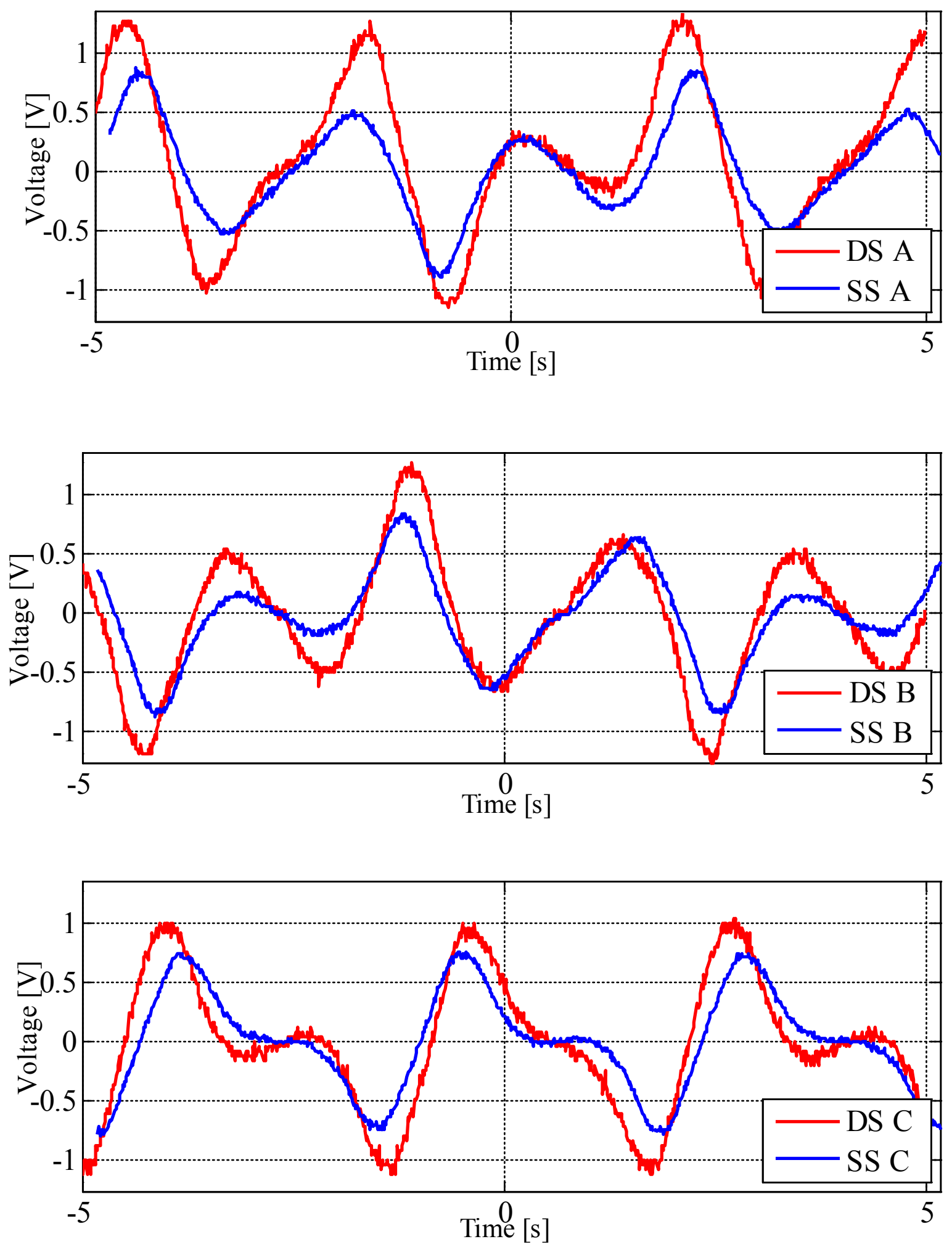

Figure 6-10 Comparison of each phase no load EMF in SS and DS three phase topology 


\subsection{Cogging force}

Cogging force estimations are based upon force readings for sine wave translator motion. Measured force is a result of complex interaction between different forces that act on the translator. Participating forces include the translator's weight, mechanical friction enhanced by radial forces and the cogging force. Translator's mass $m_{T}$ produces bias in the measured force whose value equals $g m_{T}$. However, the most dominant force, besides cogging, comes from friction. Summation of all the participating forces is:

$$
F_{c o g}(z)+g m_{T} \pm F_{f}
$$

Direction of the friction force $F_{f}$ depends on direction of motion. It adds up with the weight on the up stroke and subtracts from it on the down stroke.

Over its period, the cogging force produces zero work and its areas above and under zero force axis should be equal. In the upward portion of the translator's cycle, due to addition of the friction and weight forces, one can observe force waveform's shift upwards and its asymmetry about the axis (Fig. 6-11). Each translator's direction change is accompanied by step change in the measured force, coming from abruptly reversed direction of the friction force. 


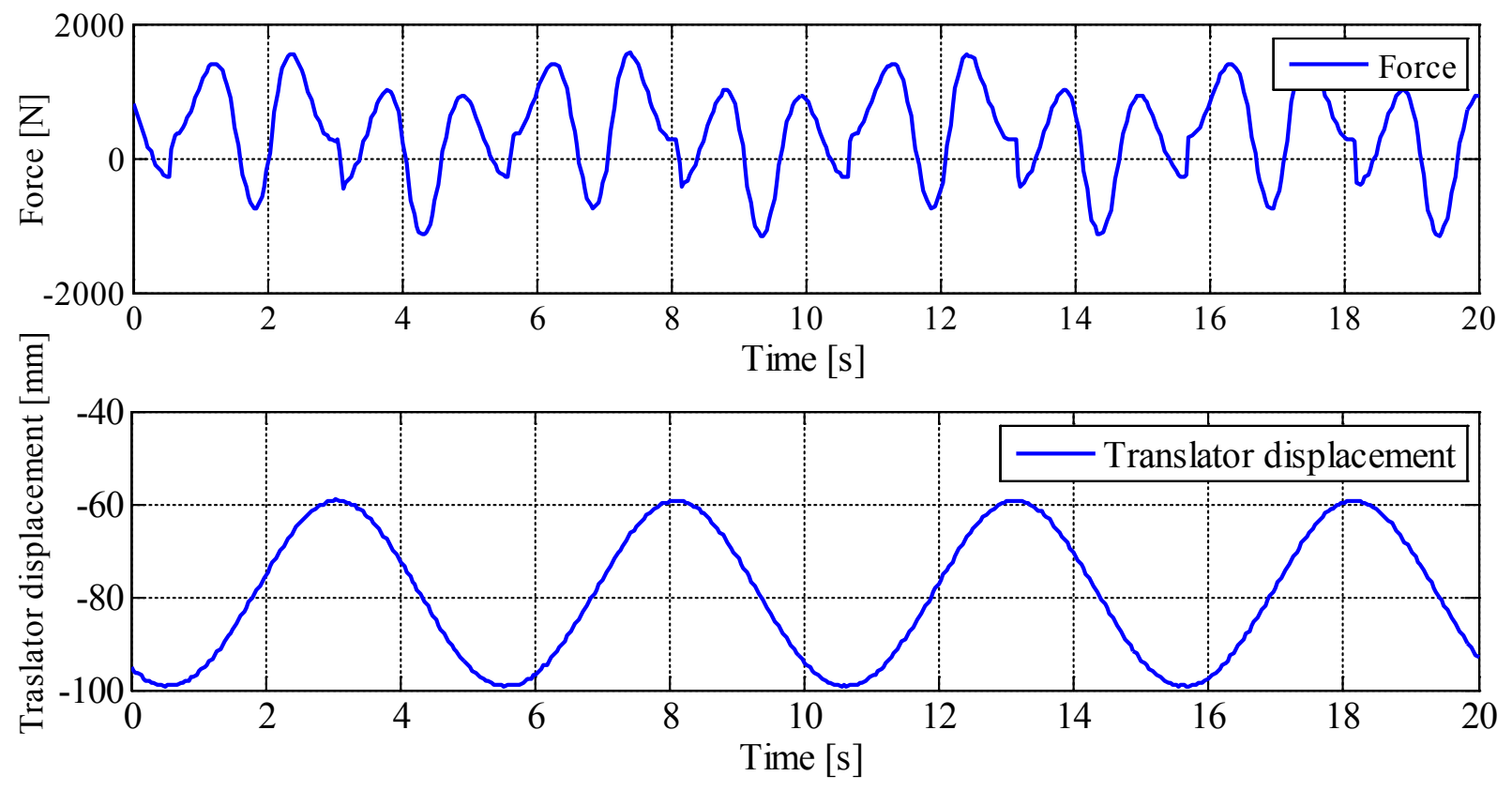

Figure 6-11 SS single phase LPMG force reading and translator displacement

Figure 6-12 displays the load cell readings as a function of translator displacement. The waveform has two distinct parts. Upper part belongs to the up stroke half period. Due to cancelation of the weight and friction force, the lower part has more-less preserved symmetry about zero force axis, which means that it belongs to the down stroke. 


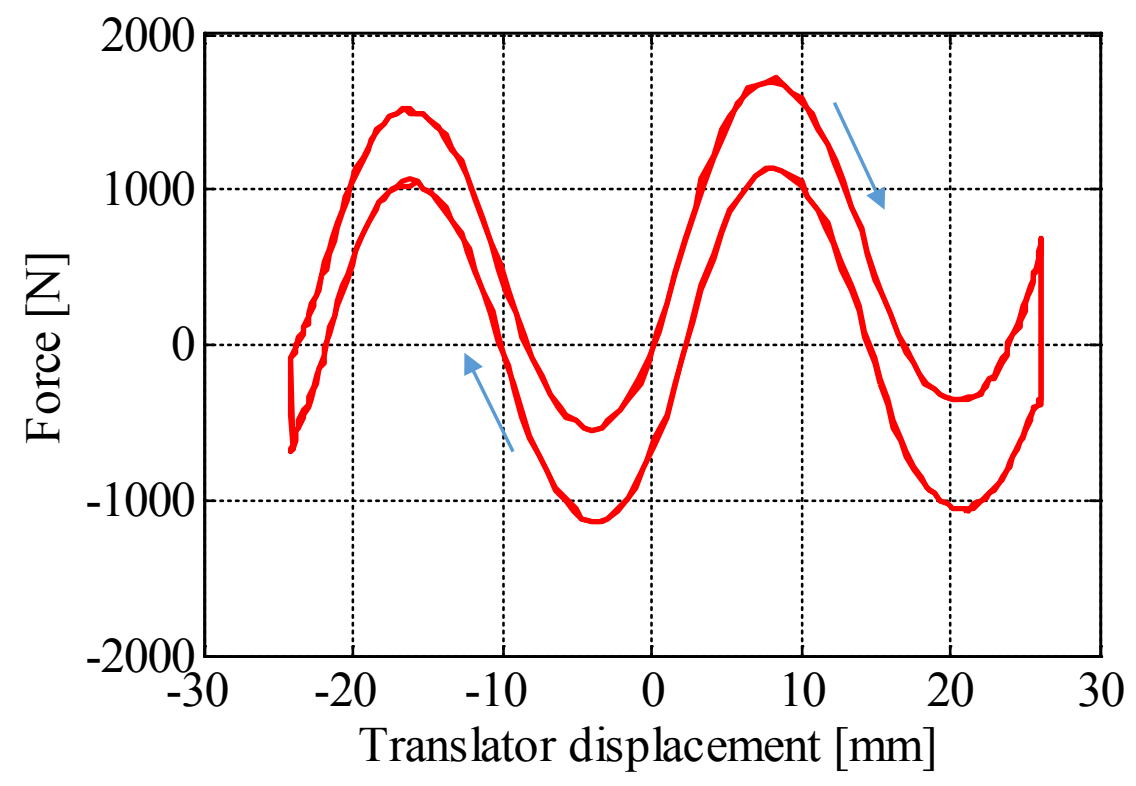

Figure 6-12 SS Single phase machine - measured force

If two halves of force reading are leveled out about the zero force axis, it is possible to compare the experimental cogging force waveform and the FEM simulation (Fig. 6-13).

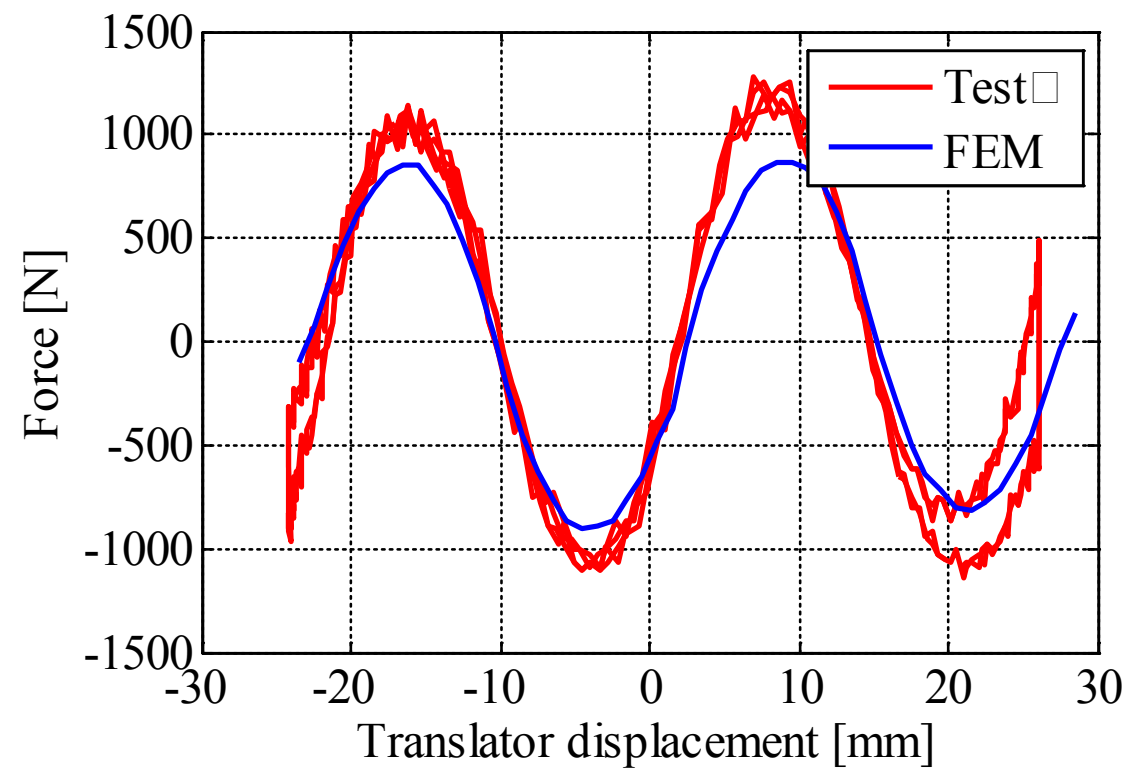

Figure 6-13 SS Single phase machine cogging force - test and FEM model 
Insertion of the internal stator for obtaining the DS two phase topology has greatly altered friction conditions. Additional friction now occurs at the point of contact between the translator sleeve and the internal stator. It is not constant, but changing, depends on the position as well as the direction of the translator. In the up stroke force readings (Fig. 6-15), two force humps are observed and attributed to the rubbing between the internal stator and translator. The effects of the interaction are evident in the surface of the internal stator once it is extracted out of the machine (Fig. 6-14). Down stroke has been free of local friction and the reading has preserved undisturbed shape which, once leveled about the zero force axis, compares well with the FEM results (Fig. 6-16). It can be concluded that the insertion of the additional stator into the SS single phase topology produces expected reduction of cogging force.

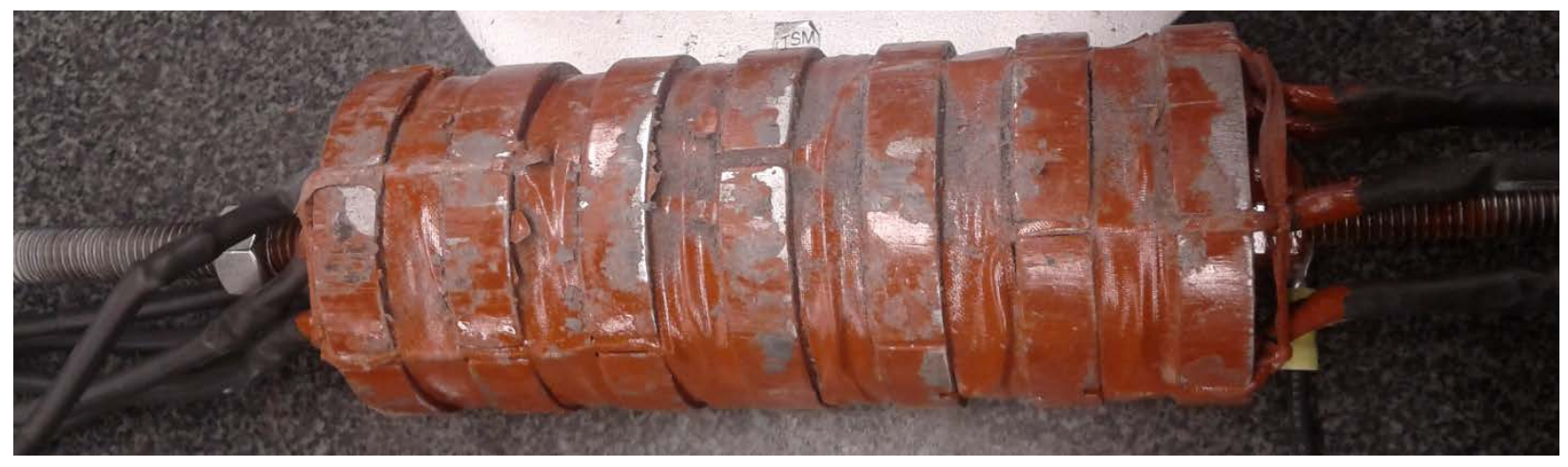

Figure 6-14 Dammage on internal stator surface from interaction with the translator sleeve 


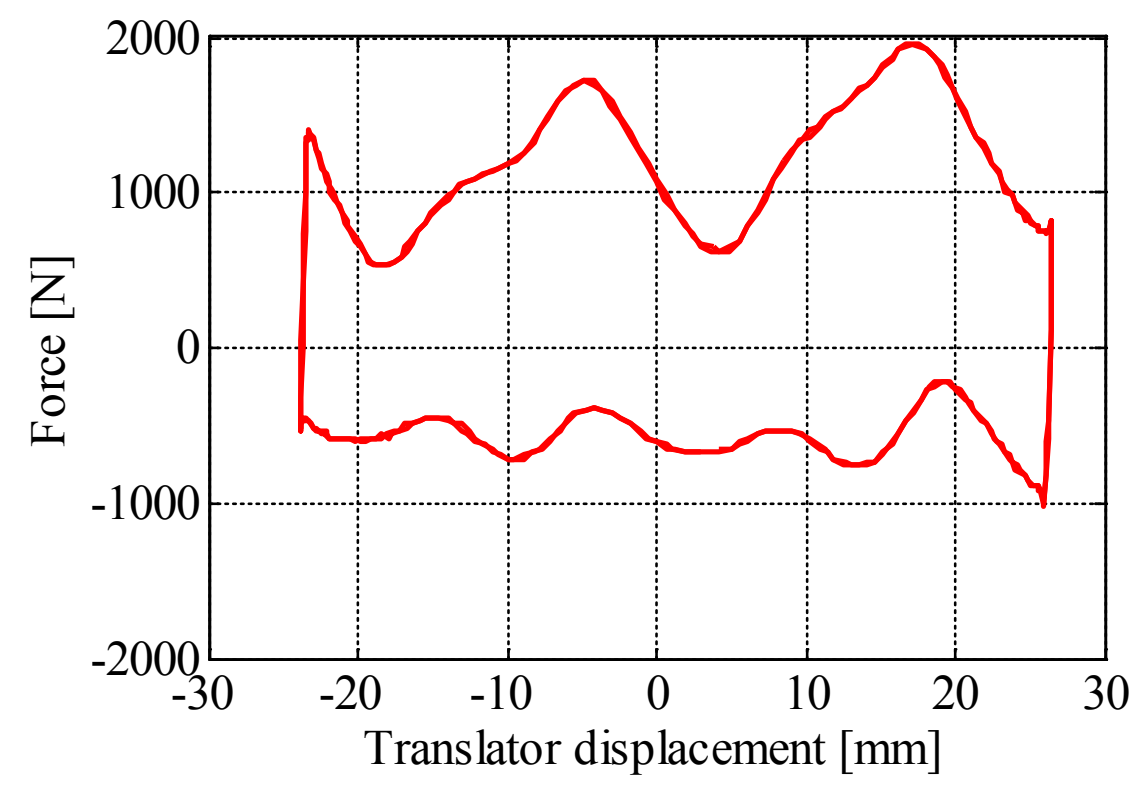

Figure 6-15 DS two phase machine - measured force

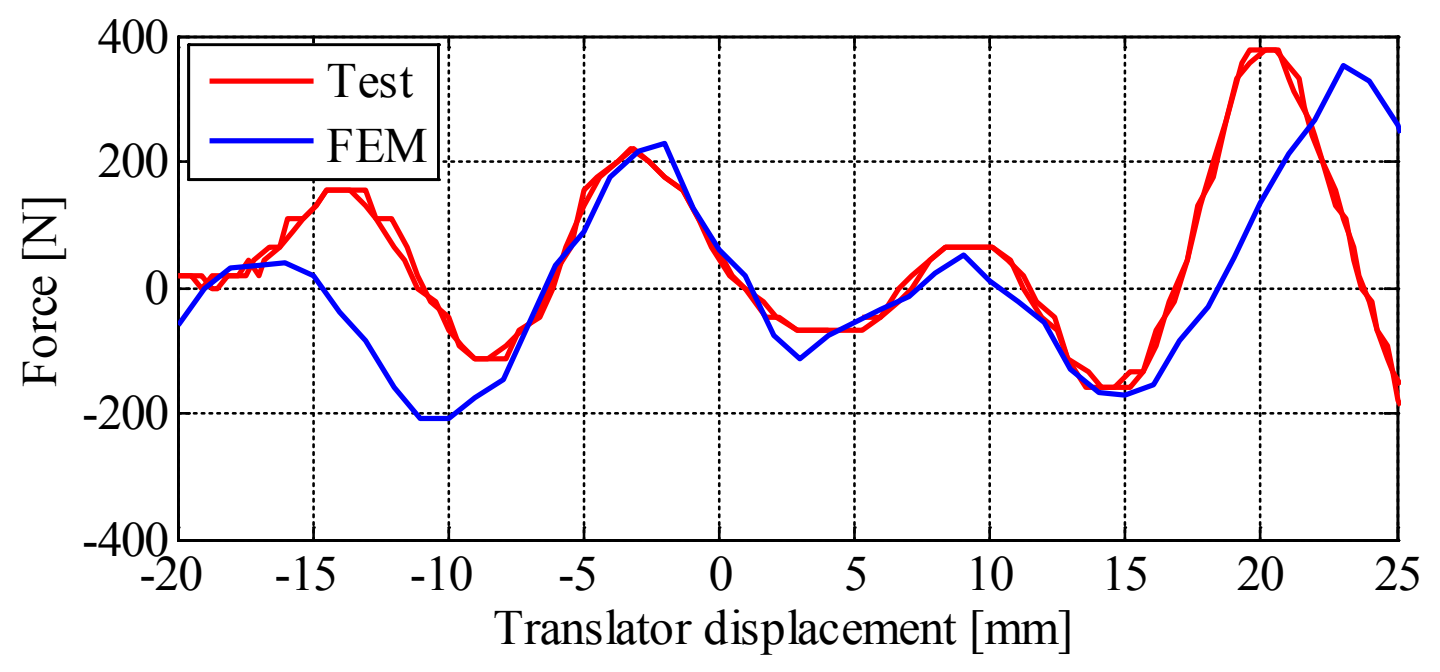

Figure 6-16 DS two phase cogging force - measurement (for two strokes) and the FEM prediction

Both up stroke and down stroke force profiles of the three phase SS machine follow the same shape for most of the stroke length (Fig. 6-17). This indicates presence of fairly constant friction over that distance $([-30 \mathrm{~mm}+20 \mathrm{~mm}])$ that contributes only to the bias of the profile. Once the bias is removed and the profile is leveled about the zero force axis, experimental estimation of cogging force can be compared to the FEM calculations (Fig. 6-18). 


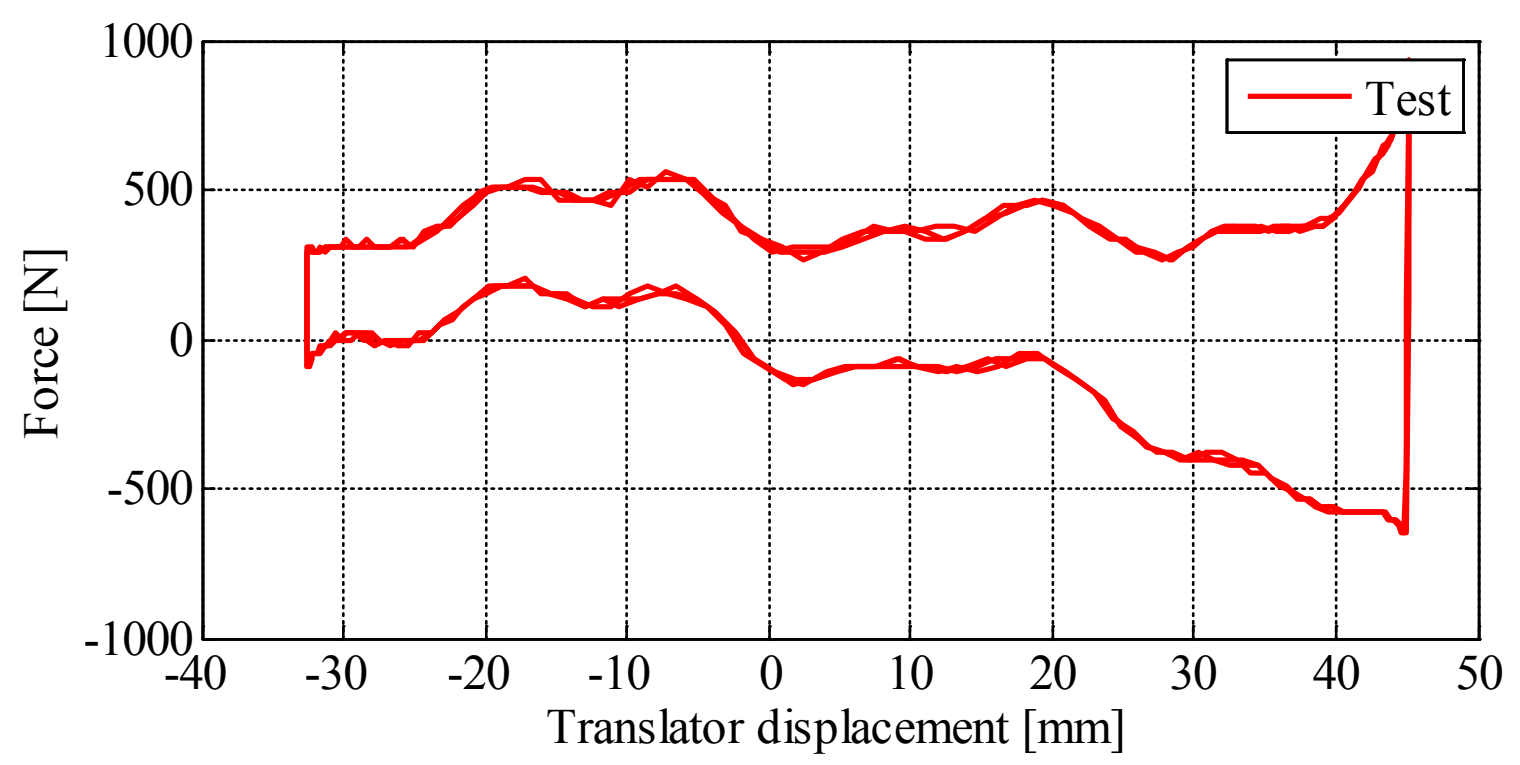

Figure 6-17 SS three phase - force measurement

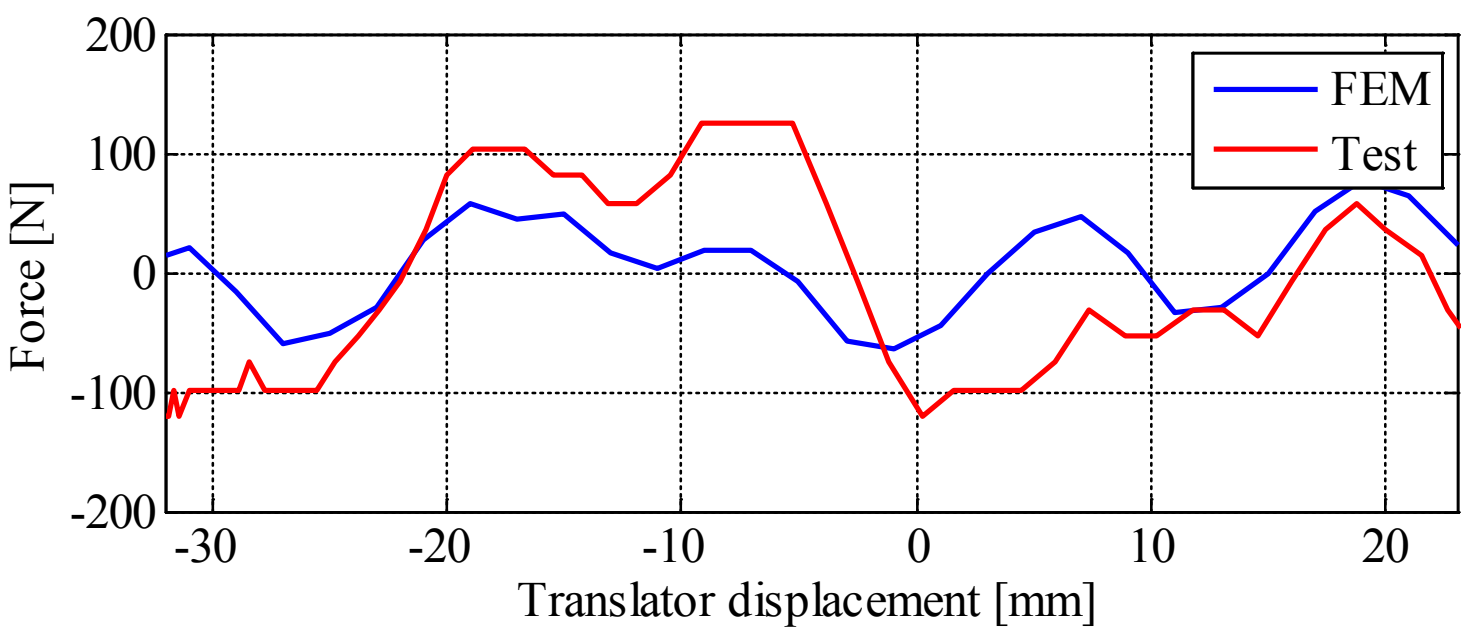

Figure 6-18 SS three phase - measured cogging force and FEM prediction

Identification of the cogging force becomes more challenging in the DS three phase force profile. In the DS two phase force profile, cogging force was clearly identified in the down stroke portion of the force. However, the DS three phase force profile contains local friction component in both up and down stroke (Fig. 6-19). The rest of the down stroke waveform agrees well with the FEM force prediction (Fig. 6-20). 


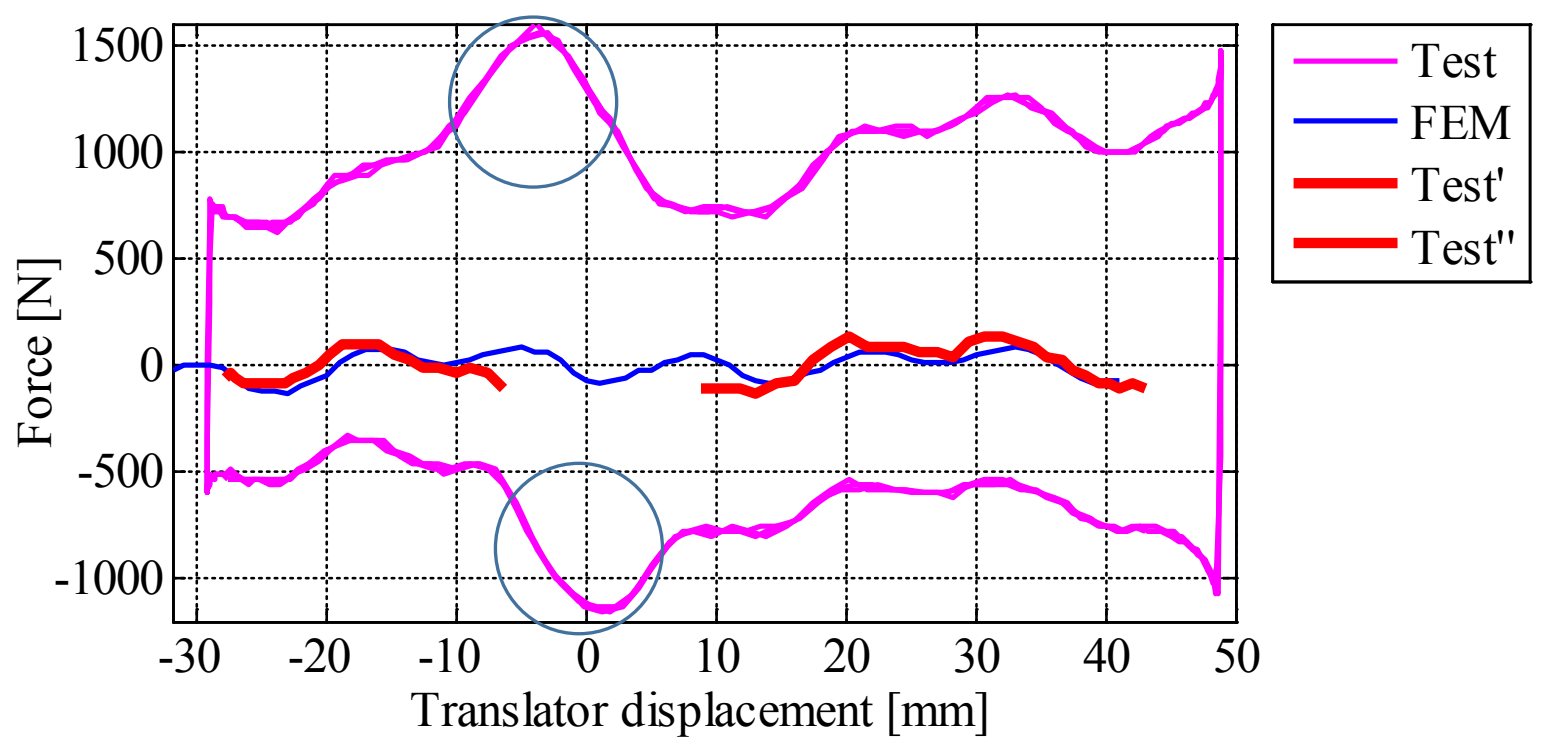

Figure 6-19 DS three phase force measurement and friction humps (encircled)

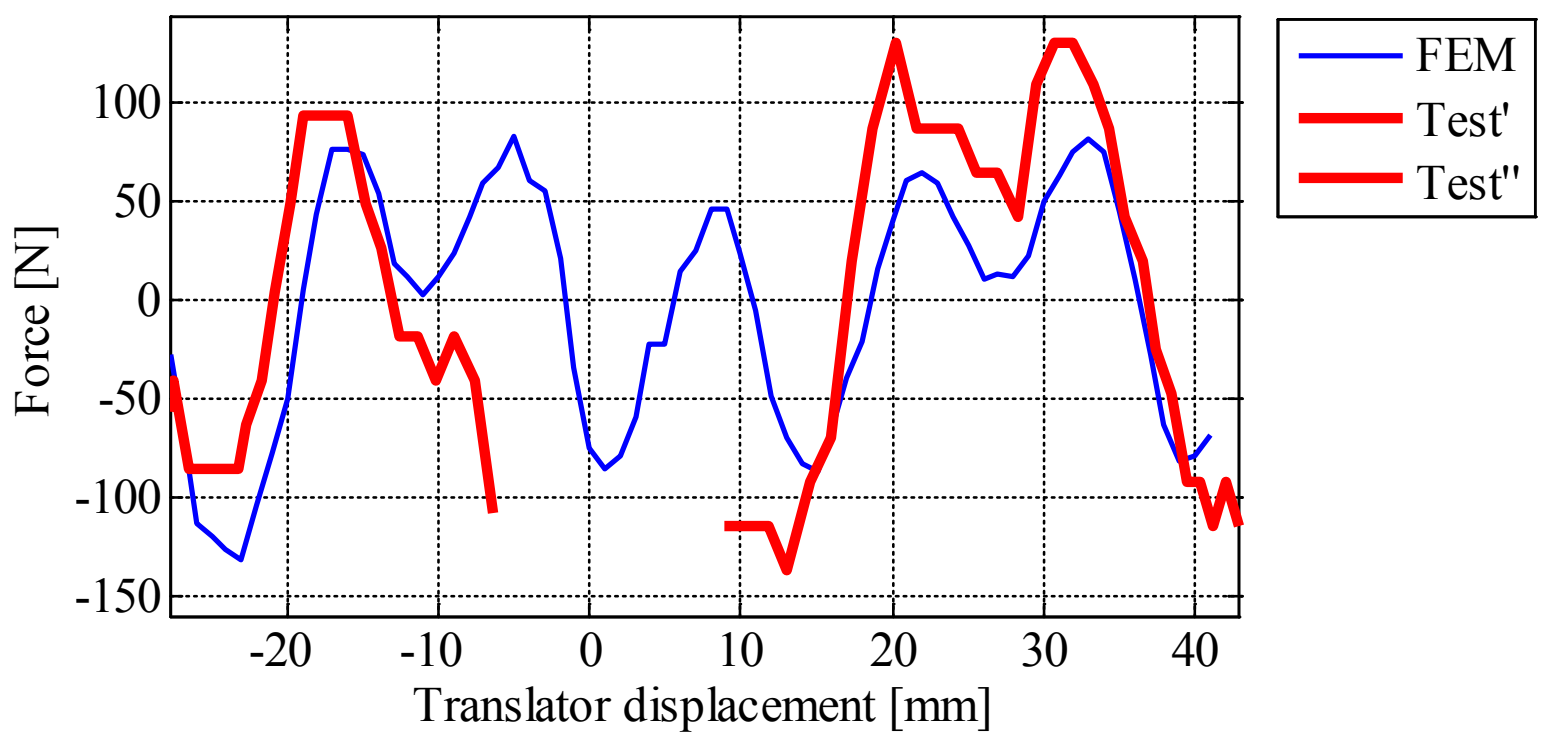

Figure 6-20 DS three phase -measured cogging force (before and after the friction interuption - Test' and Test") and FEM prediction

As expected, the SS and DS three phase topologies produce cogging force which have similar peak to peak amplitude. 


\subsection{Inductance}

Accurate information about the generator inductance values is important for design of the power rectifier. As described in experimental setup chapter, estimation of the inductance has been conducted through applied voltage and current measurements for different translator positions. The voltage had a frequency of $60 \mathrm{~Hz}$. However, the analytical and FEM model are based upon the calculation of the flux $\phi$ produced by direct phase current $I$. Inductance than follows from the flux as:

$$
L_{0}=N \frac{\phi}{I}
$$

where $N$ is the number of coil turns. This model disregarded the eddy current effects on the flux distribution and magnitude which are significant at this frequency, especially in the case of solid iron stator. Relationship between the DC current inductance $L_{0}$ and the AC inductance $L(f)$ can be written in the following form:

$$
L(f)=c(f) L_{0}
$$

where $c(f)$ is a coefficient that depends on the current frequency $f$ and the iron core dimensions [Merrikhi, 2006]. In order to determine the FEM prediction for $c(60 \mathrm{~Hz})$, the frequency dependant model of the generator has been built in time domain and used to calculate the $\mathrm{AC}$ inductance for one translator position. It has been assumed that for particular LPMG configuration, $c(f)$ does not significantly depend on the translator position. This assumption has been verified on the example of SS Single phase model by comparing $c(f)$ for three characteristic positions and showing that they are very close $(0.562,0.567,0.567)$. 
Frequency dependant model ('FEM2') has improved agreement with the experimental results for the single phase and two phase case (Fig. 6-21-6-23). However, simulation predictions for selfinductance in both SS and DS three phase case did not significantly change after additional effects were included in the model, and discrepancy has remained immense (Fig.6-24 and Fig.626).

Compared to the SS single phase case, value of the external phase self-inductance has been augmented in the DS two phase topology due the presence of the internal stator. External stator has $26 \%$ higher inductance in the double sided topology than in the single sided. As expected, the internal phase has smaller self-inductance from the external in both single phase and two phase configuration. The reason for this is higher reluctance of the internal stator's magnetic circuit.

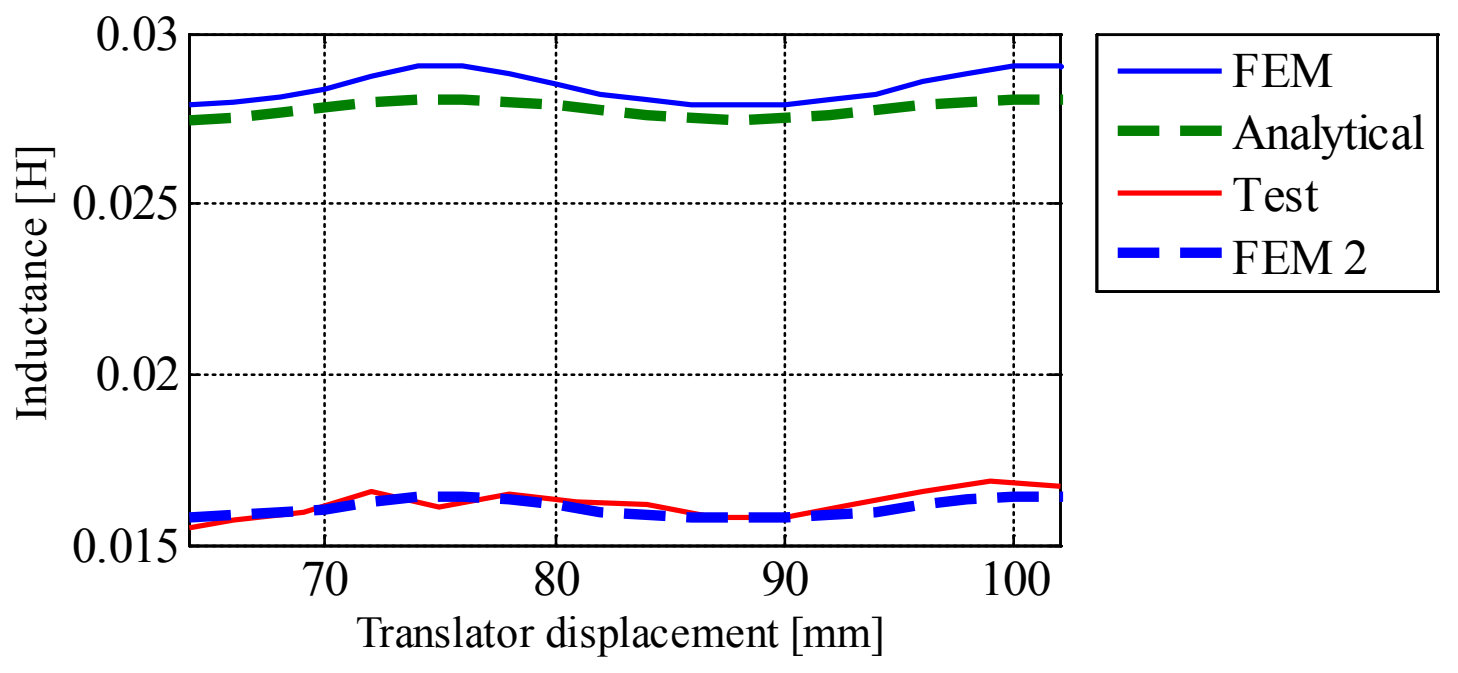

Figure 6-21 SS Single phase self-inductance 


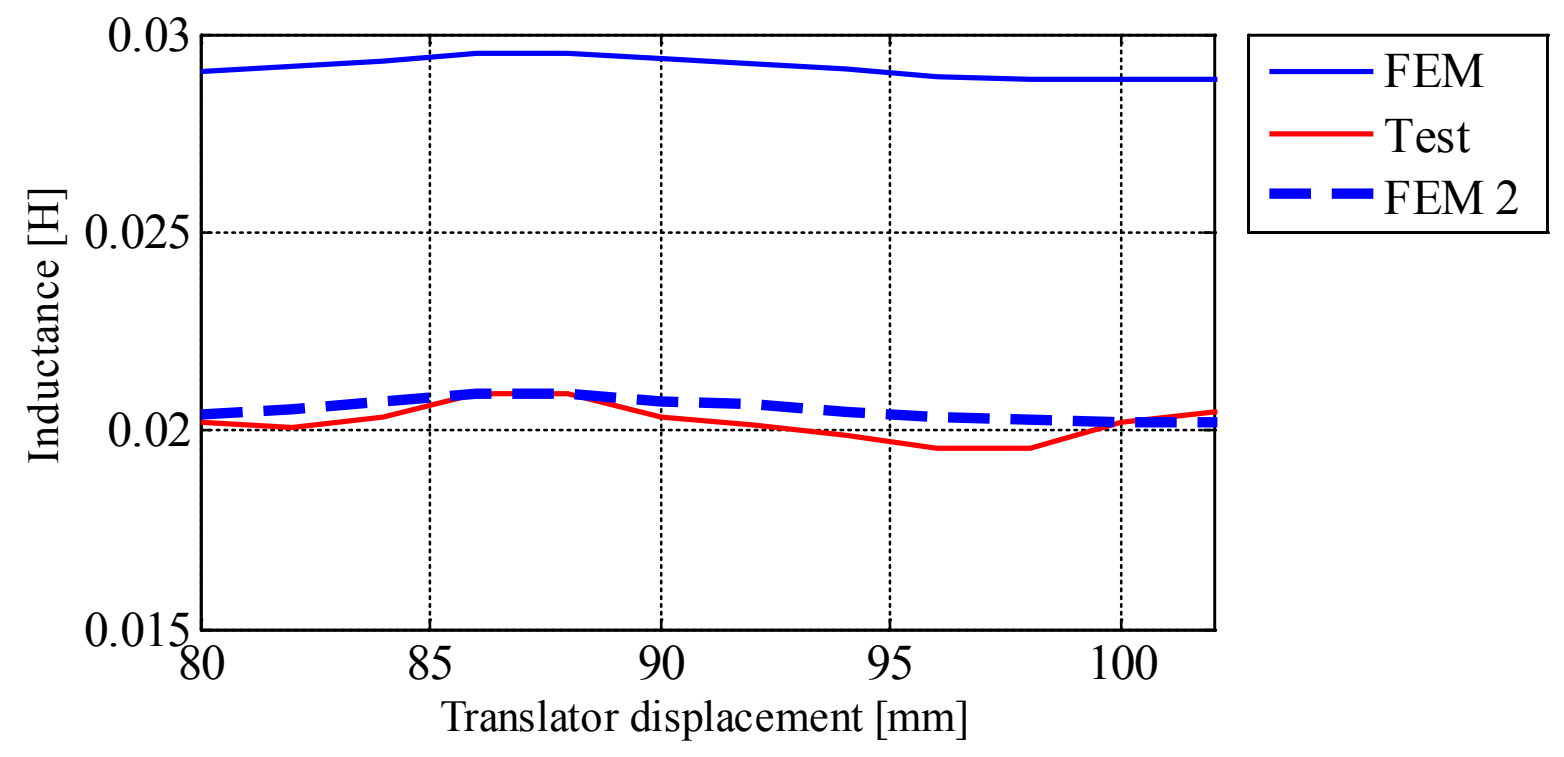

Figure 6-22 DS two phase external inductance

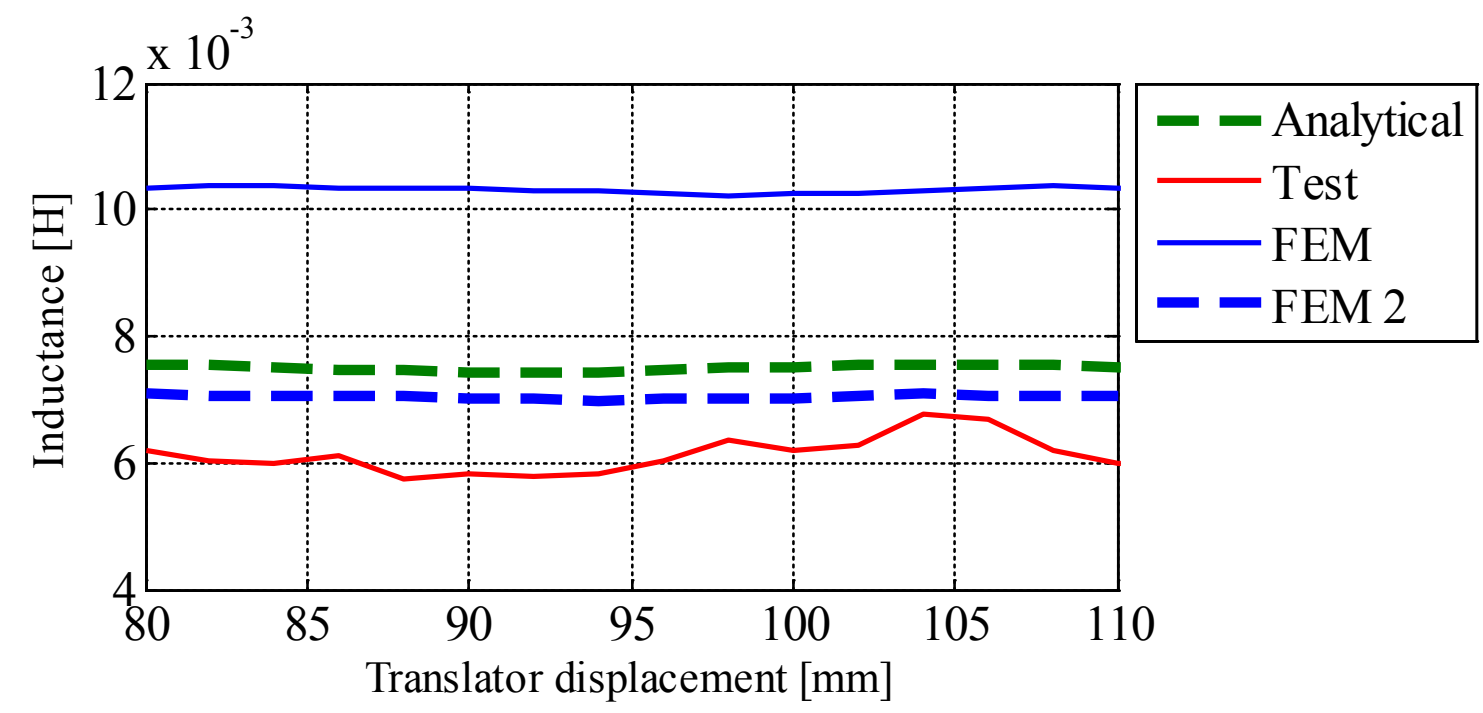

Figure 6-23 DS two phase inner inductance

Insertion of the internal stator in the three phase topology did not produce expected augmentation of armature self-inductance, on the contrary. This comes as a surprise since internal stator connects two extra coils to the phase winding together with their inductances, and both the analytical and FEM model predicted significantly higher value for the DS self-inductance. The discrepancy in three phase inductances between the experiment and the modeling results should 
probably be attributed to the experimental error, whose source is not identified at the moment . The FEM model that includes the eddy current effects (FEM 2) did produce significant change for the three phase mutual inductance prediction (Fig. 6-25 and Fig. 6-27).

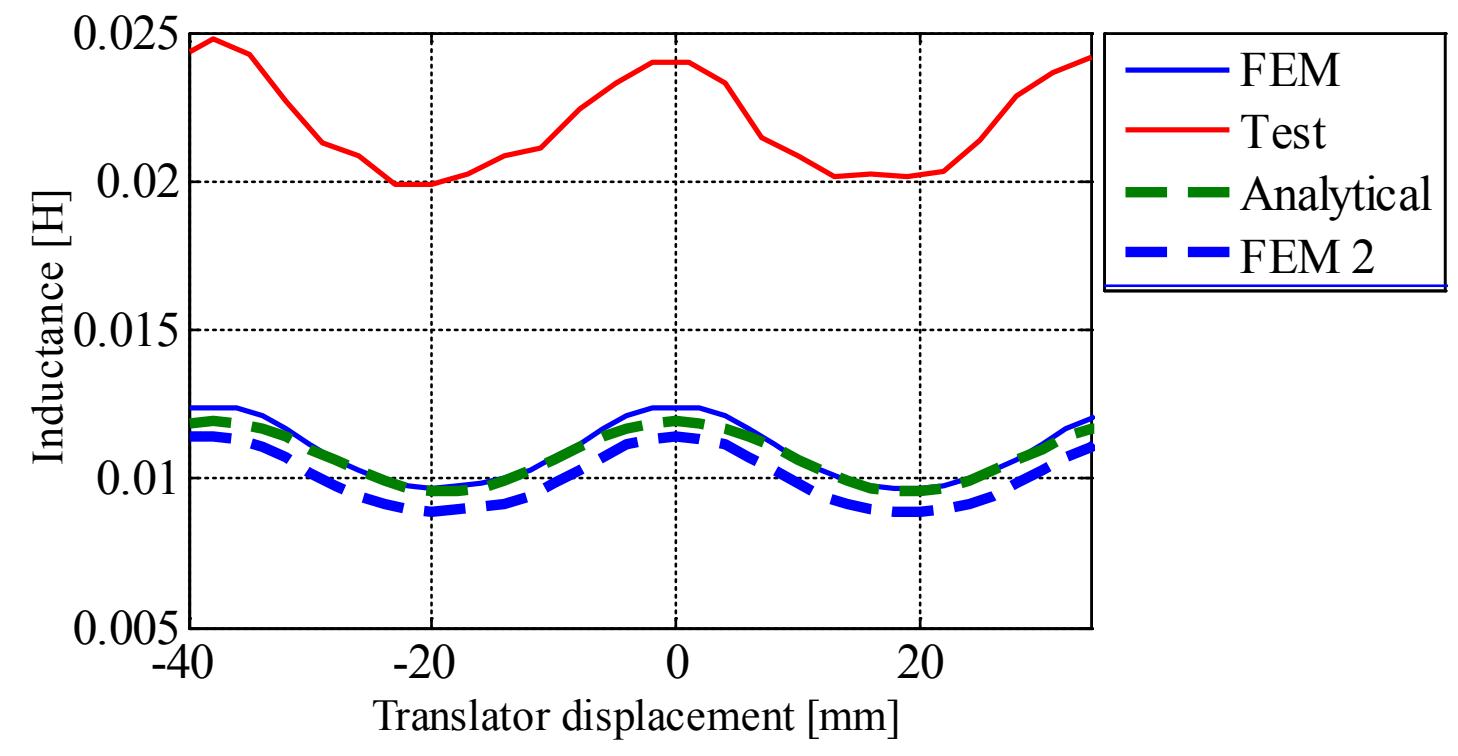

Figure 6-24 SS three phase self-inductance

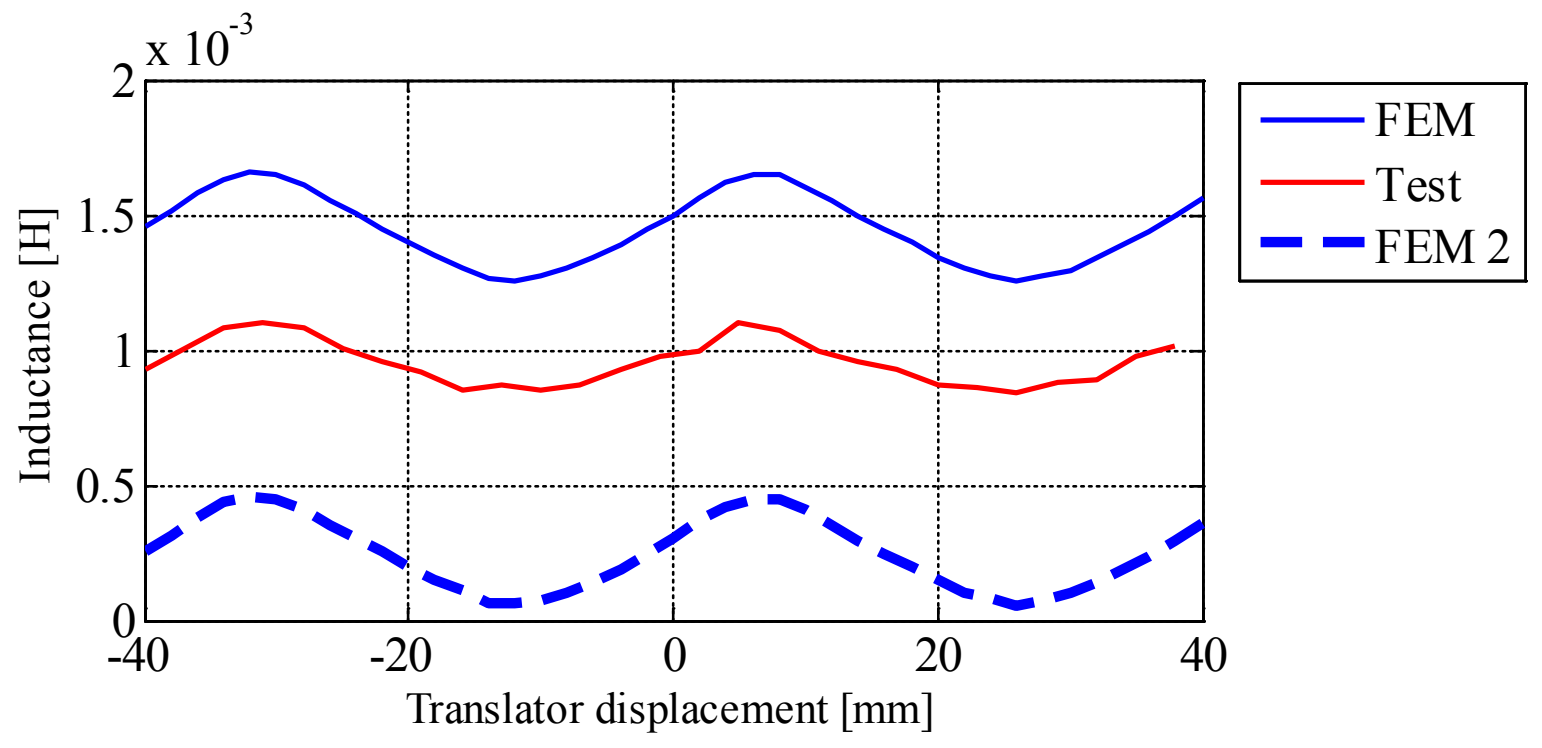

Figure 6-25 SS three phase mutual inductance 


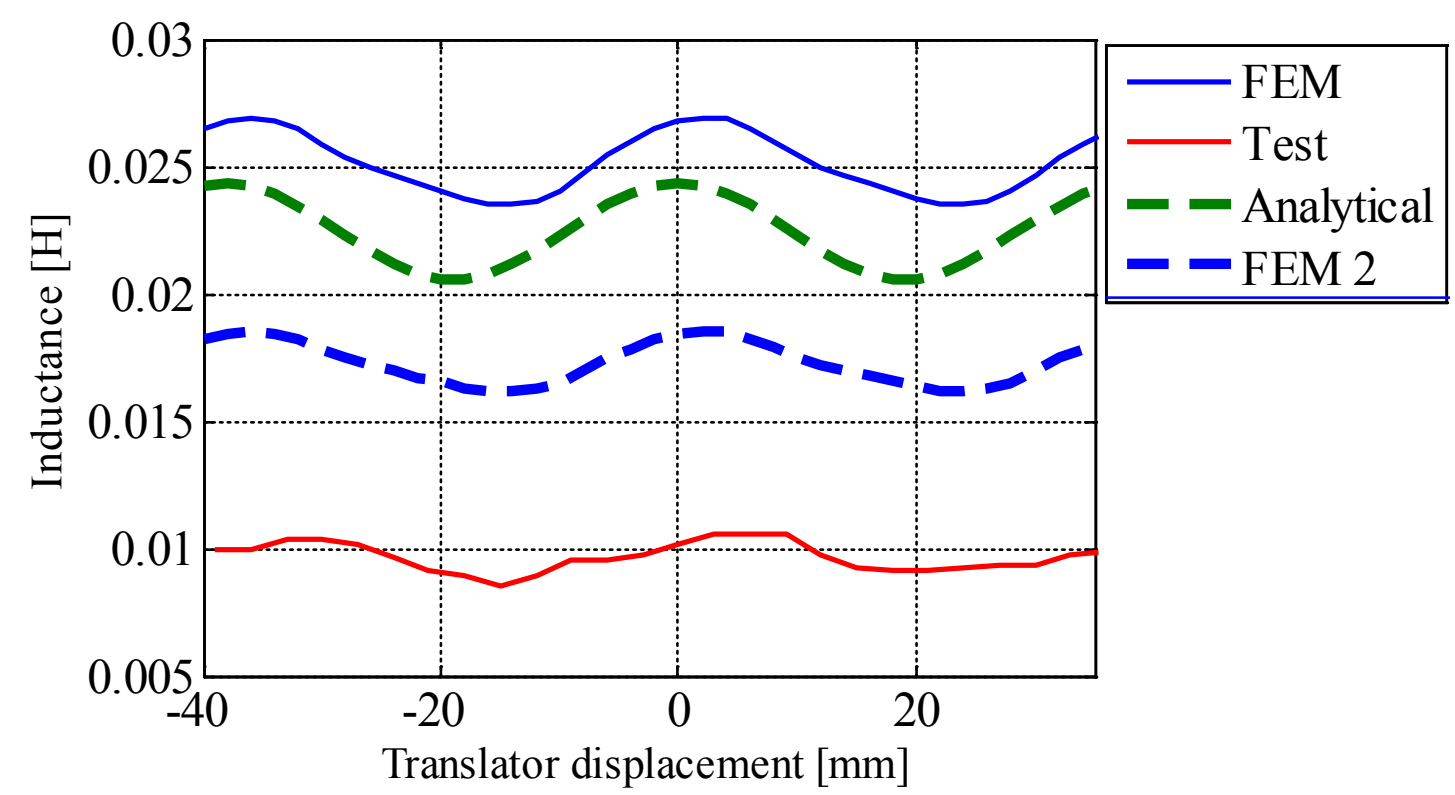

Figure 6-26 DS three phase self-inductance

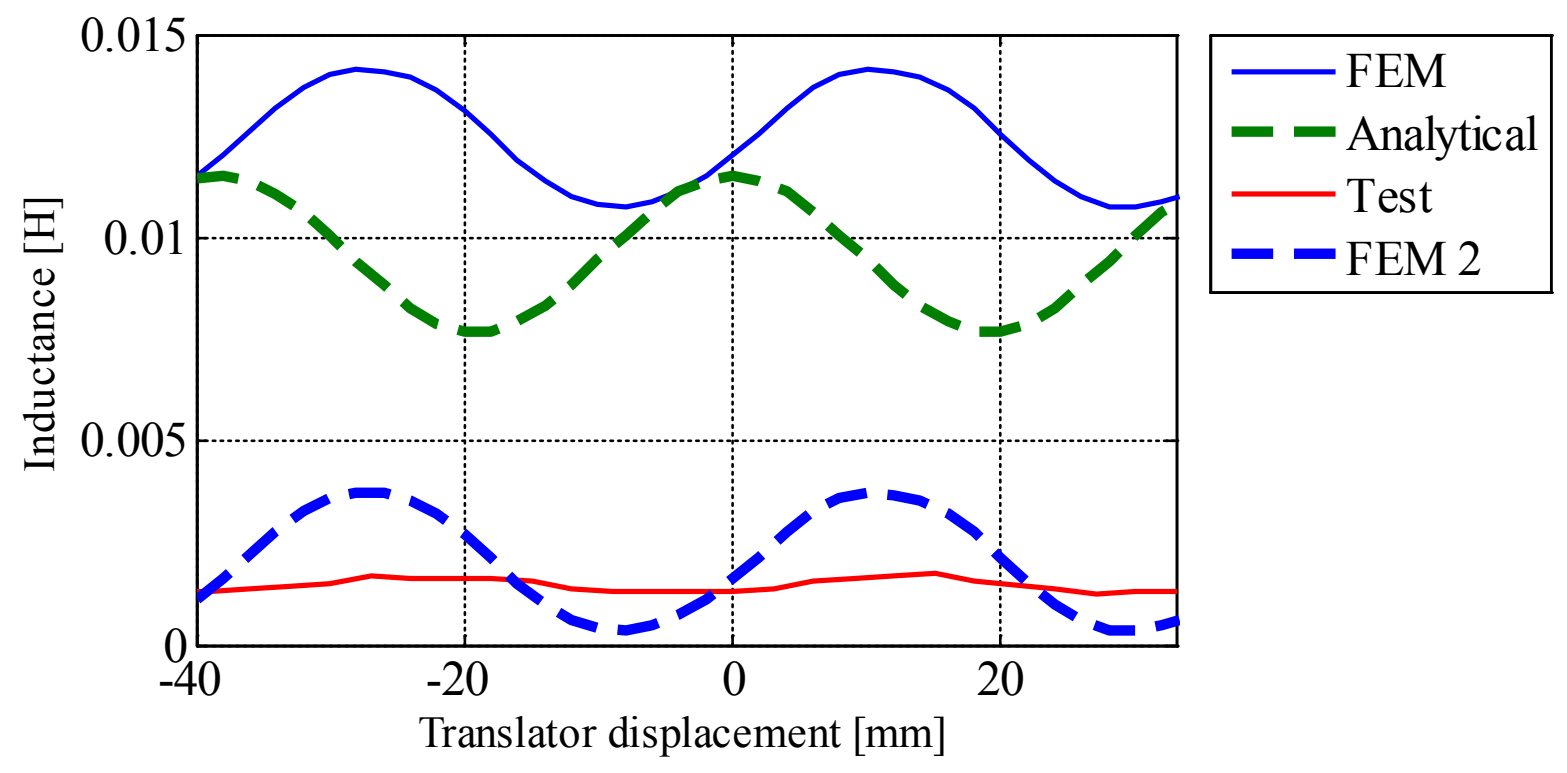

Figure 6-27 DS three phase mutual inductance

\subsection{Power}

Following set of figures displays output power of different topologies both as a function of the time and translator displacement for different load resistances. Maximum power transfer in each 
topology occurs for the load resistance that is close to the internal resistance of phase winding. For different topologies phase resistances are:

\section{Table 6.1 Phase resistance}

\begin{tabular}{|c|c|}
\hline Topology & Phase resistance $[\Omega]$ \\
\hline SS Single phase & 2.6 \\
\hline DS Two phase internal & 1.2 \\
\hline DS Two phase external & 2.6 \\
\hline SS Three phase & 0.8 \\
\hline DS Three phase & 1.2 \\
\hline
\end{tabular}

The output power of every linear generator with reciprocating prime mover motion reaches zero twice per period because the mover's speed $\vartheta$ is zero at each direction change. Besides that, output power of the linear single phase generator oscillates at the frequency of its electrical system. It reaches zero two times per period, either time period $T_{e}=\frac{2 \tau}{\vartheta}$ (Fig. 6-29) or spatial period $T_{s}=2 \tau($ Fig. 6-28). 


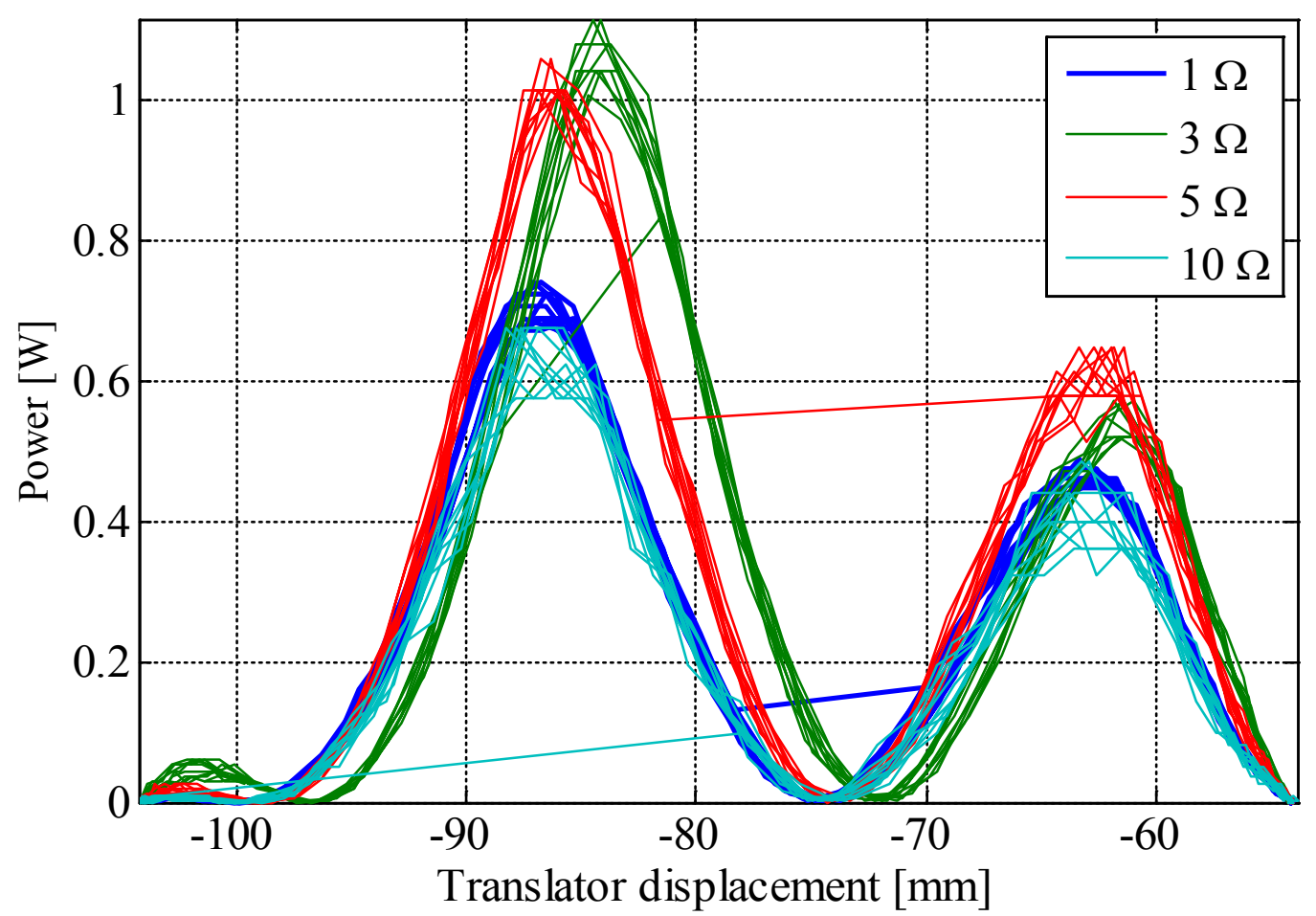

Figure 6-28 SS single phase output power [25.4mm at $0.25 \mathrm{~Hz}$

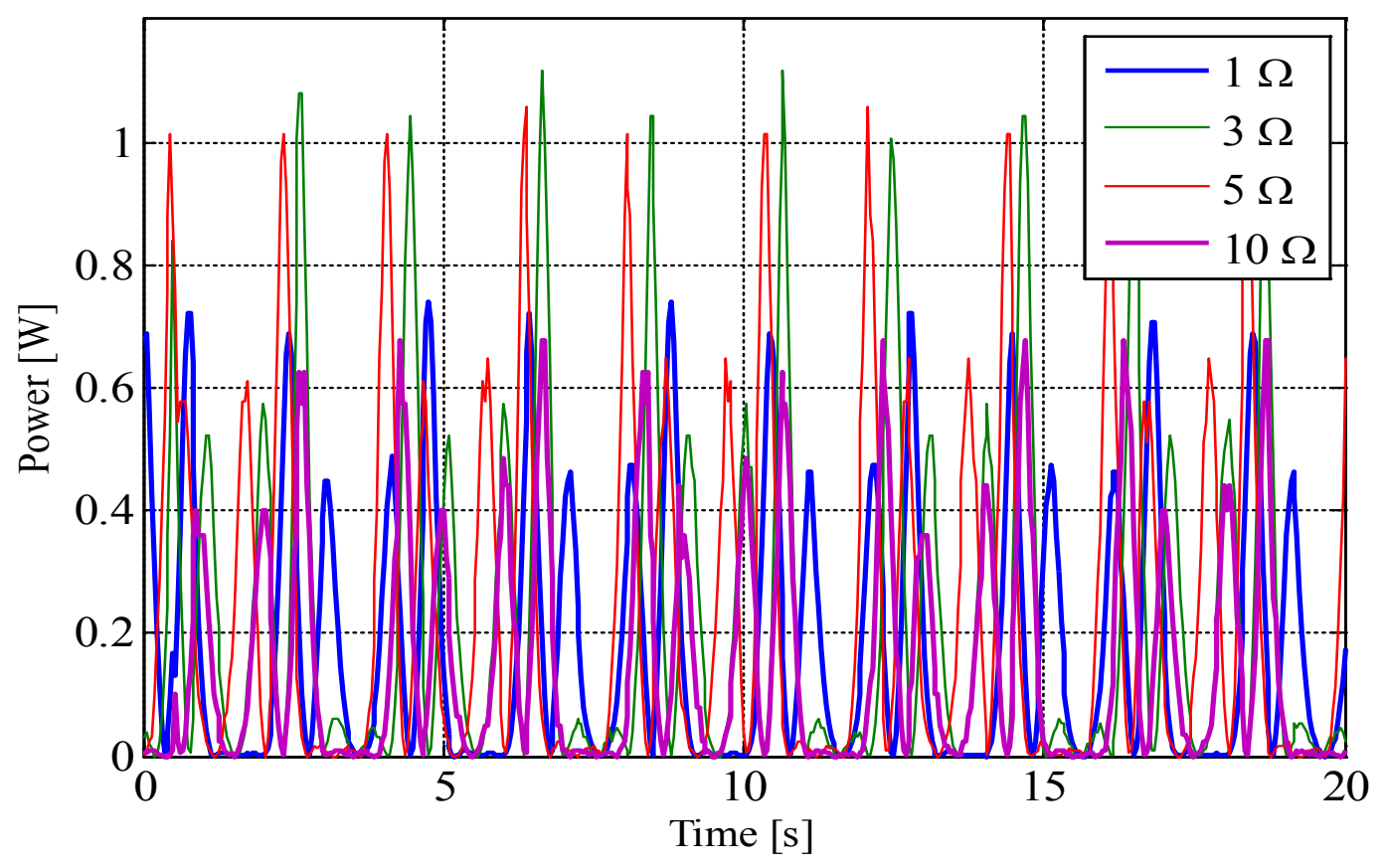

Figure 6-29 SS single phase output power [25.4mm at 0.25 Hz] 
The output power of the two phase linear generator should ideally change with the frequency of the prime mover's motion and be free of the fluctuations at the electrical frequency. However, the experimental results show different degrees of electrical frequency ripple in the power waveform for different load resistances. The reasons for this are differences in the no load EMF and internal resistance between the internal and external phase of the prototype. They are less pronounced for higher load values for whom both phases yield similar output power. Load resistances that are close to the internal resistance of each phase will maximize the output power (Fig. 6-30). The observed ripple is smaller than in the single phase topology and it results with higher RMS of the output power. For the same translator sinusoidal movement $(25.4 \mathrm{~mm}$ at $0.25 \mathrm{~Hz}$ ), the DS two phase topology produces maximum output power (for load resistances of $1 \Omega$ and $3 \Omega$ ) of $0.6538 \mathrm{~W}$ compared to $0.3558 \mathrm{~W}$ of the SS single phase generator (for $3 \Omega$ load). 


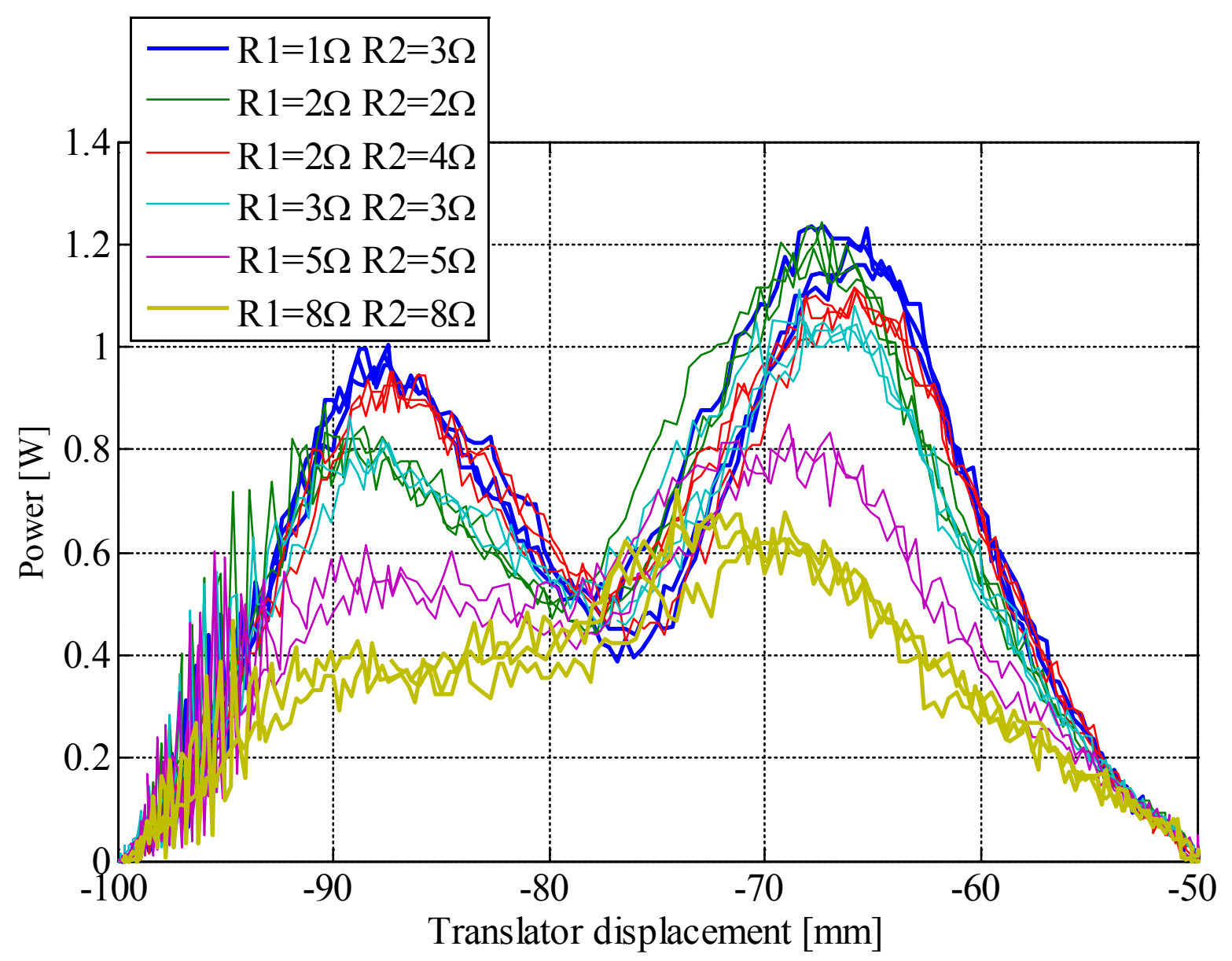

Figure 6-30 DS Two phase output power [25.4mm at 0.25 Hz] 


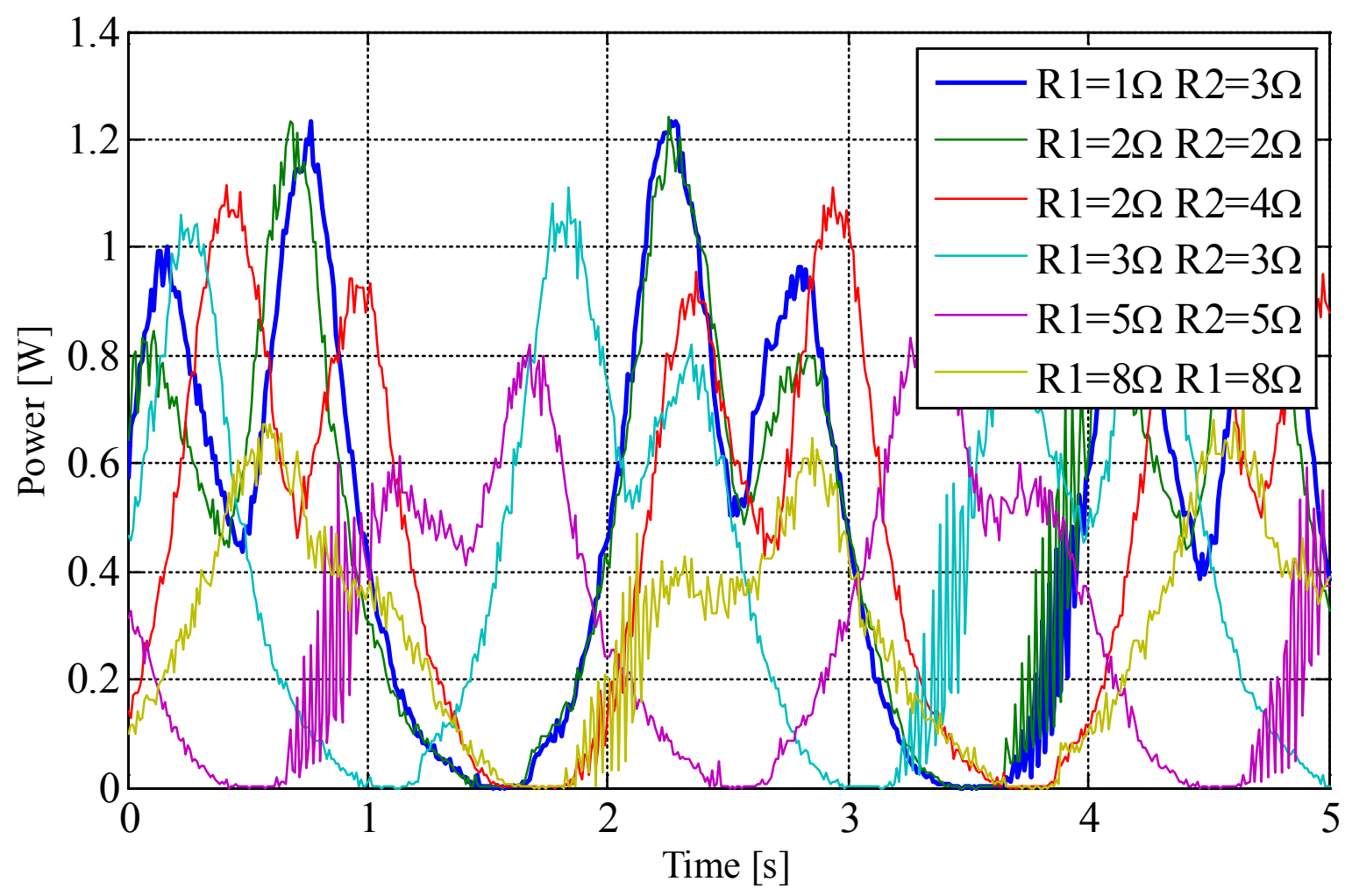

Figure 6-31 DS Two phase output power [25.4mm at $0.25 \mathrm{~Hz}]$

The power ripple in the SS three phase output power (Fig. 6-32 and Fig. 6-33) is probably caused by differences in the no load EMFs between the phases. These differences are expectable since the end effects produce uneven flux distribution among the coils along the stator [LeijonDENI].

The DS three phase waveform has relatively low ripple content in its output power for all load resistances (Fig. 6-34 and Fig. 6-35). This indicates more balanced EMFs among the phases. Higher output power in the DS three phase topology is a direct result of its higher flux linkage, i.e. higher no load EMFs. 


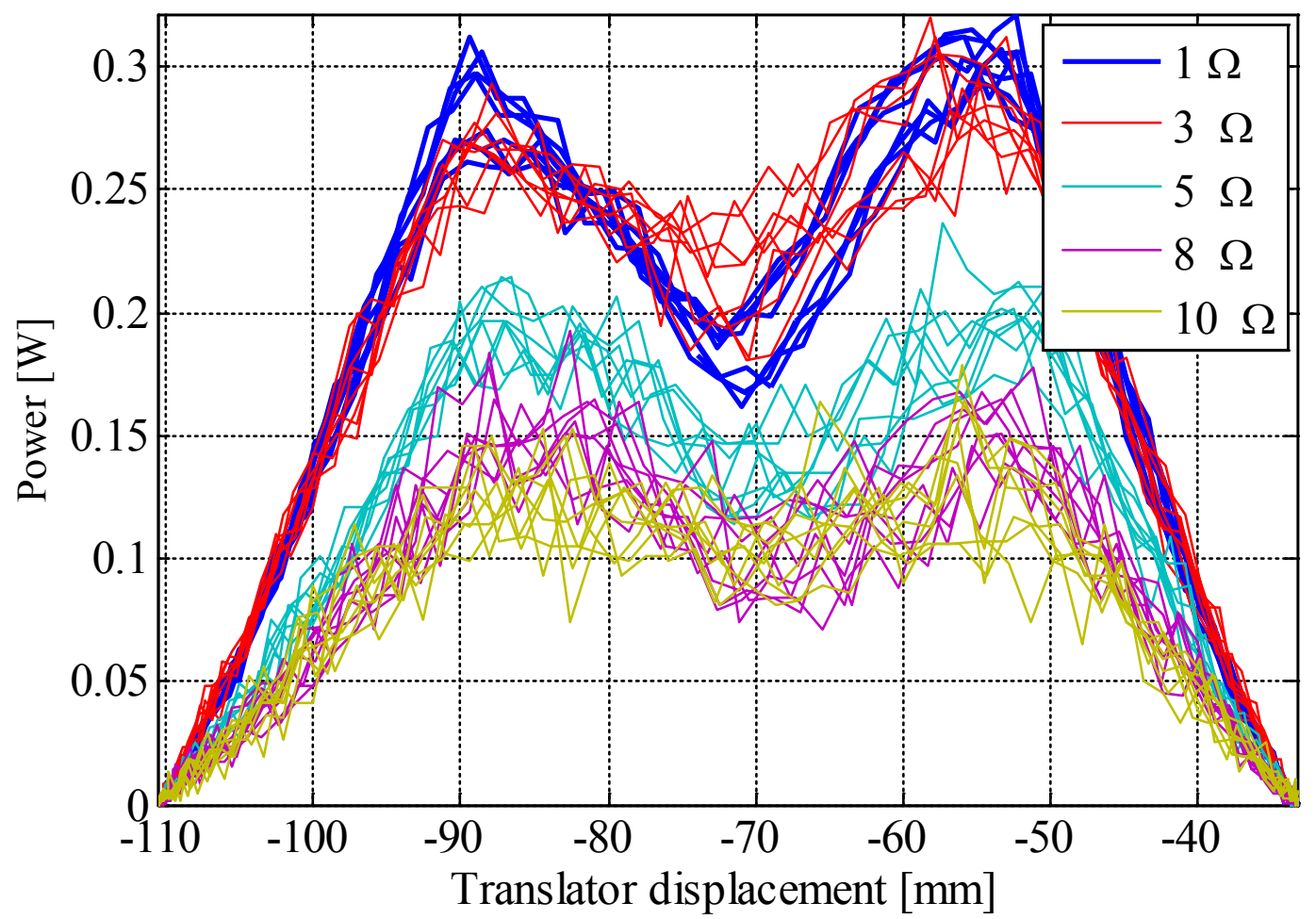

Figure 6-32 SS three phase output power [39 mm $0.2 \mathrm{~Hz}]$

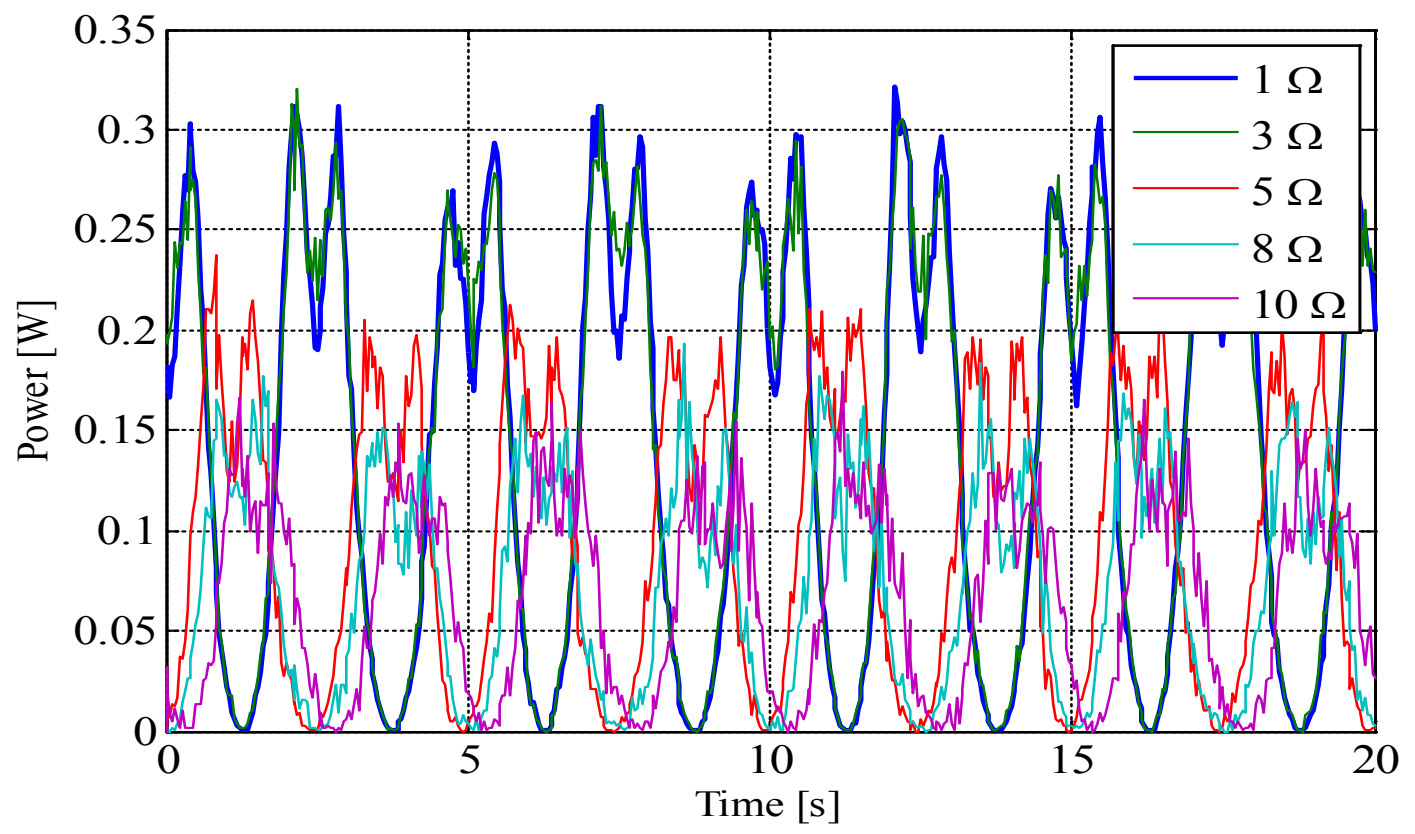

Figure 6-33 SS three phase output power [39 mm $0.2 \mathrm{~Hz}]$ 


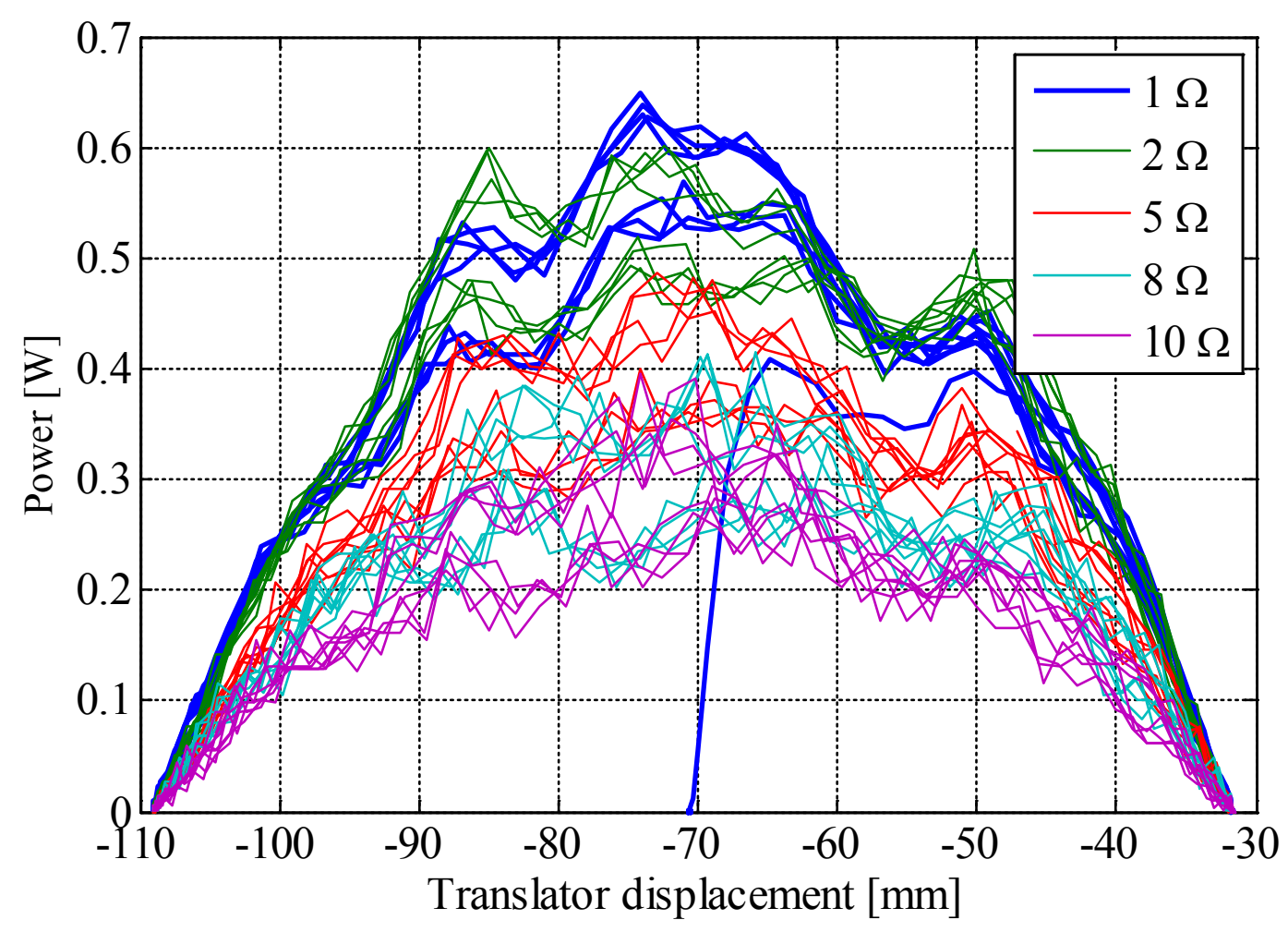

Figure 6-34 DS three phase output power [39 mm $0.2 \mathrm{~Hz}$ ]

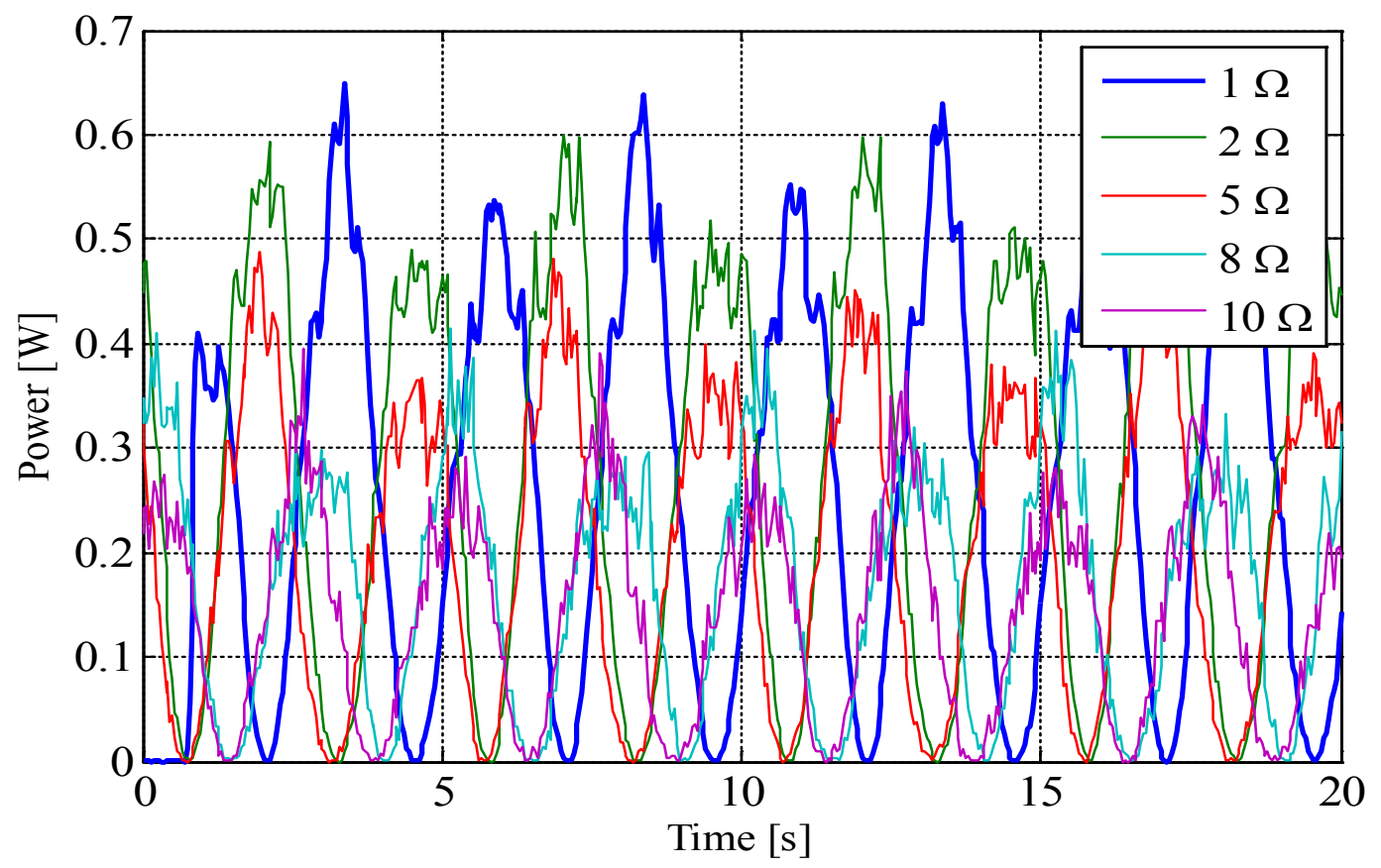

Figure 6-35 DS three phase output power [39 mm $0.2 \mathrm{~Hz}$ ] 


\subsection{Summary}

Measurement results have shown the ability of the two stator structure to produce the two phase system from the single phase generator by more efficient utilization of the existing magnetic material. Reduction in the phase EMF (peak value and RMS) compared to the SS case has been bigger than expected, however it can be attributed to differences in the stator magnetic circuit, such as little longer internal stator and the external stator channels. The DS topology increases the no load EMF in the three phase topology (peak value and RMS) by about $46 \%$.

The analytical and the FEM model predictions for the no load EMF agree well with the measurements. Besides mentioned difference in the magnetic circuit, imperfections in the properties of the used magnets have also contributed to the discrepancy between the model and the experimental results.

Excessive friction has aggravated estimation of the cogging force profile for some topologies. However, mostly preserved shape of the force profile in the down stoke has enabled estimation of cogging force. Its agreement with FEM predictions is satisfactory.

Measurements have also shown higher output power with less ripple in the DS topologies. However, differences in the no load EMF and phase resistance lead to ripple in the DS two phase output power, which should ideally be absent. 


\section{Chapter 7}

\section{Conclusion and future work}

Linear permanent magnet generator has been identified as the most appropriate solution for a direct driven WEC. Depending on a topology (single phase, two phase or three phase) there is more or less severe fluctuation of stator-translator flux linkage with translator position. For one position of the translator, flux of one of its magnets might be fully liked with the stator, however for some other position most of its flux might be turned into leakage, i.e. magnet and stator would be misaligned. Proposed double sided machine employs additional stator in order to utilize flux produced by the unaligned magnets from the single sided topology.

\subsection{Double sided two phase LPMG}

The DS two phase topology can be seen as an upgrade of the SS single phase topology. Addition of an extra stator in a complementary position with the existing one (so that their slots and teeth coincide) enables turning permanent magnet leakage flux into the main flux. Since the two stators are displaced by half of the pole pitch $\frac{\tau}{2}\left(\frac{\pi}{2}\right.$ electrical angle), the generator is a two phase machine. Single sided two phase generator with the same amount of magnetic material would have twice as wide translator poles and twice as much PM material per pole. Such topology 
would double peak flux per coil, but would also reduce electrical frequency, leading therefore to the same EMF per coil as in the DS two phase case. However, the DS topology is able to energize twice as many coils, effectively doubling the length of the stator without having to use any additional magnetic material.

Addition of the internal stator enhances the leakage of the PM flux. That is why the external stator in DS two phase topology will not have the same peak flux as in the SS topology. Models predict that the reduction of the external stator flux would be $10 \%$. Internal stator would link $20 \%$ less flux. The prototype experiments show reduction of about $20 \%$ and $27.5 \%$ in the no load EMF RMS for the external and internal stator, respectively. This discrepancy between the test and simulation can be ascribed to the differences in the magnetic circuit of the actual machine and the model.

The criteria for selection of the air gap lengths in the DS two phase topology has been the cogging force minimization. The length of the air gap can be selected based upon the analytical expression (eq. 4.3), which is in good accordance with the FEM results. Since the main focus was on the cogging force, balancing the fluxes between the internal and external air gap has been neglected. It lead to the uneven EMFs in the internal and external phase and the ripple in the output power (Fig. 6-30). Maximum output power RMS in the DS two phase topology is about $84 \%$ higher than in the SS single phase case (for $3 \Omega$ load).

Improvements produced by the addition of the internal stator had to be paid by the increase in the external stator's self-inductance of about $26 \%$, which will result with somewhat increased load angle. 


\subsection{Double sided three phase topology}

In a SS three phase topology only one half of the translator magnets fully links their flux with the stator at the time. The other half is producing leakage. The flux of the first group of the magnets is in phase with the leakage of the second. Therefore, it is possible to add those two fluxes together by addition of an extra stator, which would utilize that leakage. Simulations and experiments have shown that the DS three phase machines produces about $40 \%$ higher RMS of the no load EMF. Experimental results shown 85\% higher RMS of output power in DS topology.

The analytical and the FEM model predict strong increase of self-inductance in the DS three phase topology, because of the low reluctance bridge between the internal and external stator provided by the wide translator poles.

\subsection{Cogging force}

The cogging force in a linear machine is a result of two components. Internal component is produced by attraction between the translator magnets and stator teeth. The end component builds up as a magnet enters or leaves stator magnetic circuit. Fluctuations of air reluctance in which magnets establish their flux is a direct cause of both components (eq. 2.9).

Two stators in the DS topology can provide less severe change in the air gap reluctance of the stator magnetic circuit and reduce internal cogging force component. Although the SS single phase topology and the DS two phase topology utilize the same external stator and translator, addition of the internal stator in the first one causes a severe drop in the cogging force (Fig. 6-13 and Fig. 6-16). 
The SS and DS three phase machines exhibit similar internal component cogging force, however, end component is more pronounced in the DS topology. In order to suppress it, the segmented DS design has been employed which resulted with somewhat reduced cogging force (Fig. 3-28).

\subsection{Future work}

Reluctance network and COMSOL ${ }^{\circledR}$ results have mostly been in good agreement with the experimental readings. Therefore, they can confidently be used as a foundation for future design work. Plans for later include exploring how well DS machine principles can be applied in the flat topology. It seems very likely that the flat shape would facilitate balancing between phases in the DS two phase generator and realization of strong translator support. Obtaining appropriate magnets for flat topology is also much easier. These benefits would have to be paid by worse flux encapsulation due to the end leakage. Experimental design work in the future should be carried out with more sophisticated experimental setup and instrumentation.

Generator control strategy for optimum power take off from the scale of ocean wave amplitudes and frequencies needs to be developed. The generator can be used as an actuator during the portion of wave period in order to exercise control force on the point absorber and maximize the extracted power.

Once final generator design is obtained and control strategy defined and implemented, wave tank test should be conducted. 


\section{References}

Falnes, Johannes. "A Review of Wave-Energy Extraction." Marine Structures 20.4 (2007): 185201. Web.

Muetze, A., and J. G. Vining. "Ocean Wave Energy Conversion - A Survey". Industry Applications Conference, 2006. 41st IAS Annual Meeting. Conference Record of the 2006 IEEE. Web.

Masuda, Y., et al. "The Backward Bend Duct Buoy-an Improved Floating Type Wave Power Device". OCEANS '88. A Partnership of Marine Interests. Proceedings. Web.

Tietje, E. D. "International Standards for the Appraisal of Wave Energy Converters". OCEANS 2009, MTS/IEEE Biloxi - Marine Technology for Our Future: Global and Local Challenges. Web.

Thomson, R. C., G. P. Harrison, and J. P. Chick. "Full Life Cycle Assessment of a Wave Energy Converter". Renewable Power Generation (RPG 2011), IET Conference on. Web.

Polinder, H., M. E. C. Damen, and F. Gardner. "Linear PM Generator System for Wave Energy Conversion in the AWS." Energy Conversion, IEEE Transactions on 19.3 (2004): 583-9. Web.

Boldea, I., and S. A. Nasar. "Linear Electric Actuators and Generators". Electric Machines and Drives Conference Record, 1997. IEEE International. Web.

Leijon, M., et al. "Multiphysics Simulation of Wave Energy to Electric Energy Conversion by Permanent Magnet Linear Generator." Energy Conversion, IEEE Transactions on 20.1 (2005): 219-24. Web.

Pirisi, A., et al. "An Optimized Three Phase TPM-LiG for Marine Applications". Power Electronics Electrical Drives Automation and Motion (SPEEDAM), 2010 International Symposium on. Web.

Mueller, M. A. "Electrical Generators for Direct Drive Wave Energy Converters." Generation, Transmission and Distribution, IEE Proceedings- 149.4 (2002): 446-56. Web.

Pirisi, A., et al. "Optimization of an Energy Harvesting Buoy for Coral Reef Monitoring". Evolutionary Computation (CEC), 2013 IEEE Congress on. Web.

Grilli, Annette R., et al. "Experimental and Numerical Study of Spar Buoy-magnet/spring Oscillators used as Wave Energy Absorbers". The Seventeenth International Offshore and Polar Engineering Conference. Web. 
Ivanova, I. A., et al. "Simulation of Wave-Energy Converter with Octagonal Linear Generator." Oceanic Engineering, IEEE Journal of 30.3 (2005): 619-29. Web.

Polinder, H., et al. "Conventional and TFPM Linear Generators for Direct-Drive Wave Energy

Conversion." Energy Conversion, IEEE Transactions on 20.2 (2005): 260-7. Web.

Prudell, J., et al. "A Novel Permanent Magnet Tubular Linear Generator for Ocean Wave Energy". Energy Conversion Congress and Exposition, 2009. ECCE 2009. IEEE. Web.

Gieras, Jacek F., Zbigniew J. Piech, and Bronislaw Tomczuk. Linear Synchronous Motors: Transportation and Automation Systems. CRC press, 2011. Web.

Garcia, Joao SD, et al. "Transverse Flux Machines: What for?" IEEE multidisciplinary engineering education magazine 2.1 (2007): 4-6. Web.

Batzel, T. D., and K. Y. Lee. "Slotless Permanent Magnet Synchronous Motor Operation without a High Resolution Rotor Angle Sensor." Energy Conversion, IEEE Transactions on 15.4 (2000): 366-71. Web.

Danielsson, O., M. Leijon, and E. Sjostedt. "Detailed Study of the Magnetic Circuit in a Longitudinal Flux Permanent-Magnet Synchronous Linear Generator." Magnetics, IEEE Transactions on 41.9 (2005): 2490-5. Web.

Ivanova, I. A., et al. "Simulation of Cogging in a $100 \mathrm{~kW}$ Permanent Magnet Octagonal Linear Generator for Ocean Wave Conversion". Underwater Technology, 2004. UT '04. 2004 International Symposium on. Web.

Prudell, J., et al. "A Permanent-Magnet Tubular Linear Generator for Ocean Wave Energy Conversion." Industry Applications, IEEE Transactions on 46.6 (2010): 2392-400. Web.

Yu-wu Zhu, et al. "Investigation of Auxiliary Poles Design Criteria on Reduction of End Effect of Detent Force for PMLSM." Magnetics, IEEE Transactions on 45.6 (2009): 2863-6. Web.

Boldea, I., and S. A. Nasar. Linear Electric Actuators and Generators. Cambridge ; New York: Cambridge UP, 1997. Print.

Joseph, D. M., and W. A. Cronje. "Design and Analysis of a Double-Sided Tubular Linear Synchronous Generator with Particular Application to Wave-Energy Conversion". Power Engineering Society Conference and Exposition in Africa, 2007. PowerAfrica '07. IEEE. Web.

Brown, Forbes T. Engineering System Dynamics: A Unified Graph-Centered Approach. CRC press, 2006. Web.

Permanent magnet. (2015). Retrieved from:

https://www.comsol.fr/model/download/263881/models.acdc.permanent_magnet.pdf

Demagnetization (BH) Curves for Neodymium Magnets. (2015). Retrieved from:

https://www.kjmagnetics.com/bhcurves.asp 
Series 243 and 243T Hydraulic Actuators. (2015). Retrieved from:

https://nees.org/data/get/facility/Cornell/Equipment/29/100_016 952.pdf

Model 407 Controller. (2015). Retrieved from:

https://www.mts.com/ucm/groups/public/documents/library/dev 002063.pdf

Series 293 Hydraulic Service Manifolds. (2015). Retrieved from:

https://www.mts.com/ucm/groups/public/documents/library/dev_002101.pdf

9063 Data Acquisition and Control Interface. (2015). Retrieved from:

file:///C:/Users/MIkajlo/Downloads/datasheet 98-9063-0_en_220V_60Hz.pdf

Low-profile Pancake Style load cells Standard and metric models. (2015). Retrieved from:

http://www.omega.com/pressure/pdf/LCHD.pdf

Mixed Signal Oscilloscopes MSO4000B, DPO4000B Series Datasheet. (2015). Retrieved from:

http://www.tek.com/sites/tek.com/files/media/media/resources/MSO4000-DPO4000-Mixed-

$\underline{\text { Signal-Oscilloscope-Datasheet-23.pdf }}$

Digital Storage Oscilloscopes TBS1000 Series Datasheet. (2015). Retrieved from:

http://www.tek.com/sites/tek.com/files/media/media/resources/TBS1000-Digital-Storage-

Oscilloscope-Datasheet-4 0.pdf

TENMA Model 72-7740/72-7745 Operating Manual. (2015). Retrieved from:

http://www.farnell.com/datasheets/1490819.pdf

Merrikhi, J., J. S. Moghani, and E. Fallah. "Laminated Iron Core Inductor Model with Flux Skin Effect". Power Electronics Systems and Applications, 2006. ICPESA '06. 2nd International Conference on. Web. 


\section{Appendix: Prototype parts drawings}
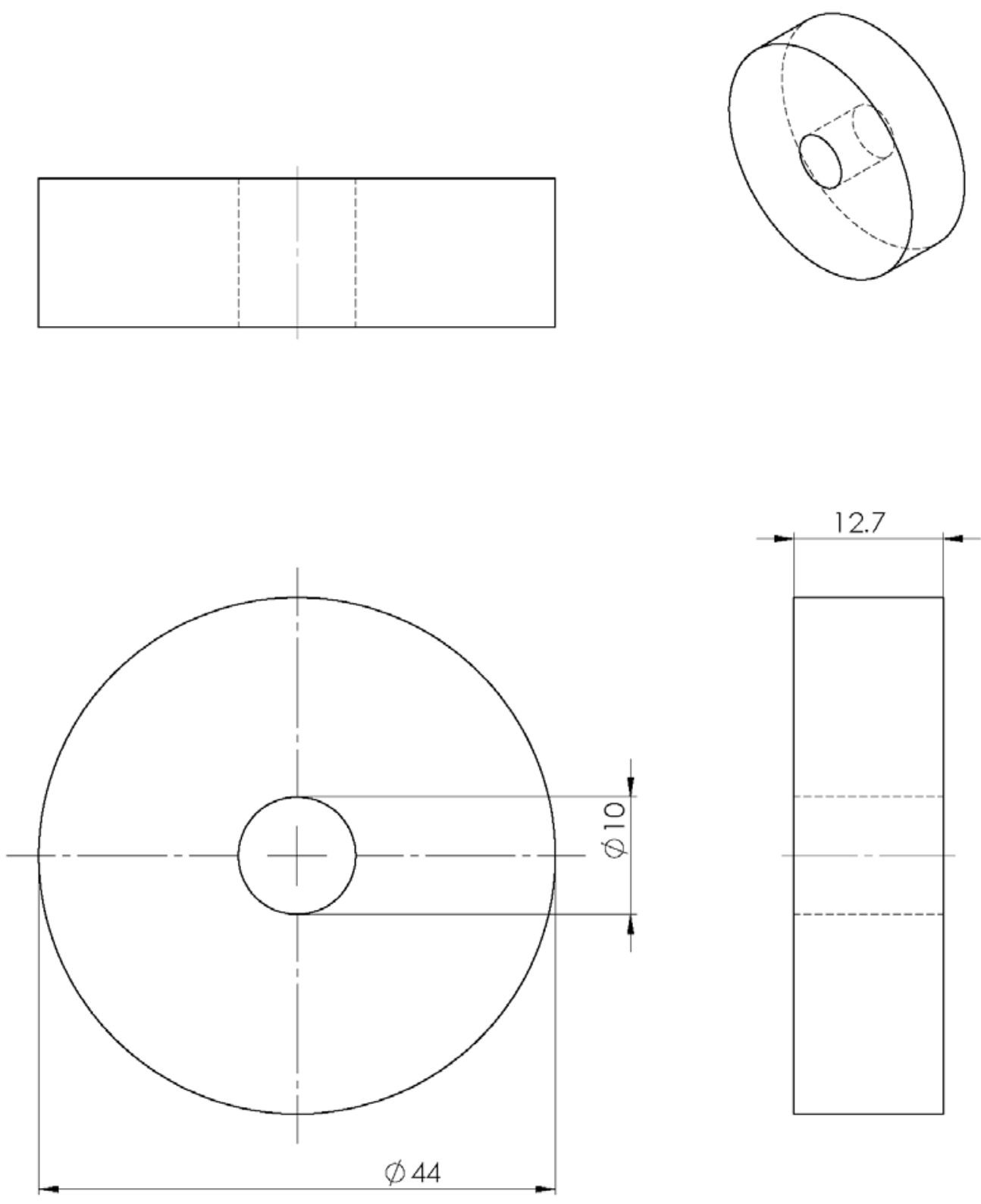

Figure 8-1 Internal stator Slot part 


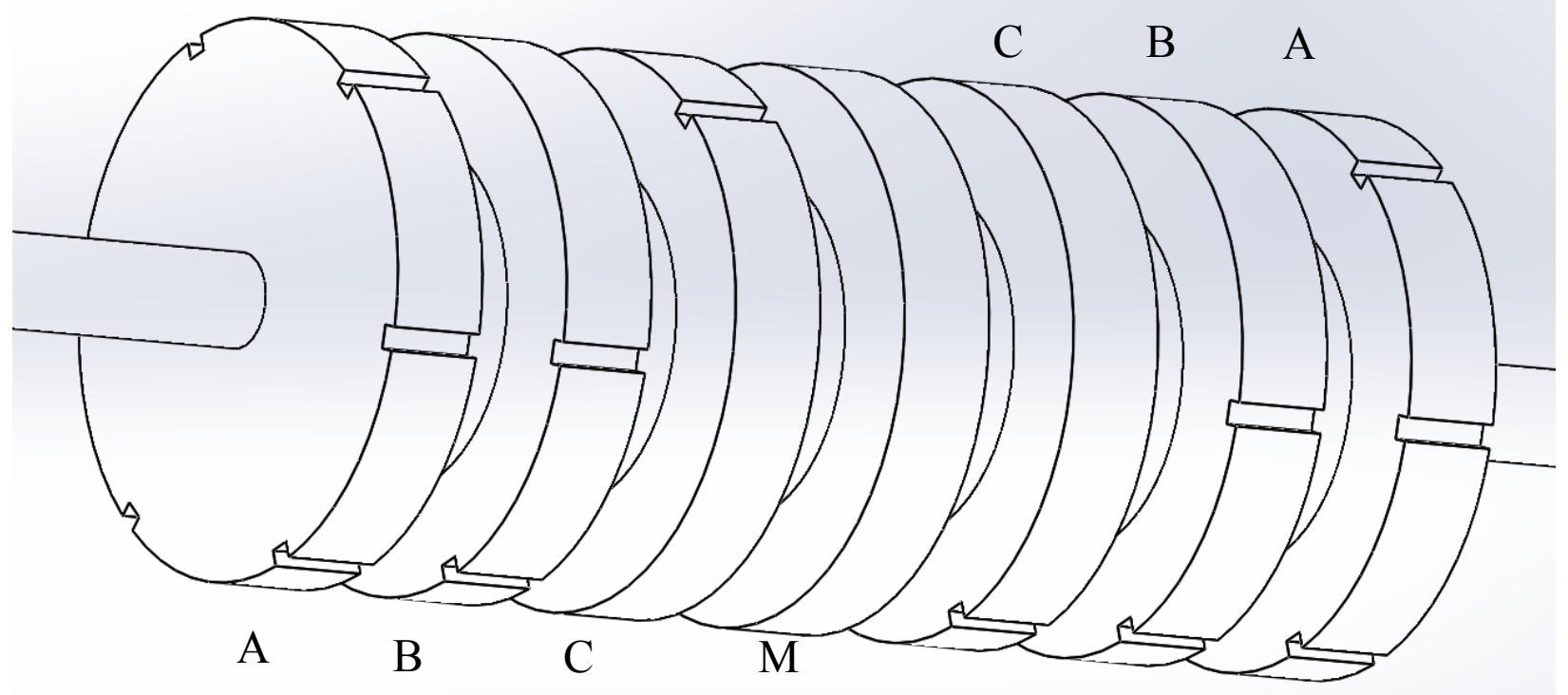

Figure 8-2 Different Internal stator tooth parts
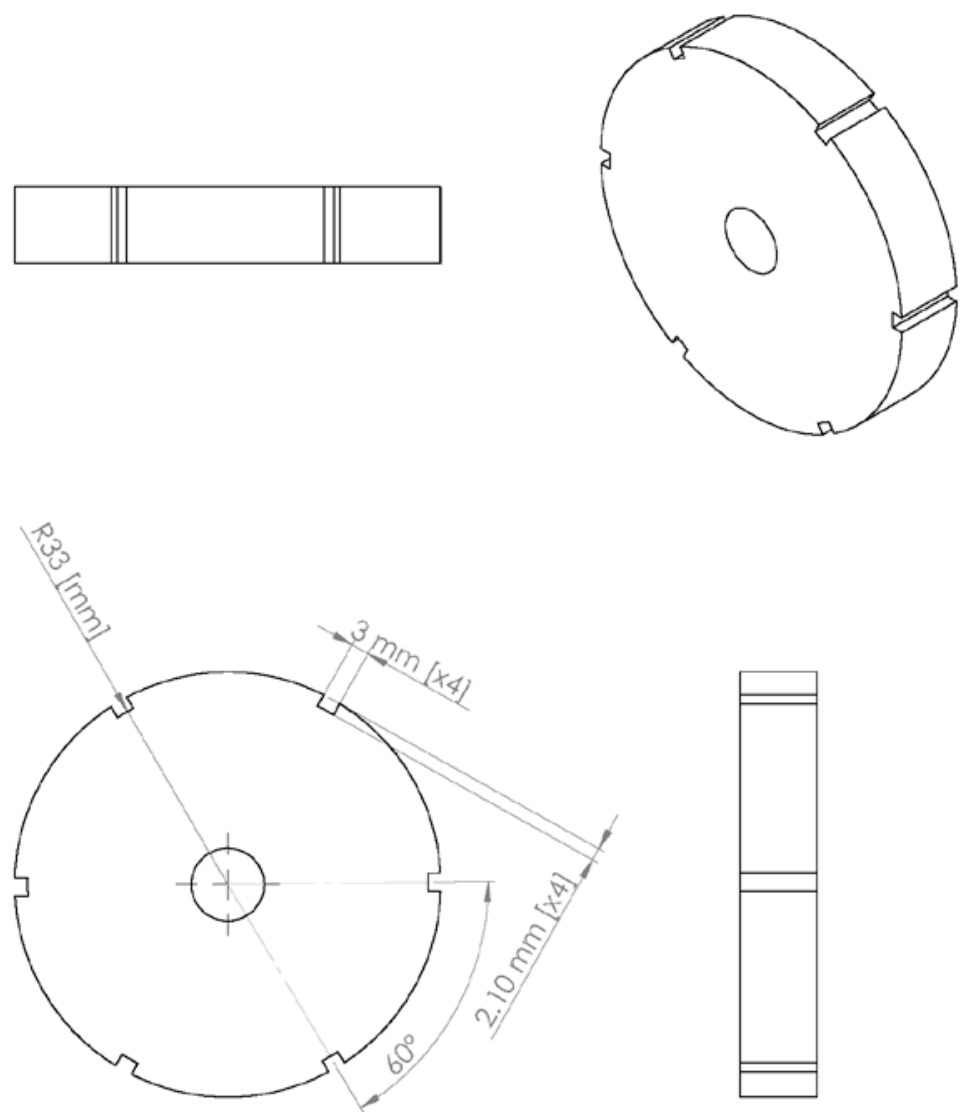

Figure 8-3 Internal stator tooth part A 

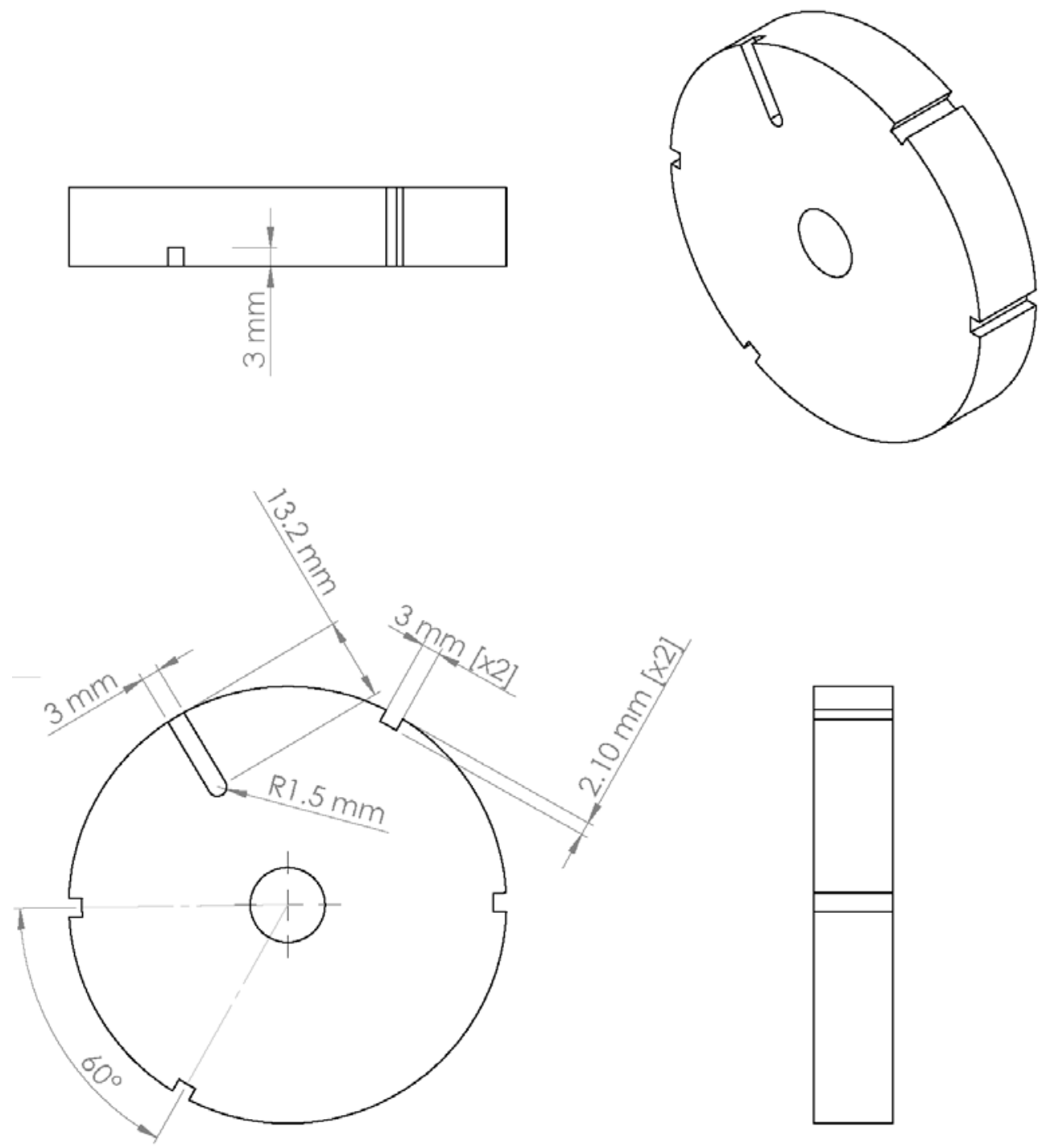

Figure 8-4 Internal stator Tooth part B 


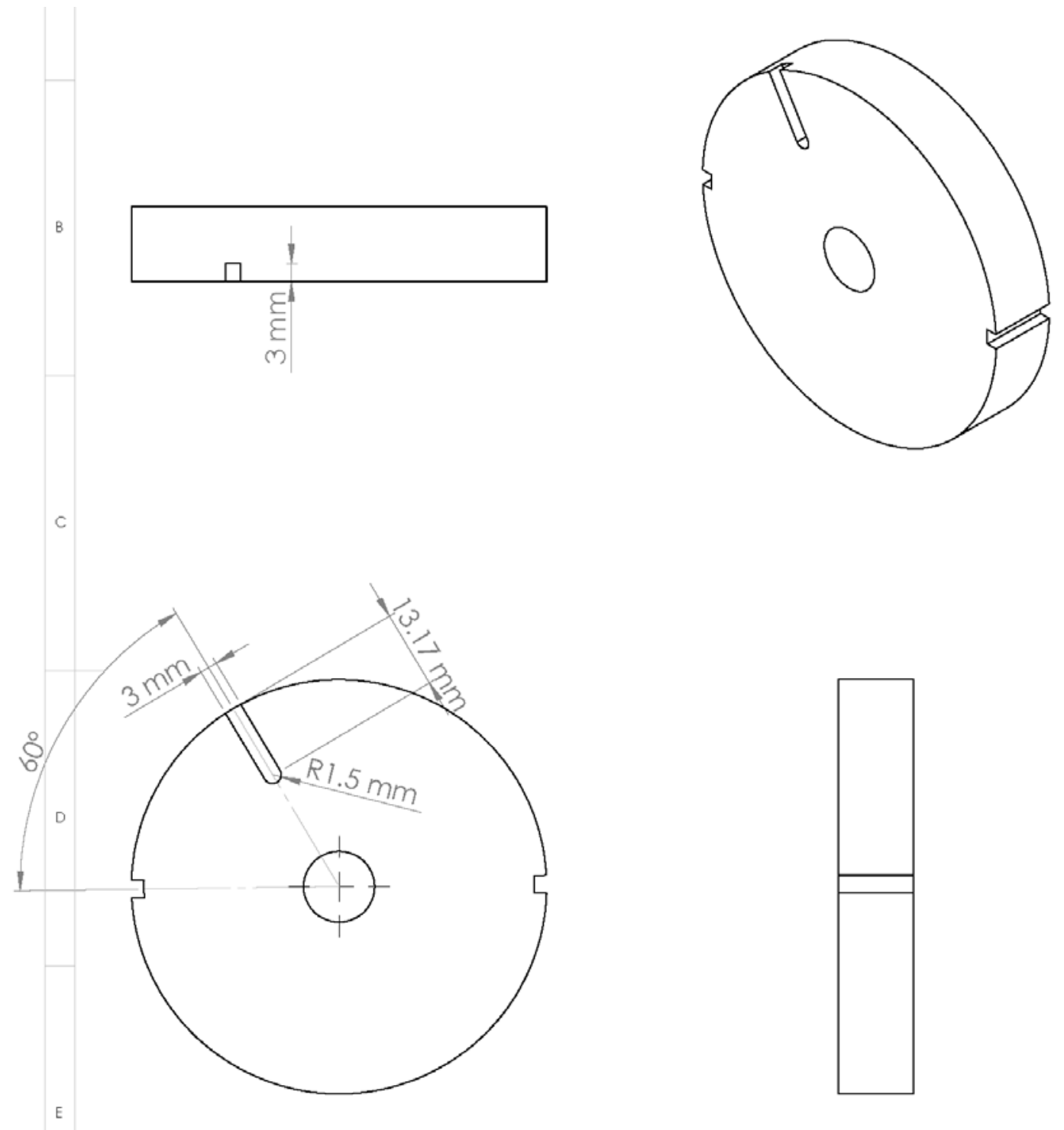

Figure 8-5 Internal stator tooth part C 

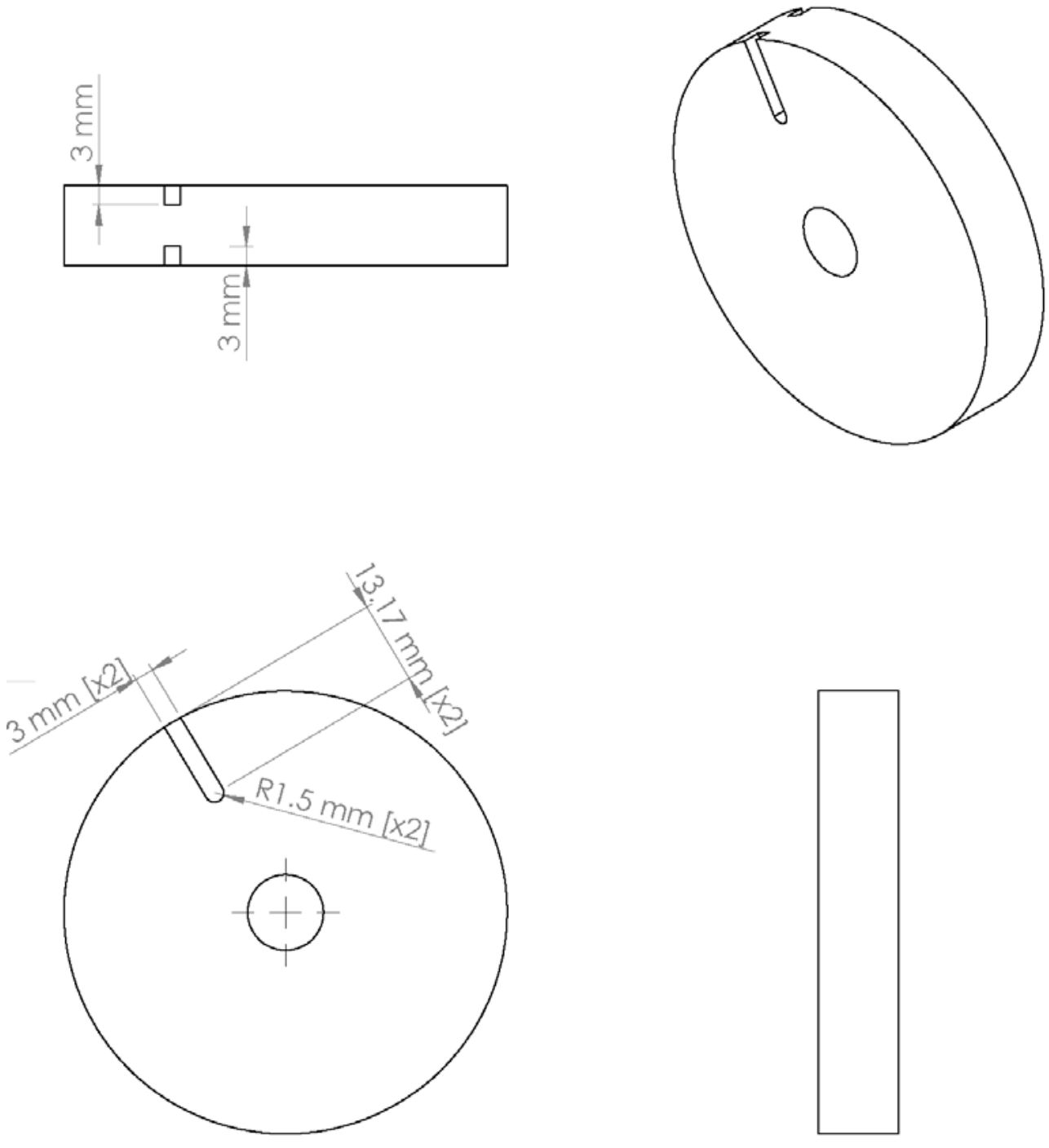

Figure 8-6 Internal stator tooth part M 

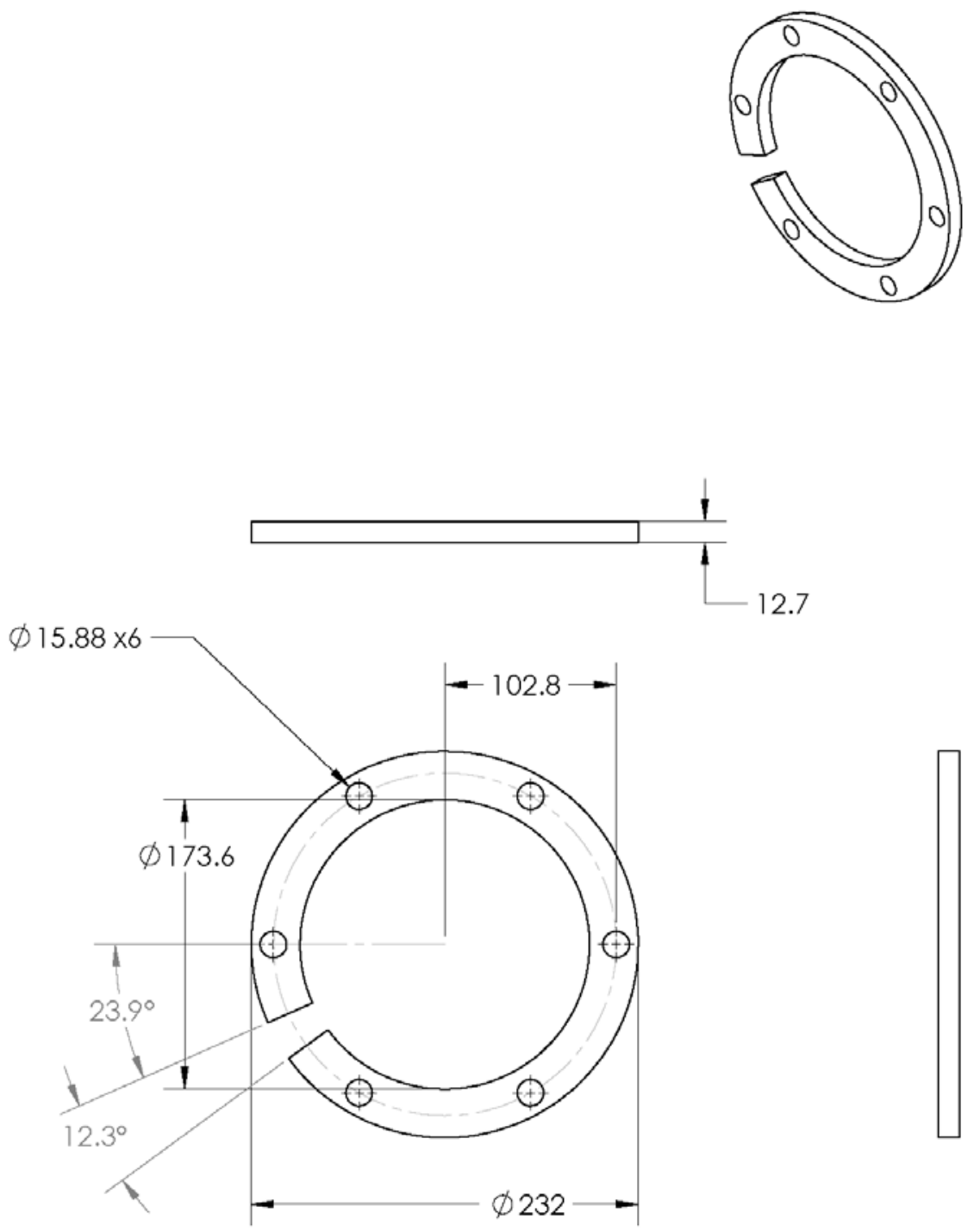

Figure 8-7 External stator Slot part 

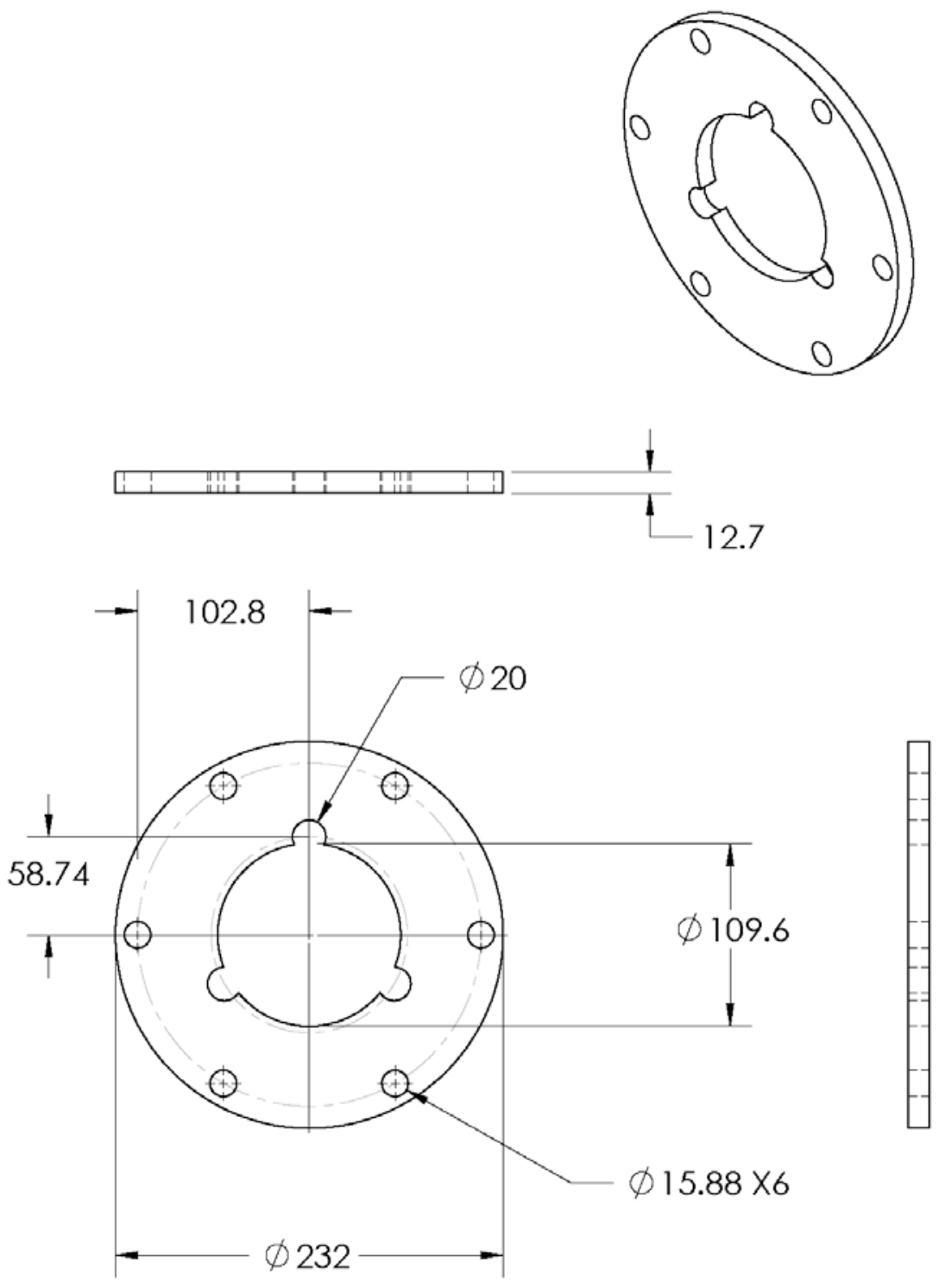

Figure 8-8 External stator Tooth part 

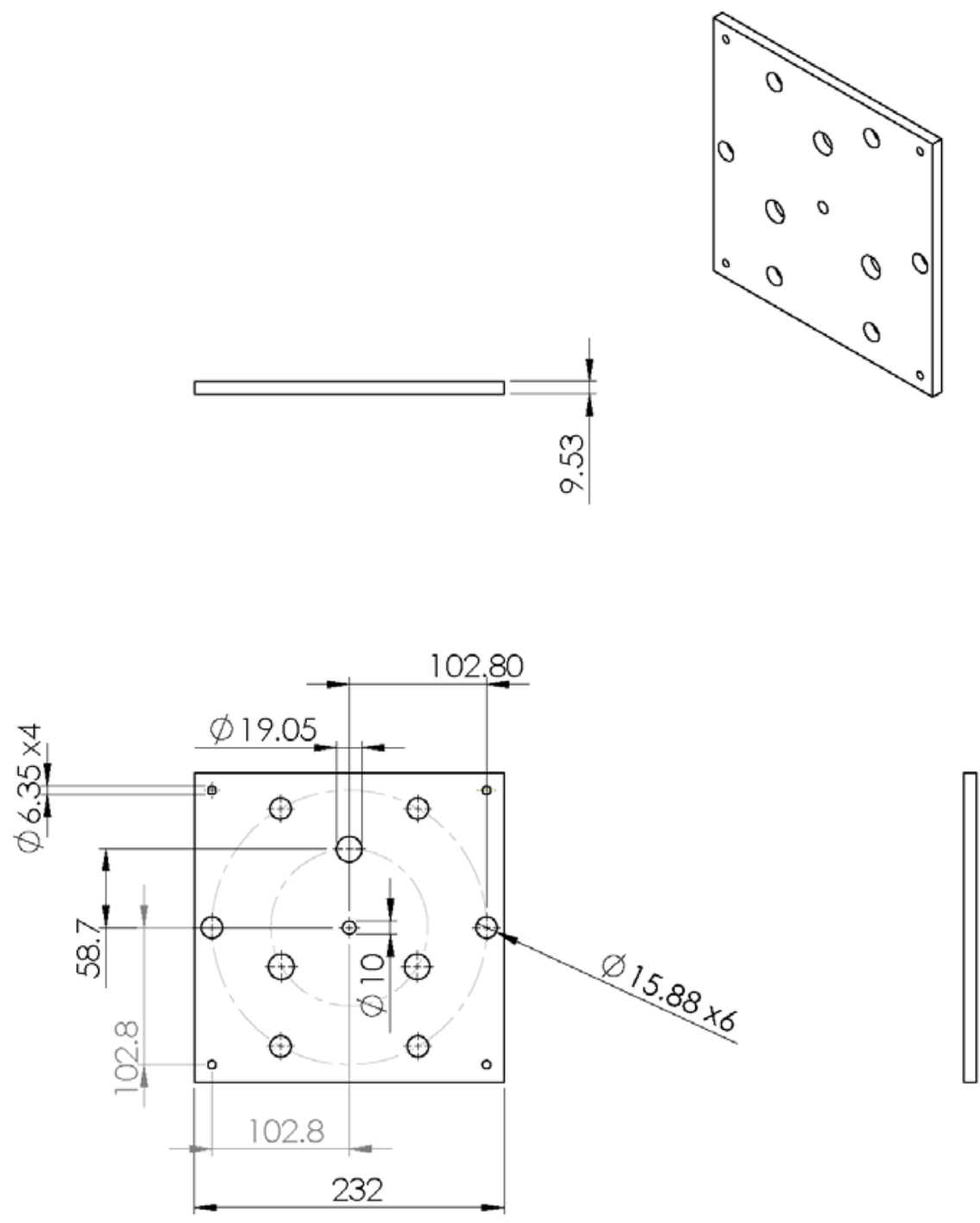

Figure 8-9 Base plate 

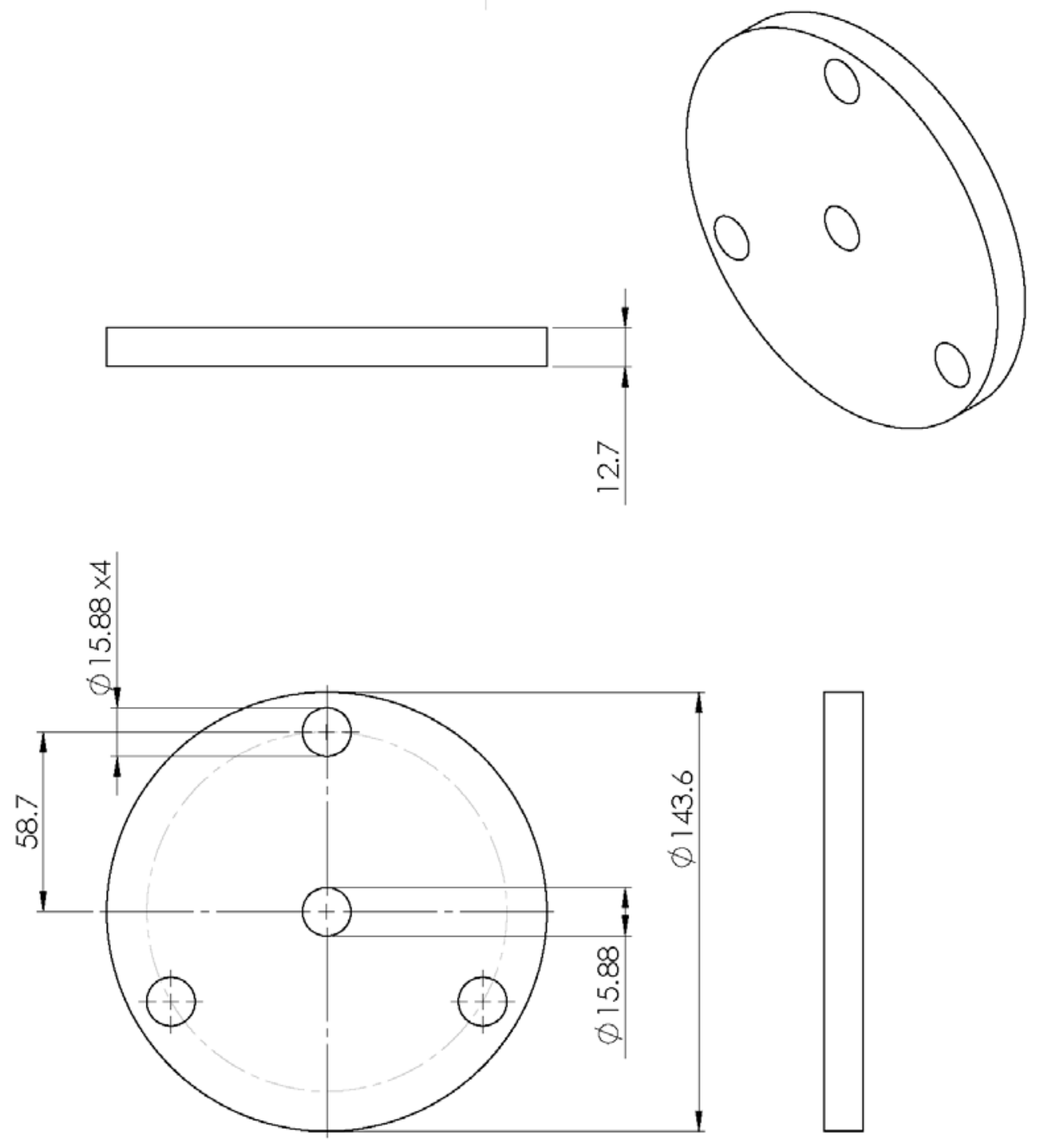

Figure 8-10 Translator-Actuator contact plate 

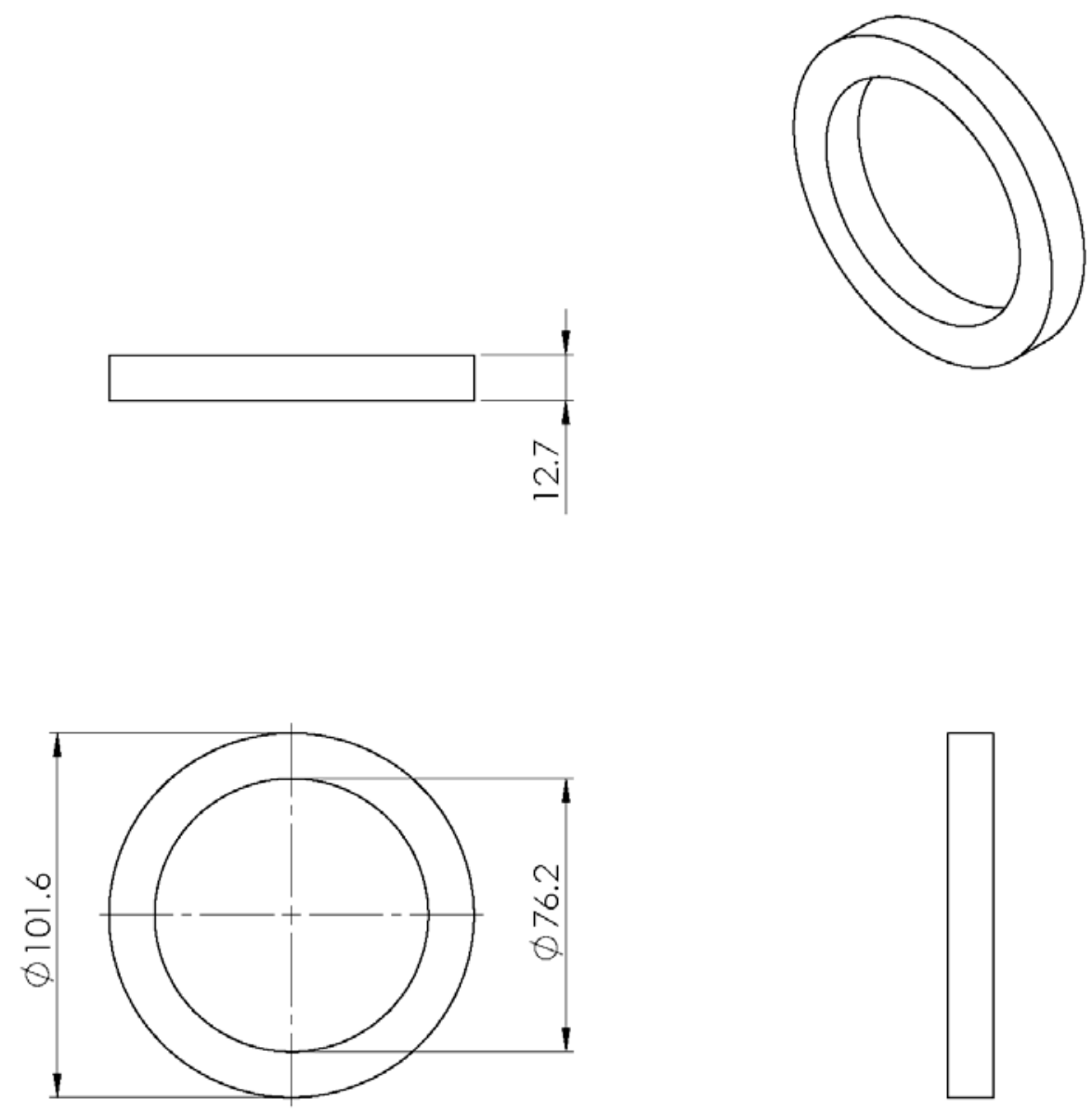

Figure 8-11 Translator poles ring (spacer) 

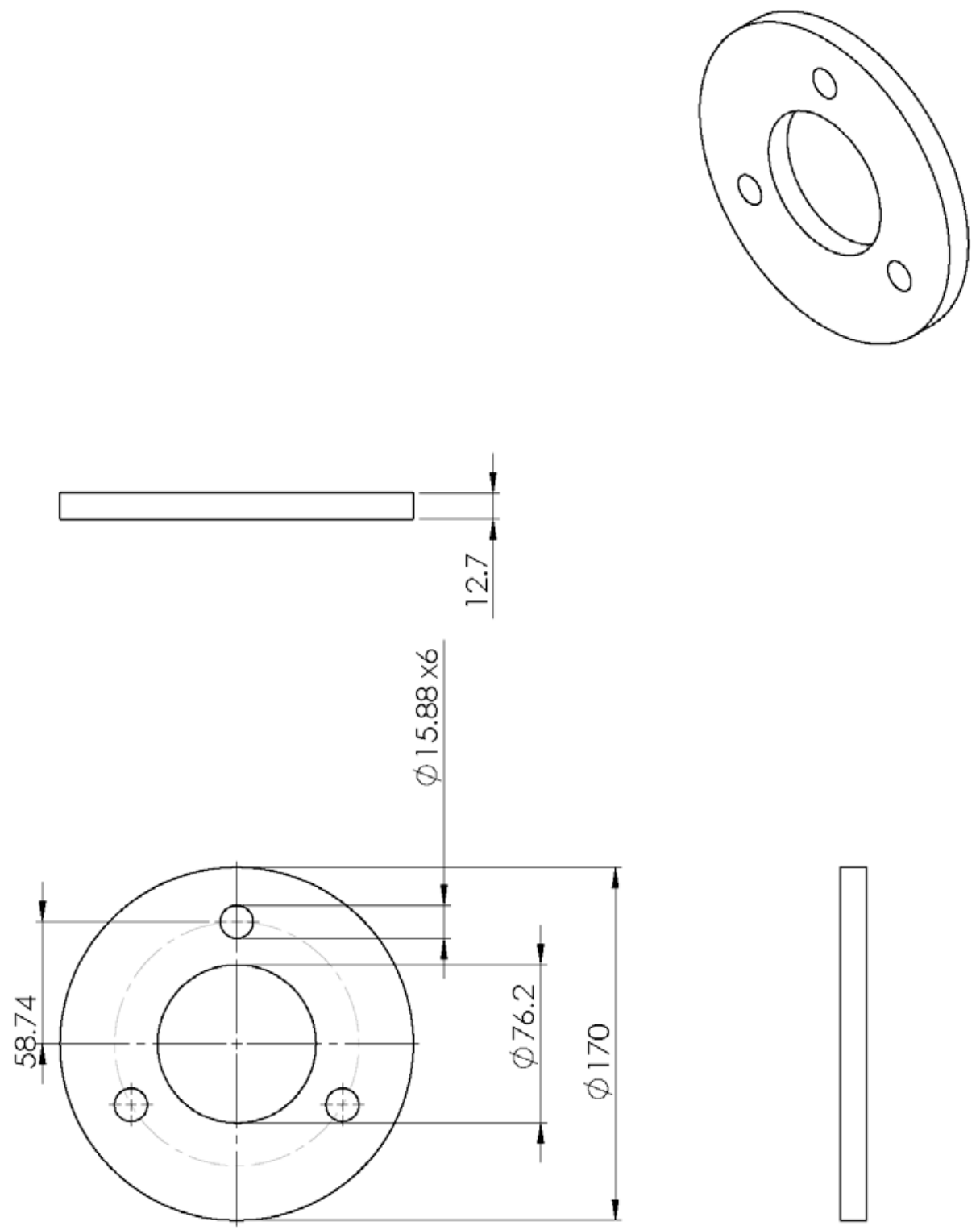

Figure 8-12 Translator end plate 